\title{
Synthese und biologische Evaluierung neuartiger
}

\section{Acronycin-Duocarmycin-Hybride}

\author{
Dissertation \\ zur Erlangung des Doktorgrades \\ „Doctor rerum naturalium” \\ der Mathematisch-Naturwissenschaftlichen Fakultäten \\ der Georg-August-Universität zu Göttingen
}

vorgelegt von

Arne Heins

aus Soltau

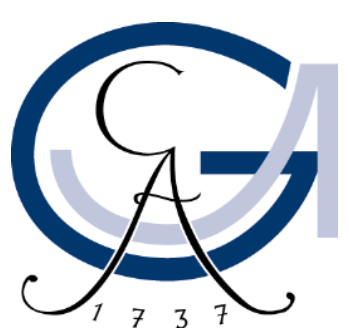

Göttingen 2011 
D 7

Referent:

Prof. Dr. Dr. h.c. Lutz F. Tietze

Korreferent:

Prof. Dr. Hartmut Laatsch

Tag der mündlichen Prüfung: $\quad$ 15.12.2012 
Die vorliegende Arbeit wurde in der Zeit von August 2008 bis August 2011 am Institut für Organische und Biomolekulare Chemie der Georg-August-Universität Göttingen unter der Leitung von Prof. Dr. Dr. h.c. Lutz F. Tietze angefertigt.

Ich danke Herrn Prof. Dr. Dr. h. c. L. F. Tietze für die interessante Themenstellung, sein stetes Interesse am Fortgang dieser Arbeit sowie für die vielen Anregungen in den zahlreichen Diskussionen. 


Meiner Familie,

meinen Freunden 

Die Zukunft hat viele Namen.

Für die Schwachen ist sie das Unerreichbare.

Für die Furchtsamen ist sie das Unbekannte.

Für die Tapferen ist sie die Chance.

Victor Hugo 




\section{A INHALTSVERZEICHNIS}

A Inhaltsverzeichnis

B Allgemeiner Teil 1

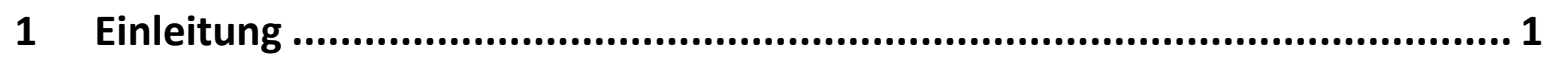

2 Tumorentstehung und Tumorwachstum ............................................... 4

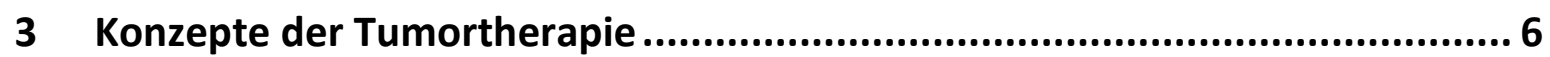

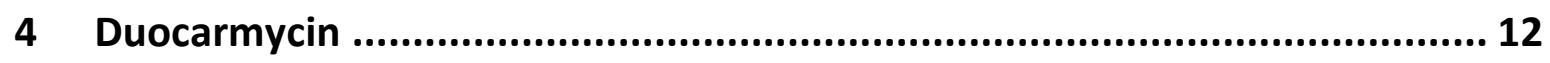

4.1 Analoga des Antibiotikums CC-1065 und der Duocarmycine ................ 15

4.2 Seco-Verbindungen und Prodrugs einiger Duocarmycin-Analoga ..........20

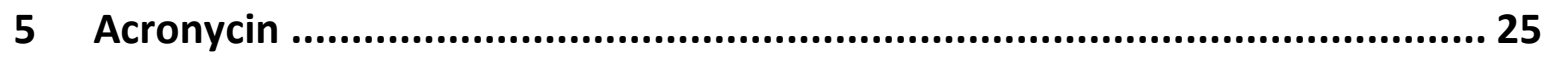

5.1 Analoga des Acronycins 45 durch Modifikation des A-Rings ................. 25

5.2 Analoga des Acronycins 45 durch Modifikation des Pyran-Rings .......... 27

5.3 Dimere Strukturen des Acronycins (45) ………….......................... 28

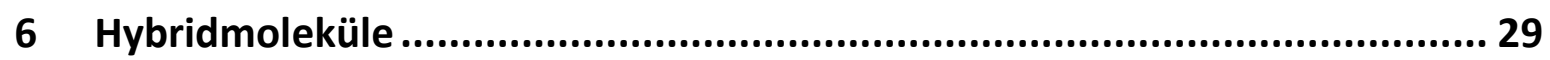

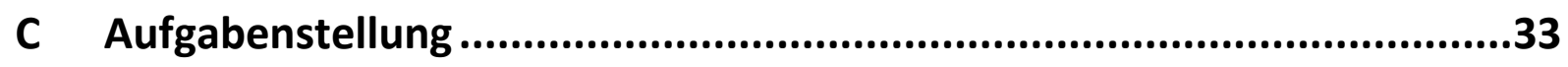

1 Stand der Forschung zu Beginn der Arbeit ............................................... 33

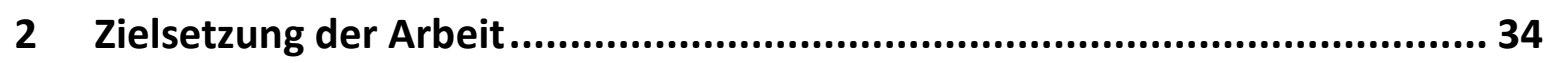

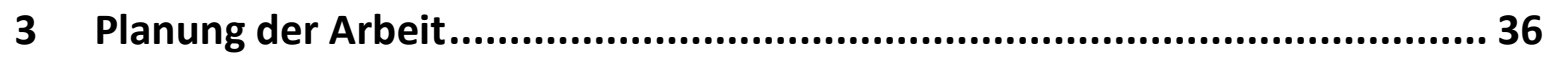

D Darstellung der Ergebnisse .................................................................37

1 Synthese der Benzo[b]acronycin-Duocarmycin-Hybride .............................. 37

1.1 Syntheseroute I zur Darstellung von 101 ........................................... 37 
1.2 Syntheseroute II zur Darstellung von 101........................................ 43

1.3 Synthese des Alkens 111 nach der veränderten Syntheseroute ........... 43

1.4 Umwandlung des Alkens 111 zum Epoxid 101................................47

1.5 Synthese des Epoxids 101 über eine Bishydroxylierung ........................48

1.6 Zyklisierung von rac-101 und Umwandlung zum seco-Drug rac-114 .... 49

1.7 Diskussion ausgewählter spektroskopischer Daten der Verbindung

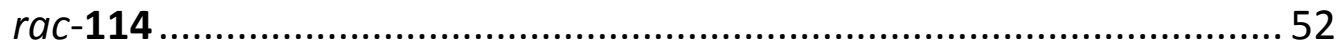

1.8 In-vitro-Zytotoxizitätsuntersuchungen des seco-Drugs rac-114 ........... 56

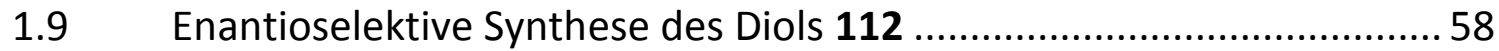

1.10 Synthese von Dimeren und Kupplung mit DMAI als DNA-bindende Einheit 60

2 Synthese der Nitro-Acronycin-Duocarmycin-Hybride .................................66

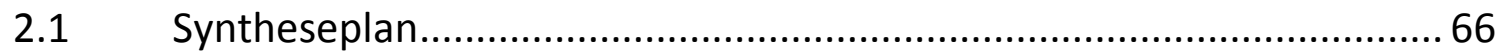

2.2 Synthese des Acridon-Grundgerüsts ..................................................67

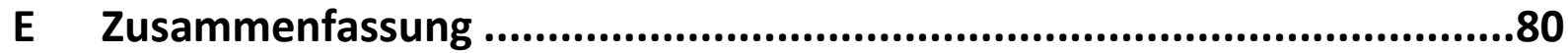

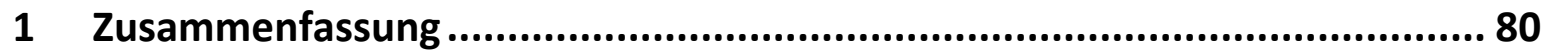

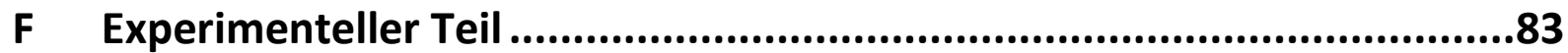

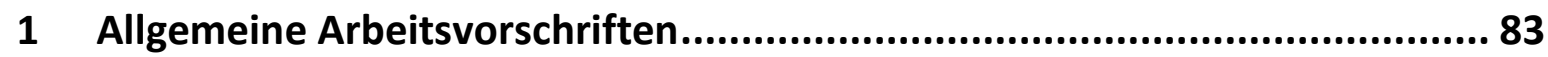

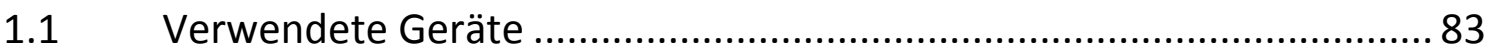

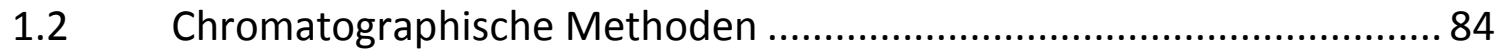

1.3 Materialien für die In-vitro-Zytotoxizitätsuntersuchungen ................... 85

2 Synthese der verwendeten Reagenzien .................................................. 87

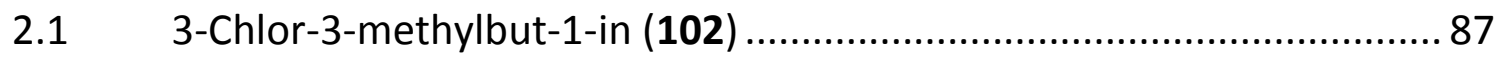


2.2 Dimethyldioxiran (144)

2.3 2-Oxiranyl-propan-2-ol (99) 88

3 Synthese des Benzo[b]acronycin-Duocarmycin-Hybrids 89

3.1 3-Amino-2-naphthoesäure 93 89

1,3-Dihydroxybenzo[b]acridin-12(5H)-on (94) ................................. 90

3.3 4-Brom-1,3-dihydroxybenzo[b]acridin-12(5H)-on (95) 91

3.4 4-Brom-3-(1,1-dimethylprop-2-inyloxy)-1-hydroxy-5H-benzo[b]acridin12-on (104)

3.5 4-Brom-3-(1,1-dimethylallyloxy)-1-hydroxy-5H-benzo[b]acridin-12-on (111)

3.6 4-Brom-3-(2,3-dihydroxy-1,1-dimethylpropoxy)-1-hydroxy-5Hbenzo[b]acridin-12-on (rac-112) 94

3.7 4-Brom-1-hydroxy-3-(1-methyl-1-oxiranylethoxy)-5H-benzo[b]acridin12-on (rac-101) .95

3.8 5-Hydroxy-1-(hydroxymethyl)-2,2-dimethyl-1,2-

dihydrobenzo[b]furo[3,2-h]acridin-6(13H)-on (rac-113) 97

3.9 1-(Chlormethyl)-5-hydroxy-2,2-dimethyl-1,2-dihydrobenzo[b]furo[3,2h]acridin-6(13H)-on (rac-114) 98

4 Synthese des Nitro-Acronycin-Duocarmycin-Hybrids.......................... 100

4.1 2-((3,5-Dimethoxyphenyl)amino)-5-nitrobenzoesäure (128) .............. 100

4.2 1,3-Dimethoxy-7-nitro-10H-acridin-9-on (129) ............................... 101

4.3 1,3-Dihydroxy-7-nitroacridin-9(10H)-on (130) .................................. 102

4.4 3-(1,1-Dimethylprop-2-inyloxy)-1-hydroxy-7-nitro-10H-acridin-9-on (132) 
4.5 4-Brom-3-(1,1-dimethylprop-2-inyloxy)-1-hydroxy-7-nitro-10H-acridin9-on (133) 104

4.6 4-Brom-3-(1,1-dimethylallyloxy)-1-hydroxy-7-nitro-10H-acridin-9-on (134) 105

4.7 4-Brom-3-(2,3-dihydroxy-1,1-dimethylpropoxy)-1-hydroxy-7-nitro-10Hacridin-9-on (rac-135). 106

4.8 4-Brom-1-hydroxy-3-(1-methyl-1-oxiranylethoxy)-7-nitro-10H-acridin-9on (rac-124) 107

G Anhang .109

1 Daten aus Röntgenstrukturanalysen ................................................. 109

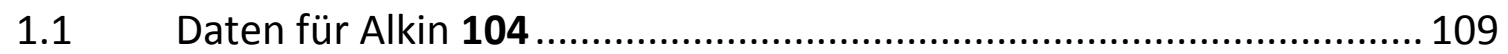

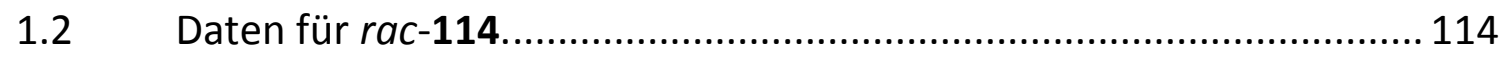

2 In-vitro-Zytotoxizitätsassays .................................................... 120

2.1 Ergebnisse des seco-Drugs rac-114 ...................................... 120

3 Abkürzungen und Akronyme .................................................... 121

$4 \quad$ Literaturverzeichnis .............................................................. 124

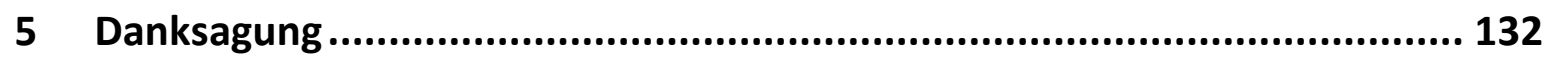

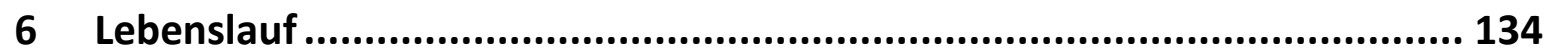




\section{B Allgemeiner Teil}

\section{$1 \quad$ Einleitung}

Seit Menschengedenken vertrauen die Völker der Erde auf die Natur. Sie bietet innen Nahrung, Kleidung und Schutz; Gewürze verleihen dem Essen einen besonderen Geschmack; Duft- und Farbstoffe spielen - wie jeder weiß - eine große Rolle beim Werben um das andere Geschlecht; und letztlich wurde auf sie seit jeher zur Bekämpfung von Krankheiten zurückgegriffen.

Erste schriftliche Zeugnisse über die heilende Wirkung von Pflanzen stammen aus dem frühen Mesopotamien. Es sind knapp einhundert um das 26. Jahrhundert v. Chr. verfasste Tontafeln mit Rezepturen für pflanzliche Öle und Pasten zur Linderung bestimmter Krankheitssymptome. ${ }^{1}$

Der Grieche Pedanios Dioscurides ist einer der berühmtesten Pharmakologen des Altertums. Er verfasste als weitgereister Militärarzt des römischen Heeres $100 \mathrm{n}$. Chr. die Bücher de materia medica, in denen erstmals systematisch Sammlung, Lagerung und Anwendungsbereiche von etwa eintausend Heilmmitteln dokumentiert wurden. Seine Werke stellten bis zum Ende des Mittelalters die Standardliteratur der Medizin dar. $^{2}$

Im 18. Jahrhundert kam erstmals die Idee einer Isolierung einzelner, reiner Stoffe aus Pflanzen auf: Bis dahin waren immer nur Gemische ganzer Pflanzen verwendet worden. Es war Friedrich Sertürner, der 1803 als Erster eine pharmakologisch aktive, reine Verbindung aus einer Pflanze isolierte. Die Isolierung des Morphins aus Papaver somniferum kann daher als Beginn der heutigen Naturstoffsythese angesehen werden. Die Vermarktung dieses ersten chemisch reinen Naturstoffs als Schmerzmittel erfolgte durch die Firma Merck im Jahr 1826. Der erste semisynthetische Wirkstoff folgte 1899 mit Aspirin, ein Derivat des schlechter verträglichen Naturstoffs Salicin, das aus Weiderinde isoliert wurde. ${ }^{3}$ 
Mit dem Jahrhundertwechsel begann die Blütezeit der Wirkstoffsynthese in Anlehnung an Naturstoffe: Alexander Fleming entdeckte 1928 das Penicillin, dessen Derivate noch heute als Antibiotika eingesetzt werden; zahlreiche Wirkstoffe gegen Herz-Kreislauf-Erkrankungen beruhen, wie zum Beispiel das Isoprenalin, auf dem 1923 von Chen isolierten Ephedrin. Auch die heutige Chemotherapie ist auf Naturstoffe zurückzuführen. Sie nahm ihren Anfang mit den sogenannten Vincaalkaloiden Vinblastin und Vincristin, die neben den Derivaten Vinorelbin und Vindesin noch heute eingesetzt werden. ${ }^{2,4}$

Der technische Fortschritt hat die Isolierung und Strukturaufklärung von Naturstoffen wesentlich vereinfacht. Doch eben dieser Fortschritt schien auch für den Niedergang der Naturstoffe in der Wirkstoffsynthese verantwortlich zu sein:

Standardisierte, roboterunterstützte Reaktionsabläufe und High-ThroughputScreenings zur Synthese und biologischen Evaluierung zehntausender neuer Verbindungen in kürzester Zeit, das sind die Schlagworte mit denen die kombinatorische Chemie vor zwei Jahrzehnten Einzug in die Wirkstoffforschung hielt. Durch dieses hochmoderne Verfahren zur Entwicklung neuer Leitstrukturen, so schien es, würde die zeitaufwendige Naturstoffsynthese abgelöst werden.

Die Zahlen sprechen jedoch eine andere Sprache: Bis zum Oktober 2007 wurde lediglich einer einzigen Wirksubstanz die Zulassung erteilt, die de novo auf kombinatorische Chemie zurückzuführen ist. ${ }^{5}$

Den Nagel auf den Kopf trifft in diesen Zusammenhang wohl ein Zitat von Samuel Danishefsky aus dem Jahr 2002: ${ }^{6}$

"A small collection of 'smart' compounds may be more valuable than a much larger hodgepodge collection mindlessly assembled."

Einen solchen "smarten" Ansatz stellt das Konzept der Naturstoffhybride dar. Durch Kombination von zwei oder mehr Naturstoffen oder deren Teilstrukturen entstehen neuartige Hybrid-Moleküle, die in ihrer biologischen Aktivität den 
Mutterverbindungen oftmals überlegen sind und als Leitstrukturen Zugang zu neuen Wirkmechanismen gewähren können. ${ }^{7}$

Die vorliegende Arbeit beschäftigt sich mit der Synthese und biologischen Evaluierung neuartiger Hybride der beiden Naturstoffe Acronycin und Duocarmycin. 


\section{Tumorentstehung und Tumorwachstum ${ }^{8}$}

Die Tumorentstehung (Kanzerogenese) beruht immer auf einer Schädigung der Regulationsmechanismen für die Proliferation somatischer Zellen. Man unterscheidet dabei benigne Tumore, sie sind vom umliegenden Gewebe gut abgegrenzt und bilden keine Ansiedlungen, von malignen Tumoren. Letztere proliferieren auch in Abwesenheit von Wachstumsfaktoren unkontrolliert, da zum Zellwachstum führende Signale permanent aktiv oder die Zellen unempfindlich gegenüber antiproliferativen Signalen geworden sind. ${ }^{9,10}$ Sie sind immortalisiert, d.h. sie können eine unbegrenzte Anzahl von Zellteilungen durchführen, da der Übergang in einen nicht mehr teilungsfähigen Zellzustand verhindert ist oder eine Apoptose trotz starker DNA-Schäden nicht erfolgen kann. ${ }^{11}$ Des Weiteren zeigen maligne Tumore keine Kontakthemmung durch andere Zellen, sie wachsen invasiv und werden schließlich beweglich, so dass sie sich über das Blut- und Lymphsystem in andere Organe ausbreiten können (Metastasenbildung). ${ }^{12}$

Die Schädigung des Erbgutes kann dabei durch physikalische Faktoren (UV-, Röntgenund $\gamma$-Strahlung), ${ }^{10,13}$ chemische Substanzen (polyzyklische aromatische Kohlenwasserstoffe, Nitrosamine, aromatische Amine, halogenierte Kohlenwasserstoffe, Asbest), ${ }^{14,15}$ eine Infektion mit Tumorviren ${ }^{16,17}$ oder spontane chemische Reaktionen (Spontanmutationen) erfolgen. Eine einzelne Veränderung reicht allerdings noch nicht aus, um aus einer gesunden Zelle eine (benigne) Tumorzelle entstehen zu lassen. Je nach genetischer Prädisposition sind vier bis sieben somatische Mutationen zu einer solchen Transformation nötig. ${ }^{10}$

Veränderungen der DNA, die zu einer Kanzerogenese führen, betreffen vor allem Gengruppen, die für die Kontrolle von Zellwachstum (Protoonkogene) und Zellproliferation (Tumorsuppressorgene) verantwortlich sind. ${ }^{18}$ Werden Protoonkogene durch Mutationen geschädigt, so dass sie ständig erhöhte Aktivität zeigen oder deren Genprodukte übermäßig exprimiert werden, so nennt man sie Onkogene. ${ }^{19}$ 
Die Umwandlung in ein Onkogen kann nahezu an jeder Stelle des mitogenen Signaltransduktionsweges zu Fehlfunktionen führen und auf diese Weise die Zelle zur Proliferation anregen. Tumorsuppressorgene sind direkt an der Regulation von Zellzyklus und Apoptose beteiligt, sie wirken wachstumsverhindernd. ${ }^{16,20}$ Das Protein p53 ist der wahrscheinlich bedeutendste Tumorsuppressor, welcher in etwa $50 \%$ aller Tumorerkrankungen einen Defekt aufweist. ${ }^{21}$ Es überwacht die Intaktheit der DNA und blockiert, wenn gravierende DNA-Schäden auftreten, den Eintritt einer Zelle in die S-Phase des Zellzyklus. Ist keine Reparatur möglich, so leitet es die Apoptose ein, so dass geschädigte Zellen sich nicht vermehren können.

Hat sich ein Tumor entwickelt, so ermöglichen weitere Mutationen die Bildung einer eigenen Blutversorgung (Angiogenese) und die Verbreitung im Organismus (Metastasierung). Erreichen Tumoren einen Durchmesser von 0.5-3 mm, so werden die Nährstoff- und Sauerstoffversorgung durch Diffusion ineffektiv. Die im Zentrum des Tumors liegenden Zellen erzeugen Stimulatoren zur Blutgefäßbildung. Blutgefäßzellen (Endothelzellen) wandern daraufhin in Richtung dieses Stimulus und beginnen zu profilieren und zu differenzieren. Ist bei Tumorzellen die Expression von Zelladhäsionsmolekülen, die für die Verankerung von Zellen an benachbarten Strukturen verantwortlich sind, verhindert, können sie sich über das Blut- und Lymphsystem im Körper verbreiten und Metastasen bilden. Diese Form der Verbreitung ist jedoch ineffektiv, man schätzt, dass nur eine von 10000 Tumorzellen, die ein den Blutstrom geraten, eine Metastase bildet. ${ }^{9,22}$ 


\section{$3 \quad$ Konzepte der Tumortherapie}

Tumore unterscheiden sich sehr stark in ihren Erscheinungsformen. Sie können fest und klar umgrenzt, aber auch schlecht definiert sein und in anderes Gewebe bzw. Organe hineinwachsen. Bei Ersteren ist meist eine operative Entfernung des betroffenen Gewebes das Mittel der Wahl, da diese Methode die höchsten Heilungschancen und geringsten Nebenwirkungen zeigt. Ist der Tumor hingegen schlecht zugänglich oder betrifft er lebenswichtige Organe, so ist eine chirurgische Entfernung oft nicht möglich. In diesem Fall wird oft eine Strahlenbehandlung (z.B. Röntgen- oder $\gamma$-Strahlung, Schwerionen) oder eine Chemotherapie vorgezogen. Für eine möglichst erfolgreiche Bekämpfung eines Tumors schließen sich die einzelnen Methoden jedoch nicht aus, sondern werden in den meisten Fällen in Kombination angewandt. Neben diesen drei "klassischen" Ansätzen der Tumortherapie gewinnen die Hormontherapie, ${ }^{23}$ die Immuntherapie ${ }^{24}$ sowie die Therapie mit Angiogenesehemmern ${ }^{25}$ und Kinaseinhibitoren ${ }^{26}$ immer mehr an Bedeutung.

Chemotherapeutika werden in der Krebstherapie u.a. eingesetzt, wenn eine Metastasenbildung zu befürchten ist, oder bereits nachgewiesen wurde. Im Rahmen einer Chemotherapie werden einem Patienten oft eine Kombination von verschiedenen Medikamenten, und damit Wirkstoffen, verabreicht. Diese verteilen sich über den Blutkreislauf nicht nur im Tumorgewebe, sondern im ganzen Körper. Da Tumorzellen jedoch eine erhöhte Stoffwechselaktivität zeigen, werden die Wirkstoffe von diesen bevorzugt aufgenommen. Neben Tumoren zeigen jedoch auch andere Zellen, wie Haarwurzel-, Knochenmarks- und Schleimhautzellen, eine hohe Proliferationsrate. Eine Chemotherapie ist daher immer mit starken Nebenwirkungen, wie der Störung des Blutbildes, Haarausfall, Immunschwäche, Schleimhautentzündung, Fieber und Übelkeit, Erbrechen und Unfruchtbarkeit verbunden. 
Die Vermehrung einer eukaryotischen Zelle folgt dem immer gleichen Zellzyklus. Da Chemotherapeutika an unterschiedlichen Stellen dieses Zyklus' eingreifen, soll er zum besseren Verständnis deren Wirkweise im Folgenden genauer beleuchtet werden. Der Zellzyklus beginnt mit der Entstehung einer neuen Zellen durch Zellteilung in der sog. Mitosephase (M) (Abbildung 1).

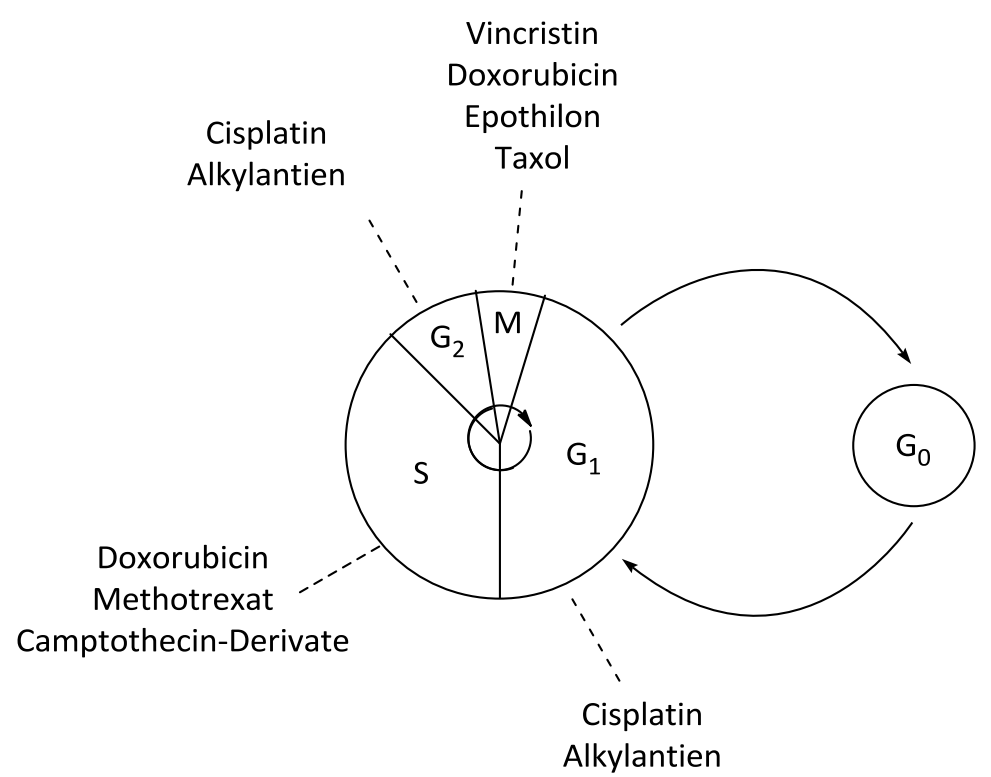

Abbildung 1: Die Phasen des Zellzyklus und Angriffspunkte verschiedener Chemotherapeutika.

In der darauf folgenden Wachstumsphase ( $\mathrm{G}_{1}$-Phase) werden die Zellbestandteile, wie RNA und Proteine, synthetisiert. Anschließend kann die Zelle durch einen noch unbekannten Stimulus entweder reversibel für eine unbestimmte Zeit in die Ruhephase $\left(\mathrm{G}_{0}\right.$-Phase) oder unter dem Einfluss verschiedener Wachstumsfaktoren in die Synthesephase (S-Phase) eintreten. In Letzterer erfolgt die Replikation der DNA gefolgt von der Postsynthesephase $\left(\mathrm{G}_{2}\right.$-Phase), in der die Zelle in Vorbereitung auf die Zellteilung ihre Form verändert und zellteilungsspezifische Proteine synthetisiert. Eine Trennung des doppelten Chromosomensatzes mit anschließender Teilung der Zellen in einer erneuten Mitosephase (M) rundet den Zellzyklus letztlich ab.

Erfolgt eine Schädigung der DNA während dieses Zyklus' wird an Kontrollpunkten zwischen der $\mathrm{G}_{1^{-}}$und S-Phase und der $\mathrm{S}$ - und $\mathrm{G}_{2}$-Phase entschieden, ob eine Reparatur erfolgen oder gar eine Apoptose eingeleitet werden soll. ${ }^{27}$ Von zentraler Bedeutung für die Chemotherapie ist die Tatsache, dass sich der überwiegende Teil 
der gesunden Körperzellen in der $\mathrm{G}_{0}$-Phase befinden, wohingegen nur $10 \%$ der Tumorzellen in dieser gegenüber Chemotherapeutika unempfindlichen Phase verharren.

Aufgrund ihres Wirkmechanismus' erfolgt eine Einteilung der Chemotherapeutika in Alkylantien, Antimetabolite, Mitosehemmstoffe, Topoisomerasehemmstoffe und zytostatischen Antibiotika.

Alkylantien bilden mit den Nukleinsäuren der DNA kovalente Bindungen aus. Die dadurch entstandenen Strangbrüche, Quervernetzungen oder abnormalen Basenpaarungen verhindern eine Replikation und führen letztlich zur Apoptose. Ein klassisches Beispiel ist das in vitro ungiftige Cyclophosphamid (1), das erst im Körper zum toxischen Lost-Derivat 2 metabolisiert wird (Abbildung 2). ${ }^{28}$

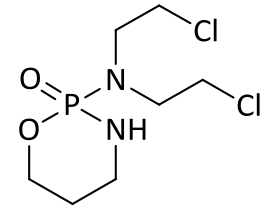

1: Cyclophosphamid

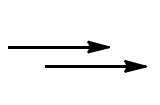

$$
\text { d }
$$

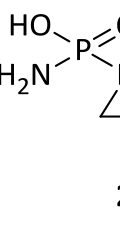

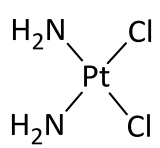

3: Cisplatin

Abbildung 2: Die Alkylantien Cyclophosphamid (1), entsprechende Lost-Derivat 2 und Cisplatin (3).

Weitere Beispiele für Alkylantien sind Cisplatin (3), ${ }^{29}$ welches DNA-Quervernetzungen hervorruft, sowie die äußerst potenten CC-1065-, Duocarmycin- und YatakemycinDerivate (s. Kapitel B4).

Antimetabolite ähneln in ihrer Struktur den natürlichen Metaboliten. Sie wirken in der S-Phase, da sie anstatt der körpereigenen Stoffwechselbausteine in Proteinen und Enzymen eingebaut werden, und somit deren Aktivität stören. Da Tumorzellen meist ein stark erhöhtes Zellwachstum aufweisen, erfolgt an ihnen eine stärkere Schädigung als an gesunden Körperzellen. ${ }^{27}$ Ein Beispiel ist der Folsäure-Antagonist Methotrexat (4), der als falsches Substrat das Coenzym Dihydrofolat-Reduktase inhibiert und dadurch die Umwandlung von Folsäure (5) zu Tetrahydrofolsäure verhindert. Da Tetrahydrofolsäure ein wichtiges Intermediat in der Purinsynthese darstellt, wird somit die Zellproliferation gestört (Abbildung 3). ${ }^{30}$ 
<smiles>[R]c1nc(N)nc2ncc(CN([R])c3ccc(C(=O)NC(CCC(=O)O)C(=O)O)cc3)nc12</smiles><smiles>[R]c1c[nH]c(=O)[nH]c1=O</smiles>
4: Methotrexat
$\mathrm{R}^{1}=\mathrm{NH}_{2}, \mathrm{R}^{2}=\mathrm{CH}_{3}$
5: Folsäure
$\mathrm{R}^{1}=\mathrm{OH}, \mathrm{R}^{2}=\mathrm{H}$

6: Uracil

7: Thymin

$\mathrm{R}=\mathrm{H}$

8: Fluorouracil

$\mathrm{R}=\mathrm{CH}_{3}$

$\mathrm{R}=\mathrm{F}$

Abbildung 3: $\quad$ Die Antimetabolite Methotrexat (4) und Fluorouracil (8).

Einen weiteren Antimetabolit stellt Fluorouracil (8) dar, in dem ein Wasserstoffatom des Uracils (6) durch ein Fluoratom substituiert wurde. Da die C-F-Bindung zwar sterisch ähnlich anspruchsvoll, aber wesentlich stärker als eine $\mathrm{C}-\mathrm{H}$-Bindung ist, wird die Umwandlung von Uracil (6) zu Thymidinmonophosphat und damit die Synthese des DNA-Bausteins Thymin (7) gehemmt. $^{31}$

Mitosehemmstoffe verhindern den Auf- (Vinca-Alkaloide) bzw. Abbau (Taxane) des Spindelapparates und führen dadurch zu einem Arrest des Zellzyklus in der M-Phase. Beispiele sind die Vinca-Alkaloide Vincristin (9) und die Taxane Docetaxel (10), Taxol und Epothilon. $^{32,33}$

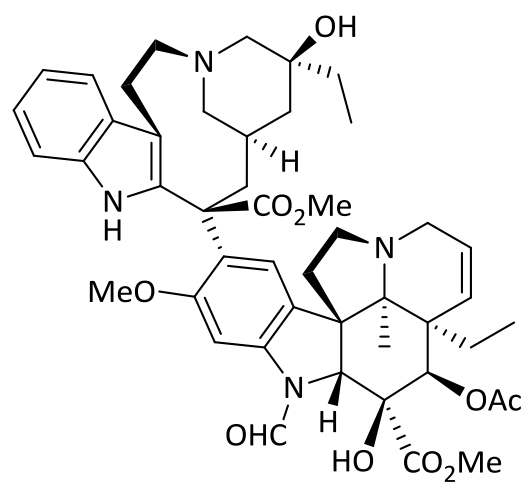

9

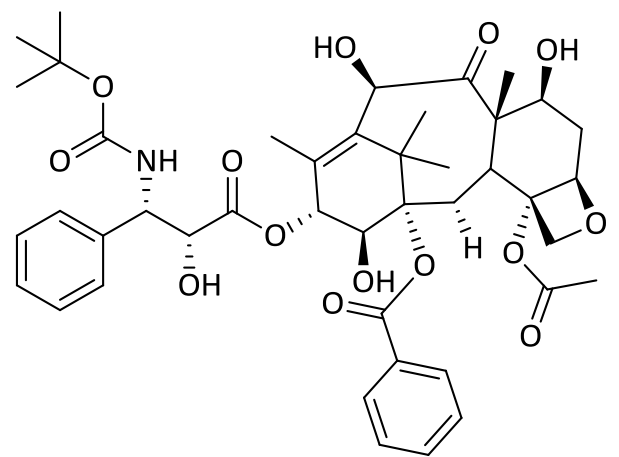

10

Abbildung 4: Die Mitosehemmstoffe Vincristin (9) und Docetaxel (10).

Eine weitere Klasse der Chemotherapeutika stellen die Topoisomerase-Hemmstoffe dar. Zur Transkription und Replikation des Erbguts ist eine Entspiralisierung der DNAbzw. RNA-Stränge durch Topoisomerasen erforderlich. Neben den gerade 
abgelesenen Stellen kommt es dadurch zu einer Verdrillung, welche ebenfalls von Topoisomerasen durch vorübergehenden Einzelstrangbruch aufgehoben wird. ${ }^{10}$ Stoffe wie Camptothecin (11) und Belotecan (12) (Abbildung 5) stabilisieren den zwischen DNA und Topoisomerase gebildeten Komplex und verhindern dadurch eine Dissoziation des Enzyms von der DNA. Die Folge sind Strangbrüche, die schließlich zum Zelltod führen. ${ }^{34}$
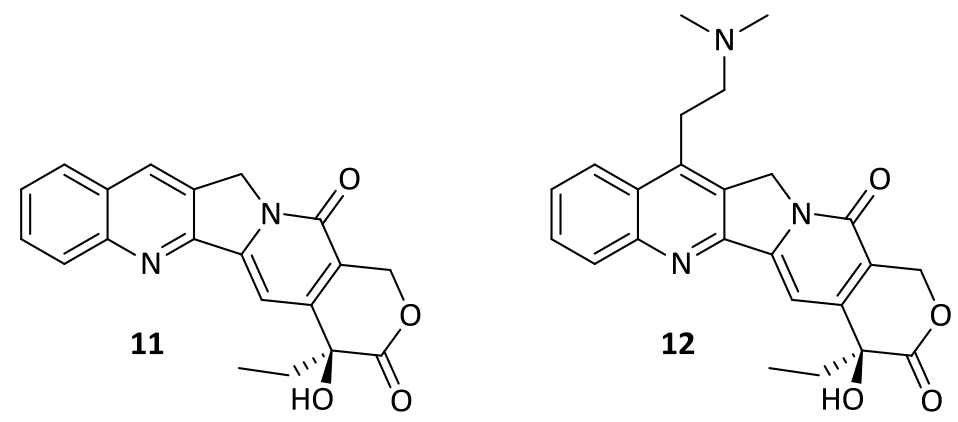

Abbildung 5: Die Topoisomerase-Hemmer Camptothecin (11) und Belotecan (12).

Die letzte Gruppe der Chemotherapeutika bilden die hauptsächlich aus StreptomycesArten isolierten zytostatischen Antibiotika. Beispiele sind die Anthracycline Daunorubicin (13) und Doxorubicin (14) (Abbildung 6). ${ }^{35}$

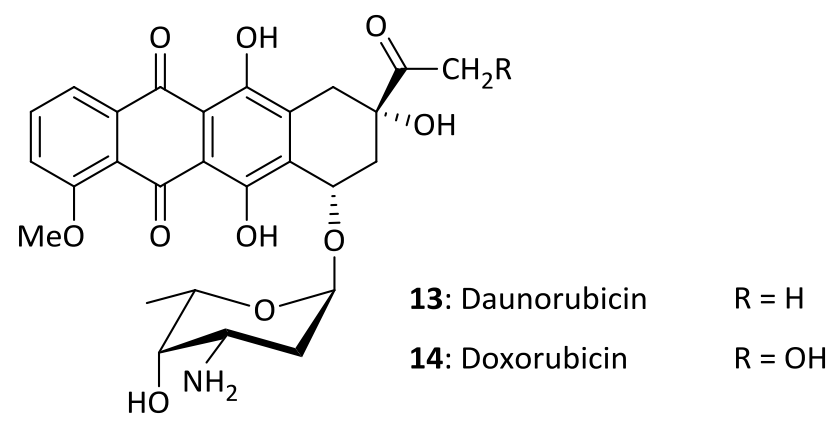

Abbildung 6: Die zytostatischen Antibiotika Daunorubicin (13) und Doxorubicin (14).

Sie interkalieren in die DNA und bewirken dadurch eine Hemmung der DNA- und RNA-Synthese. ${ }^{10,36}$

Chemotherapeutika liefern heute, insbesondere bei schwer zugänglichen Tumoren oder bei Metastasenbildung, einen wichtigen Beitrag zur erfolgreichen Tumorbehandlung. Da sie die Zellteilung hemmen, sind neben Tumorzellen auch normale, sich häufig teilende Zellen wie hämatopoetische Zellen im Knochenmark oder die Epithelzellen der Mukosa des Verdauungstraktes betroffen. Dies erklärt die oft 
gravierenden Nebenwirkungen, wie Verminderung der Zellen im peripheren Blut, Durchfall und Haarausfall. ${ }^{10}$ Ein weiteres Problem der Tumorbehandlung mittels Chemotherapie stellen Resistenzbildungen gegen einzelne Zytostatika oder -klassen durch natürliche Selektion unter den Tumorzellen dar. ${ }^{37}$

Sowohl die auftretenden Nebenwirkungen als auch die Resistenzbildung machen eine ständige Weiterentwicklung bestehender und die Entwicklung gänzlich neuer Wirkstoffe unablässlich.

Beispiele für die neuesten Entwicklungen in der Tumortherapie sind die Immuntherapie und das ADEPT-Konzept.

Die Immuntherapie umfasst die Markierung von Krebszellen durch monoklonare Antikörper ${ }^{38}$, die nicht-spezifische Tumortherapie durch Immun-Adjuvantien ${ }^{38 a, b}$ und zukünftig die passive ${ }^{39}$ und aktive ${ }^{40}$ Impfung gegen Tumore.

Das ADEPT-Konzept (Antibody-Directed Enzyme Prodrug Therapy) umfaßt die enzymatische Umwandlung im Tumorgewebe von weitgehend untoxischen Verbindungen (Prodrugs) in möglichst hochzytotoxische Wirkstoffe (Drugs). Das Ziel ist eine lokale Freisetzung des Wirkstoffs im Tumorgewebe. ${ }^{41,42}$ 


\section{Duocarmycin}

Das natürliche Antibiotikum (+)-CC-1065 (15) wurde 1978 von Mitarbeitern der Upjohn-Company erstmals aus Kulturen von Streptomyces zelensis isoliert. ${ }^{43}$ Es zeigte in biologischen Screenings sowohl in vitro als auch in vivo eine enorm hohe Zytotoxizität, eine breitgefächerte antibiotische Wirksamkeit und eine starke Antitumoraktivität. ${ }^{44}$ Die ausergewöhnliche Struktur des (+)-CC-1065 setzt sich aus drei substituierten Pyrrolo[2,3-e]-indol-Einheiten zusammen, die jeweils über Amidbindungen miteinander verknüpft sind (Abbildung 7).

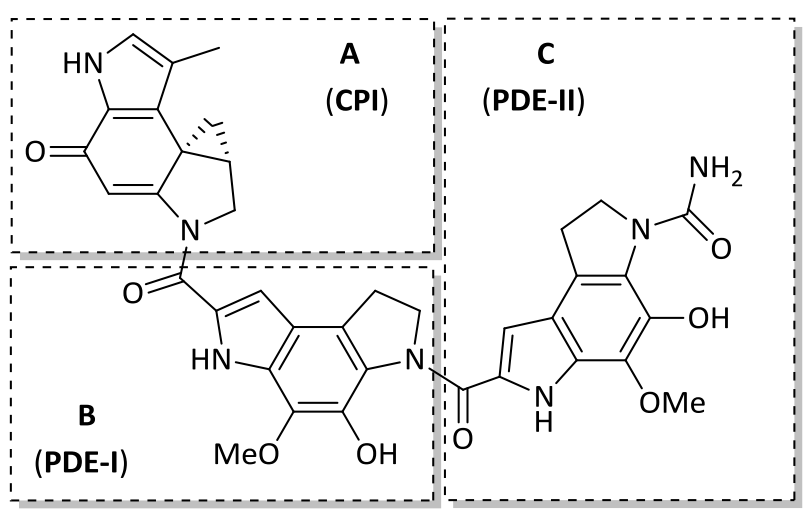

15: (+)-CC-1065

$\mathrm{IC}_{50}: 20 \mathrm{pM}(\mathrm{L} 1210)$

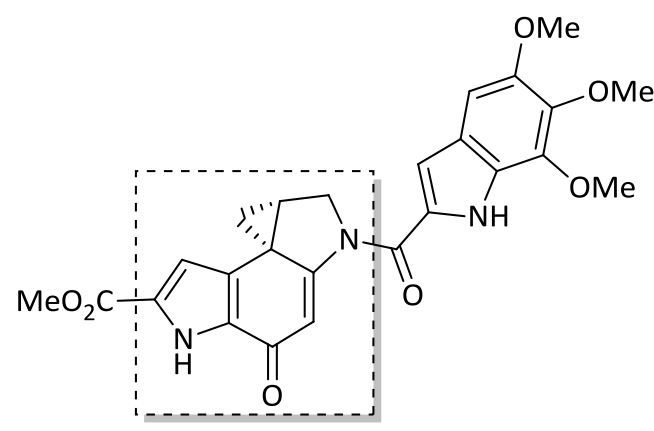

16: (+)-Duocarmycin SA

$\mathrm{IC}_{50}: 10 \mathrm{pM}(\mathrm{L} 1210)$

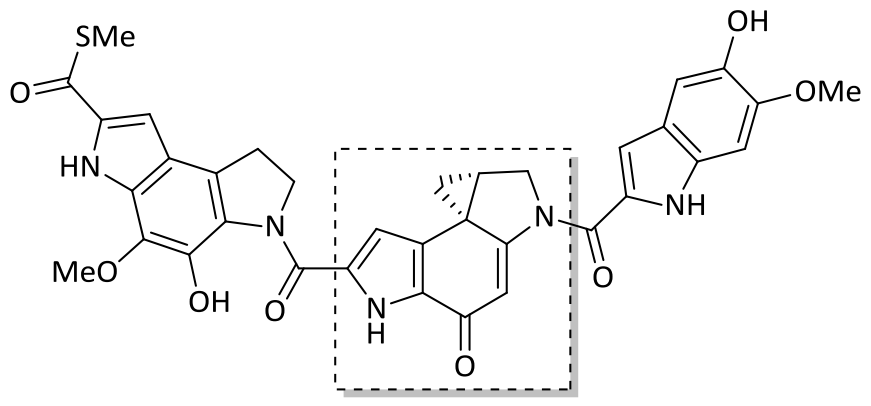

17: (+)-Yatakemycin

$\mathrm{IC}_{50}:$ 3-5 pM (L1210)

Abbildung 7: $\quad$ Die Alkylantien (+)-CC-1065 (15), (+)-Duocarmycin SA (16) und (+)-Yatakemycin (17).

Die Segmente B und $\mathbf{C}$ bestehen aus identisch substituierten 1,2-Dihydro-3H-pyrrolo[3,2-e]-indol-Systemen, die als PDE-I und PDE-II bezeichnet werden. Da sie eine hohe Affinität zu Doppelstrang-DNA besitzen, werden sie als DNA-bindende Einheiten beschrieben. Als wichtigstes Strukturelement im pharmakophoren Segment A, auch 
als CPI (Cyclopropapyrroloindol) bezeichnet, befindet sich eine Spirocyclopropylcyclohexadienon-Struktur. Sie ist ebenfalls in den strukturell verwandten Duocarmycinen $^{45}$ (z.B. (+)-Duocarmycin SA (16)) und Yatakemycin ${ }^{46}$ (17), isoliert aus anderen Streptomycetenstämmen, zu finden. Letzteres stellt mit einem $\mathrm{IC}_{50}$-Wert von 3 pM derzeit eines der potentesten Zytostatika dar. Innerhalb der Chemotherapeutika werden diese Verbindungen in die Klasse der Alkylantien (Kapitel B3) eingeordnet.

Die zytotoxische Wirkung des CC-1065 (15) und seiner Analoga beruht vermutlich auf einer sequenzspezifischen Alkylierung der DNA in AT-reichen Regionen. Hierbei addiert das Adenin- $N-3$ in der kleinen Furche doppelsträngiger DNA an das Brückenkopfatom (hier das am niedrigsten substituierte Kohlenstoffatom) der Spirocyclopropyleinheit (Abbildung 8).
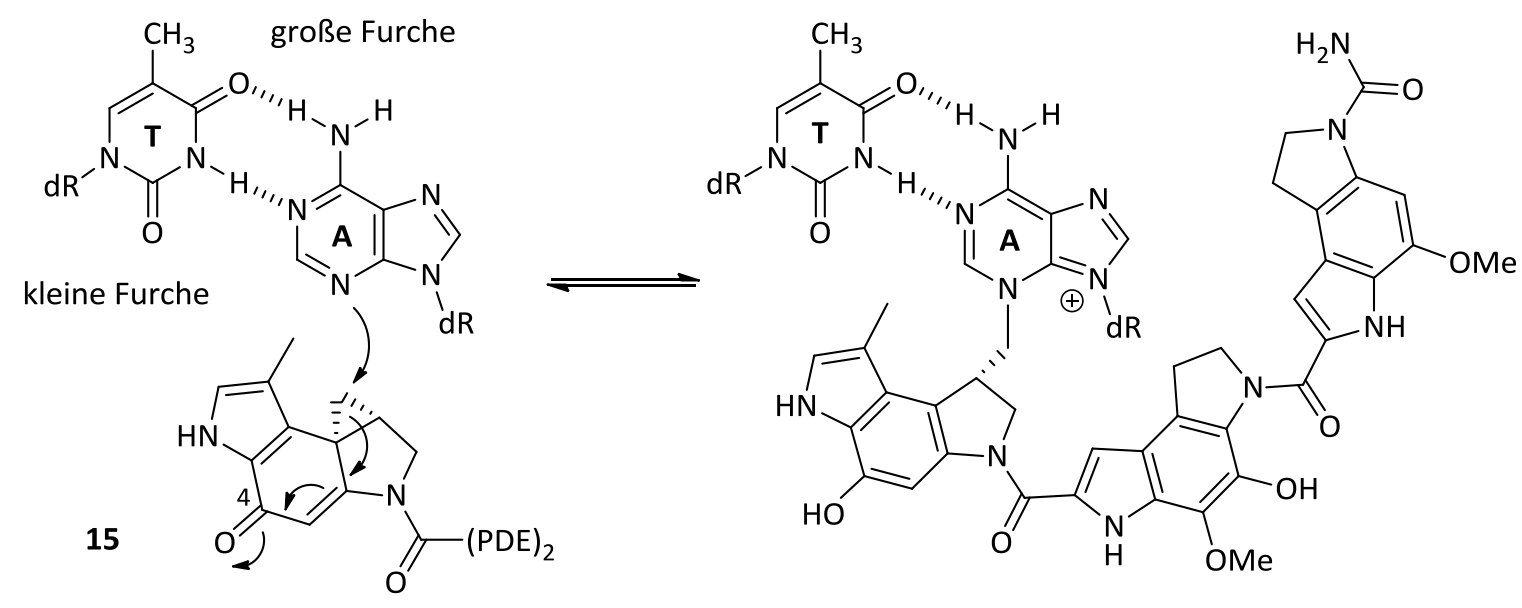

Abbildung 8: Mechanismus der DNA-Alkylierung durch CC-1065 (15) in der kleinen Furche.

Die lipophile Innenseite der gekrümmten Struktur des CC-1065 und seiner Analoga begünstigt dabei eine Wechselwirkung mit den Nukleobasen, während die hydrophile Außenseite die Einlagerung in die kleine Furche durch Wechselwirkungen mit den polaren Funktionalitäten des DNA-Rückgrates stabilisiert.

Zur Erklärung der beobachteten Alkylierungsselektivität wurden verschiedene Hypothesen aufgestellt. L. H. Hurley postuliert in seinem Modell zunächst eine Protonierung der Carbonylfunktion am C-4-Atom, die aus einer günstig angeordneten Phosphatgruppe im flexiblen DNA-Rückgrat resultiere. ${ }^{47}$ In Folge dessen ändere sich 
die Konformation der DNA, wodurch das nukleophile $\mathrm{N}$-3-Atom in einem günstigen Abstand zur elektrophilen Spirocyclopropyl-cyclohexadienon-Gruppe gelange. Gegen diese Hypothese sprechen jedoch, dass Strukturanaloga, die keine Carbonylgruppe am C-4-Atom besitzen, die gleiche Selektivität zeigen und ebenfalls alkylierend wirken, und laut Studien die Konformationsänderung der DNA bei der Bindung des Wirkstoffs nicht signifikant ist. ${ }^{48}$

Von D. L. Boger stammt hingegen das Modell der konformativen Aktivierung (conformational catalysis), $^{49}$ in dem postuliert wird, dass die DNA-bindende Untereinheit über eine formspezifische Erkennung (shape-selective recognition) tief in die kleine Furche der DNA eindringt und dann über van der Waals-Kräfte an ATreiche Sequenzen bindet. Die normalerweise elektrophile, hochreaktive Spirocyclopropyl-Gruppe ist durch eine Kreuzkonjugation mit dem vinylogen Amid stabilisiert. Durch die mit der Bindung an die DNA einhergehende Konformationsänderung der Amidbindung, wird diese Stabilisierung jedoch aufgehoben und eine Konjugation mit der Cyclohexadienon-Einheit hergestellt. ${ }^{50}$ Dies führt zu einer deutlichen Steigerung der Reaktivität gegenüber einem nukleophilen Angriff (target-based activation). Gestützt wird diese Hypothese durch Untersuchungen an den Strukturanaloga 18-21 (Abbildung 9).

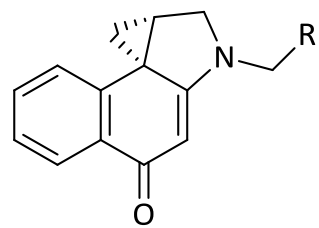

18

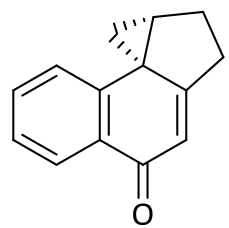

19

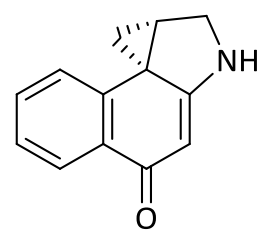

20

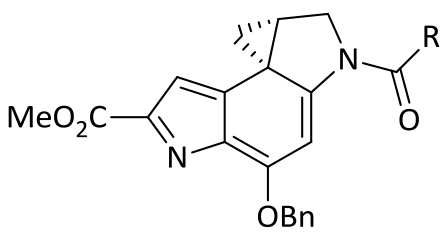

21

Abbildung 9: Verbindung 18-20 besitzen keine Amidfunktion, bei $\mathbf{2 1}$ erfolgte eine alternative Spirozyklisierung.

Verbindung 18 besitzt im Gegensatz zu den Duocarmycinen keine Amidbindung, die Spirocyclopropyl-Gruppe ist jedoch ebenfalls durch Kreuzkonjugation stabilisiert. Wie zu erwarten, zeigt 18 keine alkylierenden Eigenschaften, da aufgrund des Fehlens der Carbonylgruppe am verbindenden Amid keine Wechselwirkung mit DNA und somit keine Aktivierung der Spirocyclopropyl-Gruppe möglich ist. Der stabilisierende Effekt 
des vinylogen Amids konnte ebenfalls durch Untersuchungen an Verbindung 19, dem das entsprechende Stickstoffatom fehlt, gezeigt werden. Wie zu erwarten war, zeigte 19 im Vergleich zu CBI eine um das 1000-fache erhöhte Reaktivität gegenüber nukleophiler Addition. Weitere Anhaltspunkte für die stabilisierende Wirkung der Konjugation des vinylogen Amids lieferten Untersuchungen des Indols 21. Da es über eine alternative Spirozyklisierung hergestellt wurde, fehlt in $\mathbf{2 1}$ das vinyloge Amid. In Einklang mit den Erwartungen zeigte sich, dass 21 gegenüber Duocarmycin SA (16) eine deutlich geringere Stabilität aufweist. ${ }^{49}$

Im Gegensatz zu diesen experimentellen Befunden stehen allerdings von J. P. Bowen und $V$. Barone durchgeführte DFT-Berechnungen. ${ }^{51}$ Die Wissenschaftler konnten in ihren Berechnungen zeigen, dass eine Verdrillung der Amidbindung nur zu einer marginalen Änderung der Alkylierungsrate führt. Dies erklärt auch die Tatsache, dass Moleküle mit ähnlicher Verdrillung der Amidbindung sehr unterschiedliche Reaktivitäten zeigen. Für eine Steigerung der Reaktivität seien demnach vor allem Wechselwirkungen des Wirkstoffs mit der DNA, über nicht-kovalente Bindungen in der kleinen Furche, verantwortlich. ${ }^{52}$

\subsection{Analoga des Antibiotikums CC-1065 und der Duocarmycine}

Obwohl CC-1065 (15) und die Duocarmycine herausragende Zytotoxizitäten zeigen, stellte sich in Tierversuchen an Mäusen heraus, dass sie aufgrund ihrer starken Nebenwirkungen nicht für eine klinische Anwendung geeignet sind. In therapeutischen Dosen trat bei CC-1065 (15) eine verzögerte, letale Hepatotoxizität und bei den Duocarmycinen eine hohe Myelotoxizität auf. Verschiedene natürliche (CPI, $\mathrm{DA}, \mathrm{DSA})$ und synthetische $(\mathrm{Cl}, \mathrm{CBI}, \mathrm{CBIQ}, \mathrm{MCBI}, \mathrm{MCCPI})$ Analoga ergaben zwar ähnlich hohe Zytotoxizitäten und teilweise ebenso eine Myelotoxizität, jedoch keine Hepatotoxizität. ${ }^{53}$ Es wird daher angenommen, dass die Heptotoxizität auf die Originalstruktur des CC-1065 (15) und nicht auf den zugrunde liegenden Wirkmechanismus zurückzuführen ist. ${ }^{54}$ 


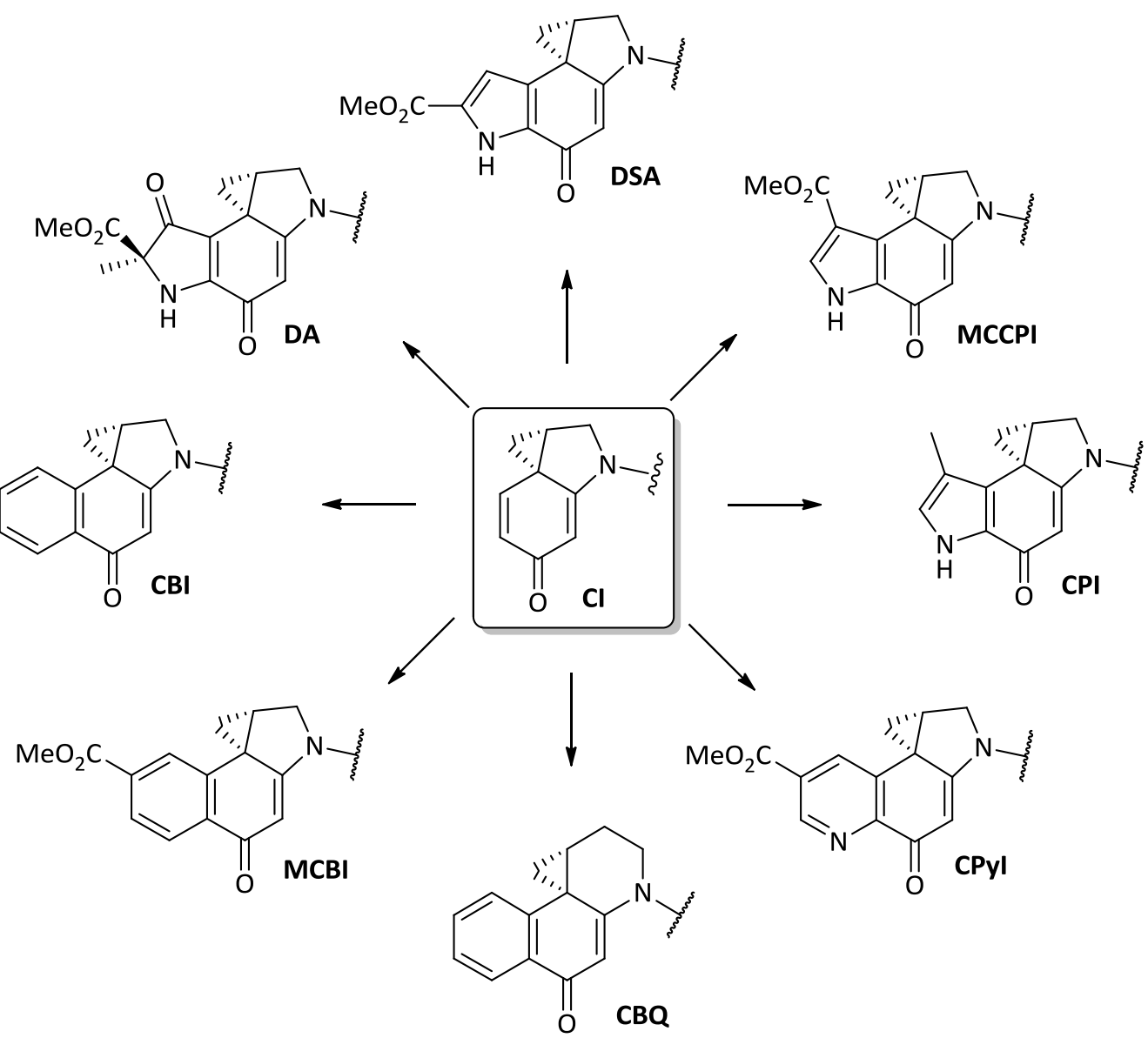

Abbildung 10: Analoga des CC-1065 mit der pharmakophoren Cl-Einheit.

Durch die Aufklärung von Struktur-Wirkungsbeziehungen konnte festgestellt werden, dass eine direkte Beziehung zwischen der Solvolysestabilität der pharmakophoren Einheit und der Zytotoxizität besteht. ${ }^{50,55}$ Es zeigte sich ein parabolischer Verlauf, demnach chemisch stabilere Verbindungen auch zytotoxischer sind, jedoch die Zytotoxizität ab einer bestimmten Stabilität wieder abnimmt. Duocarmycin SA (16) und Yatakemycin (17) liegen auf dem Maximum der Parabel. Als eine Erklärung für diesen Verlauf dient die Annahme, dass der Wirkstoff stabil genug sein muss, um ohne Solvolyse an den Wirkort transportiert werden zu können, um dann erst alkylierend zu wirken. Ist das Drug hingegen zu stabil, wird es zwar an den Wirkort transportiert, da die Alkylierungsgeschwindigkeit jedoch zu gering ist, erfolgt nur eine langsame Bindung an die DNA. Die Wirkung des Drugs ist somit geringer.

Neben der Variation der pharmakophoren Einheit wurde auch der Einfluss der DNAbindenden Einheit der Duocarmycine und verwandter Verbindungen systematisch untersucht und die entsprechenden Zytotoxizitäten verglichen. ${ }^{54,56}$ Tabelle 1 zeigt 


\section{ausgewählte Beispiele DNA-bindender Einheiten kombiniert mit den pharmakophoren Gruppen DSA, CPI und CBI.}

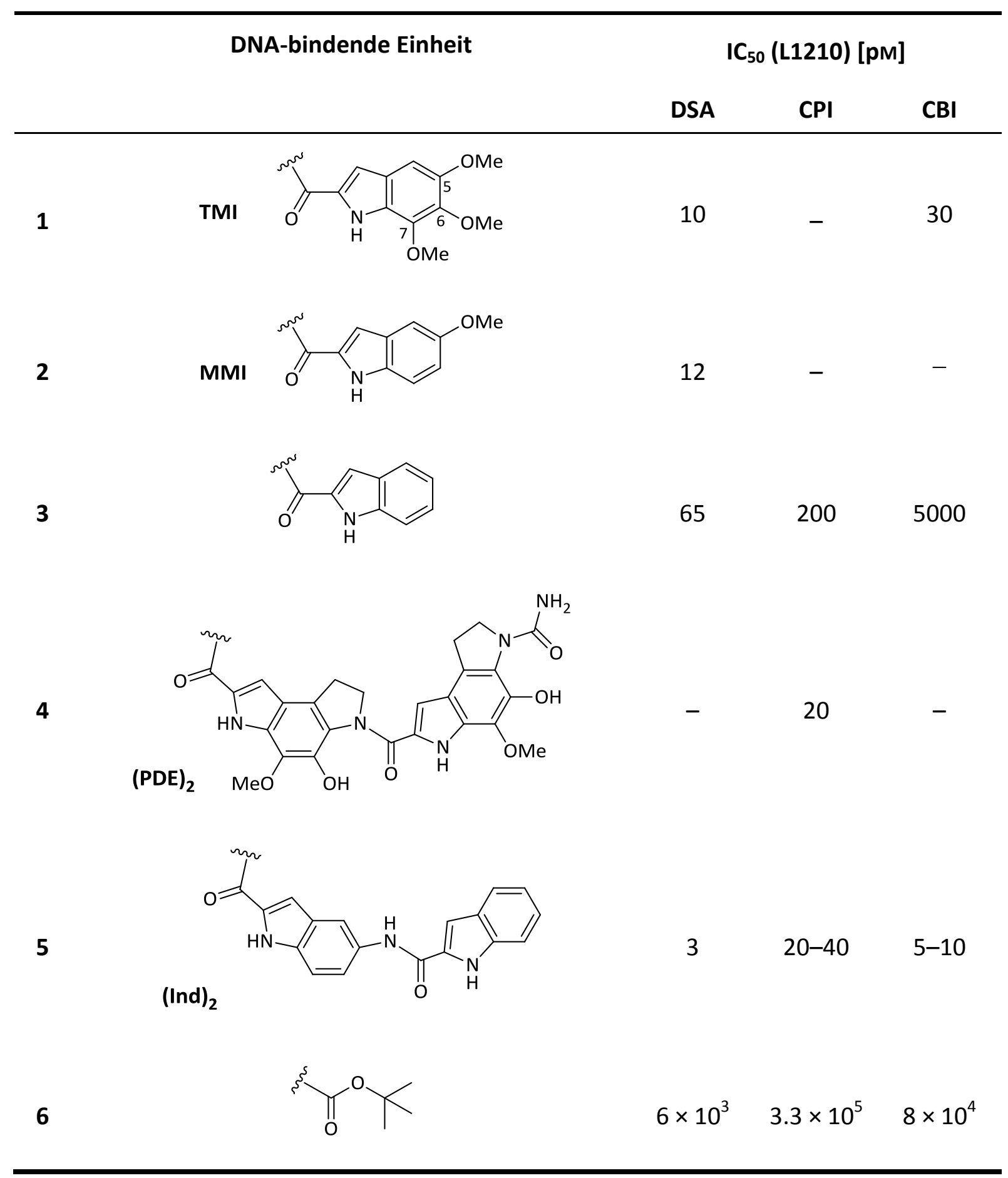

Tabelle 1: $\quad$ Einfluß der DNA-bindenden Struktureinheit auf die Antitumoraktivität von DSA-, CPI- und CBIAnaloga.

Versuche zeigten, dass die Methoxysubstituenten an C-6 und C-7 nur geringen Einfluss auf die Zytotoxizität haben, die Methoxygruppe an C-5 jedoch essentiell für die biologische Wirksamkeit ist (Einträge 1-3). Die Bisindol-Derivate (Einträge 4 u. 5) 
zeigen gegenüber den TMI-Derivaten eine um den Faktor drei bis sechs erhöhte Zytotoxizität. Dies lässt vermuten, dass diese proportional von der Größe der DNAbindenden Einheit abhängt. Analoga ohne DNA-bindende Einheit zeigten hingegen eine 1000- bis 10 000-fach verringerte biologische Wirksamkeit (Eintrag 6).

Neben den Struktur-Wirkungsbeziehungen und dem Einfluss der DNA-bindenden Einheit wurde ebenfalls der Einfluss der Konfiguration der pharmakophoren Gruppe auf die Zytotoxizität untersucht. Es stellte sich heraus, dass Wirkstoffe mit unnatürlicher Konfiguration geringere (Duocarmycine) oder ähnliche (CC-1065) Zytotoxizitäten zeigten wie ihre natürlich vorkommenden Enantiomere. ${ }^{57}$

Bei Duocarmycin A ist beispielsweise das natürliche (+)-Enantiomer (+)-22 um einen Faktor 110 zytotoxischer als das (-)-Enantiomer (-)-22 (Abbildung 11). ${ }^{57}$

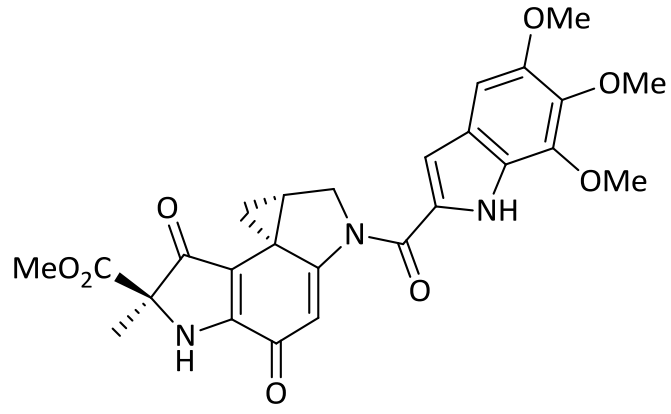

(+)-22: (+)-Duocarmycin A

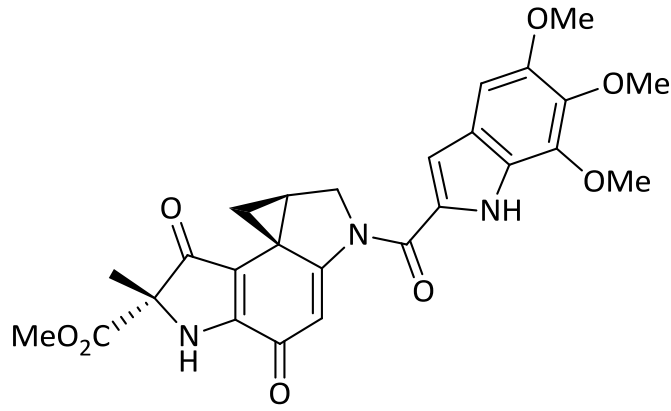

(-)-22: (-)-Duocarmycin A

Abbildung 11: Die Duocarmycine (+)-Duocarmycin A ((+)-22) und (-)-Duocarmycin A ((-)-22).

Enantiomere orientieren sich genau entgegengesetzt gegenüber Duplex-DNA. Diese logische Schlussfolgerung steht in Einklang mit der Beobachtung, dass natürlich konfigurierte Wirkstoffe mit DNA-bindender Einheit ein Adenin am 3'-Ende einer ATreichen Region und Wirkstoffe mit unnatürlicher Konfiguration ein Adenin am 3'-Ende des komplementären Stranges binden. ${ }^{54}$

Einige Vertreter der synthetischen Duocarmycine fanden aufgrund ihrer hervorragenden In-vitro-Ergebnisse Zugang zu klinischen Studien (Abbildung 12). 

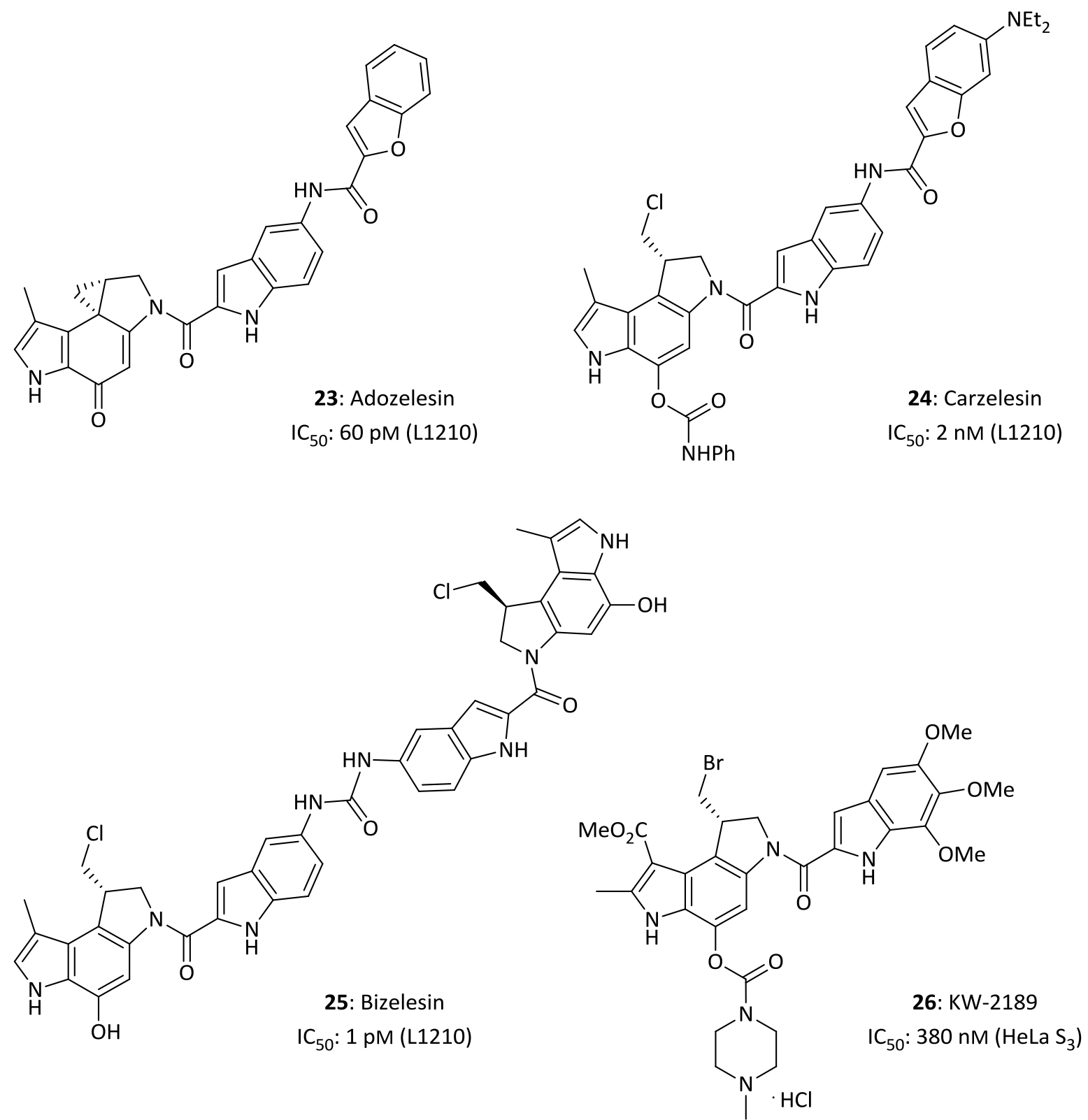

Abbildung 12: In klinischen Phasen getestete Duocarmycin-Analoga: Adozelesin (23), Carzelesin (24), Bizelesin (25) und KW-2189 (26).

Während Adozelesin $(\mathbf{2 3})^{58}$ bereits die Spirocyclopropyl-Gruppe trägt, stellen Carzelesin (24), ${ }^{59}$ Bizelesin $(25)^{60}$ und KW-2189 (26) ${ }^{61}$ seco-Vorstufen dar, aus denen die aktiven Spezies erst in situ gebildet werden. Wie bei anderen Duocarmycinen bereits bekannt, stellte sich auch bei diesen Verbindundungen, mit Ausnahme von Bizelesin (25), eine ausgeprägte Myelotoxizität heraus. ${ }^{58-61}$ Die klinischen Studien wurden daher nur für Letzteres weitergeführt. 


\subsection{Seco-Verbindungen und Prodrugs einiger Duocarmycin-Analoga}

Verbindungen vom Typ 27 oder 29, obwohl sie keine Spirocyclopropyl-Einheit im Molekül tragen, zeigen ähnliche Toxizitäten und Selektivitäten wie der Wirkstoff (28) selbst. ${ }^{41,54}$ Es wird daher angenommen, dass zunächst eine Generierung des Cyclopropanrings in situ durch Winstein-Aryl-3'-Spirozyklisierung ${ }^{62}$ und erst dann eine Alkylierung der DNA erfolgt (Abbildung 13).

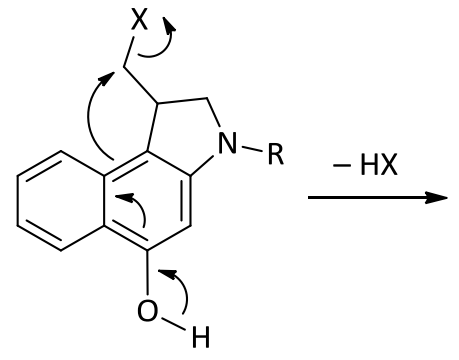

27<smiles>[R]N1CC2=CC(=O)c3ccccc3C23CC3C1</smiles>

28<smiles></smiles>

29

Abbildung 13: Winstein-Aryl-3'-Spirozyklisierung der seco-CBI-Derivate 27 und 29.

Da die phenolische Hydroxyfunktion aufgrund des Zyklisierungsmechanismus essentiell für die Bildung der aktiven Spezies ist, sollte eine Blockade somit die secoDrugs 27 und 29 in wesentlich weniger toxische Vorstufen, die detoxifizierten Prodrugs, überführen. ${ }^{63}$

Von W. A. Denny stammt der Ansatz der Gene-directed Enzyme Prodrug Therapie (GDEPT). Dabei wurden Krebszellen genetisch mit einem Vektor so verändert, dass diese das Enzym Nitroreduktase produzierten. Als Prodrug wurde ein als Carbamat geschütztes Amino-seco-CBI-Derivat eingesetzt (Abbildung 14). ${ }^{64}$ 


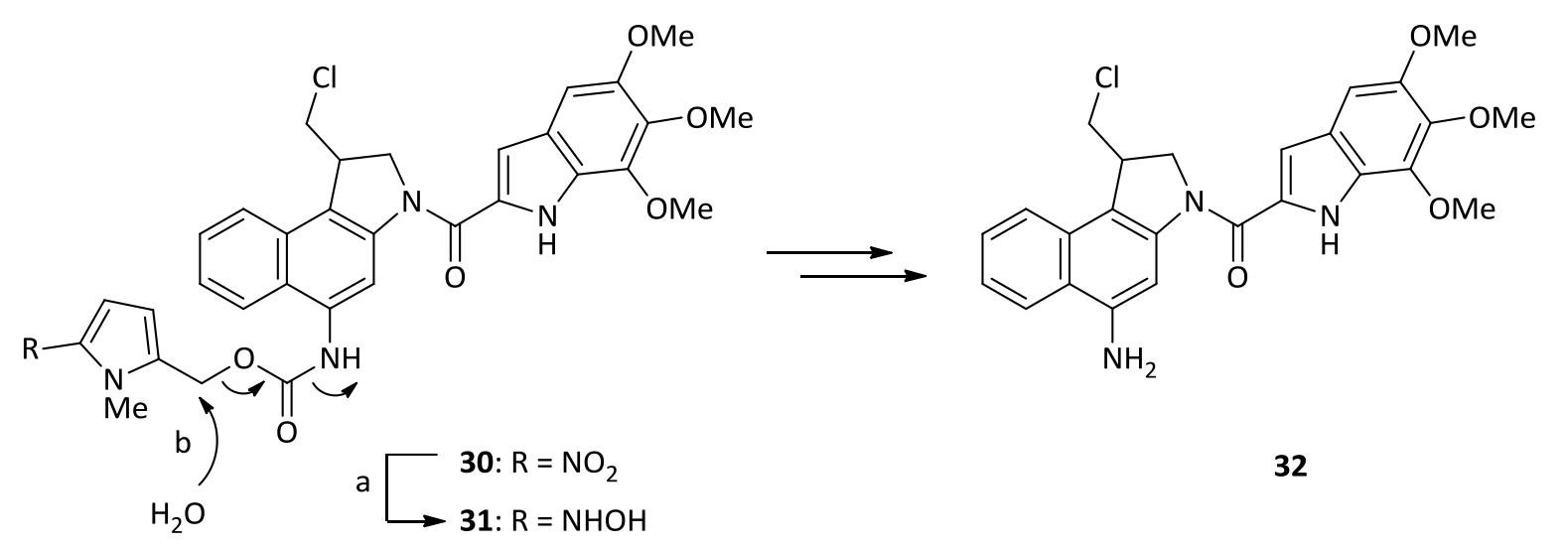

Abbildung 14: Reduktion des Prodrugs 30 durch Nitroreduktase (a) und anschließende Hydrolyse zum zytotoxischen seco-Drug 32 (b).

Dieses sollte über die in den Krebszellen exprimierte Nitroreduktase in die entsprechende seco-Form überführt werden und somit eine selektive Alkylierung erfolgen. Das Prodrug $\mathbf{3 0}$ zeigte jedoch im Vergleich von transfizierten SKOV-3-Zellen mit unbehandelten Zellen lediglich eine 20-fach verringerte Zytotoxizität. Untersuchungen an weiteren Analoga lieferten nur um bis zu 87-fach verringerte Zytotoxizitäten. ${ }^{65}$ Dies deutet auf eine nur unzureichende Aktivierung durch das Enzym hin und stellt keinen zufriedenstellenden Zytotoxizitätsunterschied dar.

Einen anderen Ansatz stellt die Modifikation der DNA-bindenden Einheit dar. Das Konzept sieht vor, diese mit einer enzymatisch spaltbaren Gruppe zu schützen, so dass sie nicht mehr mit DNA interagieren kann. Wenn dieses Prodrug gespalten wird, soll die DNA-bindende Einheit frei werden, der Wirkstoff in die kleine Furche eindringen, und an die DNA binden.

Y. Wang untersuchte Prodrugs, bei denen die DNA-bindenden Einheiten durch einen peracetylierten Glucuronsäure-Methylester ${ }^{66}$ blockiert werden sollten (Abbildung 15). 


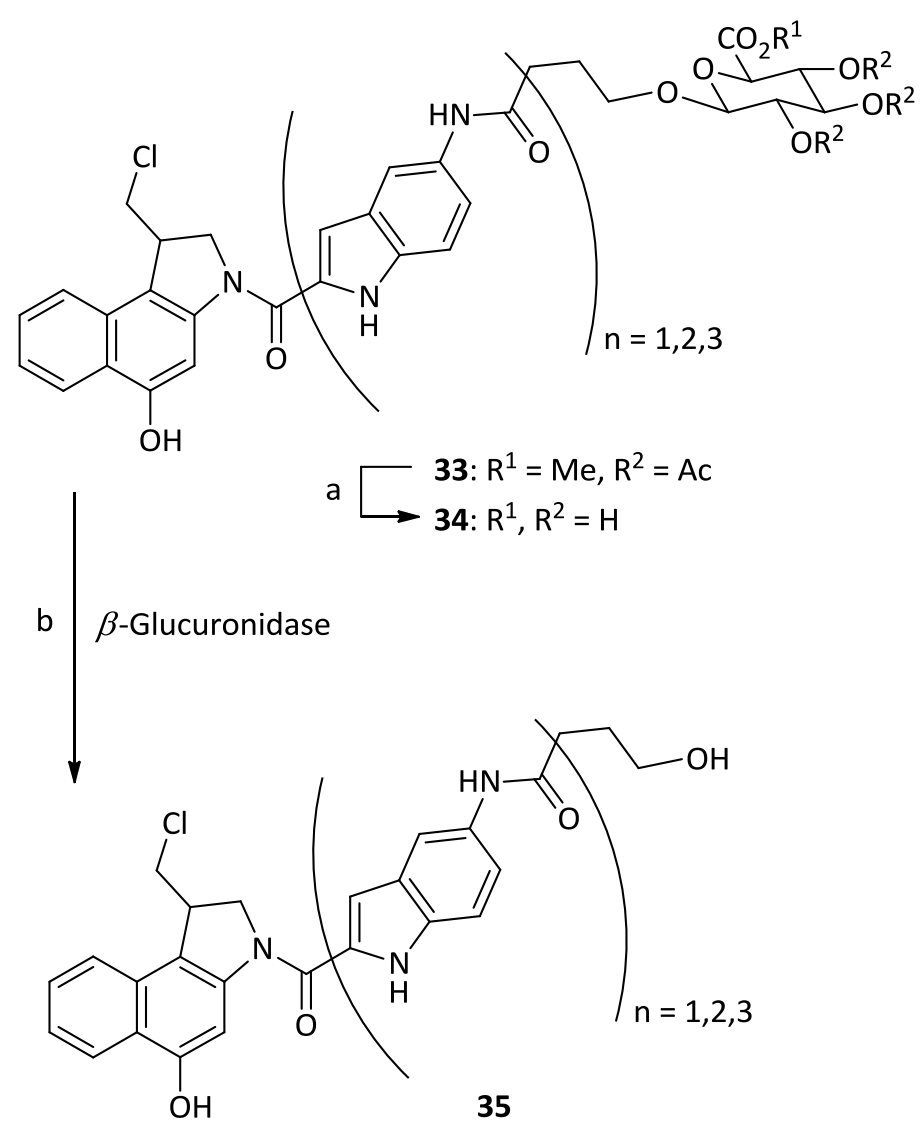

Abbildung 15 Durch einen peracetylierten Glucuronsäure-Methylester detoxifizierte Prodrugs 33.

Es zeigte sich jedoch für verschiedene Prodrugs 33 kein signifikanter Unterschied der Zytotoxizitäten gegenüber den entsprechenden seco-Drugs 35. Mögliche Erklärungen dafür sind die unzureichende Abspaltung der Acetat-Gruppen durch eine Esterase oder dass 34 ein schlechtes Substrat für die $\beta$-Glucuronidase darstellt. Des Weiteren muss hinterfragt werden, ob dieses Konzept der Detoxifizierung von seco-Drugs überhaupt sinnvoll ist, da kein Unterschied in den Zytotoxizitäten zwischen mit und ohne Enzyme inkubierten Prodrugs festzustellen war. Dies deutet darauf hin, dass die eingeführten Gruppen nicht geeignet sind, ein Eindringen in die DNA zu verhindern.

Im Arbeitskreis L. F. Tietze wurden in den letzten Jahren erfolgreich zahlreiche Duocarmycin-Analoga synthetisiert und hinsichtlich ihrer biologischen Wirksamkeit untersucht. $^{41,67,68} \mathrm{Im}$ Gegensatz zu anderen Arbeitsgruppen erfolgt eine Detoxifizierung dabei durch eine Verknüpfung der phenolischen Hydroxyfunktion mit Glykosiden. Die entstandenen Prodrugs können anschließend durch AntikörperGlycohydrolase-Konjugate (ADEPT) oder tumorassoziierte $\beta$-D-Glucuronidase (PMT) 
zu den entsprechenden seco-Drugs gespalten werden. Neben einer Zytotoxizität der seco-Drugs im $\mathrm{nM}$ bis $\mathrm{pM}$-Bereich ist ein $\mathrm{QIC}_{50}$-Wert über 1000 Vorraussetzung für eine mögliche therapeutische Anwendung. Die Forschung konzentrierte sich dabei vor allem auf $\mathrm{CBI}$ und anti-Methyl-CBI-Analoga, die mit unterschiedlichen Glykosiden und DNA-bindenden Einheiten gekuppelt wurden (Abbildung 16).
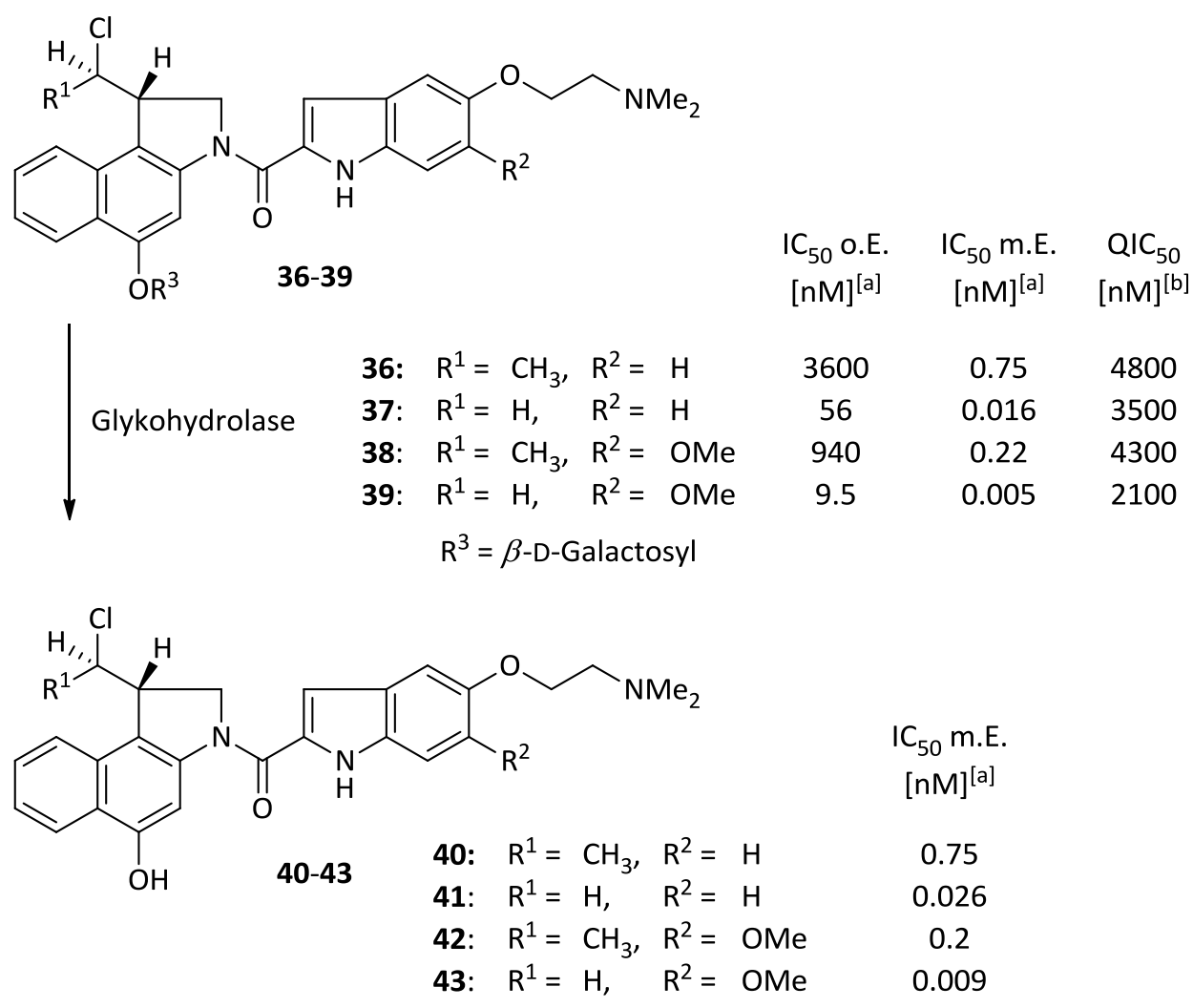

Abbildung 16: Duocarmycin-analoge, glykosidische Prodrugs aus dem Arbeitskreis Tietze, die zunächst mit Hilfe entsprechender Glykohydrolasen zu den seco-Drugs aktiviert werden, welche darauf folgend in situ zu den entsprechenden Drugs zyklisieren. [a] Bestimmung der $\mathrm{IC}_{50}$-Werte mittels Klonogenitätsassays an der Lungenkrebszelllinie A549; [b] QIC ${ }_{50}=I C_{50}$ des Prodrugs / $\mathrm{IC}_{50}$ des Prodrugs in Anwesenheit des spaltenden Enzyms. o.E. $=$ ohne Enzym, m.E. = mit Enzym.

Um die Wahrscheinlichkeit einer direkten Alkylierung der DNA durch das Prodrug zu verringern, wurde der sterische Anspruch an der pharmakophoren Einheit durch Einführung einer Methyl-Gruppe erhöht. Die Zytotoxizitäten der CBI-Prodrugs $(37,39)$ und seco-Drugs $(\mathbf{4 1}, \mathbf{4 3})$ liegen daher deutlich über denen der Methyl-Prodrugs (36, 38) und seco-Drugs $(40,42)$. Der Vergleich der $\mathrm{QIC}_{50}$-Werte der Methyl-Prodrugs 36 und $38\left(\mathrm{QIC}_{50}=4800\right.$ bzw. 4300) mit den CBI-Prodrugs 37 und $39\left(\mathrm{QIC}_{50}=3500\right.$ bzw. 
2100) macht deutlich, dass die Einführung der sterisch anspruchsvollen Methylgruppe eine direkte Alkylierung der DNA durch das Prodrug vermindern kann, ohne dass die Wirksamkeit des seco-Drugs ebenfalls proportional abnimmt. Des Weiteren wurde deutlich, dass neben dem Pharmakophor, die Wahl der Zucker- und DNA-bindenden Einheit für die biologische Aktivität von Bedeutung sind. Hier zeigten Kupplungen mit einem Galactosyl-Rest und DMAI $\left(R^{2}=H\right)$ oder DMMI $\left(R^{2}=\right.$ OMe $)$ die besten biologischen Aktivitäten.

Bis dahin unerreichte $\mathrm{QIC}_{50}$-Werte von bis zu einer Million und Zytotoxizitäten des seco-Drugs im femtomolaren Bereich konnten in Arbeiten von J. M. von Hof mit bifunktionalen Prodrugs ohne DNA-bindende Einheit erreicht werden (Abbildung 17). ${ }^{69}$

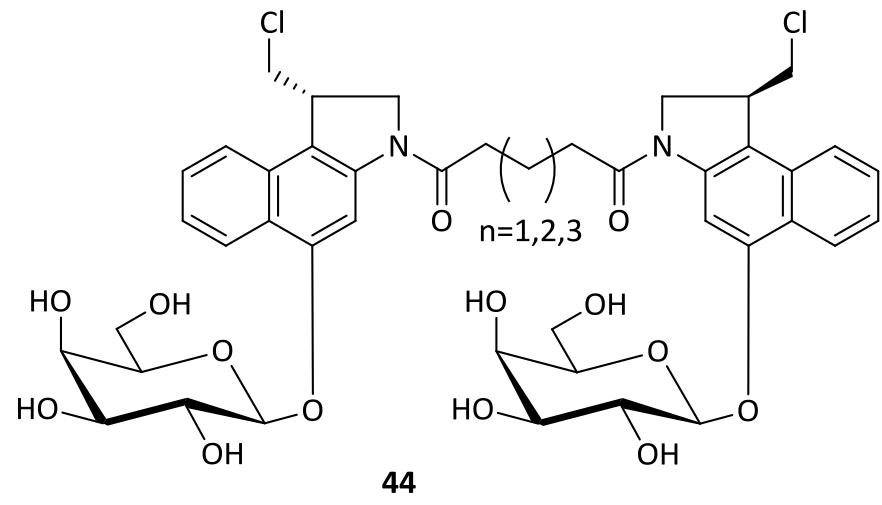

Abbildung 17: Im Arbeitskreis Tietze synthetisierte Dimere.

Im Gegensatz zu den bisher bekannten Wirkstoffen zeigten bifunktionale Verbindungen ohne DNA-bindende Einheit keinerlei Wechselwirkungen mit Doppelstrang DNA. $^{70}$ Mit Hilfe von ABPP-Studien konnte jedoch das Enzym Aldehyddehydrogenase $1 \mathrm{~A} 1$ als Target identifiziert werden. Obwohl die Bindung überraschenderweise nicht an das aktive Zentrum erfolgt, konnte dennoch eine Inhibierung des Enzyms festgestellt werden. 


\section{Acronycin}

Das Acridon-Alkaloid Acronycin (45) wurde zuerst 1948 aus der Pflanze Acronychia baueri Schott (Rutaceae) isoliert. ${ }^{71}$ Es zeigte in biologischen Screenings eine breitgefächerte Wirksamkeit gegenüber einer Vielzahl an Tumoren ${ }^{72}$ und wurde daraufhin bis in die klinische Phase 2 gebracht, aufgrund lediglich moderater Zytotoxizität und sehr geringer Löslichkeit jedoch nicht weiter verfolgt. ${ }^{73}$

Es wird angenommen, dass $\mathbf{4 5}$ intermediär unter Bildung des instabilen Epoxids $\mathbf{4 6}$ toxifiziert wird, welches dann als Alkylans der DNA wirkt. ${ }^{74}$ Dementsprechend wurde versucht, Löslichkeit und Aktivität durch Modifikationen des Pyran- und des A-Rings zu steigern und gleichzeitig das Reaktionsverhalten des Epoxids 46 gegenüber Nukleophilen bei gesteigerter Stabilität nachzuahmen (Abbildung 18).

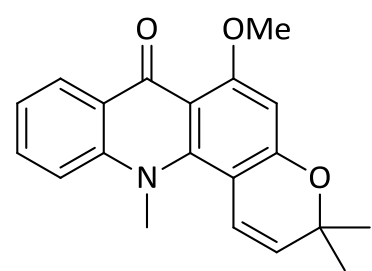

45

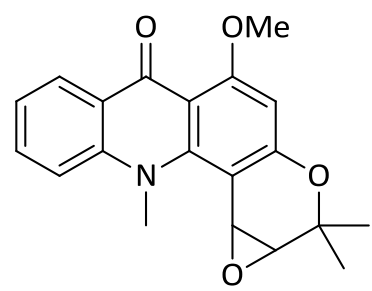

46

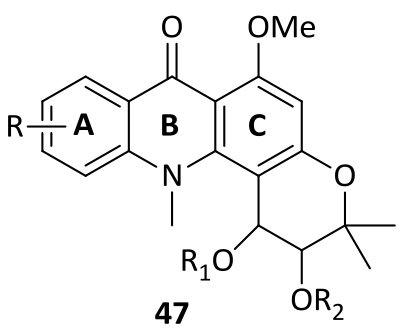

47

Abbildung 18: Acronycin (45), Acronycin-Epoxid (46) und Derivate 47.

\section{1}

Analoga des Acronycins 45 durch Modifikation des A-Rings

Durch eine Variation der Substitutionen am A-Ring des Acronycins (45) konnten Aussagen über Struktur-Wirkungsbeziehungen erzielt werden (Abbildung 19). Es zeigte sich, dass die Einführung einer Methylgruppe am Stickstoff nur einen geringen Einfluss auf die Zytotoxizität hat und somit vermutlich keine Auswirkungen auf die Wirkweise hat. ${ }^{75,76}$ Die Einführung einer Nitrofunktion in $\mathbf{4 9}$ und 50 führte im Vergleich zum Acronycin (45) zu einer leichten Herabsetzung der Zytotoxizität. Derivate mit Amino- $(\mathbf{5 1})$ oder Methoxyfunktionen $(\mathbf{5 2}, \mathbf{5 3})$ zeigten etwas höhere Zytotoxizitäten, die sich aber immer noch in der gleichen Größenordnung befanden. 
Das Substitutionsmuster am A-Ring scheint somit nur einen marginalen Einfluss auf die Zytotoxizität zu haben.

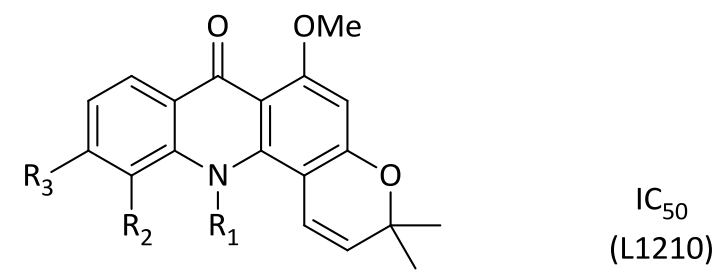

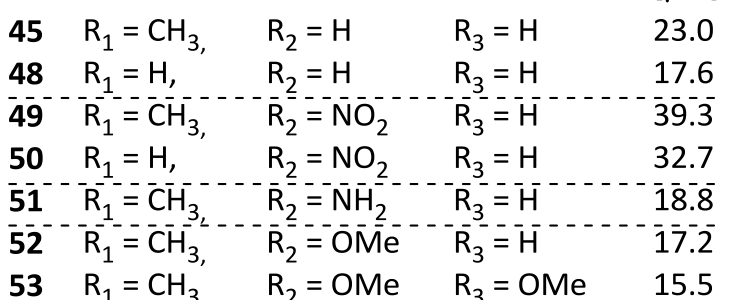

Abbildung 19: Analoga des Acronycins, substituiert am A-Ring.

Es ist durch eine Vielzahl an Beispielen belegt, dass große, koplanare aromatische Chromophore für eine gute Wechselwirkung mit der DNA verantwortlich sind. ${ }^{77} \mathrm{Da}$ für Acronycin (45) eine Alkylierung der DNA als Wirkmechanismus angenommen wird, wurde der Einfluss einer verstärkten Wechselwirkung auf die Zytotoxizität durch eine Erweiterung des aromatischen Grundkörpers untersucht (Abbildung 20). ${ }^{78}$
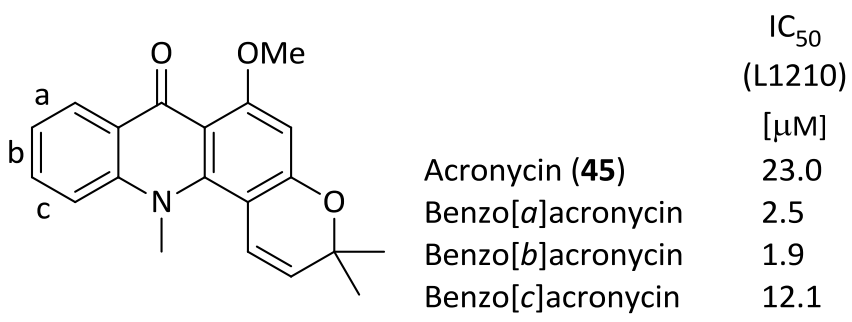

Abbildung 20: Analoga des Acronycins.

Die Vergrößerung des aromatischen Ringsystems des A-Rings, linear zur b-Seite und gewinkelt zur a-Seite, führte zu einer Steigerung der Zytotoxizität um den Faktor 12 bzw. 9. Eine gewinkelte Verknüpfung an der c-Seite hingegen führte lediglich zu einer Verdoppelung der Aktivität. Dies steht im Einklang mit dem angenommenen Mechanismus, für den eine Bioaktivierung der Doppelbindung des Pyran-Rings und anschließender Alkylierung der 2-Aminofunktion des Guanins der DNA angenommen wird. ${ }^{77}$ Dem positiven Effekt einer Erweiterung des Grundgerüsts steht im letzten Fall 
der schlechtere Zugang zur Doppelbindung durch die sterische Hinderung des zusätzlichen aromatischen Rings gegenüber. ${ }^{79}$

\subsection{Analoga des Acronycins 45 durch Modifikation des Pyran-Rings}

Die Identifizierung der Doppelbindung als entscheidene Struktureinheit und die Entdeckung von Acronycin-Epoxid (46) als vermutlich aktive Spezies führte zu dem Ansatz, dessen Reaktionsverhalten gegenüber Nukleophilen nachzuahmen und gleichzeitig die Stabilität zu verbessern. ${ }^{77}$ Es wurden daher eine Reihe an cis-Diolen und cis-Estern auf ihre biologische Wirksamkeit untersucht (Abbildung 21). ${ }^{80}$

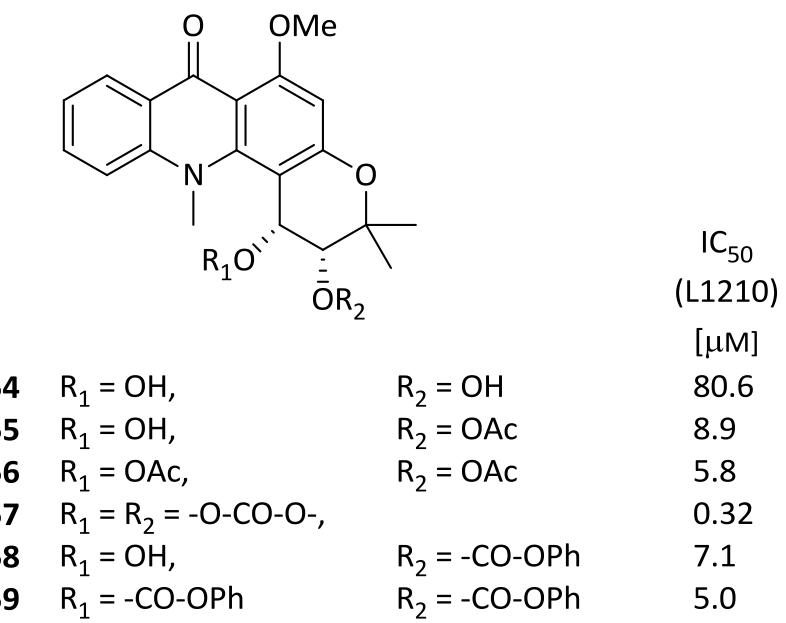

Abbildung 21: Analoga des Acronycins substituiert am Pyran-Ring.

Das Hydrolyseprodukt des Acronycin-Epoxids (46), das cis-Diol 54, zeigte erwartungsgemäß eine verschlechterte Zytotoxizität gegenüber Acronycin (45). Verschiedene Mono- und Diester jedoch zeigten eine Steigerung der biologischen Aktivität um bis zu das Vierfache. Eine Steigerung um den Faktor 75 konnte durch die Bildung des Carbamats erreicht werden.

Das bisher potenteste Analogon $\mathbf{6 0}$ des Acronycins besitzt folgerichtig einen zusätzlichen aromatischen Ring, linear verknüpft mit dem Acridon-Grundgerüst, und ein Carbamat als gute Abgangsgruppe gegenüber Nukleophilen (Abbildung 22). ${ }^{81}$ 


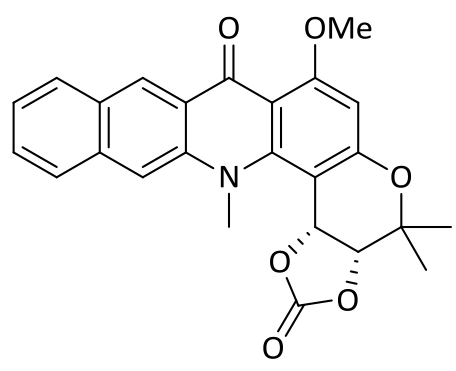

$60 \quad \mathrm{IC}_{50}: 0.014 \mu \mathrm{M}(\mathrm{L} 1210)$

Abbildung 22: Bisher potentestes Acronycin-Derivat 60.

\subsection{Dimere Strukturen des Acronycins (45)}

Dimere Strukturen zeigen gegenüber den Monomeren oft eine stark erhöhte biologische Aktivität (s. Kapitel B4.2). Beispiele sind die Bisindolderivate Toxiferin und Tubocurarin ${ }^{82}$ oder der DNA-bindene Wirkstoff Ditercalinium. ${ }^{83}$

Es wurde daher versucht, die biologische Aktivität durch Bildung von Dimeren, verknüpft durch eine Ether-Brücke an der phenolischen Hydroxyfunktion, zu steigern (Abbildung 23). ${ }^{84}$

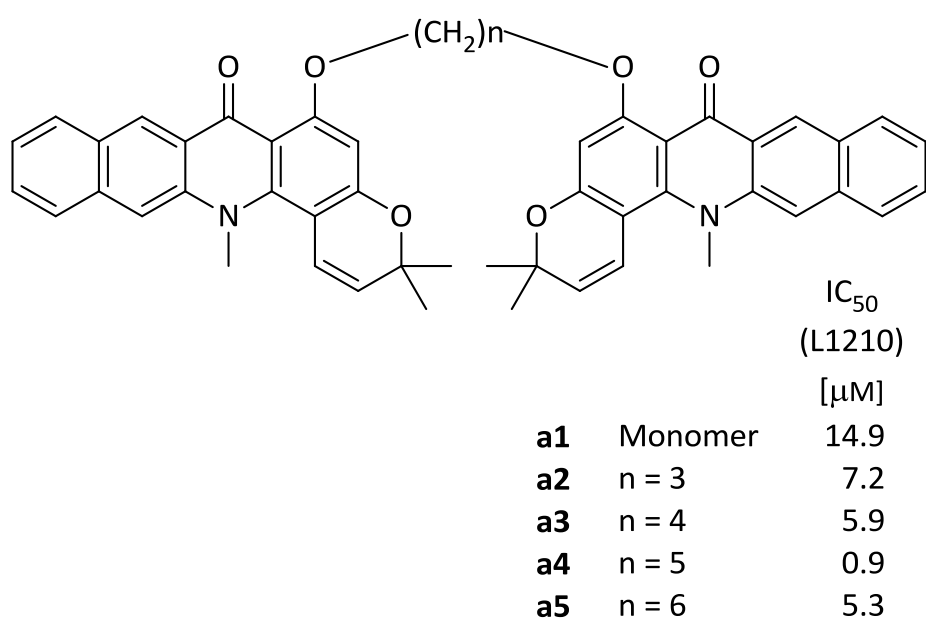

Abbildung 23: Dimere des Benzo $[b]$ acronycins.

Die synthetisierten Dimere zeigten gegenüber dem Monomer eine um bis zu sechzehnfach erhöhte Zytotoxizität. Eine Steigerung um mehrere Größenordnungen wie bei den in der Arbeitsgruppe Tietze entwickelten Duocarmycin-Dimeren ${ }^{69}$ konnte jedoch nicht erreicht werden. 


\section{Hybridmoleküle}

Naturstoffe spielen seit jeher eine große Rolle bei der Entwicklung neuer Wirkstoffe. Es wird geschätzt, dass im Bereich der Krebstherapeutika etwa 60\% der in den letzten Jahren zugelassenen Wirkstoffe Naturstoffe, deren Derivate oder Analoga sind. ${ }^{85}$ Die Zahl der Naturstoffe ist, obwohl natürlich sehr groß, letztlich jedoch begrenzt. Eine Kombination verschiedener Naturstoffe, oder Teile derer, zu Hybridmolekülen gewährt hingegen Zugang zu einer nahezu unbegrenzten Zahl an Stoffen mit vielfältigen, verschiedenen Eigenschaften. Hybridmoleküle zeigen im Vergleich zu ihren Stammverbindungen oft neuartige biologische Eigenschaften. Dies macht sie von besonderem Interesse für die Entdeckung neuer Wirkstoffe und Wirkmechanismen. ${ }^{7}$

Das Prinzip einzelne Naturstoffe zu Hybriden zu verbinden ist bereits in der Natur zu finden. Ein Beispiel dafür ist der natürlich vorkommende Hybridnaturstoff Thiomarinol (68), der aus dem Meeresbakterium Alteromonas rava sp. nov. SANK 73390 isoliert wurde (Abbildung 24). ${ }^{86}$<smiles>C/C(=C\C(=O)O)C(O)[C@H]1OC[C@H](C/C=C/[C@H](C)[C@H](C)O)[C@@H](O)[C@H]1O</smiles>

66<smiles>O=C(CCCCCCCO)NC1=C2SC=C2NC1=O</smiles>

67: Holothin<smiles>C/C(=C\C(=O)OCCCCCCCC(=O)Nc1c2sscc-2[nH]c1=O)C(O)[C@H]1OC[C@H](C/C=C/[C@@H](C)[C@H](C)O)[C@@H](O)[C@H]1O</smiles>

68: Thiomarinol

Abbildung 24: Der Naturstoff Thiomarinol (68) und seine Stammverbindungen.

Er zeigt gegenüber seinen Stammverbindungen, dem Pseudodomonsäure C-Derivat 66 und Holothin 67, eine deutlich gesteigerte antimikrobielle Aktivität und vereint dabei Wirkspektren beider Mutterverbindungen. 
Ein Beispiel für die Verknüpfung ganzer Naturstoffe zu neuartigen, synthetischen Hybridmolekülen ist der Geldanamycin-Östradiol-Hybrid 71 (Abbildung 25). ${ }^{87}$

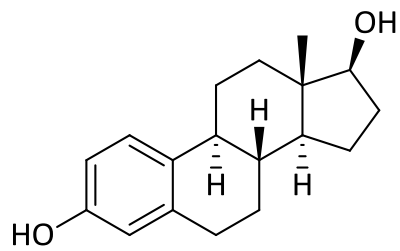

69: Östradiol

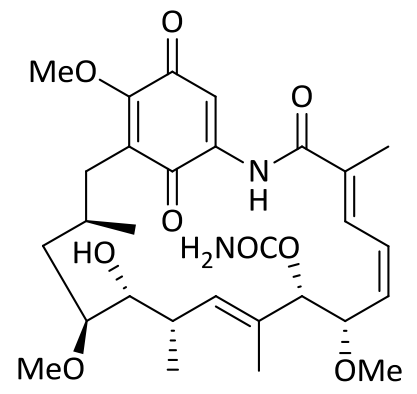

70: Geldanamycin

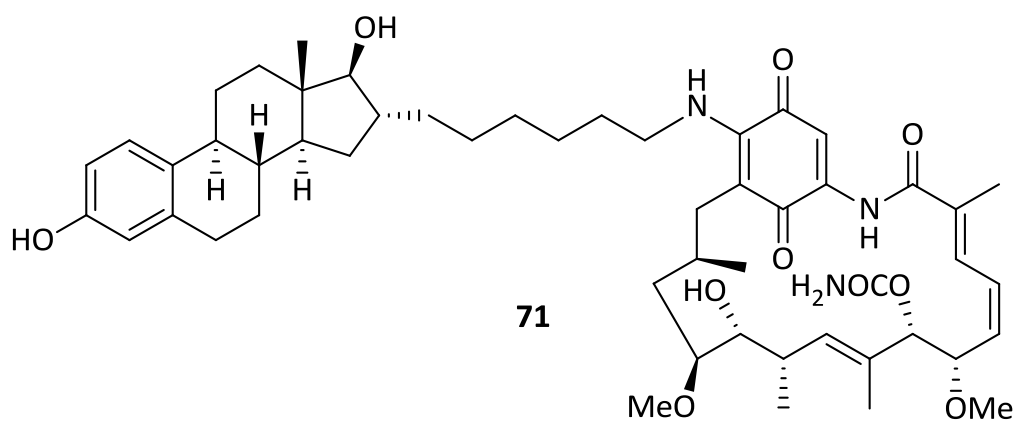

Abbildung 25: Östradiol (69), Geldanamycin (70) und deren Hybridstruktur 71.

Geldanamycin (70) ist ein Asamycin-Antibiotikum, isoliert aus Streptomyces hygroscopicus. Es bindet an das Hsp90-Chaperonsystem und bewirkt dadurch eine Inhibierung einer Reihe von Signalproteinen. Von einer Verknüpfung von Geldanamycin (70) mit Östradiol (69) zu dem Hybridmolekül 71 versprach man sich eine selektive Hemmung des Östrogen-Rezeptors (ER). Erste Untersuchungen bestätigten, dass das Hybridmolekül $\mathbf{7 1}$ selektiv an das ER-Hsp90 bindet und andere Hsp90-verbundene Proteine nicht hemmt.

Ein weiteres Bespiel für die Verknüpfung zweier Naturstoffe sind die Hybridmoleküle 74 und 75 (Abbildung 26). ${ }^{88}$ Dystamin A (73) ist einer der bis jetzt am meisten untersuchten DNA-Binder. Es zeigt eine hohe Sequenzspezifität und bindet selektiv an AT-reiche Regionen in der kleinen Furche. ${ }^{89}$ DC-81 (72) ist ein Naturstoff der Pyrrolo[2,1-c][1,4]-benzodiazepin-Gruppe. Durch einen nukleophilen Angriff der $\mathrm{NH}_{2}-$ Gruppe eines Guanins der kleinen Furche auf das Imin-Kohlenstoffatom bilden sie 
leicht eine kovalente Bindung aus. ${ }^{90}$ Die Kombination des Wirkstoffs DC-81 (72) mit dem "DNA-Binder" Distamycin A (73) konnte die Zytotoxizität erheblich gesteigert werden.<smiles>COc1cc2c(cc1O)N=C[C@@H]1CCCN1C2=O</smiles>

72: DC-81

$\mathrm{IC}_{50}: 1 \mu \mathrm{M}(\mathrm{K} 562)$

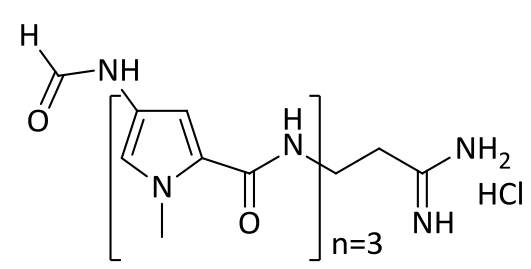

73: Distamycin A

$\mathrm{IC}_{50}: 12 \mu \mathrm{M}$ (K562)<smiles>COc1cc2c(cc1OCCC(=O)Nc1cc(C(=O)NC(C)(C)CC(=N)NCl)n(C)c1)N=C[C@H]1CCCN1C2=O</smiles>

$$
\begin{array}{lll}
\mathrm{n}=3 & \mathbf{7 4} & \mathrm{IC}_{50}: 0.7 \mu \mathrm{M}(\mathrm{K} 562) \\
\mathrm{n}=4 & \mathbf{7 5} & \mathrm{IC}_{50}: 0.04 \mu \mathrm{M}(\mathrm{K} 562)
\end{array}
$$

Abbildung 26: Hybride des Distamycin A (73) und DC-81 (72).

Ein Beispiel für die Verbindung von Teilstrukturen einzelner Naturstoffe sind die Moleküle 78 und 79 (Abbildung 27). ${ }^{91}$ Der Metabolit des Östradiols (69), 2-Methoxyöstradiol (76) ist einer der potentesten endogenen Tubulinpolymerisations-Inhibitoren. $\mathrm{Er}$ zeigt gute mitosehemmende Eigenschaften ohne dabei zytotoxisch auf umliegendes Gewebe zu wirken. ${ }^{92}$ Im Gegensatz dazu zeigt Colchicin (77) lediglich eine sehr geringe Selektivität bei gleichzeitig jedoch sehr hoher Zytotoxizität. Durch Kombination von Teilstrukturen der beiden Naturstoffe konnten die Hybridmoleküle $\mathbf{7 8}$ und $\mathbf{7 9}$ erhalten werden. Sie zeichnen sich durch eine zwei- bis dreifach gesteigerte Inhibition der Tubulin-Polymerisation gegenüber ihren Stammverbindungen aus. 
<smiles>COc1cc2c(cc1O)CC[C@@H]1[C@@H]2CC[C@@]2(C)[C@H]1CC[C@H]2O</smiles>

76: 2-Methoxyöstradiol<smiles>C[C@]12CC[C@H]3C4C=CC(=O)C=CC4CC[C@H]3[C@H]1CC[C@@H]2O</smiles>

78

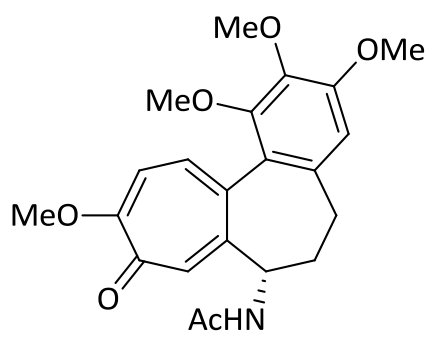

77: Colchicin

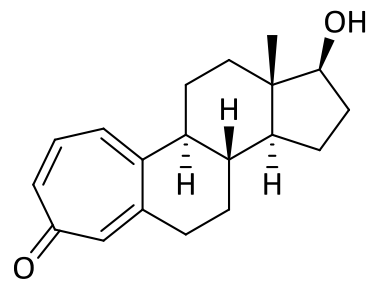

79

Abbildung 27: Die Tubulinpolymerisations-Inhibitoren 2-Methoxyöstradiol (76), Colchicin (77) und Hybridstrukturen 78 und 79. 


\section{Aufgabenstellung}

\section{Stand der Forschung zu Beginn der Arbeit}

Die Chemotherapie ist neben der operativen Entfernung, der Strahlentherapie und dem neueren Ansatz der Krebsimmuntherapie eine der wichtigsten Behandlungsmöglichkeiten zur Bekämpfung maligner Tumore. Die Wirkungsweise von Chemotherapeutika beruht auf der Störung wichtiger Stoffwechselvorgänge der Zellproliferation. Dies führt zum Zelltod stark proliferierender Zellen, wodurch neben Tumorzellen auch andere sich schnell teilende Zellen des Körpers, wie Haarwurzel-, Knochenmarks- und Schleimhautzellen, betroffen sind. Die Nebenwirkungen, wie Haarausfall, Immunschwäche, Schleimhautentzündung, Fieber, Übelkeit und Erbrechen, sind erheblich und oft der limitierende Faktor einer Chemotherapie. Da jedoch nur eine sehr hohe Gabe an Zytostatika, appliziert in sehr kurzen Zeitintervallen, zum Erfolg führen kann, ${ }^{93}$ ist die Synthese wirksamerer und besser verträglicher Wirkstoffe weiterhin Gegenstand der medizinischen Forschung.

Einen Ansatz zur Auffindung neuer Wirkstoffe stellen Hybrid-Naturstoffe dar. Durch die Kombination von Teilen bekannter Naturstoffe zu künstlichen Hybrid-Molekülen sollen neuartige Wirkstoffe mit bisher unbekannten biologischen Eigenschaften entstehen.

Acronycin (45) wurde bereits 1948 aus Acronychia baueri Schott (Rutaceae) isoliert (Abbildung 28). ${ }^{71}$ Es zeigte in biologischen Screenings eine breitgefächerte Wirksamkeit gegenüber einer Vielzahl an Tumoren und wurde daraufhin bis in die klinische Phase 2 gebracht, aufgrund lediglich moderater Zytotoxizität und sehr geringer Löslichkeit jedoch nicht weiter verfolgt (s. Kapitel B5). ${ }^{72-74}$

Duocarmycin SA (16) wurde 1986 aus Streptomyces sp. DO-113 isoliert. ${ }^{43}$ Es zeigt gegenüber Acronycin (45) eine sehr viel höhere Zytotoxizität, führte jedoch zu 
schweren Nebenwirkungen, wie Knochenmarksdepression, und ist deswegen für den klinischen Einsatz ebenfalls nicht geeignet (s. Kapitel B4). ${ }^{44}$<smiles></smiles>

45: Acronycin $\mathrm{IC}_{50}: 23 \mu \mathrm{M}(\mathrm{L} 1210)$<smiles></smiles>

16: (+)-Duocarmycin SA $\mathrm{IC}_{50}: 10 \mathrm{pM}(\mathrm{L} 1210)$

Abbildung 28: Die Naturstoffe Acronycin (45) und (+)-Duocarmycin SA (16).

Ein neuartiges Acronycin-Duocarmycin-Hybridmolekül könnte die positiven Eigenschaften beider Naturstoffe verbinden und somit Zugang zu neuen Wirkstoffen gewähren.

\section{$2 \quad$ Zielsetzung der Arbeit}

Das Ziel dieser Arbeit bestand in der Synthese und biologischen Evaluierung von neuartigen Acronycin-Duocarmycin-Hybriden vom Typ 80 (Abbildung 29). Hierzu sollte der Einfluss einer Derivatisierung am A-Ring auf die biologische Wirksamkeit untersucht werden. Die synthetisierten seco-Vorstufen $\mathbf{8 0 a}$ und $\mathbf{8 0 b}$ sollten in situ durch Winstein-Zyklisierung ${ }^{62}$ in die entsprechenden postulierten, toxischen Spezies 81a und 81b umgewandelt werden.

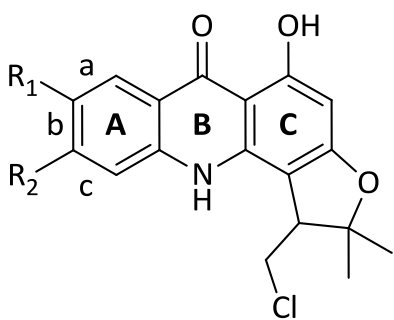

80a: $R_{1}=R_{2}=C_{4} H_{4}$

80b: $\quad R_{1}=\mathrm{NH}_{2}, \mathrm{R}_{2}=\mathrm{H}$

\section{Winstein-}

Zyklisierung
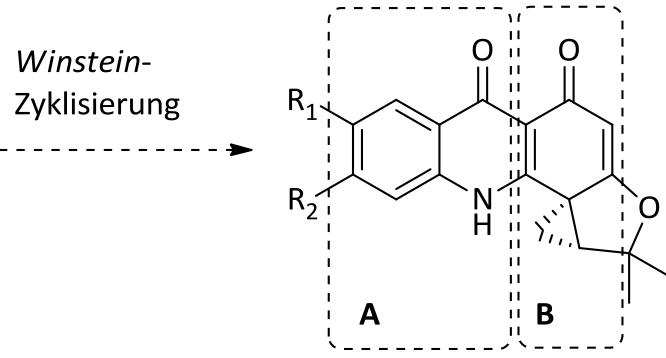

81a: $R_{1}=R_{2}=C_{4} H_{4}$

81b: $\quad R_{1}=\mathrm{NH}_{2}, \mathrm{R}_{2}=\mathrm{H}$

Abbildung 29: Die seco-Formen der Acronycin-Duocarmycin-Hybride 80a und 80b, sowie die postulierten aktiven Spezies 81a und 81b mit den Teilstrukturen des Acronycin (A) und Duocarmycin (B). 
Aus früheren Arbeiten in der Arbeitsgruppe Tietze ${ }^{8}$ und anderen Arbeitsgruppen ${ }^{49}$ war bekannt, dass eine Verknüpfung mit DNA-bindenen Einheiten, wie beispielsweise dem DMAI-Carbonsäure-Hydrochlorid (84), oder die Bildung von Dimeren ${ }^{8 b}$ zu einer erheblichen Steigerung der biologischen Wirksamkeit führen können. Es sollten daher modifizierte Hybride vom Typ 82 und 85, die DMAl als Seitenkette enthalten, sowie dimere Strukturen wie $\mathbf{8 3}$ und $\mathbf{8 6}$ synthetisiert und auf ihre biologische Wirksamkeit hin untersucht werden (Abbildung 30).<smiles>Cn1c2cc3ccccc3cc2c(=O)c2c(O)cc3c(c21)C(CCl)C(C)(C)O3</smiles>

82<smiles>CC(=O)n1c2cc3ccccc3cc2c(=O)c2c(O)cc3c(c21)C(CCl)C(C)(C)O3</smiles>

83: $n=3$<smiles>[R]c1cc2[nH]c(C(=O)O)cc2cc1OCCN(C)C</smiles>

84<smiles>CC(C)(C)Nc1ccc2[nH]c3c4c(cc(O)c3c(=O)c2c1)OC(C)(C)C4CCl</smiles>

85<smiles>CC(C)(C)C(=O)Nc1ccc2[nH]c3c4c(cc(O)c3c(=O)c2c1)OC(C)(C)C4CCl</smiles>

86: $n=3$

Abbildung 30: Weitere Syntheseziele dieser Arbeit.

Zusammenfassend ergaben sich folgende Teilaufgaben:

- Entwicklung einer Synthese von neuartigen Acronycin-Duocarmycin-Hybriden vom Typ 80

- Synthese von Acronycin-Duocarmycin-Hybriden

82 und 85 mit DMAISeitenkette

- $\quad$ Synthese von dimeren Strukturen $\mathbf{8 3}$ und $\mathbf{8 6}$

- In-vitro-Untersuchungen zur Zytotoxizität aller neu synthetisierten Verbindungen 


\section{$3 \quad$ Planung der Arbeit}

Die Retrosynthese der Acronycin-Duocarmycin-Hybride $\mathbf{8 0}$ ist in Abbildung 31 dargestellt. Der Syntheseplan sieht zunächst eine Kondensation der Säure 88 mit Phloroglucin (89) zur Darstellung des Acridon-Grundgerüsts vor. Nach anschließender regioselektiver Bromierung sollte die Kupplung mit dem Epoxid 91 die Zyklisierungsvorstufe $\mathbf{8 7}$ liefern. Diese sollte anschließend zum seco-Drug $\mathbf{8 0}$ umgewandelt werden.<smiles>[R]c1cc2[nH]c3c4c(cc(O)c3c(=O)c2cc1[R])OC(C)(C)C4CCl</smiles><smiles>[R]c1cc(N)c(C(=O)O)cc1[R]</smiles>

88<smiles>Oc1cc(O)cc(O)c1</smiles>

89

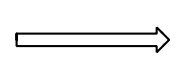<smiles>[R]c1cc2[nH]c3c(Br)c(OC(C)(C)C4CO4)cc(O)c3c(=O)c2cc1[R2]</smiles>

87<smiles>C=C=C</smiles>

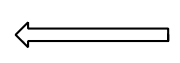<smiles>[R]c1cc2[nH]c3c(Br)c(O)cc(O)c3c(=O)c2cc1[R]</smiles>

90

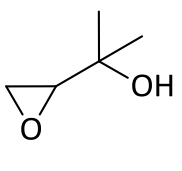

91

Abbildung 31: Retrosynthese der Acronycin-Duocarmycin-Hybride 80.

Die Kupplung mit DMAI (84) als DNA-bindende Einheit und die Bildung von Dimeren sollte in Anlehnung an im Arbeitskreis Tietze etablierte Methoden erfolgen. ${ }^{8}$ 


\section{DARSTELLUNG DER ERGEBNISSE}

\section{Synthese der Benzo[b]acronycin-Duocarmycin-Hybride}

\section{$1.1 \quad$ Syntheseroute I zur Darstellung von 101}

Die Synthese des Benzo[b]acronycin-Duocarmycin-Hybridmoleküls $\mathbf{8 0 a}$ sollte ausgehend von kommerziell erhältlicher 3-Hydroxy-2-naphthoesäure (92) in neun Stufen erfolgen.

3-Hydroxy-2-naphthoesäure (92) wurde in einem Maßstab von ca. 50 g in 3-Amino-2naphthoesäure (93) überführt (Abbildung 32).<smiles>O=C(O)c1cc2ccccc2cc1O</smiles>

92
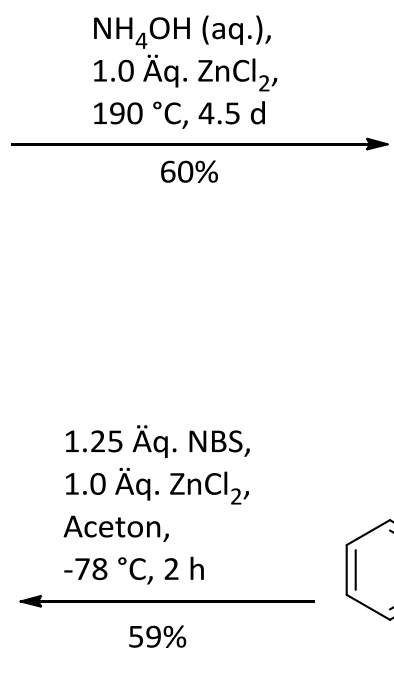

1.25 Äq. NBS,

95<smiles>Nc1cc2ccccc2cc1C(=O)O</smiles>

93<smiles>O=c1c2cc3ccccc3cc2[nH]c2c(Br)c(O)cc(O)c12</smiles><smiles>O=c1c2cc3ccccc3cc2[nH]c2cc(O)cc(O)c12</smiles>

1.1 Äq. Phloroglucin, 0.1 Äq. p-TsOH, Heptanol, Reflux, $19 \mathrm{~h}$

Abbildung 32: Synthese des Grundgerüsts.

Unter sehr harschen Bedingungen ${ }^{94}$ und ohne chromatographische Aufarbeitung erfolgte die Substitution in einer befriedigenden Ausbeute von 60\%. Der Aufbau des Grundgerüsts durch Kondensation mit Phloroglucin unter Verwendung katalytischer Mengen $p$-Toluolsulfonsäure nach $F$. Tillquin ${ }^{77}$ lieferte nach Umkristallisation die Acridon-Struktur (94) in ebenfalls befriedigender Ausbeute von 59\%. Eine selektive Bromierung der chemisch sehr ähnlichen Positionen C-2 und C-4 in 94 war aufgrund ihrer hohen Reaktionsgeschwindigkeit schwierig. Bei Verwendung von NBS unter Zusatz von Zinkchlorid und einer Reaktionstemperatur von $-78^{\circ} \mathrm{C}$ gelang jedoch die 
regioselektive Umsetzung von 94 zum gewünschten C-4-bromierten Produkt 95 in 59\% Ausbeute. Tabelle 2 zeigt die untersuchten Reaktionsbedingungen und resultierenden Produktgemische der Bromierungsreaktion, die sich aus 94, 95, 96 und 97 zusammensetze (Abbildung 33). Die Verhältnisse der Produkte wurde über die Integrale des 1-OH im ${ }^{1} \mathrm{H}-\mathrm{NMR}$ (Abbildung 35 ) bestimmt.
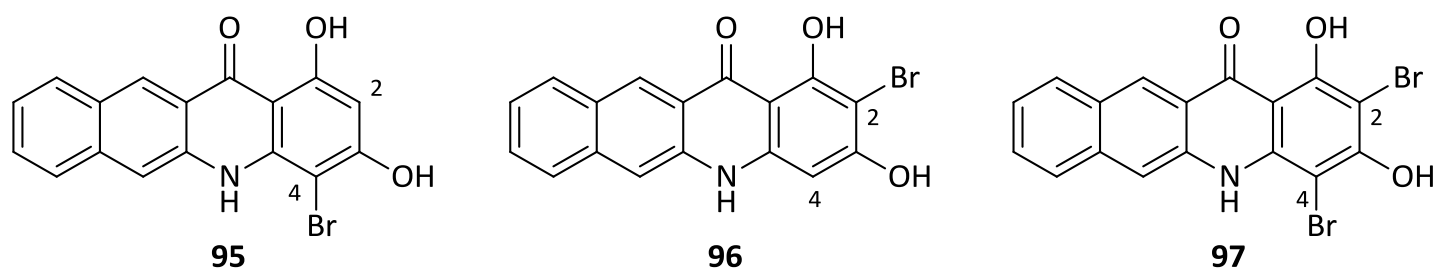

Abbildung 33: Mögliche Produkte der Bromierung.

\begin{tabular}{c|ccc|cccc}
\hline \# & \multicolumn{3}{|c|}{ Bedingungen $^{[\mathrm{a}]}$} & \multicolumn{4}{c}{ Verhältnisse (NMR) } \\
& Äq. NBS & T. $\left.{ }^{\circ} \mathrm{C}\right]$ & Additiv $^{[\mathrm{b}]}$ & $\mathbf{9 5}$ & $\mathbf{9 6}$ & $\mathbf{9 7}$ & Substrat \\
\hline 1 & 1.00 & $\mathrm{RT}$ & - & $\mathbf{2 2 \%}$ & $21 \%$ & $23 \%$ & $9 \%$ \\
\hline 2 & 1.00 & -78 & - & $\mathbf{2 5 \%}$ & $43 \%$ & $5 \%$ & $23 \%$ \\
\hline 3 & 1.00 & -78 & $\mathrm{CuCl}_{2}$ & $\mathbf{3 8 \%}$ & $22 \%$ & $30 \%$ & $9 \%$ \\
\hline 4 & 1.00 & -78 & $\mathrm{ZnCl}_{2}$ & $\mathbf{5 7 \%}$ & $15 \%$ & $4 \%$ & $20 \%$ \\
\hline 5 & 1.25 & -78 & $\mathrm{ZnCl}_{2}$ & $\mathbf{6 4 \%}$ & $16 \%$ & $5 \%$ & $10 \%$ \\
\hline & 1.35 & -78 & $\mathrm{ZnCl}_{2}$ & $\mathbf{7 0 \%}$ & $10 \%$ & $18 \%$ & $0 \%$ \\
\hline
\end{tabular}

${ }^{[a]}$ Aceton, $1 \mathrm{~h} ; \quad{ }^{[b]} 1.00$ Äq Additiv

Tabelle 2: $\quad$ Voruntersuchungen zur selektiven Bromierung von 94.

Bei Raumtemperatur erhielt man bevorzugt das dibromierte Produkt 97. Erniedrigung der Temperatur auf $-78{ }^{\circ} \mathrm{C}$ führte zu einer bevorzugten Monobromierung, das Hauptprodukt war jedoch die unerwünschte, an C-2 bromierte Verbindung 96 (Tabelle 2, Einträge 1 u. 2). Durch Zusatz von Kupfer-(II)- und Zink-Salzen sollte eine Komplexierung der vinylogen Säurefunktion und damit einhergehend eine sterische Abschirmung der C-2-Position erreicht werden. Wie erwartet zeigte sich eine Umkehrung der Selektivität hin zum an C-4-Position bromierten Produkt 95, wobei 
$\mathrm{Zn}^{2+}$ die bessere Lewis-Säure für diese Art von Komplexierung zu sein scheint (vgl. Eintrag 2 mit 3 u. 4). Da jedoch auch immer ein Anteil an dibromiertem Produkt 97 auftrat, musste zur vollständigen Umwandlung des Substrats 94 NBS im Überschuss zugegeben werden (Einträge 4-6). Die Unterscheidung der Produkte erfolgte mit Hilfe zweidimensionaler NMR und wurde durch Röntgenstrukturanalyse einer Folgestufe bestätigt (s. Abbildung 39).

1.1.1 Diskussion ausgewählter spektroskopischer Daten der Verbindung 95

Die NMR-Signale wurden mit Hilfe von ${ }^{1} \mathrm{H}-\mathrm{COSY}-$, HSQC- und HMBCKorrelationsspektren zugeordnet.

In Abbildung 34 ist das ${ }^{1} \mathrm{H}-\mathrm{NMR}-$ Spektrum $\left(300 \mathrm{MHz}\right.$, DMSO- $\left.\mathrm{d}_{6}\right)$ der an C-4 bromierten Spezies 95 mit der entsprechenden Zuordnung der Signale dargestellt. Am weitesten im Hochfeld bei $\delta=6.27 \mathrm{ppm}$ resoniert das zu beiden phenolischen Hydroxygruppen benachbarte 2-H. Eine eindeutige Differenzierung zur C-4-Position erfolgte durch die Identifizierung der ${ }^{2}$ J-Kopplung zum C-1 im HMBC (nicht dargestellt). Weiter im Tieffeld resonieren die Protonen des Naphtholrings, beginnend mit $8-\mathrm{H}$ bei $\delta=7.47 \mathrm{ppm}$, das als Dublett vom Dublett vom Dublett mit den Kopplungskonstanten von $J=8.0,6.7$ und $1.1 \mathrm{~Hz}$ aufspaltet. Das 9-H resoniert bei $\delta=7.60 \mathrm{ppm}$ ebenfalls als Dublett vom Dublett vom Dublett mit den Kopplungskonstanten von $J=8.1,6.7$ und $1.2 \mathrm{~Hz}$. Bei $\delta=7.92$ und $8.14 \mathrm{ppm}$ resonieren als Dubletts mit Kopplungskonstanten von $J=8.0$ und $8.1 \mathrm{~Hz}$ das $7-\mathrm{H}$ und das $10-\mathrm{H}$. Die beiden isolierten Protonen $6-\mathrm{H}$ und $11-\mathrm{H}$ resonieren als Singuletts bei $\delta=8.47$ und 8.86 ppm. Das Proton des sekundären Amins resoniert als Singulett sehr weit im Tieffeld bei $\delta=10.47 \mathrm{ppm}$. Diese für ein sekundäres Amin sehr starke Entschirmung ist ein Hinweis auf seinen Charakter als vinyloges Amid. Das sehr breite Singulett bei $\delta=11.51 \mathrm{ppm}$ ist auf das phenolische 3-OH zurückzuführen, während das 1-OH durch Konjugation mit der Carbonylgruppe als vinyloge Säure anzusehen ist und eine Resonanz bei $\delta=14.33$ ppm zeigt. 


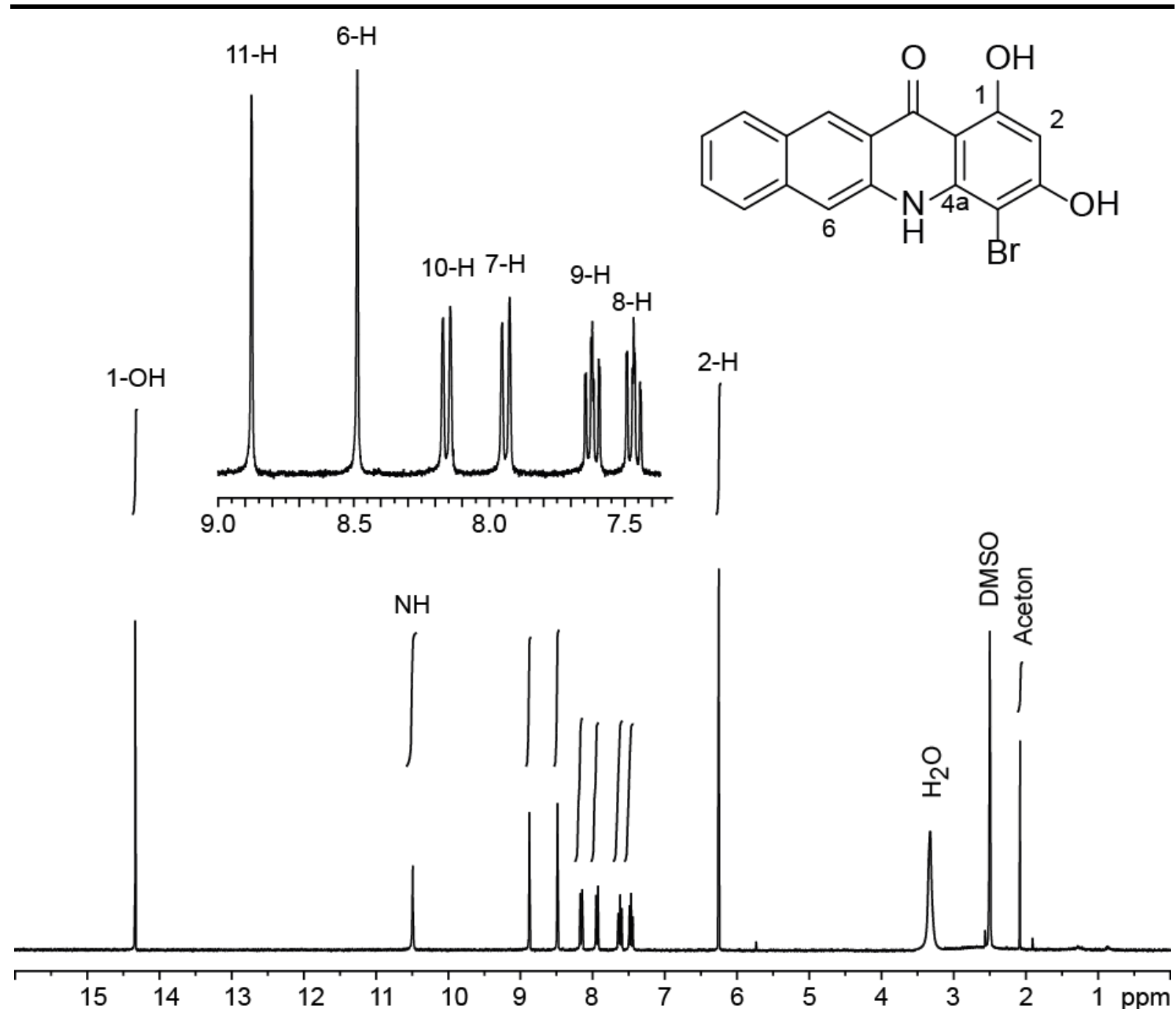

Abbildung 34: $\quad{ }^{1} \mathrm{H}-\mathrm{NMR}-S p e k t r u m\left(300 \mathrm{MHz}, \mathrm{DMSO}-\mathrm{d}_{6}\right.$ ) der bromierten Spezies 95.

Das Signal der vinylogen Säure-Funktion unterscheidet sich sehr stark bei den unterschiedlichen Bromierungsprodukten (Abbildung 35). Es war daher möglich, das Verhältnis der gebildeten Produkte mittels ${ }^{1} \mathrm{H}$-NMR ohne vorherige Aufreinigung über die Integrale zu bestimmen. Es bleibt jedoch anzumerken, dass die Bestimmung der Integral-Grenzen manuell erfolgte und daher nur Tendenzen aufzeigen kann. 


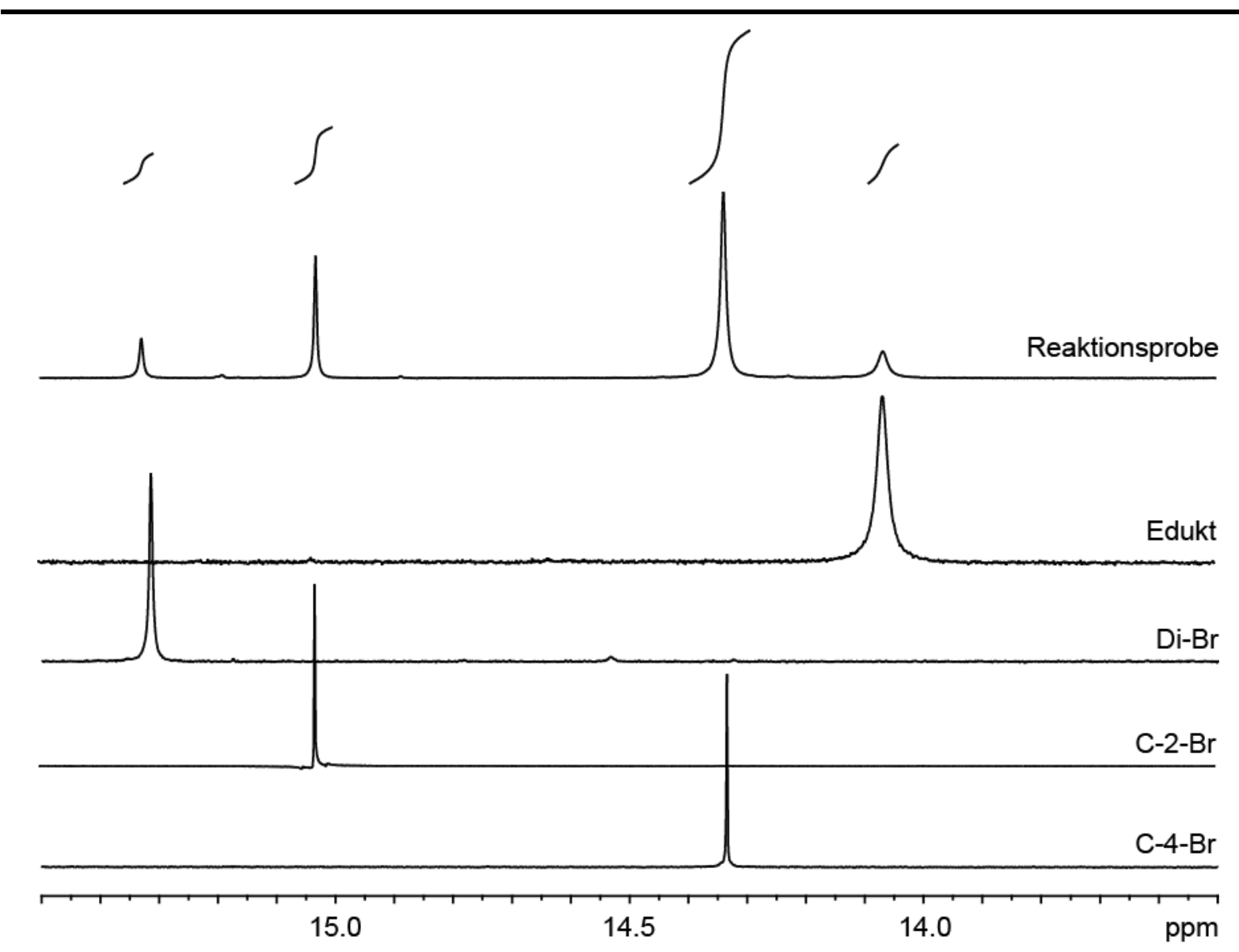

Abbildung 35: Beispielhaftes ${ }^{1} \mathrm{H}-\mathrm{NMR}-$ Spektren $\left(300 \mathrm{MHz}, \mathrm{DMSO}-\mathrm{d}_{6}\right.$ ) zur Reaktionsverfolgung einer Probe.

\subsubsection{Synthese des zu kuppeInden Epoxids 91}

Für die Kupplung mit dem bromierten Diol 95 wurde zunächst das Epoxid 99 in racemischer Form durch Epoxidierung des Alkens 98 mit $98 \%$ Ausbeute hergestellt. ${ }^{95}$ Ausgehend von diesem sollte das mesyl- ${ }^{96}$ 91a oder tosylgeschützte ${ }^{97}$ 91b Epoxid synthetisiert werden (Abbildung 36, Tabelle 3).

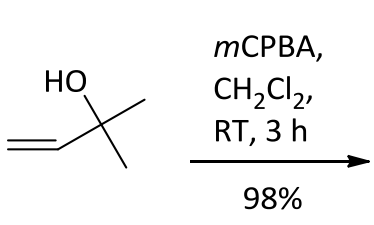

98

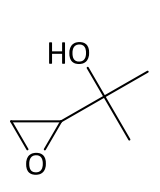

99

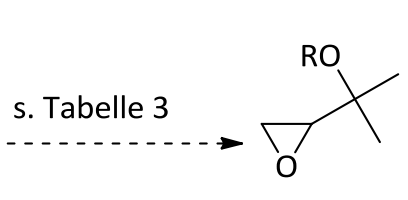

91a: $\mathrm{R}=\mathrm{Ms}$ 91b: $R=T s$

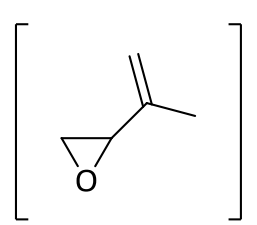

100

Abbildung 36: Darstellung der Epoxide 91. 


\begin{tabular}{|c|c|c|c|c|c|c|}
\hline \multirow[t]{2}{*}{ \# } & \multicolumn{5}{|c|}{ Bedingungen $^{[\mathrm{a}]}$} & \multirow[t]{2}{*}{ Ergebnis } \\
\hline & Äq. R-Cl & $\ddot{\mathrm{A} q}$. NEt 3 & Lsgm. & T. $\left[{ }^{\circ} \mathrm{C}\right]$ & Zeit & \\
\hline 1 & $1.50 \mathrm{TsCl}$ & 3.00 & DCM & $\mathrm{RT}$ & $12 \mathrm{~d}$ & kein Umsatz \\
\hline 2 & $1.50 \mathrm{TsCl}$ & 3.00 & DCM & 60 & $3.5 \mathrm{~h}$ & kein Umsatz \\
\hline 3 & $1.50 \mathrm{TsCl}$ & 3.00 & DMF & 120 & $3.5 \mathrm{~h}$ & 100 \\
\hline 4 & $1.10 \mathrm{TsCl}$ & 1.10 & $\mathrm{MeCN}$ & 82 & $15 \mathrm{~h}$ & 100 \\
\hline 5 & $1.50 \mathrm{MsCl}^{[\mathrm{a}]}$ & 3.00 & DCM & 60 & $3 \mathrm{~h}$ & 100 \\
\hline 6 & $1.50 \mathrm{MsCl}^{[\mathrm{a}]}$ & 3.00 & DCM & $\mathrm{RT}$ & $7 d$ & 100 \\
\hline 7 & $1.00 \mathrm{MsCl}^{[\mathrm{a}]}$ & 1.00 & DCM & 35 & $2 h-3 d$ & 100 \\
\hline 8 & $1.50 \mathrm{TsCl}$ & - & DMF & 120 & $2 \mathrm{~h}$ & Multispot \\
\hline 9 & 1.10 TsCl & - & $\mathrm{MeCN}$ & 82 & $15 \mathrm{~h}$ & 100 \\
\hline
\end{tabular}

${ }^{[a]}$ kat. DMAP

Tabelle 3: $\quad$ Reaktionsbedingungen zur Aktivierung des Epoxids 99.

Reaktion von 99 mit Tosylchlorid in DCM bei $20^{\circ} \mathrm{C}$ und $60^{\circ} \mathrm{C}$ führte nicht zu dem gewünschten Produkt (Einträge 1 u. 2), bei höheren Temperaturen unter Verwendung von DMF oder MeCN erfolgt eine Eliminierung unter Bildung von 100. Als mögliche Erklärung könnte angenommen werden, dass sich unter diesen Bedingungen das gewünschte Tosylat bildet, das dann sofort eine Eliminierung eingeht. Wahrscheinlicher ist jedoch eine direkte Eliminierung in Gegenwart von $\mathrm{Et}_{3} \mathrm{NHCl}$, das sich aus dem Tosylchlorid und $\mathrm{Et}_{3} \mathrm{~N}$ bildet (Einträge 3 u. 4). 100 konnte aufgrund seiner hohen Flüchtigkeit jedoch nur qualitativ nachgewiesen werden. Es wurde versucht, das mesylgeschützte Epoxid 91a zu synthetisieren. Hier wurde jedoch ein ähnliches Ergebnis erhalten wie bei der Umsetzung mit TsCl (Eintrag 5). Weder durch eine Reaktionsführung bei geringerer Temperatur (Eintrag 6) noch mit nur einem Äquivalent an eingesetzter Base, zugetropft über einen Zeitraum von 
2-29h per Spritzenpumpe (Eintrag 7), konnte das mesylgeschützte Epoxid 91a gewonnen werden. Auch ein basenfreier Ansatz unter Indium-Katalyse ${ }^{98}$ lieferte lediglich das Eliminierungsprodukt (Einträge 7 u. 8).

Da die anschließende Kupplung mit dem bromierten Diol 95 mit $\mathrm{K}_{2} \mathrm{CO}_{3}$ als Base und damit unter stark basischen Bedingungen stattfinden sollte, wäre spätestens in diesem Reaktionsschritt eine Eliminierung zu erwarten gewesen. Es wurde daher eine alternative Syntheseroute gewählt.

\subsection{Syntheseroute II zur Darstellung von 101}

Statt einer Kupplung des bromierten Diols 95 mit dem Epoxid 91 sollte das wesentlich stabilere Propargylchlorid 102 verwendet werden. Dieses sollte durch eine nukleophile Substitution aus 2-Methylbut-3-in-2-ol erhalten werden. Anschließende selektive Hydrierung und Epoxidierung sollten schließlich den Baustein 101 liefern.<smiles>CC(C)(Oc1cc(O)c2c(=O)c3cc4ccccc4cc3[nH]c2c1Br)C1CO1</smiles>

101

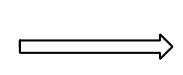<smiles>O=c1c2cc3ccccc3cc2[nH]c2c(Br)c(O)cc(O)c12</smiles>

95

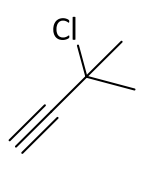

102

Abbildung 37: Veränderter retrosynthetischer Ansatz zum Aufbau von 101.

1.3 Synthese des Alkens 111 nach der veränderten Syntheseroute

Zunächst wurde der kommerziell erhältliche Propargylalkohol 103 nach literaturbekannter Vorschrift ${ }^{99}$ in das entsprechende Propargylchlorid 102 überführt (Abbildung 38). 


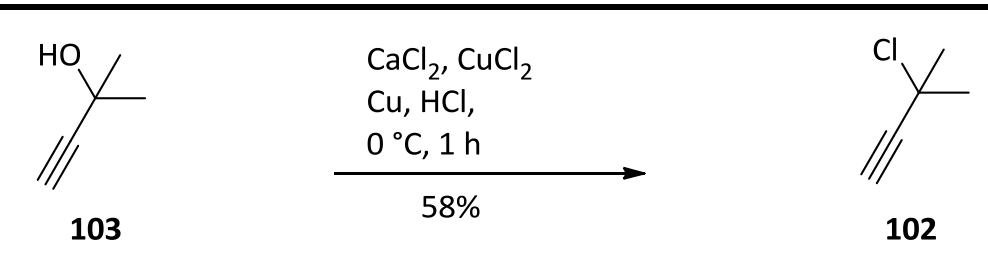<smiles>O=c1c2cc3ccccc3cc2[nH]c2c(Br)c(O)cc(O)c12</smiles>

95<smiles></smiles>

s. Tabelle 4<smiles>C#CC(C)(C)Oc1cc(O)c2c(=O)c3cc4ccccc4cc3[nH]c2c1Br</smiles>

104<smiles>CC1(C)C=Cc2c(c(Br)c3[nH]c4cc5ccccc5cc4c(=O)c3c2O)O1</smiles>

Abbildung 38: Synthese des Propargylchlorids 102 und anschließende Kupplung zu 104.

Die Umsetzung erfolgte im $50 \mathrm{~mL}$ Maßstab und die Aufreinigung destillativ mit 58\% Ausbeute. Die anschließenden Untersuchungen zur Kupplung mit dem bromierten Diol 95 sind in Tabelle 4 dargestellt.

\begin{tabular}{|c|c|c|c|}
\hline \# & Bedingungen $^{[\mathrm{a}]}$ & \multicolumn{2}{|c|}{ Ergebnis } \\
\hline 1 & $65^{\circ} \mathrm{C}, 24 \mathrm{~h}$ & $21 \% 104$ & $17 \% 106,21 \% 95$ \\
\hline 2 & 2.00 Äq. KI, $65^{\circ} \mathrm{C}, 24 \mathrm{~h}$ & & $25 \% 106,50 \% 105$ \\
\hline 3 & 2.00 Äq. $\mathrm{KBr}, 65^{\circ} \mathrm{C}, 24 \mathrm{~h}$ & & $10 \% 106,64 \% 95$ \\
\hline 4 & $2.00 \mathrm{Äq} .{ }^{t} \mathrm{Bu}_{4} \mathrm{NBr}, 65^{\circ} \mathrm{C}, 24 \mathrm{~h}$ & $6 \% 104$ & $64 \% 95$ \\
\hline 5 & $1.00 \mathrm{Äq} . \mathrm{ZnBr} 2,50^{\circ} \mathrm{C}, 42 \mathrm{~h}$ & & $34 \% 106,28 \% 95$ \\
\hline 6 & $1 \mathrm{~mol}-\% \mathrm{CuCl}, \mathrm{RT}, 24 \mathrm{~h}$ & $68 \% 104$ & \\
\hline
\end{tabular}

Tabelle 4: $\quad$ Kupplung des Alkins 102 mit der bromierten Spezies 94.

Eine Kupplung des im Überschuss eingesetzten Alkins 102 mit $\mathrm{K}_{2} \mathrm{CO}_{3}$ als Base in DMF lieferte nach 24 h 21\% Ausbeute der gewünschten Verbindung 104 (Eintrag 1). Es 
konnte zudem neben nicht umgesetztem Substrat 95 das Nebenprodukt 106 isoliert werden, das aus 104 durch Zyklisierung entstanden sein dürfte. So ist die thermische Umlagerung von Aryl-Propargyl-Ethern eine bekannte Reaktion zum Aufbau von Chromenen. ${ }^{100}$ Es wurde daher versucht, unter Zusatz von Kaliumiodid und verschiedenen Bromid-Salzen eine schnellere Umwandlung durch Halogenaustausch zu erreichen. Dieser Ansatz war jedoch nicht erfolgreich, sondern führte in Gegenwart von Iodid-Ionen zu dem bereits bekannten zyklisierten Produkt 106 und einem Austausch des Aryl-Bromids zum Aryl-lodid 105 (Eintrag 2). Der Einsatz verschiedener Bromid-Quellen führte ebenfalls zu keiner Umsatzsteigerung und keiner befriedigenden Produktbildung (Einträge 3-5). Erst durch den Zusatz von Kupfer-(I)-Chlorid als Katalysator war eine milde Reaktionsführung bei Raumtemperatur möglich, wodurch die thermische Zyklisierung verhindert und das gewünschte Alkin 104 in 68\% Ausbeute isoliert werden konnte (Eintrag 6). ${ }^{101}$

Das Alkin 104 konnte aus Ethylacetat, in das langsam Pentan eingedampft wurde, auskristallisiert und seine Struktur, insbesondere die Position des Bromsubstituenten, röntgenkristallographisch bestätigt werden (Abbildung 39). 


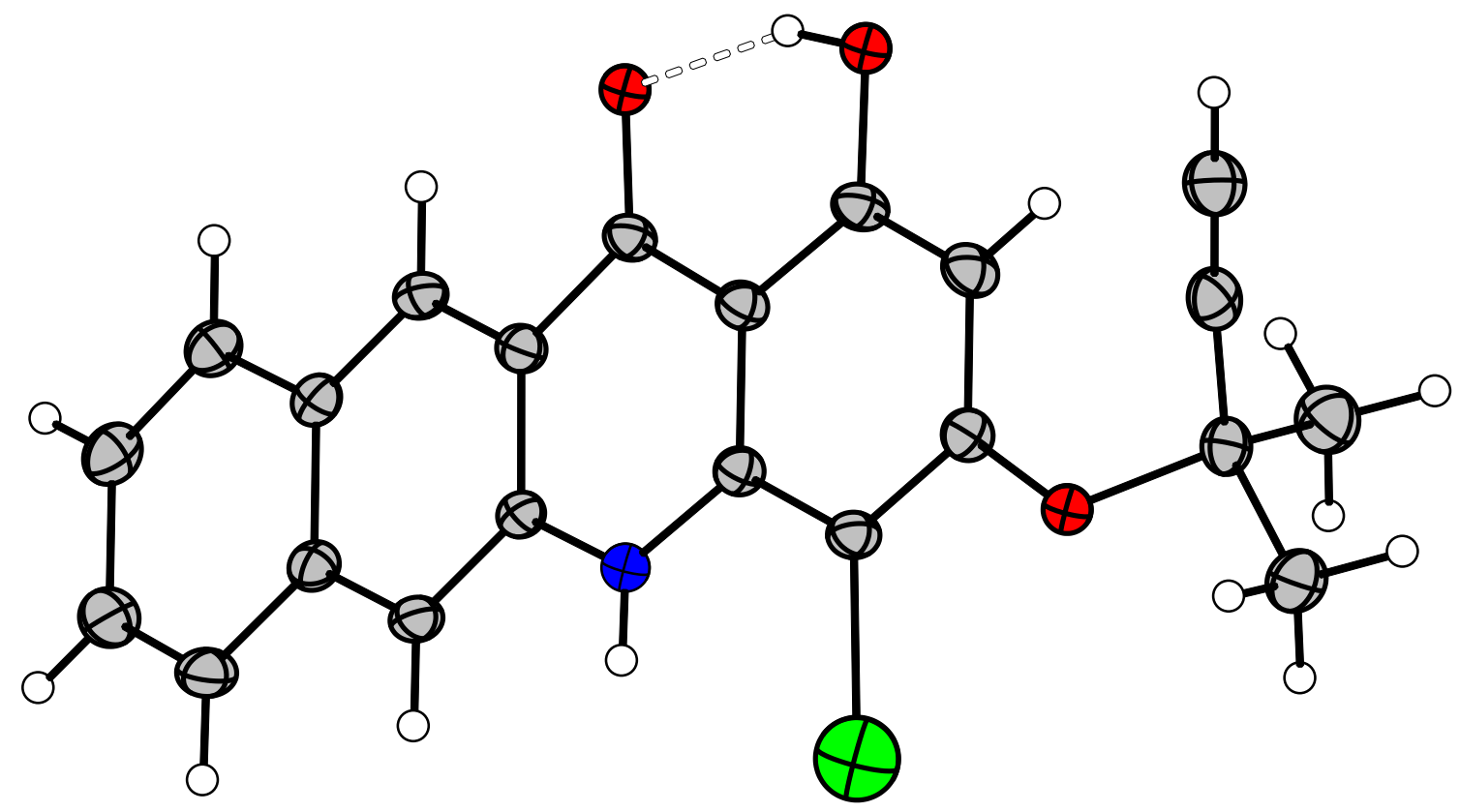

Abbildung 39: Kristallstruktur des Alkins 104.

Die erhaltene Spezies 104 sollte hydriert und anschließend das stereogene Zentrum durch eine enantioselektive Epoxidierung eingeführt werden.

Um eine Reduktion der Dreifachbindung bis hin zur Einfachbindung zu verhindern, war der Einsatz von vergifteten Palladiumkatalysatoren nötig (Tabelle 5). Unter Verwendung des mit Chinolin vergifteten Lindlar-Katalysators ${ }^{102}$ zeigte sich jedoch auch nach langer Reaktionslaufzeit kein Umsatz (Eintrag 1). Eine Reaktionsführung ohne das Katalysatorgift war ebensowenig erfolgreich wie die Verwendung von Raney-Nickel $^{103}$ (Einträge 2 u. 4). Dies ist vermutlich auf die große sterische Hinderung der Dreifachbindung (s. Abbildung 39) und die damit einhergehende schlechtere Koordination an den heterogenen Katalysator zu erklären. Die Verwendung von Palladium auf Bariumsulfat ${ }^{104}$ führte hingegen unter Spaltung der labilen Aryl-Alkyl-Ether-Bindung zum Nebenprodukt 95 (Eintrag 3). Als am besten geeignete Palladium-Spezies stellte sich Palladium auf Aktivkohle vergiftet mit Chinolin heraus (Eintrag 5). ${ }^{105}$ Nach $2.5 \mathrm{~h}$ unter $\mathrm{H}_{2}$-Atmosphäre in Aceton bei RT konnte das Alken 111 in einer Ausbeute von 79\% erhalten werden. Es wurde 
außerdem versucht, die auftretende Spaltung der Ether-Bindung durch ein Herabsetzen der Reaktionstemperatur zu vermeiden (Eintrag 6). Es zeigte sich jedoch, dass bei tieferen Temperatur keine Hydrierung mehr stattfand. Ferner hing die Reproduzierbarkeit der Ergebnisse stark von der verwendeten Pd/C-Charge ab. Hier traten erhebliche Schwankungen in der Reaktionsdauer auf.

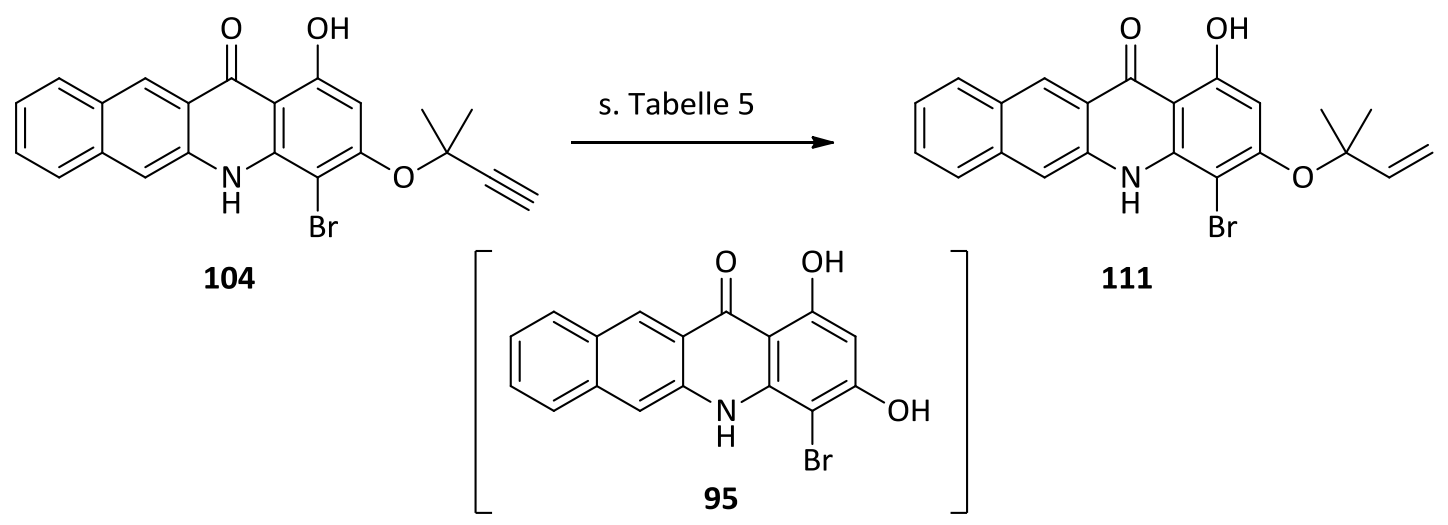

Abbildung 40: Hydrierung des Alkins 104.

\begin{tabular}{|c|c|c|c|c|c|}
\hline \# & & lingungen & & & Ergebnis \\
\hline & Katalysator & Additiv & T. $\left[{ }^{\circ} \mathrm{C}\right]$ & Zeit & \\
\hline 1 & $1.6 \mathrm{~mol}-\% \mathrm{Pd} / \mathrm{CaCO}_{3}{ }^{[\mathrm{a}]}$ & Chinolin & RT & $7 d$ & kein Umsatz \\
\hline 2 & $4.3 \mathrm{~mol}-\% \mathrm{Pd} / \mathrm{CaCO}_{3}{ }^{[\mathrm{a}]}$ & - & RT & $18 \mathrm{~h}$ & kein Umsatz \\
\hline 3 & $2.6 \mathrm{~mol}-\% \mathrm{Pd} / \mathrm{BaSO}_{4}{ }^{[\mathrm{a}]}$ & - & RT & $1.5 \mathrm{~h}$ & 95 \\
\hline 4 & 18 mol-\% Raney-Ni ${ }^{[\mathrm{b}]}$ & - & RT & $24 \mathrm{~h}$ & kein Umsatz \\
\hline 5 & $1.0 \mathrm{~mol}-\% \mathrm{Pd} / \mathrm{C}^{[\mathrm{a}]}$ & Chinolin & RT & $2.5 \mathrm{~h}$ & $79 \% 111,20 \% 95$ \\
\hline 6 & $1.0 \mathrm{~mol}-\% \mathrm{Pd} / \mathrm{C}^{[\mathrm{a}]}$ & Chinolin & 15 & $4 \mathrm{~h}$ & kein Umsatz \\
\hline
\end{tabular}


Tabelle 5: $\quad$ Getestete Bedingungen für die Hydrierung zum Alken 104.

\section{$1.4 \quad$ Umwandlung des Alkens 111 zum Epoxid 101}

Bei der anschließenden Umwandlung des Alkens 111 zum Epoxid 101 wurden zunächst Methoden eingesetzt, die zum racemischen Gemisch führen sollten (Abbildung 41, Tabelle 6).<smiles>C=CC(C)(C)Oc1cc(O)c2c(=O)c3cc4ccccc4cc3[nH]c2c1Br</smiles>

111 s. Tabelle 6<smiles>CC(C)(Oc1cc(O)c2c(=O)c3cc4ccccc4cc3[nH]c2c1Br)C1CO1</smiles>

rac-101

Abbildung 41: $\quad$ Epoxidierung des Alkens 111.

\begin{tabular}{|c|c|c|c|c|}
\hline \multirow[t]{2}{*}{ \# } & \multicolumn{3}{|c|}{ Bedingungen $^{[\mathrm{a}]}$} & \multirow[t]{2}{*}{ Ergebnis } \\
\hline & Ox. Reagenz & $\mathrm{T} .\left[{ }^{\circ} \mathrm{C}\right]$ & Zeit & \\
\hline 1 & DMDO & 0 & $7 d$ & Zersetzung \\
\hline 2 & DMDO & -35 & $18 \mathrm{~h}$ & Zersetzung \\
\hline 3 & $m \mathrm{CPBA}$ & 0 & $1.5 \mathrm{~h}$ & kein Umsatz \\
\hline 4 & $m \mathrm{CPBA}$ & RT & $24 \mathrm{~h}$ & kein Umsatz \\
\hline 5 & $t-\mathrm{BuOOH}$ & RT & $2.5 \mathrm{~h}$ & kein Umsatz \\
\hline 6 & $t-\mathrm{BuOOH}$ & RT & $4 \mathrm{~h}$ & kein Umsatz \\
\hline
\end{tabular}

Tabelle 6: Bedingungen für die Epoxidierung.

Die Umsetzung mit frisch hergestelltem Dimethyldioxiran (DMDO) ${ }^{106}$ führte jedoch auch bei tieferen Temperaturen lediglich zur Zersetzung des Substrats 111 (Einträge 1 u. 2). Der Einsatz von meta-Chlorperbenzoesäure ${ }^{107}$ und tert-Butylhydroperoxid ${ }^{108}$ als oxidierende Reagenzien führte dagegen auch nach langer Reaktionszeit nicht zur Bildung von 101 (Einträge $3-6)$. 
Da eine direkte Darstellung des Epoxids 101 keine Erfolg hatte, wurde ein zusätzlicher Syntheseschritt in den Syntheseplan eingebaut. Zunächst sollte das Alken 111 in den dihydroxylierten Alkohol rac-112 überführt und dieser anschließend durch selektive Aktivierung und Eliminierung der primären Hydroxyfunktion in das Epoxid rac-101 überführt werden (Abbildung 42).

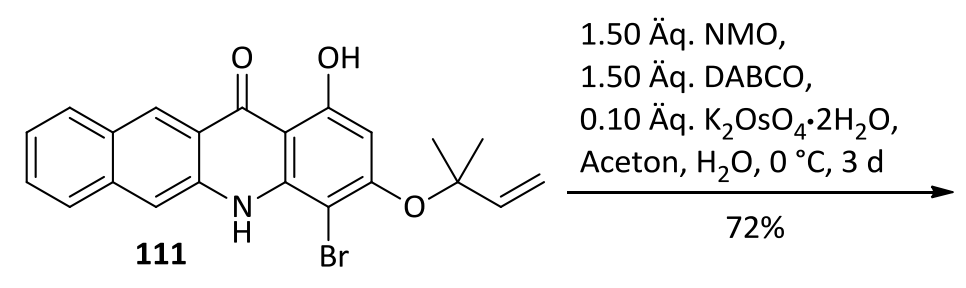<smiles></smiles>

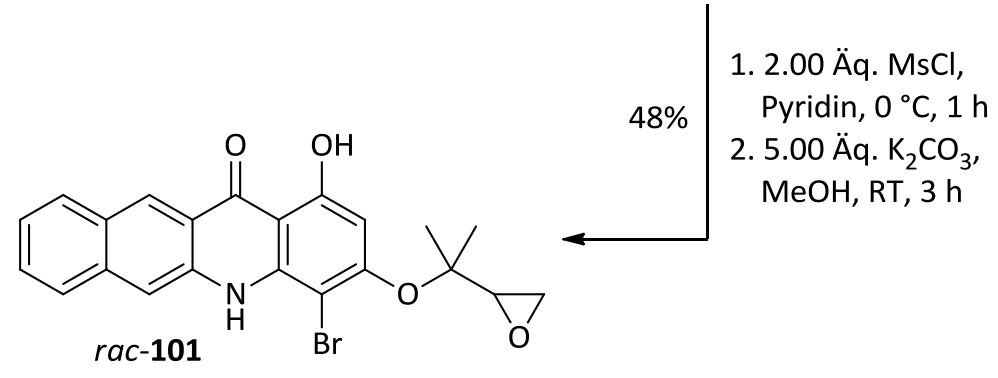

Abbildung 42: Veränderte Syntheseroute zur Darstellung des Epoxids 101.

Die racemische Umsetzung zum Diol rac-112 gelang durch Upjohn-Dihydroxylierung $^{109}$ mit Kaliumosmat und $N$-Methylmorpholin- $N$-oxid (NMO) als Reoxidans in guter Ausbeute von 72\%. Die nachfolgende selektive Mesylierung der primären Hydroxyfunktion bei $0{ }^{\circ} \mathrm{C}$ mit Mesylchlorid und anschließender Substitution des Mesylats unter Bildung des Epoxids rac-101 erfolgte dagegen mit lediglich $48 \%{ }^{110}$

Basierend auf vorangegangenen Arbeiten von S. Hampel ${ }^{111}$ sollte ein Metall-HalogenAustausch mit anschließender Öffnung des Epoxids mit Hilfe eines in situ gebildeten Zinkkomplexes erfolgen (Abbildung 43, Tabelle 7). ${ }^{112}$ Dabei sollte Verbindung 113 entstehen. 


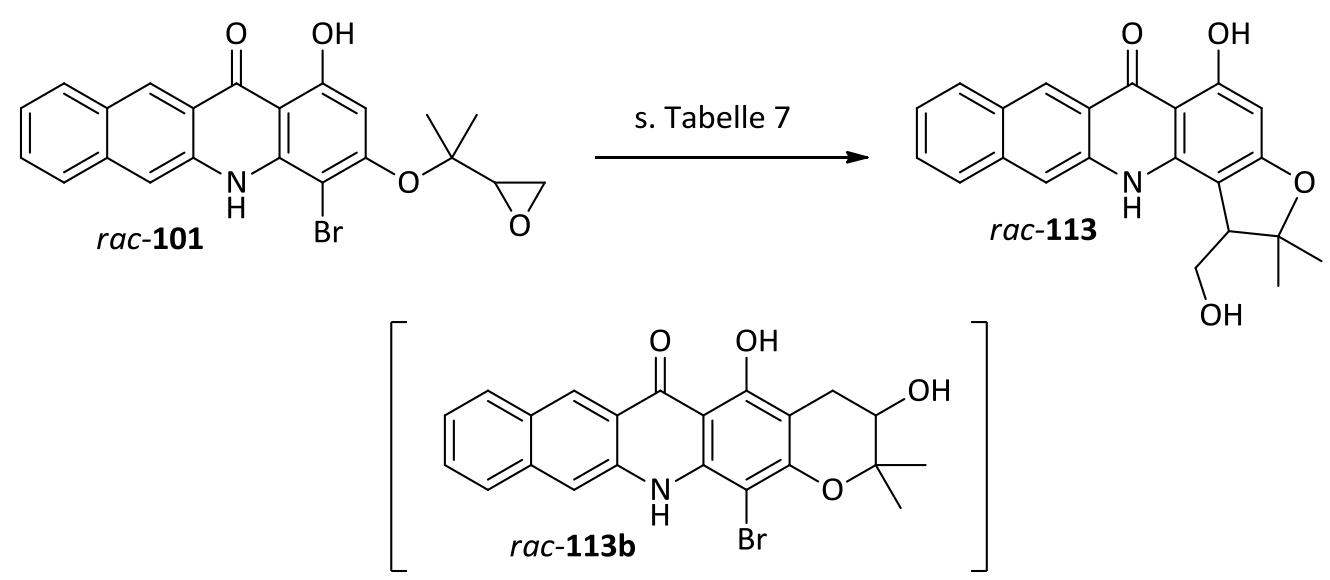

Abbildung 43: Zyklisierung des Epoxids rac-101.

\begin{tabular}{|c|c|c|c|}
\hline \# & \multicolumn{2}{|c|}{ Bedingungen $^{[\mathrm{a}]}$} & Ergebnis \\
\hline 1 & 3.50 Äq. Li $2 \mathrm{Zn}(\mathrm{SCN}) \mathrm{Me}_{3}$ & $\begin{array}{c}-78^{\circ} \mathrm{C} \text { für } 90 \mathrm{~min} \text {, dann } 0^{\circ} \mathrm{C} \text { für } \\
1 \mathrm{~h} \text {, dann RT für } 16 \mathrm{~h}\end{array}$ & $10 \%$ rac-113b \\
\hline 2 & 3.50 Äq. $i \mathrm{PrMgCl} \cdot \mathrm{LiCl}$ & $-78^{\circ} \mathrm{C}$ für $2 \mathrm{~h}$, dann RT für $16 \mathrm{~h}$ & $10 \%$ rac-113b \\
\hline 3 & 3.50 Äq. $n$-BuLi & $\begin{array}{c}-78^{\circ} \mathrm{C} \text { für } 90 \mathrm{~min} \text {, dann } 0^{\circ} \mathrm{C} \text { für } \\
1 \mathrm{~h} \text {, dann RT für } 16 \mathrm{~h}\end{array}$ & $62 \%$ rac -113 \\
\hline
\end{tabular}

Tabelle 7: $\quad$ Getestete Zyklisierungsbedingungen.

Es zeigte sich allerdings, dass statt des Metall-Halogen-Austausches eine $\mathrm{C}-\mathrm{H}$ Aktivierung mit anschließender Epoxidöffnung unter Bildung von rac-113b auftrat (Eintrag 1). Auch bei Verwendung des käuflich erhältlichen Grignard-Reagenzes iPrMgCl-LiCl wurde lediglich rac-113b erhalten (Eintrag 2). Unter den beschriebenen Bedingungen trat außerdem eine teilweise Zersetzung des Substrats rac-101 auf. Dagegen war die Verwendung von $n$-Butyllithium bei $-78^{\circ} \mathrm{C}$ zur Epoxidöffnung, die ebenfalls in vorangegangenen Arbeiten in der Arbeitsgruppe Tietze $e^{113}$ eingesetzt worden war, sehr erfolgreich. Unter diesen Bedingungen wurde aus rac-101 das gewünschte Produkt rac-113 in 62\% Ausbeute erhalten (Eintrag 3).

Die Darstellung des seco-Drugs rac-114 erfolgte unter Appel-Bedingungen. ${ }^{114}$ Unter leicht erhöhter Temperatur und mit 1,2-Dichlorethan (1,2-DCE) als Lösungsmittel 
konnte das seco-Drug rac-114 in einer sehr guten Ausbeute von 85\% isoliert werden (Abbildung 44).<smiles>CC(C)(C)C1=Cc2cc3ccccc3cc2Nc2c1c(O)cc1c2C(CO)C(C)(C)O1</smiles>

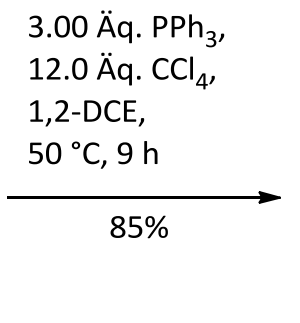<smiles>CC(C)(C)c1cc2ccccc2cc1C(=O)O</smiles>

Abbildung 44: Appel-Reaktion zur Darstellung des seco-Drugs rac-114.

Die anschließende Reinigung erfolgte mittels HPLC an chiraler $\mathrm{C}_{18}$-Phase mit den Eluenten Methanol/Wasser = 90:10. Die Entfernung des Lösungsmittels bei leicht erhöhter Temperatur $\left(30^{\circ} \mathrm{C}\right)$ führte zu einer teilweisen Eliminierung von $\mathrm{HCl}$. Dies konnte durch eine Temperaturverminderung auf $0{ }^{\circ} \mathrm{C}$ verhindert werden (Abbildung 45).<smiles></smiles>

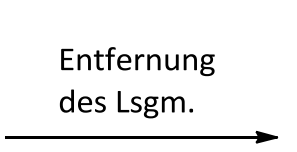<smiles>C=C1c2c(cc(O)c3c(=O)c4cc5ccccc5cc4[nH]c23)OC1(C)C</smiles>

Abbildung 45: Eliminierung von $\mathrm{HCl}$ aus dem seco-Drug rac-114 bei Entfernung des Lösungsmittels bei $30^{\circ} \mathrm{C}$.

Das seco-Drug rac-114 konnte aus Ethylacetat, in das langsam Pentan eingedampft wurde, auskristallisiert und seine Struktur röntgenkristallographisch bestätigt werden (Abbildung 46). 


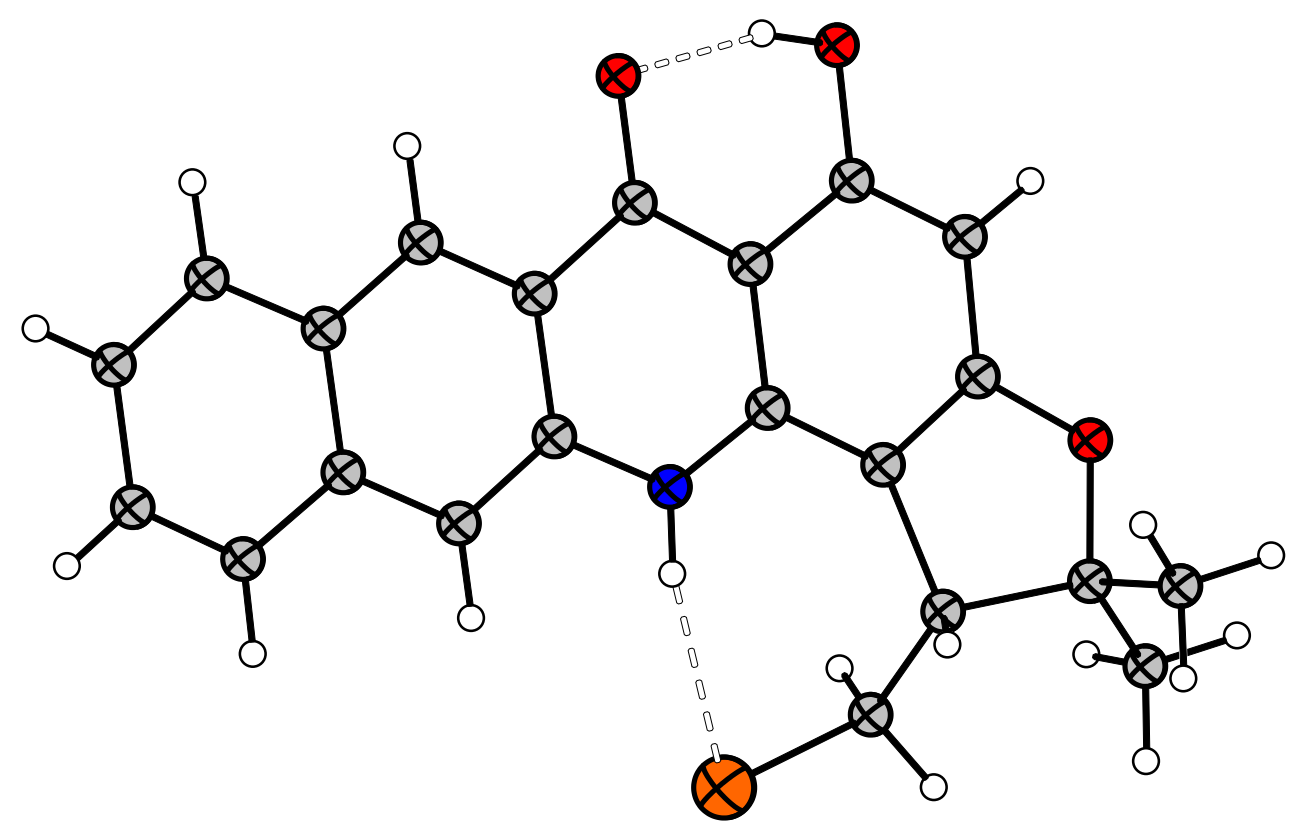

Abbildung 46: Kristallstruktur des seco-Drugs rac-114.

\section{7}

Diskussion ausgewählter spektroskopischer Daten der Verbindung rac-114

Die NMR-Signale wurden mit Hilfe von ${ }^{1} \mathrm{H}-\mathrm{COSY}$-, HSQC- und HMBC-Korrelationsspektren zugeordnet.

In Abbildung 47 ist das ${ }^{1} \mathrm{H}-\mathrm{NMR}-S p e k t r u m\left(600 \mathrm{MHz}, \mathrm{DMSO}-\mathrm{d}_{6}\right.$ ) des seco-Drugs rac114 mit der entsprechenden Zuordnung der Signale dargestellt. Am weitesten im Hochfeld bei $\delta=1.42$ und $1.71 \mathrm{ppm}$ resonieren die diastereotopen Protonen der beiden an C-2 gebundenen Methylgruppen als Singuletts. Bei $\delta=3.77 \mathrm{ppm}$ ist ein Dublett vom Dublett mit den Kopplungskonstanten $J=6.9$ und $2.5 \mathrm{~Hz} z$ finden, das dem 1-H zuzuordnen ist. $1^{\prime}-\mathrm{H}_{\mathrm{a}}$ resoniert bei $\delta=3.95 \mathrm{ppm}$ als Dublett vom Dublett mit den Kopplungskonstanten $J=12.1$ und $2.5 \mathrm{~Hz}$. Etwas weiter im Tieffeld befindet sich das zu $1^{\prime}-\mathrm{H}_{\mathrm{a}}$ diastereotope $1^{\prime}-\mathrm{H}_{\mathrm{b}}$ bei $\delta=4.01 \mathrm{ppm}$ ebenfalls als Dublett vom Dublett mit Kopplungskonstanten von $J=12.0$ und $7.0 \mathrm{~Hz}$. Das isolierte $4-\mathrm{H}$ resoniert als Singulett bei $\delta=6.05 \mathrm{ppm}$ gefolgt von zwei zentrierten Multipletts bei $\delta=7.46$ und 7.62 ppm. Diese können den Protonen 10-H und 9-H des Naphtholrings zugeordnet 
werden. Bei einer Verschiebung von $\delta=8.00$ und 8.16 ppm resonieren $11-\mathrm{H}$ und $8-\mathrm{H}$ jeweils als Dublett mit Kopplungskonstanten von $J=8.7$ und $8.4 \mathrm{~Hz}$, getrennt durch ein Singulett bei $\delta=8.06$ ppm, das dem 12-H zugeordnet werden kann. Das ebenfalls isolierte $7-\mathrm{H}$ resoniert als Singulett weiter im Tieffeld bei $\delta=8.90 \mathrm{ppm}$, gefolgt von dem NH des vinylogen Amids bei $\delta=11.12$ ppm. Als scharfes Singulett am weitesten im Tieffeld resoniert das Proton der vinylogen Säure bei $\delta=14.63$ ppm.

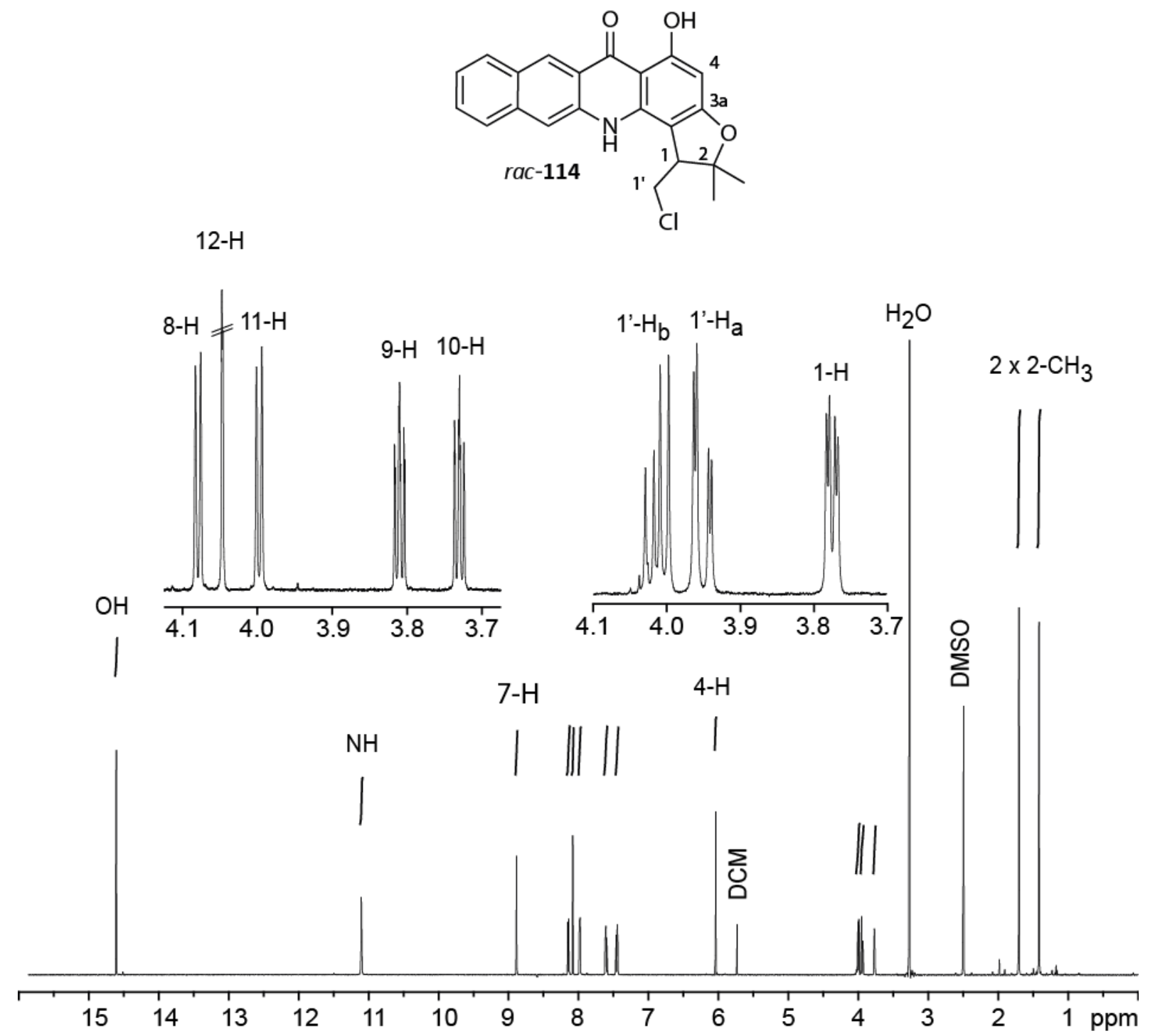

Abbildung 47: $\quad{ }^{1} \mathrm{H}-\mathrm{NMR}-$ Spektrum $(600 \mathrm{MHz}$, DMSO-d 6 ) der Verbindung rac-114.

Im ${ }^{13} \mathrm{C}-\mathrm{NMR}-S p e k t r u m\left(126 \mathrm{MHz}, \mathrm{DMSO}-\mathrm{d}_{6}\right.$ ) des seco-Drugs rac-114 findet man im Hochfeldbereich die Signale der an C-2 gebundenen diastereotopen Methylgruppen bei $\delta=21.6$ und 28.7 ppm (Abbildung 48). Weiter zum tiefen Feld verschoben tritt das Signal des $C-1$ ' bei $\delta=43.0$ ppm auf, gefolgt von dem Signal des C-1 bei 
$\delta=48.7 \mathrm{ppm}$. Das aromatische Kohlenstoffatom C-4 und das quartäre Kohlenstoffatom C-2 resonieren bei $\delta=89.9$ und $90.3 \mathrm{ppm}$. Die Signale bei $\delta=100.4$ und 102.4 ppm können C-13b und C-5a zugeordnet werden. Die benachbarten Kohlenstoffatome $\mathrm{C}-12$ und $\mathrm{C}-12$ a resonieren bei $\delta=112.0$ und $119.6 \mathrm{ppm}$, gefolgt von den Signalen der Kohlenstoffatome C-10, C-7, C-11, C-11a, C-9 und C-8 im Bereich von $\delta=124.3$ bis $129.3 \mathrm{ppm}$. Die weiter ins Tieffeld verschobenen Signale bei $\delta=135.6,137.1$ und 139.7 ppm entsprechen den Brückenatomen C-7a, C-6a und C13a. Deutlich weiter im Tieffeld bei $\delta=165.2$ und $165.6 \mathrm{ppm}$ resonieren C-3a und C5. Die Resonanz des Carbonylkohlenstoffatoms C-6 ist typisch für eine vinyloge Säure weit im Tieffeld bei $\delta=181.0$ ppm zu finden. 


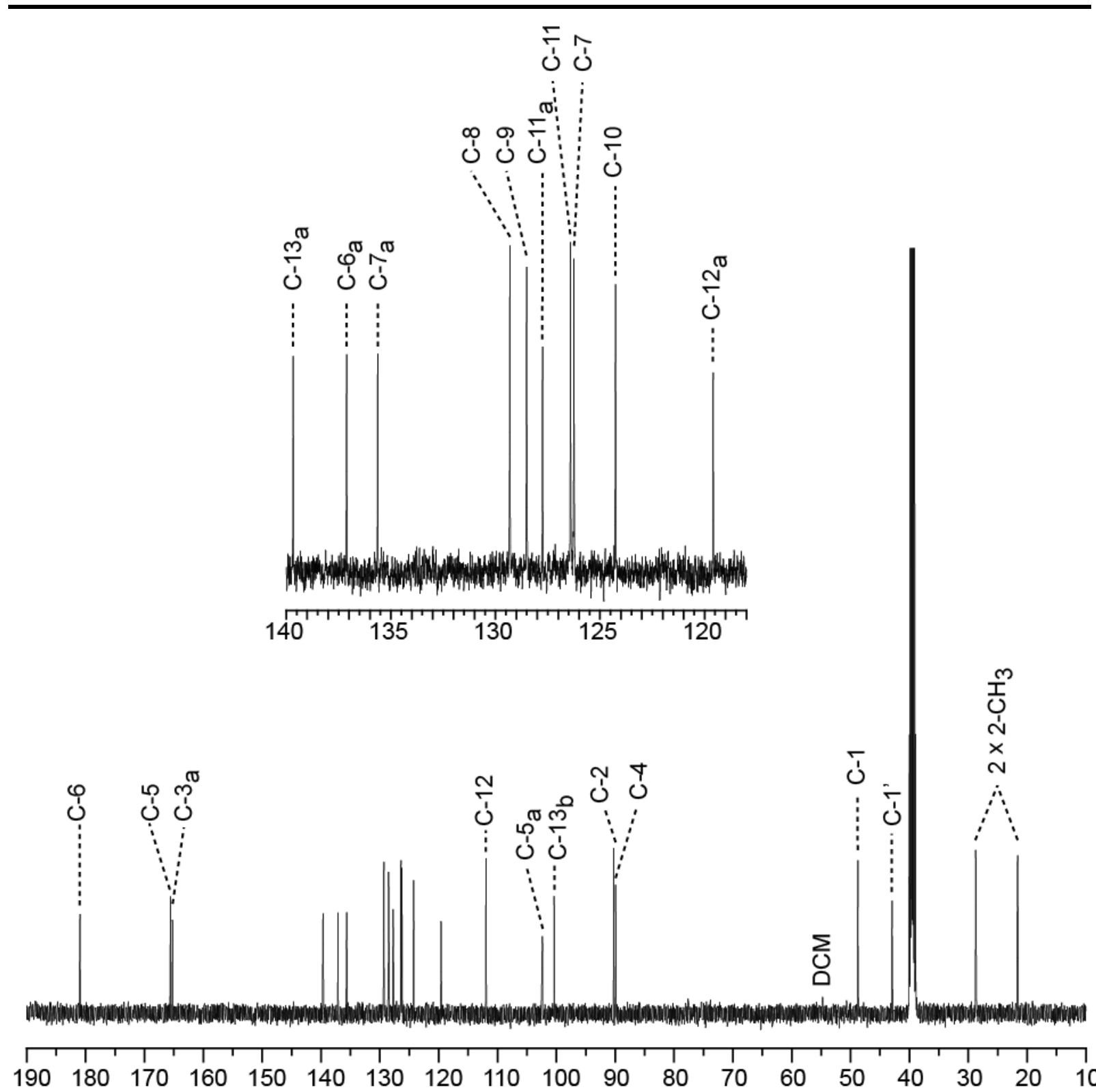

Abbildung 48: ${ }^{13} \mathrm{C}-\mathrm{NMR}$-Spektrum (126 MHz, DMSO-d $\mathrm{d}_{6}$ ) der Verbindung rac-114.

Im ESI-MS-Spektrum des seco-Drugs rac-114 sind im positiven lonenmodus bei $m / z 402.1$ (Basispeak), $m / z 781.2$ und 1162.3 Signale mit typischem Chlorisotopenmuster zu finden, die dem $\left[\mathrm{M}+\mathrm{Na}^{+}\right]^{+}-,\left[2 \mathrm{M}+\mathrm{Na}^{+}\right]^{+}-$sowie dem $\left[3 \mathrm{M}+\mathrm{Na}^{+}\right]^{+}-$Ion entsprechen. Im negativen Ionenmodus sind Signale bei $m / z 378.1$ (Basispeak) und $m / z 757.2$ zu finden, die dem $\left[\mathrm{M}-\mathrm{H}^{+}\right]^{-}$- und dem $\left[2 \mathrm{M}-\mathrm{H}^{+}\right]^{-}-$Ion entsprechen. Das ESIHRMS-Spektrum zeigt für das $\left[\mathrm{M}-\mathrm{H}^{+}\right]^{-}$-Ion ein Masse-Ladung-Verhältnis von $m / z$ 378.0886, was mit 4.2 ppm Abweichung gut mit dem berechneten Wert von $m / z 378.0902$ übereinstimmt. 
Zur Bestimmung der In-vitro-Zytotoxizität der im Rahmen dieser Arbeit dargestellten neuen Zytostatika wurden von Dr. Ingrid Schuberth, Anja Herdlitschke und Angela Rübeling in der Abteilung für Zellbiologie des Institutes für Organische und Biomolekulare Chemie In-vitro-Untersuchungen durchgeführt. Die Bestimmung der Zytotoxizität erfolgte hierbei nach dem HTCFA-Test (ㅂuman Iumor olony Forming Ability-Test).

\subsubsection{Der HTCFA-Test zur Bestimmung der Zytotoxizität}

Um die zytotoxische Wirkung der neu synthetisierten Substanzen auf adhärent wachsende humane Tumorzellen zu untersuchen, erfolgte ein Klonogenitätstest, der sich an den HTCFA-Test anlehnt und die Proliferationsfähigkeit von einzelnen Zellen widerspiegelt (Abbildung 49). Als Zelllinie diente das adhärent wachsende humane Bronchialkarzinom der Linie A549. Die Aussaat der Tumorzellen erfolgte aus einer Stammkultur, in der diese in einem Kulturmedium (DMEM mit Zusatz von 10\% fötalem Kälberserum, $44 \mathrm{mM} \mathrm{NaHCO}_{3}$ und $4 \mathrm{mM}$ Glutamin) permanent bei $37^{\circ} \mathrm{C}$ und $7.5 \%$ $\mathrm{CO}_{2}$-Begasung in Luft gehalten wurden, in Konzentrationen von $10^{2}$ bis $10^{4}$ Zellen in 6-Well-Multischalen. Nach $24 \mathrm{~h}$ wurde das Kulturmedium entfernt, die Zellen einmal mit dem serumfreien Inkubationsmedium UltraCULTURE ${ }^{\text {TM }}$ gewaschen und anschließend in diesem Medium $24 \mathrm{~h}$ mit zehn bis zwölf verschiedenen Konzentrationen (drei dekadische Größenordnungen) der zu testenden Substanz inkubiert. Diese wurde vorher frisch in einer DMSO-Stammlösung angesetzt und mit dem Inkubationsmedium verdünnt, sodass in den Näpfen letztlich eine DMSO-Konzentration von $1 \%$ vorlag. Nach Entfernen der Testsubstanz und einem weiteren Waschgang mit dem Kulturmedium wurden die verbliebenen Zellen zwölf Tage in normalem Kulturmedium kultiviert. Anschließend wurde dieses entfernt, die gebildeten Klone wurden getrocknet, mit Löfflers Methylenblau angefärbt und ab einer Klongröße von ca. 500 um makroskopisch ausgezählt. Die Bestimmung der relativen Klonbildungsraten erfolgte anhand der in Abbildung 49 angegebenen Formel, wobei sich die Klonzahl des Kontrollversuches aus unbehandelten Zellen ergab und gleich 100\% gesetzt wurde. 


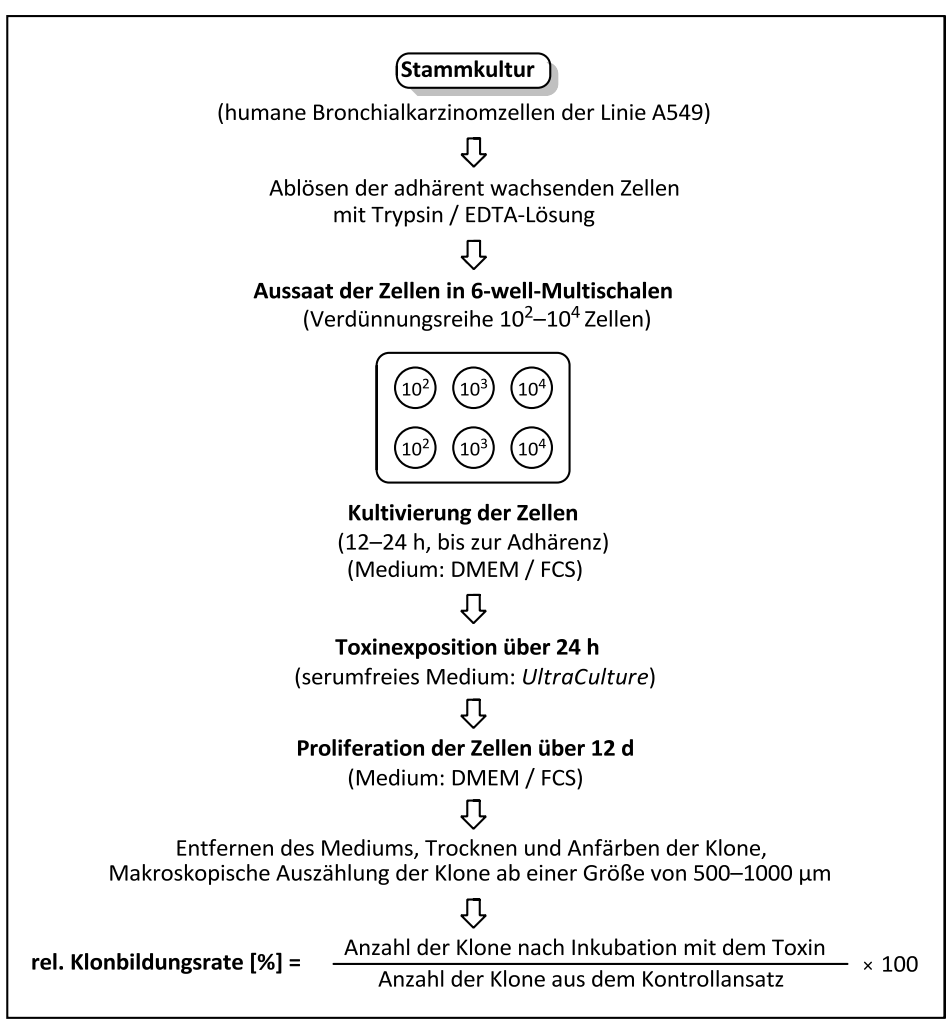

Abbildung 49: Schematische Darstellung des nach I. Schuberth modifizierten HTCFA-Tests.

\subsubsection{Ergebnisse der Untersuchungen zur In-vitro-Zytotoxizität an} humanen Bronchialkarzinomzellen (A549) für das seco-Drug rac-114

In Abbildung 50 sind die Ergebnisse der Untersuchungen zur In-vitro-Zytotoxizität an humanen Bronchialkarzinomzellen (A549) für das seco-Drug rac-114 dargestellt. Es wurde ein $\mathrm{IC}_{50}$-Wert von $1.04 \mu \mathrm{M}$ gefunden. 


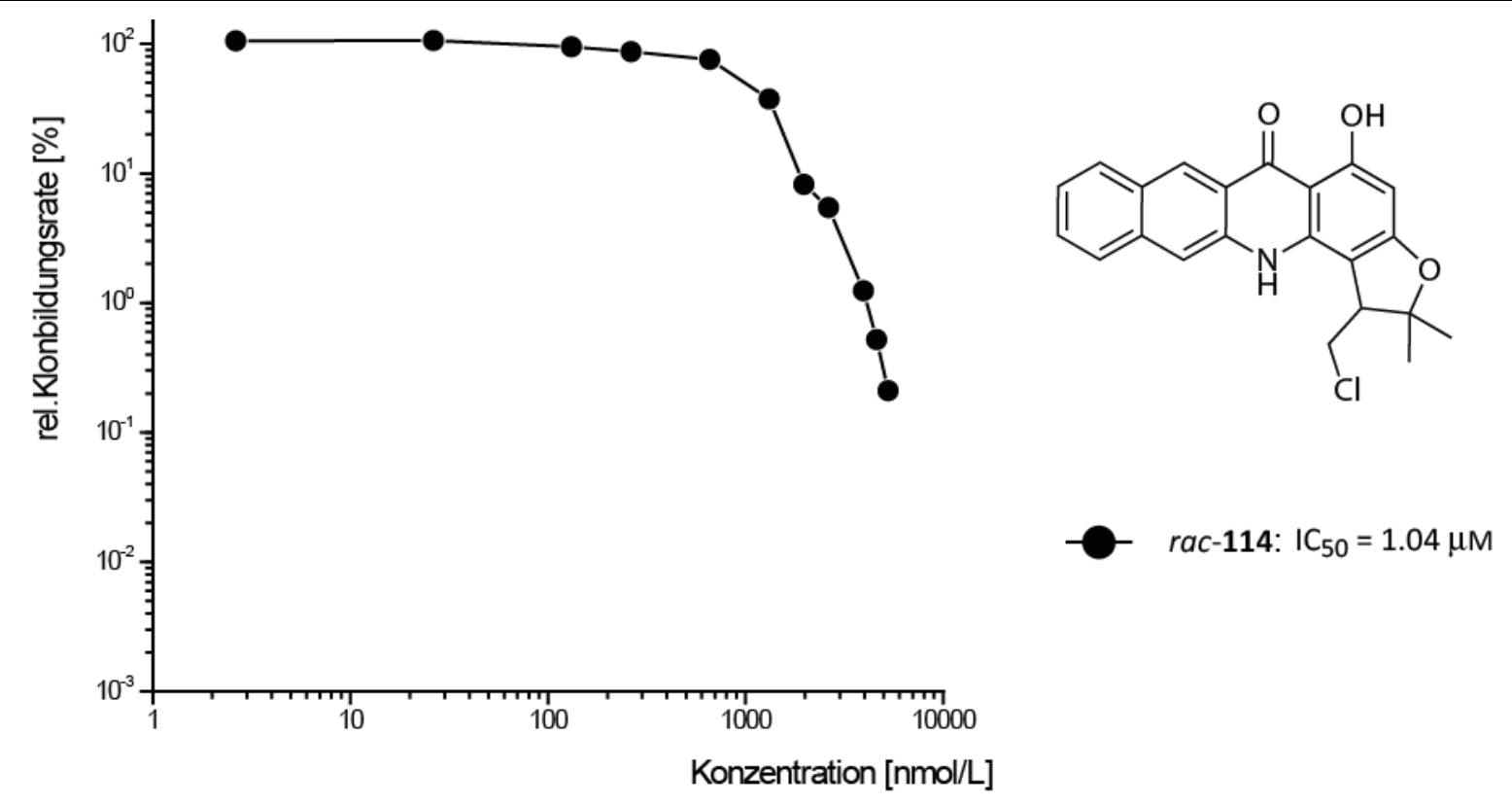

Abbildung 50: In-vitro-Zytotoxizitäten (A549) des seco-Drugs rac-114.

Die Stammverbindungen Acronycin (45) und Duocarmycin SA (16) weisen einen $\mathrm{IC}_{50}$-Wert von $23 \mu \mathrm{M}^{78 \mathrm{~b}}$ bzW $10 \mathrm{pM}^{44}$ gemessen an murinen lymphatischen Leukämiezellen (L1210), auf. Da die Zytotoxizitätsbestimmungen an unterschiedlichen Testsystemen und Zelllinien erfolgten, ist ein direkter Vergleich der numerischen Werte nicht möglich, auch wenn erfahrungsgemäß die Tests an murinen lymphatischen Leukämiezellen (L1210) eher höhere Zytotoxizitäten liefern als die an humanen Bronchialkarzinomzellen (A549). Es kann festgehalten werden, dass es gelungen ist, durch Kombination der Teilstrukturen zweier Naturstoffe ein neuartiges, biologisch aktives Hybrid-Molekül zu entwickeln, dessen Aktivität mit dem der einen Stammverbindung, des Acronycins (45) vergleichbar ist.

\subsection{Enantioselektive Synthese des Diols $\mathbf{1 1 2}$}

Für den Einsatz des neuen Hybridwirkstoffs in der Therapie ist es wünschenswert, eine Methode zur enantioselektiven Synthese zu entwickeln. So ist bekannt, dass Enantiomere in einem Organismus sehr unterschiedlich Eigenschaften haben können. Das in der Öffentlichkeit wohl bekannteste Beispiel ist die unterschiedliche Wirkung der Enantiomere des Thalidomids, besser bekannt als Contergan ${ }^{\circledR}$. Während von dem $(R)$-Thalidomid eine beruhigende Wirkung ausgeht, besitzt das (S)-Thalidomid frucht- 
schädigende Eigenschaften. ${ }^{115}$ Bei den Enantiomeren der Acronycin-Derivate ${ }^{77}$ konnten zwar bisher keine signifikanten Unterschiede in den Zytotoxizitäten festgestellt werden, die Duocarmycin-Analoga unterscheiden sich jedoch zum Teil erheblich. ${ }^{116}$ Es sollte daher ausgehend vom Alken 111 ein enantioselektiver Zugang zum Diol 112 durch eine Sharpless-Dihydroxylierung erfolgen (Abbildung 51, Tabelle 8). ${ }^{117}$<smiles>C=CC(C)(C)Oc1cc(O)c2c(=O)c3cc4ccccc4cc3[nH]c2c1Br</smiles>

s. Tabelle 8<smiles>CCCCC(C)(Oc1cc(O)c2c(=O)c3cc4ccccc4cc3[nH]c2c1Br)[C@@H](O)CO</smiles>

Abbildung 51: Enantioselektive Synthese des Diols 112.

\begin{tabular}{|c|c|c|c|c|c|}
\hline \multirow[t]{2}{*}{ \# } & \multicolumn{4}{|c|}{ Bedingungen ${ }^{[a]}$} & \multirow[t]{2}{*}{ Ergebnis } \\
\hline & Additiv & Lsgm. & T. $\left[{ }^{\circ} \mathrm{C}\right]$ & Zeit & \\
\hline 1 & - & $\mathrm{THF} / \mathrm{H}_{2} \mathrm{O}$ & RT & $3 d$ & Zersetzung \\
\hline 2 & - & $\mathrm{THF} / \mathrm{H}_{2} \mathrm{O}$ & 0 & $6 \mathrm{~h}$ & Zersetzung \\
\hline 3 & $\begin{array}{c}3.00 \mathrm{Äq} \mathrm{NaHCO}_{3}, \\
1.00 \ddot{\mathrm{Aq} \mathrm{MeSO}} \mathrm{NH}_{2}\end{array}$ & $\mathrm{THF} / \mathrm{H}_{2} \mathrm{O}$ & 0 & $3 d$ & kein Umsatz \\
\hline 4 & $\begin{array}{c}3.00 \ddot{\mathrm{Aq}} \mathrm{NaHCO}_{3}, \\
1.00 \ddot{\mathrm{Aq}} \mathrm{MeSO}_{2} \mathrm{NH}_{2}\end{array}$ & ${ }^{t} \mathrm{BuOH} / \mathrm{H}_{2} \mathrm{O}$ & 0 & $5 d$ & kein Umsatz \\
\hline
\end{tabular}

${ }^{[a]} \mathrm{AD}-\mathrm{mix}-\beta$

Tabelle 8: $\quad$ Bedingungen für die Sharpless-Dihydroxylierung.

Der Einsatz des käuflich erweblichen AD-mix- $\beta$, bestehend aus Kaliumosmat, Kaliumhexacyanoferrat, Kaliumcarbonat und dem chiralen Liganden (DHQD) 2 PHAL, führte jedoch nur zu einer Zersetzung des Substarts 111 (Einträge 1 u. 2). Es wurde daher die Reaktion unter milderen, d.h. weniger basischen Reaktionsbedingungen durchgeführt. Unter Verwendung von Natriumhydrogencarbonat als Puffer und Methansulfonamid zur Beschleunigung der Reaktion konnte eine Zersetzung vermieden werden. Es zeigte sich jedoch, dass das Katalysatorsystem unter diesen Bedingungen unreaktiv und eine Umsetzung des Substrats, auch nach mehreren 
Tagen Reaktionszeit, nicht festzustellen war (Einträge 3 u. 4). Auf weitere Versuche zur enantioselektiven Synthese wurde zunächst verzichtet, da das Hauptaugenmerk auf einer Steigerung der biologischen Aktivität durch Bildung von Dimeren und auf der Kupplung mit DMAI (84) als DNA-bindende Einheit lag.

\subsection{Synthese von Dimeren und Kupplung mit DMAI als DNA-bindende Einheit}

In der Reihe der Duocarmycin-Analoga konnte in vielen Arbeiten eine bis zu tausendfache Steigerung der Zytotoxizität durch Kupplung mit einer DNA-bindenden Einheit, insbesondere DMAI (84), beobachtet werden (vgl. Kapitel B4.1). ${ }^{116}$ Dimere Strukturen, aufgebaut im Arbeitskreis Tietze, zeigen bis jetzt unerreichte Zytotoxizitäten und $\mathrm{QIC}_{50}$-Werte gegenüber dem Wirkstoff-Monomer (vgl. Kapitel B4.2). ${ }^{8 b}$

Das Ziel war es daher, sowohl dimere Strukturen vom Typ $\mathbf{8 3}$ als auch das mit dem DNA-Binder DMAI- $\mathrm{CO}_{2} \mathrm{H}$ (84) gekoppelte seco-Drug rac-82 zu synthetisieren (Abbildung 52).
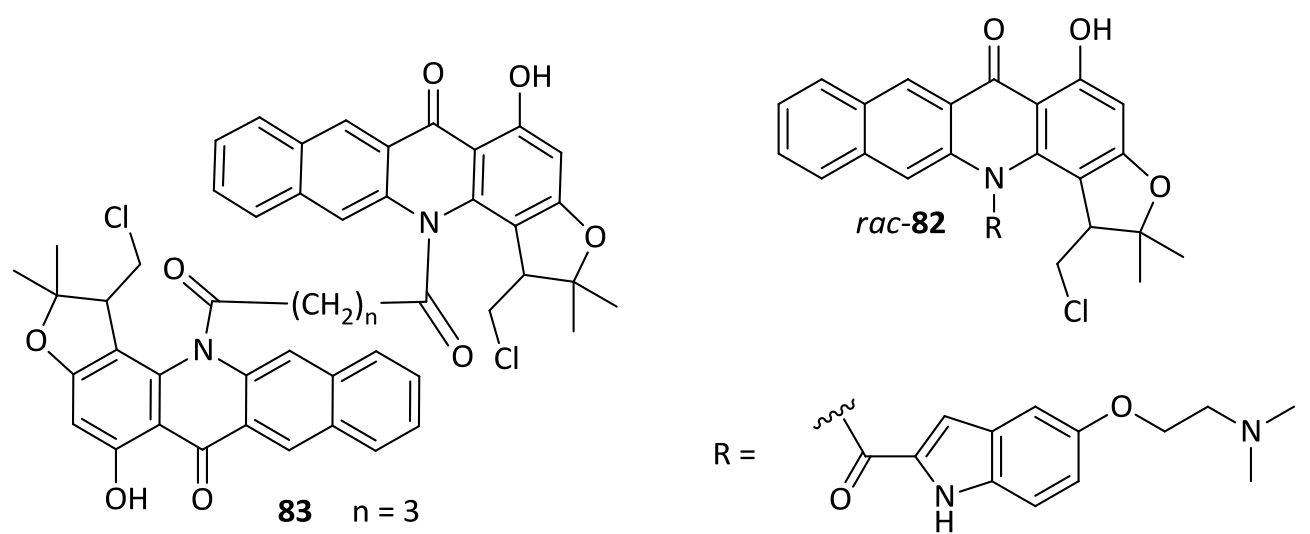

Abbildung 52: $\quad$ Dimer 83 und mit DMAI- $\mathrm{CO}_{2} \mathrm{H}(\mathbf{8 4})$ gekuppeltes seco-Drug rac-82.

\subsubsection{Kupplung mit DMAI (84) als DNA-Binder}

Aufgrund der bereits erwähnten Instabilität des seco-Drugs rac-82 unter wässrigen Bedingungen wurde beschlossen, die Kupplung mit DMAI (84) bereits auf der Stufe des Alkohols rac-113 oder des Alkens 111 durchzuführen. 
Die Synthese von Amiden ist eine bekannte Reaktion und dementsprechend ist die Zahl möglicher Synthesestrategien sehr groß. Die einfachste Möglichkeit der Kupplung eines Amins mit einer Carbonsäure besteht in der Aktivierung der Säurefunktion durch Umwandlung in das entsprechende Säurechlorid. Da dieses jedoch wasserempfindlich ist, werden heutzutage, besonders in der Peptidchemie, andere Möglichkeiten der Aktivierung bevorzugt. Diese erfolgt dabei z.B. mit Hilfe eines Carbodiimids wie EDC (116) ${ }^{118}$ oder durch Umwandlung der Säurefunktion in einen Aktivester mit PyBOP (117) $)^{119}$ oder DIC (118)/HOAT (119) $)^{120}$ (Abbildung 53).

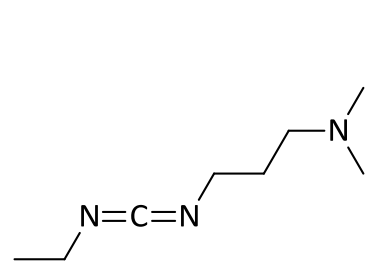

116

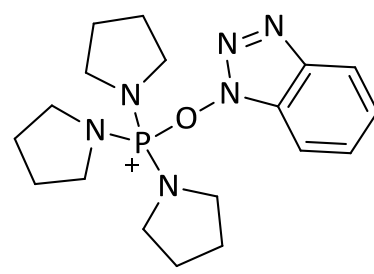

117

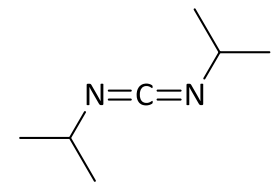

118<smiles>On1nnc2cccnc21</smiles>

119

Abbildung 53: Verschiedene Reagenzien zur Aktivierung von Carbonsäuren.

Zunächst musste geklärt werden, ob das Stickstoffatom in rac-113 und rac-111 überhaupt als Nukleophil zugänglich ist. Dazu wurden verschiedene Bedingungen getestet, eine Probe zur Mikroaufarbeitung entnommen und diese sowohl massenspektrometrisch als auch mittels Dünnschichtchromatographie untersucht. Eine Isolierung und Strukturaufklärung mit Hilfe der NMR-Spektroskopie erfolgte nur bei erkennbarem Umsatz des jeweiligen Substrats (Abbildung 54, Tabelle 9).<smiles>CC(C)(C)C(C)(C)C</smiles><smiles>C=CC(C)(C)Oc1cc(O)c2c(=O)c3cc4ccccc4cc3[nH]c2c1Br</smiles>

111<smiles>COOCC1c2c(cc(O)c3c(=O)c4cc5ccccc5cc4[nH]c23)OC1(C)C</smiles>

Abbildung 54: Substrate $(\mathbf{1 1 3}, \mathbf{1 1 1})$ für die Kupplung mit DMAI $(\mathbf{8 4})$ und ein Nebenprodukt $(\mathbf{1 2 0})$ der Reaktion. 


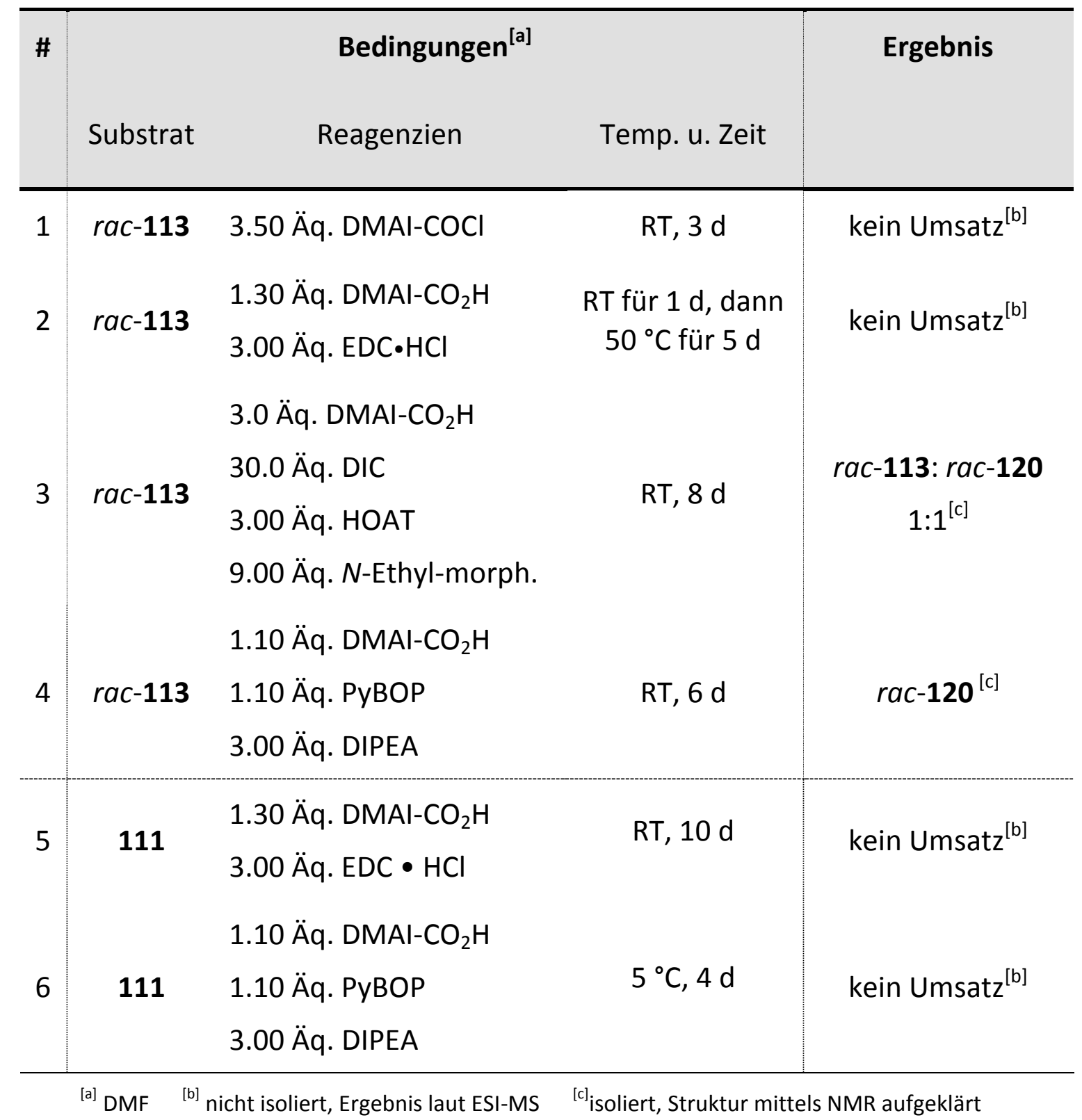

Tabelle 9: $\quad$ Bedingungen für die Kupplung.

DMAl- $\mathrm{CO}_{2} \mathrm{H}$ (84) wurde mit Oxalylchlorid zum aktivierten Carbonsäure-Derivat umgesetzt und anschließend ohne weitere Aufarbeitung zur Kupplung mit rac-113 eingesetzt (Eintrag 1). Es zeigte sich jedoch auch nach mehreren Tagen Reaktionszeit kein erkennbarer Umsatz zum gekuppelten Produkt. Die im Arbeitskreis Tietze etablierte Methoden der Aktivierung mit $\mathrm{EDC}^{8 \mathrm{~d}}$ führte auch nach erheblich verlängerter Reaktionszeit weder mit dem Alkohol rac-113 noch mit dem Alken 111 zu einem Umsatz (Einträge 2 u. 5). Durch die Transformation von DMAI-COOH (84) in hochreaktive Aktivester mit HOAT (119) und PyBOP (117) konnte eine Umwandlung 
des Alkohols rac-113 in ein Produkt mit der gewünschten Masse beobachtet werden (Einträge 3 u. 4). Nach Isolierung und Strukturaufklärung mittels NMR stellte es sich jedoch als der strukturisomere Ester rac-120 heraus. Das Alken 111 zeigte sich gegenüber dem mit PyBOP 117 und DMAI-COOH (84) gebildeten Aktivester als gänzlich unreaktiv (Eintrag 6).

\subsubsection{Versuche zur Synthese von Dimeren}

Parallel zu den Untersuchungen zur Kupplung mit DMAI als DNA-bindende Einheit sollten dimere Strukturen mit Glutarsäure als Spacer-Einheit synthetisiert werden, da diese in früheren Arbeiten die höchsten Zytotoxizitäten zeigten. ${ }^{67 a}$ Der Reaktionsverlauf wurde nach Probenentnahme und Mikroaufarbeitung ebenfalls dünnschichtchromatographisch und massenspektrometrisch verfolgt. Als Substrate wurden aufgrund der o.g. Empfindlichkeit des seco-Drugs rac-114, der Alkohol rac-113, das Alken 111 und das Epoxid rac-101 gewählt (Abbildung 55, Tabelle 10).<smiles>CC(C)(C)C(C)(C)C</smiles><smiles>CC(C)(Oc1cc(O)c2c(=O)c3cc4ccccc4cc3[nH]c2c1Br)C1CO1</smiles>

rac-101<smiles>C=CC(C)(C)Oc1cc(O)c2c(=O)c3cc4ccccc4cc3[nH]c2c1Br</smiles>

111

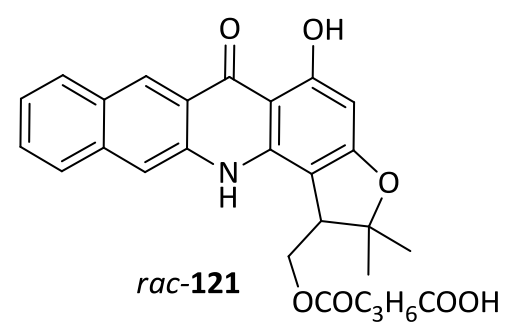

Abbildung 55: Substrate für die Bildung von dimeren Strukturen $(\mathbf{1 1 3}, \mathbf{1 1 1}, \mathbf{1 0 1})$, sowie ein Nebenprodukt der Reaktion (121). 


\begin{tabular}{|c|c|c|c|}
\hline \# & & Bedingungen & Ergebnis \\
\hline & Substrat & Reagenzien & \\
\hline 1 & $\operatorname{rac}-113^{[\mathrm{a}]}$ & $\begin{array}{l}0.50 \text { Äq. Glutarsäuredichlorid } \\
2.00 \text { Äq. Pyridin }\end{array}$ & kein Umsatz $^{[c]}$ \\
\hline 2 & $r a c-113^{[\mathrm{a}]}$ & $\begin{array}{l}0.50 \text { Äq. Glutarsäure } \\
1.00 \text { Äq. PyBOP } \\
3.00 \text { Äq. DIPEA }\end{array}$ & $\operatorname{rac}-121^{[\mathrm{d}]}$ \\
\hline 3 & $111^{[\mathrm{a}]}$ & $\begin{array}{l}0.50 \text { Äq. Glutarsäure } \\
1.00 \text { Äq. PyBOP } \\
3.00 \text { Äq. DIPEA }\end{array}$ & $\begin{array}{l}\text { kein Umsatz, } \\
\text { Zersetzung }^{[c]}\end{array}$ \\
\hline 4 & $\operatorname{rac}-101^{[\mathrm{b}]}$ & $\begin{array}{l}2.00 \text { Äq. n-BuLi, dann } \\
0.50 \text { Äq. Glutarsäuredichlorid }\end{array}$ & kein Umsatz $^{[c]}$ \\
\hline 5 & $\operatorname{rac}-101^{[b]}$ & $\begin{array}{l}2.50 \text { Äq. n-BuLi, dann } \\
10.0 \text { Äq. Glutarsäuredichlorid }\end{array}$ & $\begin{array}{l}\text { Zyklisierung, } \\
\text { Substrat }^{[\mathrm{c}]}\end{array}$ \\
\hline
\end{tabular}

Tabelle 10: $\quad$ Reaktionsbedingungen für die Dimerbildung.

Während bei der Umsetzung des Alkohols rac-113 mit Glutarsäuredichlorid und Pyridin als Base in DMF nach mehreren Tagen Reaktionzeit keine Produktbildung festgestellt werden konnte, führte die Verwendung von PyBOP wieder zur Veresterung der primären Alkoholfunktion und damit zum Produkt rac-121 (Einträge 1 u. 2). Das Alken 111 zeigte sich unter diesen Reaktionsbedingungen, analog zu den Untersuchungen in Kap. 1.10.1, unreaktiv; es konnte lediglich eine teilweise Zersetzung des Substrats festgestellt werden (Eintrag 3). Um die Reaktivität der sekundären Aminofunktionalität zu erhöhen, sollte die Nukleophilie des Stickstoffatoms durch Deprotonierung gesteigert werden. Die doppelte Deprotonierung 
des Epoxids rac-101 an der phenolischen Hydroxyfunktion und dem sekundären Amin mit $n$-BuLi und anschließende Zugabe des Glutarsäuredichlorids brachte jedoch keinen Umsatz des Substrats bzw. führte bei 2.50 Äq. $n$-BuLi lediglich zu einer teilweisen Zyklisierung zum Alkohol rac-113 (Einträge 4 u. 5).

Die Reaktion eines sekundären Amins mit einem Carbonsäurederivat scheint auf den ersten Blick trivial zu sein, führte aber dennoch nicht zum gewünschten Produkt, da das Amin sich als Nukleophil gänzlich unreaktiv zeigte. Neben der starken sterischen Abschirmung setzt die Konjugation des Stickstoffs mit der Carbonylfunktion die Nukleophilie stark herab. Dies lässt sich am anschaulichsten erklären, wenn man von einer Mesomeriestabilisierung mit dem benachbarten aromatischen Ring ausgeht und die Aminofunktion somit als vinyloges Amid betrachtet (Abbildung 56). Diese Beobachtung steht in Einklang mit der für ein Amin untypisch weiten Tieffeldverschiebung des NH-Protons (s. Kapitel D1.1.1)

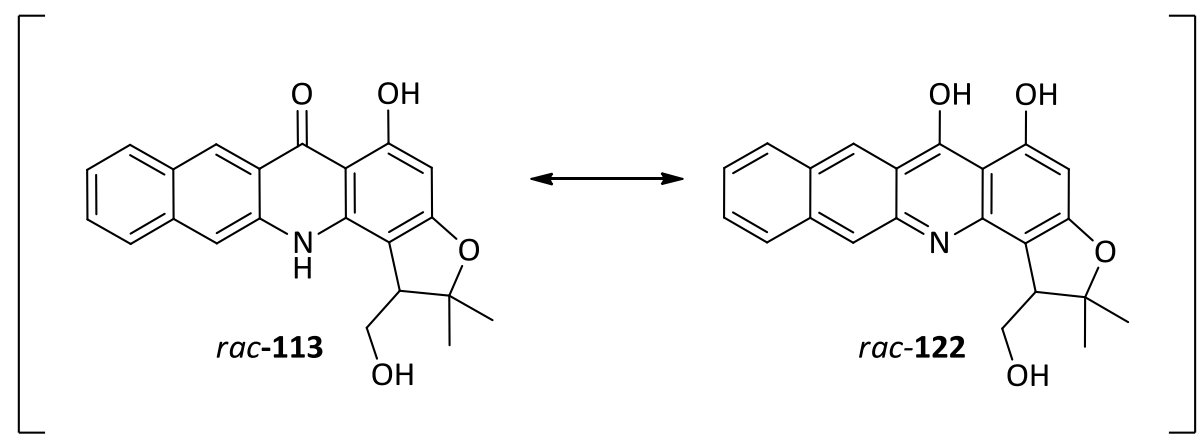

Abbildung 56: Mesomeriestabilisierung des Acridon-Gerüsts.

Es sollte daher ein Derivat mit leicht zugänglicher Aminofunktion zur Kupplung mit einer DNA-bindenden Einheit und Dimerbildung synthetisiert und auf seine Zytotoxizität untersucht werden. 


\section{Synthese der Nitro-Acronycin-Duocarmycin-Hybride}

\section{$2.1 \quad$ Syntheseplan}

Durch die Einführung einer leicht zugänglichen Aminofunktion am A-Ring sollte die Kupplung mit einer DNA-binden Einheit vereinfacht werden. Die Synthese sollte zunächst analog zu Kap. D1.1 mit einer Kondensation von 2-Amino-5nitrobenzoesäure und Phloroglucin (89) beginnen. Aufgrund der starken Desaktivierung des Aromaten durch die Nitrofunktion führte dies jedoch nicht zur Bildung des Acridon-Grundgerüsts (Ergebnisse nicht dargestellt). Es wurde daher ein alternativer Syntheseplan aufgestellt:

Das seco-Drug rac-123 mit leicht zugänglicher, arylischer Aminofunktion sollte ausgehend von den käuflich zugänglichen Substanzen 2-Chlor-5-nitrobenzoesäure (126) und Dimethoxyanilin (127) erhalten werden (Abbildung 57). Das Grundgerüst sollte dabei durch eine nukleophile aromatische Substitution des Chloratoms in 126 durch die Aminofunktion in $\mathbf{1 2 7}$ mit anschließendem Ringschluss durch eine Art Friedel-Crafts-Acylierung synthetisiert werden. Selektive Bromierung würde zu 125 führen, welches mit dem Propargylchlorid 102 gekuppelt werden sollte. Anschließende Einfachhydrierung der Dreifachbindung, Dihydroxylierung und Aktivierung der primären Hydroxyfunktion mit anschließender intramolekularer Eliminierung würde das Epoxid rac-124 liefern. Dieses sollte nach Zyklisierung, Reduktion der Nitrogruppe und Substitution der entstandenen Hydroxyfunktion zum seco-Drug rac-123 führen. 
<smiles>CC(C)(C)C(C)(C)C</smiles>

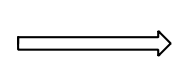<smiles>O=C(O)c1cc([N+](=O)[O-])ccc1Cl</smiles>

126<smiles>COc1cc(N)cc(OC)c1</smiles>

127<smiles>CC(=O)Oc1ccc2[nH]c3c(Br)c(OC(C)(C)C4CO4)cc(O)c3c(=O)c2c1</smiles>

rac-124<smiles>C=C</smiles><smiles>O=c1c2cc([N+](=O)[O-])ccc2[nH]c2c(Br)c(O)cc(O)c12</smiles>

125<smiles>C#CC(C)(C)Cl</smiles>

102
Abbildung 57: Retrosynthetischer Ansatz zum Aufbau von rac-123.

\subsection{Synthese des Acridon-Grundgerüsts}

Ausgehend von 2-Chlor-5-nitrobenzoesäure (126) und 3,5-Dimethoxyanilin (127) wurde Verbindung 128 nach $\mathrm{H}$. Ullman ${ }^{121}$ mit Kupfer-(II) als Katalysator in einer guten Ausbeute von $76 \%$ erhalten (Abbildung 58).<smiles>O=C(O)c1cc([N+](=O)[O-])ccc1Cl</smiles>

126<smiles>COc1cc(N)cc(OC)c1</smiles>

127 2.50 Äq. KOAc,

1.70 Äq. $\mathrm{NEt}_{3}$, 0.05 Äq. $\mathrm{Cu}(\mathrm{OAc})_{2}$, ${ }^{t} \mathrm{BuOH}$, Reflux, $5 \mathrm{~d}$ $76 \%$<smiles>COc1cc(Nc2ccc([N+](=O)[O-])cc2C(=O)O)cc(OC)c1</smiles>

128 $83 \% \mid \begin{aligned} & 7.50 \text { Äq. } \mathrm{POCl}_{3}, \\ & 1.50 \text { Äq. } \mathrm{NEt}_{3}, \\ & \text { DCE, Reflux, } 3 \mathrm{~h}\end{aligned}$<smiles>O=c1c2cc([N+](=O)[O-])ccc2[nH]c2cc(O)cc(O)c12</smiles>

s. Tabelle 11<smiles>COc1cc(OC)c2c(=O)c3cc([N+](=O)[O-])ccc3[nH]c2c1</smiles>

129

Abbildung 58: Synthese des Diols 130. 
Für den Ringschluss zu 129 durch eine Art Friedel-Crafts-Acylierung war eine Aktivierung der Carboxylfunktion nötig. Die Bildung eines gemischten Anhydrids mit Trifluoressigsäureanhydrid ${ }^{122}$ war nicht erfolgreich, da lediglich eine Acylierung der Aminofunktion stattfand. Eine Aktivierung mit Phosphorylchlorid ${ }^{123}$ zum Carbonsäurechlorid und anschließendem Ringschluss lieferte das Acridon-Gerüst 129 in einer sehr guten Ausbeute von $83 \%$.

Nachfolgend sollten die beiden Arylmethylether-Gruppen in $\mathbf{1 2 9}$ gespalten werden, wobei sich die beiden Funktionalitäten deutlich in ihrer Reaktivität unterscheiden. Während die O-Me-Bindung des vinylogen Esters an C-1 sehr labil ist und bereits unter schwach sauren Bedingungen gespalten wird (eine Spaltung trat als Nebenprodukt bei der Umwandlung von 128 zu 129 auf), ist die Spaltung des Ethers an C-3 wesentlich schwieriger. Es bot sich hierbei eine Umsetzung mit starken Lewisoder Brönsted-Säuren an. ${ }^{124}$ Das bei der Reaktion mit $\mathrm{BBr}_{3}$ bzw. $\mathrm{HBr}$ erhaltene Produkt 130 ist nur in DMSO und DMF löslich, eine säulenchromatographische Aufreinigung und eine damit verbundene genaue Ausbeutebestimmung war daher bei den in kleinem Maßstab durchgeführten Reaktionen nicht möglich. Aus diesem Grund wurden Vorversuche ohne Aufarbeitung durchgeführt und der Umsatz anhand der relativen Intensitäten der ESI-MS-Peaks abgeschätzt. Die Ergebnisse sind in Abbildung 59 und Tabelle 11 dargestellt.

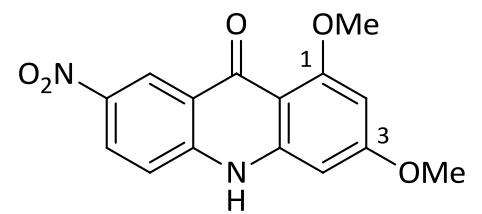

129<smiles>O=c1c2cc([N+](=O)[O-])ccc2[nH]c2cc(O)cc(O)c12</smiles>

130<smiles>COc1cc(O)c2c(=O)c3cc([N+](=O)[O-])ccc3[nH]c2c1</smiles>

131

Abbildung 59: Produkte der Etherspaltung. 


\begin{tabular}{|c|c|c|c|c|c|}
\hline \multirow[t]{2}{*}{ \# } & \multirow[t]{2}{*}{ Bedingungen } & \multicolumn{4}{|c|}{ Höhe des Peaks im ESI-MS ${ }^{[a]}$} \\
\hline & & 130 & 131 & 129 & N.P. ${ }^{[b]}$ \\
\hline 1 & $\begin{array}{c}2.20 \ddot{\mathrm{Aq} \mathrm{BBr}}, \mathrm{DCM},-78^{\circ} \mathrm{C} \text { auf } \mathrm{RT}, \\
20 \mathrm{~h}\end{array}$ & 0 & 100 & 30 & 0 \\
\hline 2 & $5.00 \ddot{\mathrm{Aq} \mathrm{BCl}}, \mathrm{DCM}, \mathrm{RT}, 15 \mathrm{~h}$ & 0 & 100 & 0 & 0 \\
\hline 3 & konz. $\mathrm{HBr}, \mathrm{AcOH}, \mathrm{RT}, 2.5 \mathrm{~h}$ & 0 & 0 & 100 & 0 \\
\hline 4 & konz. $\mathrm{HBr}, \mathrm{AcOH}, 50^{\circ} \mathrm{C}, 2 \mathrm{~d}$ & 0 & 15 & 100 & 80 \\
\hline 5 & $\begin{array}{l}\text { konz. } \mathrm{HBr}, \mathrm{AcOH}, \mathrm{MW}, 100, \\
30-180 \mathrm{~min}\end{array}$ & 10 & 100 & 25 & 0 \\
\hline 6 & $\begin{array}{l}\text { konz. } \mathrm{HBr}, \mathrm{AcOH}, \mathrm{MW}, 120^{\circ} \mathrm{C}, \\
\quad 30-60 \mathrm{~min}\end{array}$ & 25 & 100 & 10 & 20 \\
\hline 7 & konz. HBr, Reflux, $3.5 \mathrm{~h}$ & 35 & 50 & 100 & 80 \\
\hline 8 & konz. $\mathrm{HBr}, \mathrm{MW}, 120^{\circ} \mathrm{C}, 30 \mathrm{~min}$ & 100 & 50 & 5 & 30 \\
\hline 9 & konz. $\mathrm{HBr}, \mathrm{MW}, 120^{\circ} \mathrm{C}, 60 \mathrm{~min}$ & 10 & 50 & 0 & 100 \\
\hline 10 & konz. $\mathrm{HBr}, \mathrm{MW}, 140^{\circ} \mathrm{C}, 30 \mathrm{~min}$ & 100 & 25 & 0 & 20 \\
\hline 11 & konz. $\mathrm{HBr}, \mathrm{MW}, 140^{\circ} \mathrm{C}, 45 \mathrm{~min}$ & 100 & 5 & 0 & 20 \\
\hline
\end{tabular}

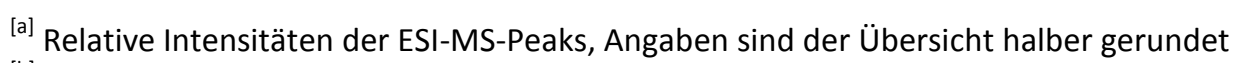

[b] nicht identifiziertes Nebenprodukt

Tabelle 11: Vorversuche zur Etherspaltung.

Zunächst wurden mildere Spaltungsbedingungen durch die Lewis-Säuren Bortribromid $^{125}$ und Bortrichlorid ${ }^{126}$ getestet (Einträge 1 u. 2). In beiden Fällen konnte eine saubere Reaktion ohne Nebenproduktbildung zum einfach entschützten 131 beobachtet werden. Die stabilere Etherbindung an C-3 wurde unter diesen Bedingungen auch nach langer Reaktionszeit jedoch nicht gespalten.

Die Spaltung mittels konzentrierter Bromwasserstofflösung ${ }^{127}$ stellt bereits eine sehr harsche Reaktionsführung dar. Die mildere Variante verwendet ein Gemisch aus 
konzentrierter Bromwasserstofflösung und Essigsäure. ${ }^{128}$ Testversuche unter milderer Reaktionsführung bei Raumtemperatur und $50{ }^{\circ} \mathrm{C}$ führten jedoch zu keinem bzw. minimalem Umsatz des Substrats (Einträge 3 u. 4). Durch eine Erhöhung der Reaktionstemperatur auf $100{ }^{\circ} \mathrm{C} \mathrm{bzw} .120^{\circ} \mathrm{C}$ und Reaktion in der Mikrowelle, konnte zwar eine Bildung der monoentschützten Spezies 131, jedoch nur eine minimale Produktbildung von 130, nachgewiesen werden (Einträge 5 u. 6). Es wurde daher beschlossen, harschere Bedingungen zu testen.

Eine Reaktionsführung ohne Essigsäure als Additiv führte im offenen Reaktionsgefäß nach $3.5 \mathrm{~h}$ zu einem Gemisch aus dem Produkt 130, dem monoentschützten 131 und dem Substrat 129 (Eintrag 7). Es wurde ebenfalls ein erheblicher Anteil eines nicht identifizierbaren Nebenprodukts gebildet. Eine schnellere Reaktionsführung durch erhöhte Temperatur in der Mikrowelle schien sinnvoll, um die Nebenproduktbildung so weit wie möglich zu unterbinden.

Es zeigte sich, dass eine Temperarturerhöhung auf $120^{\circ} \mathrm{C}$ den Anteil des zweifach entschützten 130 gegenüber 131 erhöhte. Eine Verlängerung der Reaktionszeit zur Umwandlung von noch verbliebenem 131 führte jedoch zu stetiger Zersetzung des Produkts 130 und damit einhergehend zu einer vermehrten Bildung des Nebenprodukts (Einträge 8 u. 9).

Eine weitere Erhöhung der Reaktionstemperatur auf $140{ }^{\circ} \mathrm{C}$ führte zu fast vollständigem Umsatz unter Bildung von 130 bei minimaler Nebenproduktbildung (Einträge 10 u. 11). Die Entschützung unter den optimierten Bedingungen im GrammMaßstab lieferte nach Umkristallisation aus Wasser das gewünschte Produkt $\mathbf{1 3 0}$ mit 83\% Ausbeute.

\subsubsection{Alkylierung und selektive Bromierung an C-4}

Analog zu Kap. D1.1 wurde versucht, eine selektive Bromierung an C-4 zu erreichen. Aufgrund der bereits erwähnten schlechten Löslichkeit von 130 war eine Reaktionsführung lediglich in DMSO und DMF bei höheren Temperaturen möglich. Unter diesen Bedingungen gelang eine selektive Einfachbromierung der C-4-Position 
nicht (Ergebnisse nicht dargestellt). Es wurde daher beschlossen, zunächst die Löslichkeit durch eine Alkylierung der C-3-Hydroxyfunktion zu verbessern (Abbildung $60)$.<smiles>COc1cc(OC)c2c(=O)c3cc([N+](=O)[O-])ccc3[nH]c2c1</smiles>

129<smiles>C#CC(C)(C)Oc1cc(O)c2c(=O)c3cc([N+](=O)[O-])ccc3[nH]c2c1Br</smiles>

133

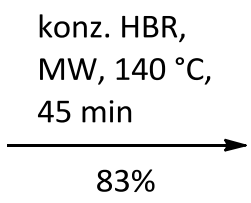

s. Tabelle 12<smiles>O=c1c2cc([N+](=O)[O-])ccc2[nH]c2cc(O)cc(O)c12</smiles>

130 10.0 Äq. 102, 2.00 Äq. $\mathrm{K}_{2} \mathrm{CO}_{3}$ 0.03 Äq. $\mathrm{CuCl}$, $\mathrm{DMF}, 0{ }^{\circ} \mathrm{C}, 11 \mathrm{~h}$<smiles>C#CC(C)(C)Oc1cc(O)c2c(=O)c3cc([N+](=O)[O-])ccc3[nH]c2c1</smiles>

132

Abbildung 60: Synthese der bromierten Spezies 133.

Die Kupfer-(I)-katalysierte Alkylierung des Acridons 130 bei $0{ }^{\circ} \mathrm{C}$ lieferte nach $11 \mathrm{~h}$ das Alkin 132 in einer befriedigenden Ausbeute von 56\%. Im Gegensatz zur Synthese der Benzo[b]-Struktur 104 traten ebenfalls eine 1-OH-Alkylierung und eine $\mathrm{N}$-Alkylierung als Nebenreaktionen auf.

Die beiden arylischen Positionen C-2 und C-4 sind in ihrer Reaktivität sehr ähnlich. Es wurden daher Vorversuche im Milligramm-Maßstab unternommen, um Bedingungen für die Bildung eines möglichst hohen Anteil des an C-4 bromierten Produkts 133 zu entwickeln (Tabelle 12). 


\begin{tabular}{c|c|cccc}
\hline$\#$ & Bedingungen & \multicolumn{4}{|c}{ Ergebnis $^{[\mathrm{b}]}$} \\
& Additiv & $\mathrm{C}_{4}-\mathrm{Br}$ & $\mathrm{C}_{2}-\mathrm{Br}$ & $\mathrm{Di}-\mathrm{Br}$ & Substrat \\
\hline 1 & - & $36 \%$ & $30 \%$ & $10 \%$ & $24 \%$ \\
\hline 2 & $1.00 \mathrm{Äq} \mathrm{ZnCl} 2$ & $\mathbf{2 0 \%}$ & $60 \%$ & $10 \%$ & $10 \%$ \\
\hline 3 & $1.00 \mathrm{Äq} \mathrm{CuCl} 2$ & $45 \%$ & $41 \%$ & $6 \%$ & $9 \%$ \\
\hline
\end{tabular}

[a] 1.00 Äq NBS, Aceton, $-78^{\circ} \mathrm{C}, 1 \mathrm{~h}$;

${ }^{[b]}$ Isoliert durch Säulenchromatographie, jedoch nicht rein, daher Ergebnisse gerundet

Tabelle 12: $\quad$ Vorversuche zur selektiven Bromierung von 132.

Es zeigte sich, dass eine Bromierung mit äquimolarer Menge NBS in Aceton bei $-78^{\circ} \mathrm{C}$ nicht selektiv erfolgte, sondern zu einem 1:1-Gemisch der beiden an C-2 und C-4 bromierten Produkte führte (Eintrag 1). Es wurde daher versucht, durch Zusatz von Salzen eine Komplexbildung an der vinylogen Säurefunktion und damit eine Bevorzugung der C-4-Position zu erreichen. Der bewährte Zusatz von Zinkchlorid brachte zwar eine Steigerung der Selektivät, es wurde aber überraschenderweise bevorzugt das nicht gewünschte C-2-bromierte Isomer gebildet (Eintrag 2). Der Zusatz von Kupfer-(II)-Chlorid führte schließlich zu einer leichten Steigerung der Selektivität zum C-4-bromierten Isomer, das nach säulenchromatographischer Reinigung mit 45\% Ausbeute erhalten wurde.

An dieser Stelle soll darauf hingewiesen werden, dass die Abtrennung von 133 von der doppelt bromierten Verbindung schwierig war. Um die Doppelbromierung einzudämmen wurde NBS nur in kleinen Portionen zugegeben bis laut DC kein Substrat mehr vorhanden war. Die doppelte Bromierung konnte so fast vollständig vermieden und die chromatographische Aufreinigung deutlich vereinfacht werden. Die Differenzierung der beiden Isomeren erfolgte mittels 2D-NMR. 


\subsubsection{Reduktion, Dihydroxylierung und Epoxidbildung}

Zur Reduktion der Dreifachbindung in 133 zum Alken 134 wurde das erfolgreich eingesetzte Katalysatorsystem Palladium auf Aktivkohle vergiftet mit Chinolin gewählt. Bei niedriger Temperatur und stark verkürzter Reaktionszeit konnte das Alken 134 in einer guten Ausbeute von 70\% erhalten werden (Abbildung 61). Bei längerer Reaktionsführung trat eine Spaltung der Etherbindung auf.<smiles>C#CC(C)(C)Oc1cc(O)c2c(=O)c3cc([N+](=O)[O-])ccc3[nH]c2c1Br</smiles>

133<smiles>CC(C)(Oc1cc(O)c2c(=O)c3cc([N+](=O)[O-])ccc3[nH]c2c1Br)C1CO1</smiles>

rac-124

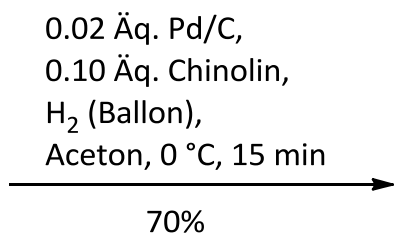

$70 \%$

1. $2.00 \mathrm{Äq} . \mathrm{MsCl}$, Pyridin, $0{ }^{\circ} \mathrm{C}, 1 \mathrm{~h}$ 2. 5.00 Äq. $\mathrm{K}_{2} \mathrm{CO}_{3}$, $\frac{\mathrm{MeOH}, \mathrm{RT}, 30 \mathrm{~min}}{62 \%}$<smiles>C=CC(C)(C)Oc1cc(O)c2c(=O)c3cc([N+](=O)[O-])ccc3[nH]c2c1Br</smiles>

134

$0.10 \mathrm{Aq} \cdot \mathrm{K}_{2} \mathrm{OsO}_{4} \cdot \mathrm{H}_{2} \mathrm{O}$, 0.20 Äq. DABCO, 1.50 Äq. NMO, Aceton, $\mathrm{H}_{2} \mathrm{O}, 0^{\circ} \mathrm{C}, 12 \mathrm{~d}$<smiles>CC(C)(Oc1cc(O)c2c(=O)c3cc([N+](=O)[O-])ccc3[nH]c2c1Br)C(O)CO</smiles>

rac-135

Abbildung 61: Synthese des Epoxids rac-124.

Die Synthese des Diols 135 erfolgte zunächst racemisch nach Upjohn ${ }^{109}$ unter Verwendung von Kaliumosmat als Katalysator und $N$-Methylmorpholin- $N$-oxid (NMO) als Reoxidans in einer guten Ausbeute von 74\%. Die Überführung der primären Hydroxyfunktion in den entsprechenden Sulfonsäureester und die anschließende intramolekulare Eliminierung des Mesylats unter basischen Bedingungen führte zum Epoxid rac-135 in einer befriedigenden Ausbeute von 62\%. ${ }^{110}$

2.2.3 Diskussion ausgewählter spektroskopischer Daten der Verbindung rac-124

Die NMR-Signale wurden mit Hilfe von ${ }^{1} \mathrm{H}-\mathrm{COSY}-$, HSQC- und HMBCKorrelationsspektren zugeordnet. 
In Abbildung 62 ist das ${ }^{1} \mathrm{H}-\mathrm{NMR}-\mathrm{Spektrum}\left(600 \mathrm{MHz}, \mathrm{DMSO}-\mathrm{d}_{6}\right)$ mit der entsprechenden Zuordnung der Signale dargestellt. Im Hochfeldbereich bei $\delta=1.31$ und $1.51 \mathrm{ppm}$ resonieren die diastereotopen Protonen der beiden an C-1' gebundenen Methylgruppen. Etwas weiter zu tieferem Feld verschoben resonieren die Protonen des Oxiran-Rings: Bei $\delta=2.84 \mathrm{ppm}$ findet sich ein Dublett vom Dublett mit Kopplungskonstanten von $J=4.7$ und $2.8 \mathrm{~Hz}$, das dem $3^{\prime}-\mathrm{H}_{\mathrm{a}}$ zugeordnet werden kann. Das dazu diastereotope Proton $3^{\prime}-\mathrm{H}_{\mathrm{b}}$ resoniert als scheinbares Triplett bei $\delta=2.90 \mathrm{ppm}$ mit einer Kopplungskonstanten von $J=4.6 \mathrm{~Hz}$. Bei einer chemischen Verschiebung von $\delta=3.35 \mathrm{ppm}$ ist ein Dublett vom Dublett mit den Kopplungskonstanten $J=4.1$ und $2.8 \mathrm{~Hz}$ zu finden. Es kann dem $2 '-\mathrm{H}$ zugeordnet werden. Im aromatischen Bereich bei $\delta=6.77 \mathrm{ppm}$ kann zunächst das isolierte $2-\mathrm{H}$ als Singulett beobachtet werden. Weiter zu tiefem Feld verschoben resonieren die Protonen des elektronenarmen aromatischen Rings. Bei $\delta=8.20 \mathrm{ppm}$ zeigt sich ein scheinbares Triplett mit einer Kopplungskonstanten von $\mathrm{J}=7.9 \mathrm{~Hz}$, das dem $5-\mathrm{H}$ zugeordnet werden kann. Das $6-\mathrm{H}$ ist bei $\delta=8.45 \mathrm{ppm}$ als Dublett vom Dublett mit den Kopplungskonstanten $J=9.2$ und $2.6 \mathrm{~Hz} z \mathrm{z}$ beobachten. Des Weiteren ist ein zentriertes Multiplett bei $\delta=8.82 \mathrm{ppm}$ zu beobachten. Dies kann dem $8-\mathrm{H}$ zugeordnet werden. Das Proton der NH-Gruppe resoniert als breites Singulett bei $\delta=11.14$ ppm, das der OH-Gruppe zeigt ein scharfes Singulett bei $\delta=13.84$ ppm. 


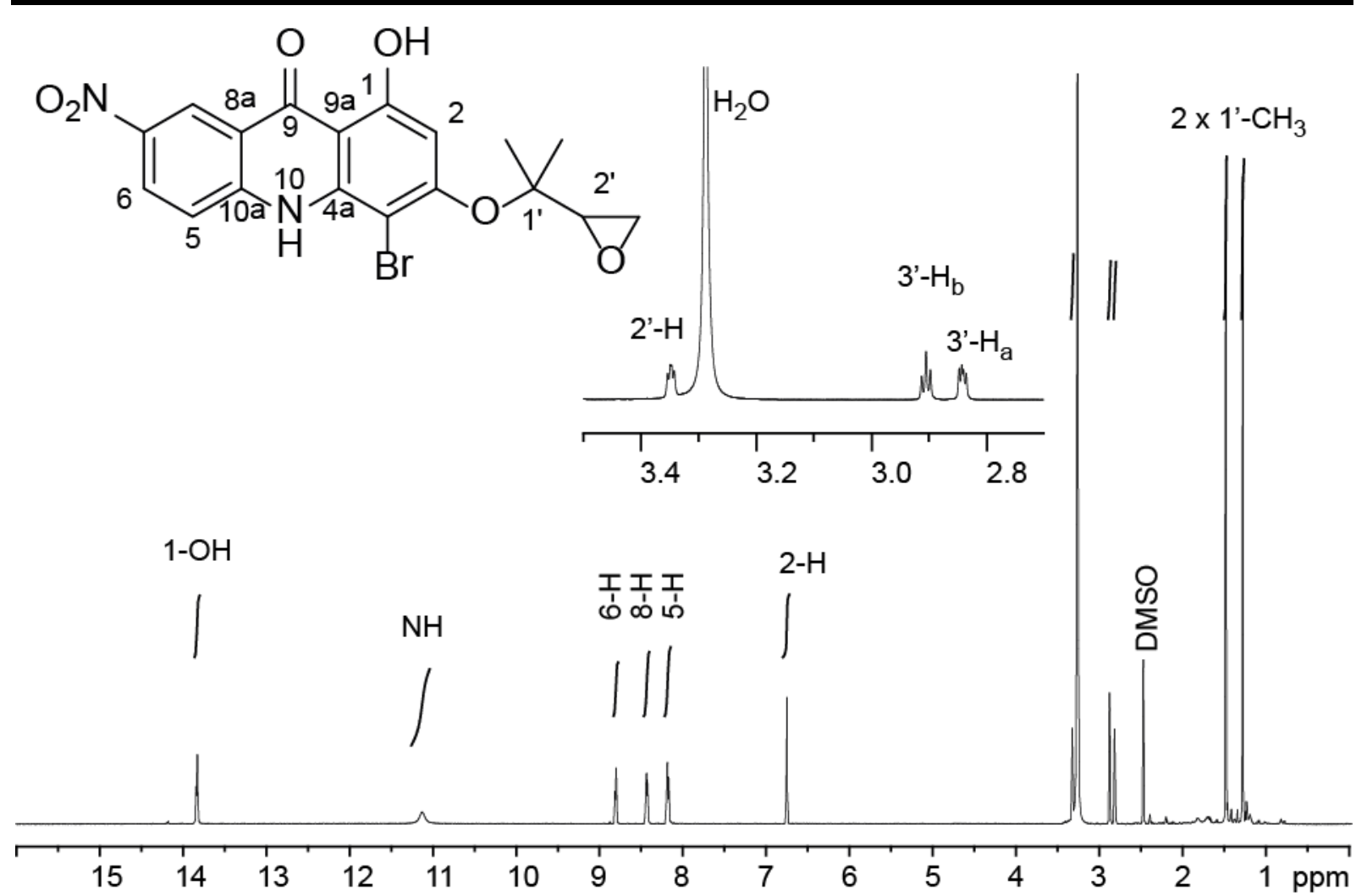

Abbildung 62: $\quad{ }^{1} \mathrm{H}-\mathrm{NMR}-\mathrm{Spektrum}\left(600 \mathrm{MHz}\right.$, DMSO- $\left.\mathrm{d}_{6}\right)$ der Verbindung rac-124.

Im ${ }^{13} \mathrm{C}-\mathrm{NMR}-S p e k t r u m$ (151 MHz, DMSO- $\left.\mathrm{d}_{6}\right)$ des Epoxids rac-124 sind im Hochfeldbereich die Signale der an C-1' gebundenen Methylgruppen bei $\delta=19.9$ und $25.1 \mathrm{ppm}$ zu finden (Abbildung 63). Es folgen die Signale der Kohlenstoffatome C-3', C-2' und C-1' der Seitenkette bei $\delta=44.6,56.4$ und 82.7 ppm. Die Atome C-4 und C-2 des elektronenreichen Aromaten sind bei $\delta=91.0$ und 100.6 ppm zu finden, gefolgt von den Brückenkohlenstoffatomen C-9a und C-8a bei $\delta=105.1$ und 117.7 ppm. Die benachbarten Kohlenstoffatome C-5 und C- 6 resonieren bei $\delta=119.9$ und 127.5 ppm, getrennt durch das C-8 bei $\delta=121.4$ ppm. Im Bereich von $\delta=139.6$ bis 144.4 ppm resonieren C-4a, C-10a und C-7. Die Kohlenstoffatome C-3 und C-1 sowie das Carbonylkohlenstoffatom C-9 zeigen typische Verschiebungen ins Tieffeld bei $\delta=158.9,162.2$ und $179.7 \mathrm{ppm}$. 


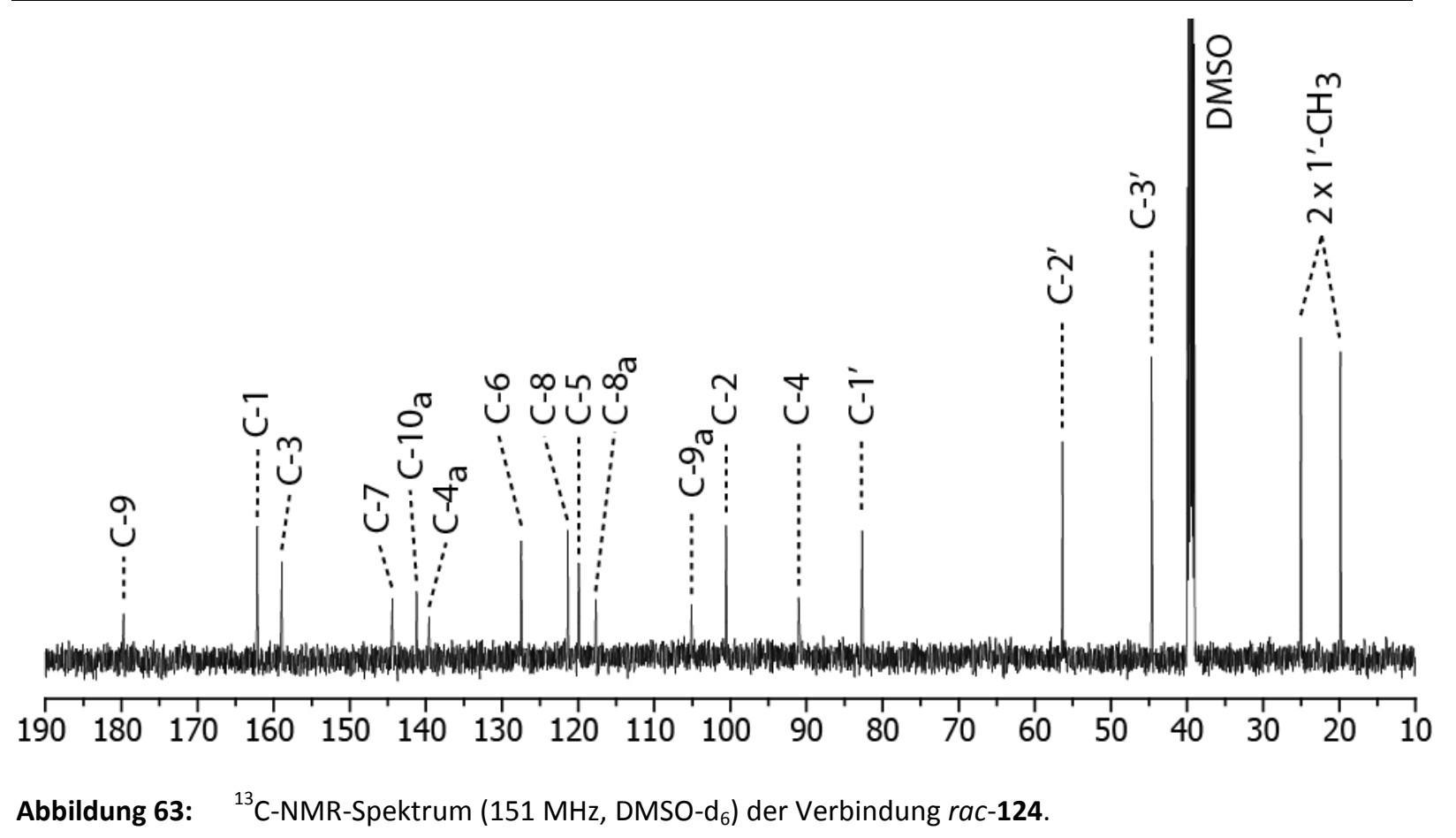

\subsubsection{Zyklisierung des Epoxids rac-124}

Zur Zyklisierung des Epoxids rac-124 wurden zunächst Vorversuche im MilligrammMaßstab durchgeführt (Abbildung 64, Tabelle 13). Dazu wurden nach einer bestimmten Reaktionszeit Proben entnommen, eine Mikroaufarbeitung durchgeführt und das Ergebnis mittels ESI-MS bestimmt. Da der Umsatz des Substrats stets gering war, stellt der MS-Peak des Substrats immer den Basispeak dar. Der Peak des gebildeten Produkts rac-136 wurde dazu in Relation gesetzt. Die Bildung von Nebenprodukten wurde der Übersicht halber nicht detailliert, sondern in Form einer Abstufung dargestellt. 


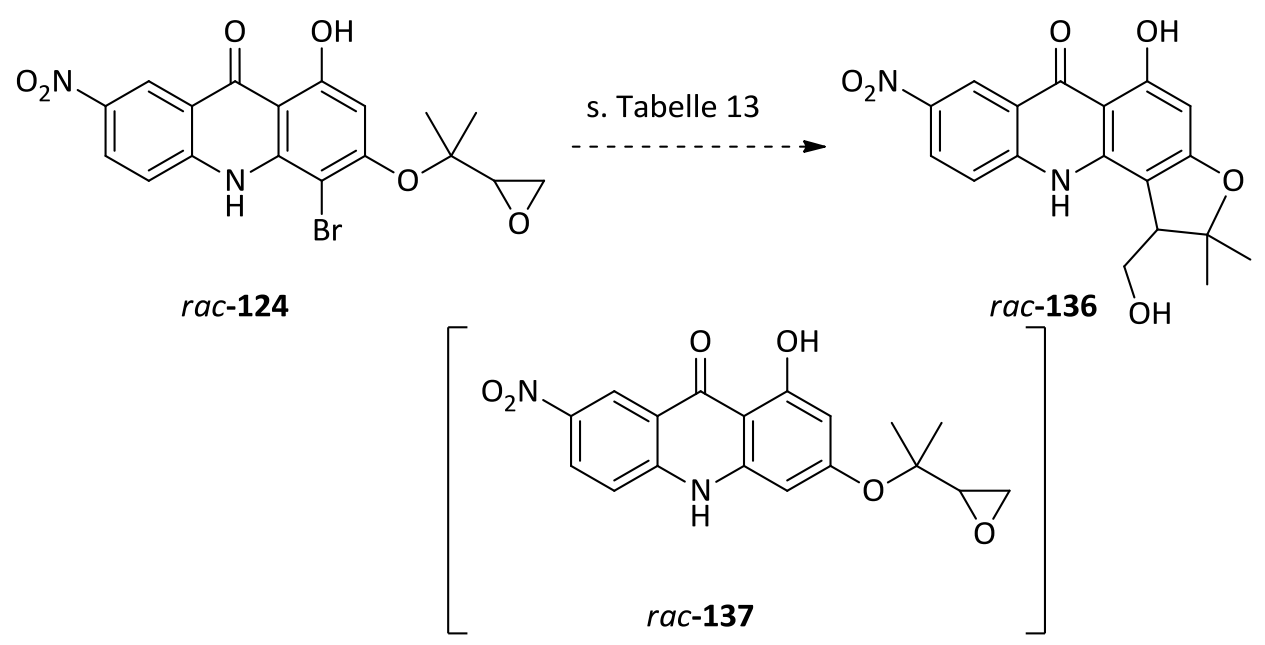

Abbildung 64: Zyklisierung zu rac-136 und Nebenprodukt 137.

\begin{tabular}{|c|c|c|c|c|}
\hline$\#$ & Bedingungen & Temp. u. Zeit & & $\begin{array}{l}\text { bnis }^{[c]} \\
\text { rac-136 }\end{array}$ \\
\hline 1 & 3.50 Äq. $\mathrm{Li}_{2} \mathrm{Zn}(\mathrm{SCN}) \mathrm{Me}_{3}{ }^{[a]}$ & $\begin{array}{c}-78^{\circ} \mathrm{C}, 1 \mathrm{~h} \\
\text { dann } \mathrm{RT}, 15 \mathrm{~h}\end{array}$ & & $0 \%$ \\
\hline 2 & 3.50 Äq. iPrMgCl•LiCl & $\begin{array}{c}-78^{\circ} \mathrm{C}, 1 \mathrm{~h} \\
\text { dann } \mathrm{RT}, 15 \mathrm{~h}\end{array}$ & & $0 \%$ \\
\hline 3 & 3.50 Äq. $n$-BuLi ${ }^{[\mathrm{a}]}$ & $\begin{array}{c}-78^{\circ} \mathrm{C}, 1 \mathrm{~h} \\
\text { dann } \mathrm{RT}, 15 \mathrm{~h}\end{array}$ & & $0 \%$ \\
\hline 4 & 5.00 Äq. $n$-BuLi ${ }^{[\mathrm{a}]}$ & $\begin{array}{c}-78^{\circ} \mathrm{C}, 1 \mathrm{~h} \\
\text { dann RT, } 15 \mathrm{~h}\end{array}$ & & $5 \%$ \\
\hline 5 & $\begin{array}{c}3.50 \text { Äq. } n \text {-BuLi, }{ }^{[\mathrm{a}]} \\
+2.00 \text { Äq. } n \text {-BuLi, nach } 1 \mathrm{~h} \\
3.50 \text { Äq. TMEDA }\end{array}$ & $\begin{array}{c}-78^{\circ} \mathrm{C} \text { dann } \\
0^{\circ} \mathrm{C}, 24 \mathrm{~h}\end{array}$ & $\begin{array}{r}1 \mathrm{~h} \\
2 \mathrm{~h} \\
24 \mathrm{~h}\end{array}$ & $\begin{array}{c}7 \% \\
13 \% * \\
22 \% * *\end{array}$ \\
\hline 6 & $\begin{array}{l}10.0 \text { Äq. } n \text {-BuLi, }{ }^{[a]} \\
3.50 \text { Äq. TMEDA }\end{array}$ & $\begin{array}{c}-78^{\circ} \mathrm{C} \text { dann } \\
\text { RT, } 24 \mathrm{~h}\end{array}$ & $\begin{array}{r}1 \mathrm{~h} \\
24 \mathrm{~h}\end{array}$ & $\begin{array}{l}10 \% \\
0 \% * *\end{array}$ \\
\hline 7 & $\begin{array}{l}4.00 \text { Äq. } n \text {-BuLi, }{ }^{[b]} \\
3.50 \text { Äq. TMEDA }\end{array}$ & $\begin{array}{c}-78^{\circ} \mathrm{C} \text { dann } \\
40^{\circ} \mathrm{C}, 24 \mathrm{~h}\end{array}$ & $\begin{array}{r}1 \mathrm{~h} \\
2 \mathrm{~h} \\
24 \mathrm{~h}\end{array}$ & $\begin{array}{c}6 \% \\
9 \% \\
19 \% *\end{array}$ \\
\hline 8 & 3.50 Äq. $t$-BuLi ${ }^{[a]}$ & $\begin{array}{c}-78^{\circ} \mathrm{C} 2 \mathrm{~h} \\
\text { dann RT, } 15 \mathrm{~h}\end{array}$ & $\begin{array}{r}1 \mathrm{~h} \\
15 \mathrm{~h}\end{array}$ & $\begin{array}{c}3 \% \\
1 \% * *\end{array}$ \\
\hline
\end{tabular}




\begin{tabular}{|c|c|c|c|c|}
\hline \multirow{3}{*}{9} & 5.00 Äq. $t$-BuLi, ${ }^{[a]}$ & & $1 \mathrm{~h}$ & $10 \% * *$ \\
\hline & +2.00 Äq. $t$-BuLi, nach $1 \mathrm{~h}$, & $-78^{\circ} \mathrm{C}$ dann & $2 \mathrm{~h}$ & $17 \% * *$ \\
\hline & +2.00 Äq. $t$-BuLi, nach $2 \mathrm{~h}$ & & $24 \mathrm{~h}$ & $3 \% * *$ \\
\hline \multirow{3}{*}{10} & 5.00 Äq. $t$-BuLi, ${ }^{[b]}$ & & $1 \mathrm{~h}$ & $8 \% * *$ \\
\hline & + 2.00 Äq. $t$-BuLi, nach $1 \mathrm{~h}$, & -18 C dann & $2 \mathrm{~h}$ & $9 \% * *$ \\
\hline & +2.00 Äq. $t$-BuLi, nach $2 \mathrm{~h}$ & & $24 \mathrm{~h}$ & $5 \% * *$ \\
\hline
\end{tabular}

Tabelle 13: $\quad$ Vorversuche zur Zyklisierung des Epoxids rac-124.

Zunächst wurden die bereits von S. Hampel ${ }^{111}$ erfolgreich eingesetzten Methoden der Zyklisierung durch einen in situ gebildeten Zinkkomplex bzw. durch das GrignardReagenz $\mathrm{PrMgCl} \cdot \mathrm{LiCl}$ getestet (Einträge $1 \mathrm{u}$. 2). Nach $15 \mathrm{~h}$ Reaktionszeit bei Raumtemperatur war jedoch keine Produktbildung zu erkennen. Die etablierte Zyklisierungsmethode (s. Kapitel D1.6) ${ }^{111}$ mit $n$-BuLi führte zu keiner bzw. bei deutlichem Überschuss von $n$-BuLi zu minimaler Produktbildung (Einträge 3 u. 4).

Da das Substrat in allen Versuchen zurückgewonnen und keine dehalogenierte Spezies rac-137 festgestellt werden konnte, kann gefolgert werden, dass der BromLithium-Austausch und nicht die anschließende Öffnung des Epoxids der limitierende Schritt dieser Reaktion ist.

Es wurde daher versucht, durch eine Erhöhung der Reaktionstemperatur und durch Zusatz des Deaggregations-Reagenzes TMEDA die Reaktivität des n-BuLi zu steigern. ${ }^{129}$ Da $n$-BuLi bei Temperaturen oberhalb von $-78^{\circ} \mathrm{C}$ nicht stabil ist - die Halbwertszeit beträgt beispielsweise bei $20^{\circ} \mathrm{C}$ in THF nur 23 min und in $\mathrm{Et}_{2} \mathrm{O} 10 \mathrm{~h}^{130}$ wurde jeweils ein Überschuss eingesetzt. Es wurde jedoch im Temperaturbereich von $0-40^{\circ} \mathrm{C}$ weder eine zufriedenstellende Umwandlung zum Produkt rac-136 noch die dehalogenierte Spezies rac-137 beobachtet (Einträge 5-7). Gegen eine weitere Erhöhung der zugegebenen Äquivalente an $n$-BuLi spricht die vermutliche Instabilität des Produkts unter diesen Bedingungen (Eintrag 6). Es wurde daher beschlossen, das reaktivere $t$-BuLi zu einzusetzen. 
Da die Halbwertszeit von $t$-BuLi in THF bei RT nur wenige Minuten beträgt, ${ }^{130}$ wurde zunächst eine Zyklisierung bei $-78{ }^{\circ} \mathrm{C}$ untersucht (Eintrag 8). Da jedoch nur ein minimaler Umsatz festzustellen war, wurde die Reaktionstemperatur auf RT erhöht und aufgrund der Instabilität nach jeweils einer Stunde zwei weitere Äquivalente $t$-BuLi zugegeben (Einträge 9 u. 10). Sowohl in THF als auch in $\mathrm{Et}_{2} \mathrm{O}$ wurde neben vielen nicht identifizierten Nebenprodukten nur eine minimale Umwandlung zum Produkt rac-136 und keine dehalogenierte Spezies rac-137 detektiert.

Durch den Brom-Lithium-Austausch würde intermediär nach Deprotonierung der $\mathrm{OH}$ und NH-Funktion eine dreifach negativ geladene Spezies 124b entstehen (Abbildung 65). Diese, bezogen auf die Größe des Moleküls, sehr hohe Dichte an negativer Ladung dürfte der Grund dafür sein, dass der Austausch so schwierig ist. Eine Lösung wäre die Methylierung des Stickstoffs und der OH-Funktion. Aus früheren Arbeiten ist bekannt, dass die Methylierung am Stickstoff die biologische Aktivität des Acronycins kaum beeinflusst und eine Methylether-Funktion an C-1 leicht wieder abgespalten werden kann (s. Kapitel B5.1). ${ }^{75,76}$
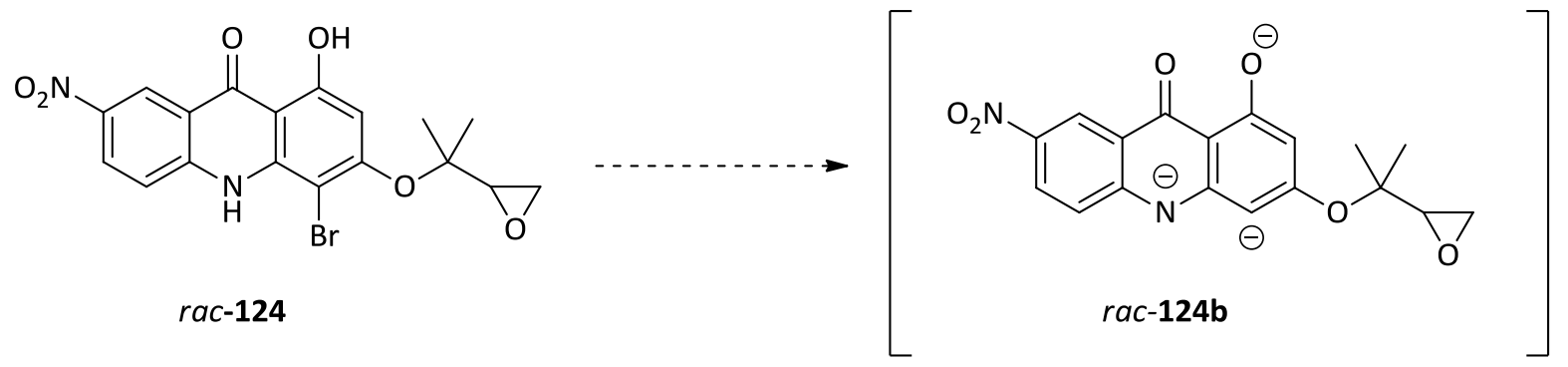

Abbildung 65: Intermediär gebildete, dreifach negativ geladene Spezies rac-124b.

Aus Zeitgründen konnten diese Untersuchungen nicht mehr durchgeführt werden. 


\section{E ZUSAMMENFASSUNG}

\section{Zusammenfassung}

Das Risiko, an Krebs zu erkranken, ist für Menschen in hochentwickelten Gesellschaften sehr hoch. Für Männer betrug es in Deutschland im Jahr 2006 47\% und für Frauen 38\%. Die Fünfjahres-Überlebensraten lagen bei 56\% bzw. 62\%. ${ }^{131}$ Dies zeigt, dass die Therapie maligner Tumorerkrankungen eines der Hauptziele der modernen medizinischen Forschung sein muss. Die Chemotherapie stellt dabei neben der operativen Entfernung und der Strahlentherapie, insbesondere bei schwer zugänglichen Tumoren oder bei Metastasenbildung, eine wichtige Behandlungsmöglichkeit dar. Allerdings ist die Differenzierung von malignen und gesunden Zellen, unter Verwendung der zurzeit verfügbaren Chemotherapeutika, die auf unterschiedlichen Proliferationsraten der Zellen beruhen, nicht ausreichend, da es auch gesunde, sich schnell teilende Zellen im Körper gibt. Dies führt zu starken Nebenwirkungen, die oft den limitierenden Faktor einer Chemotherapie darstellen. Die Entwicklung neuer Strukturen mit speziellen Wirkmechanismen ist daher ein wichtiges Forschungsziel.

Trotz der medizinischen Notwendigkeit sank die Anzahl zugelassener Wirkstoffe in den letzten zehn Jahren stetig. ${ }^{132}$ Dies ist auf den ersten Blick verwunderlich, da durch die kombinatorische Chemie so viele neue Verbindungen wie nie zuvor in kürzester Zeit synthetisiert und auf ihre Aktivität untersucht werden können. Entgegen anfänglicher Annahmen stellt diese rein zufallsgesteuerte Generierung neuer Verbindungen nicht die Ideallösung zur Entdeckung neuer Leitstrukturen dar.

Ein Ansatz zur Entwicklung neuer Leitstrukturen ist das Konzept der HybridNaturstoffe. Die Kombination von Naturstoffen oder deren Teilstrukturen zu künstlichen Hybridmolekülen bietet den Zugang zu neuartigen Wirkstoffen mit einer biologischen Aktivität, die oft derjenigen der entsprechenden Mutterverbindungen überlegen ist. ${ }^{7}$ 
Das Ziel dieser Arbeit war die Synthese und biologische Evaluierung neuartiger Acronycin-Duocarmycin-Hybride wie 80 (Abbildung 66). Es handelt sich dabei um sogenannte seco-Verbindungen, die erst in situ durch eine Winstein-Zyklisierung ${ }^{62}$ in die toxische Form $\mathbf{8 1}$ umgewandelt werden.

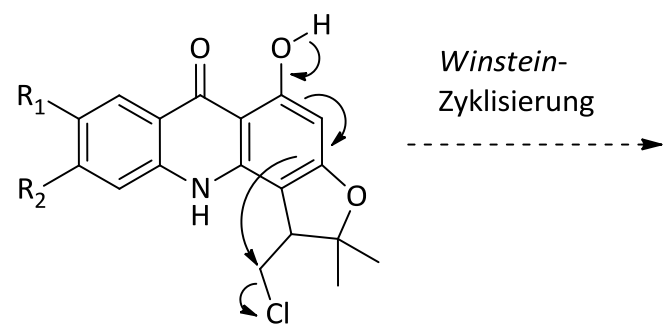

80a: $\quad R_{1}=R_{2}=C_{4} H_{4}$

80b: $R_{1}=\mathrm{NH}_{2}, \mathrm{R}_{2}=\mathrm{H}$

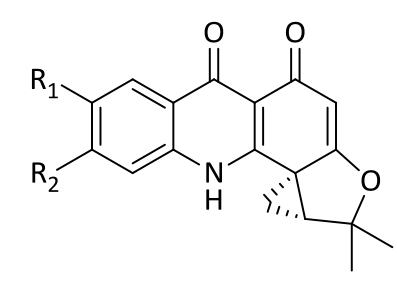

81a: $R_{1}=R_{2}=C_{4} H_{4}$

81b: $R_{1}=\mathrm{NH}_{2}, \mathrm{R}_{2}=\mathrm{H}$

Abbildung 66: Acronycin-Duocarmycin-Hybride 80a und 80b, sowie deren toxische Formen 81a und 81b.

Die Synthese des seco-Drug rac-114 erfolgte unter Verwendung klassischer Synthesemethoden ausgehend von 3-Hydroxy-2-naphthoesäure in neun Stufen (Abbildung 67).
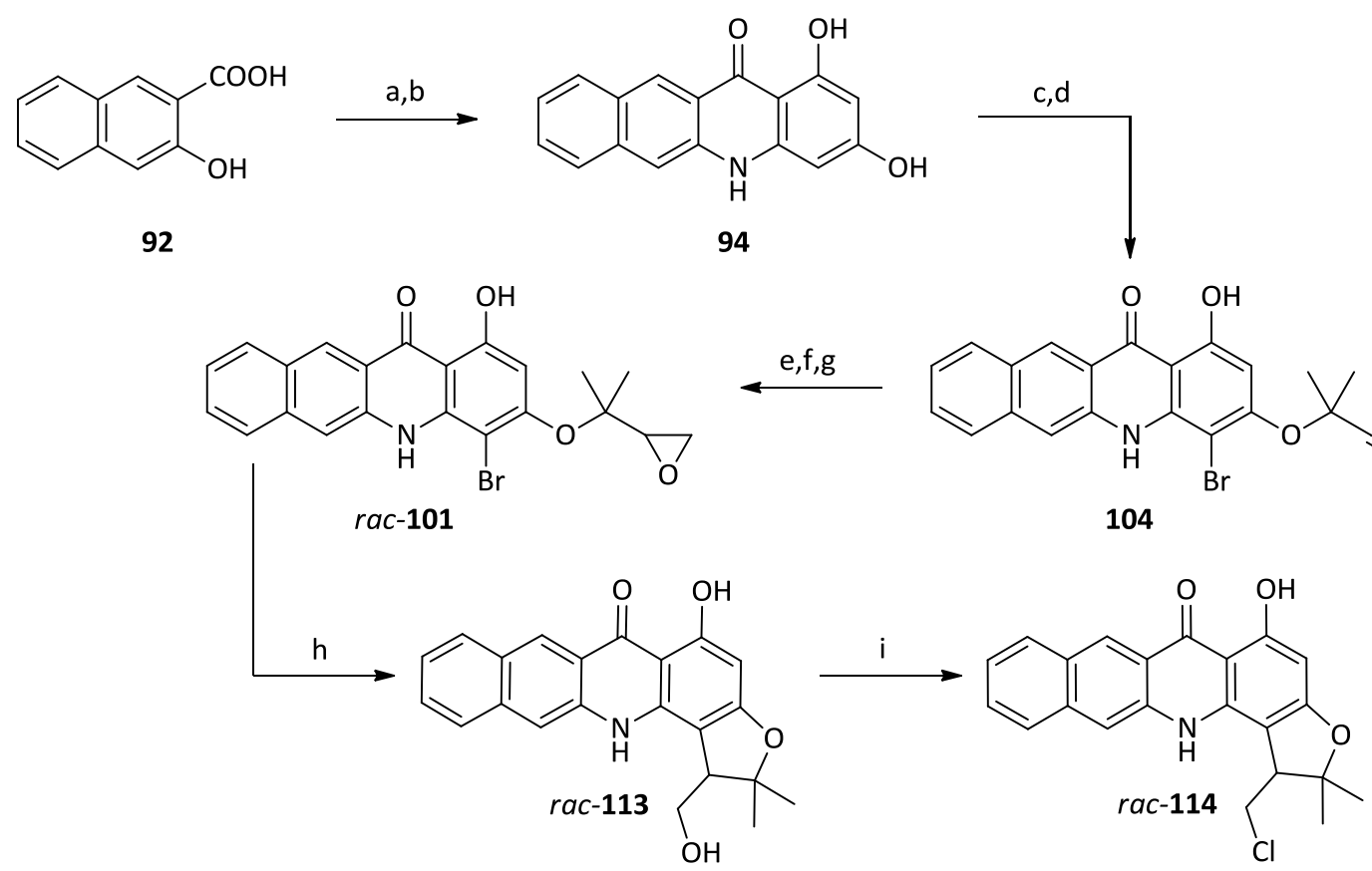

Abbildung 67: Synthese des seco-Drugs rac-114: a) $\mathrm{NH}_{4} \mathrm{OH}$ (aq.), $\mathrm{ZnCl}_{2}, 190{ }^{\circ} \mathrm{C}, 4.5 \mathrm{~d}, 60 \%$; b) Phloroglucin, $p$-TsOH (kat.), $n$-Heptanol, Reflux, 19 h, 59\%; c) NBS, $\mathrm{ZnCl}_{2}$, Aceton, $-78{ }^{\circ} \mathrm{C}, 2 \mathrm{~h}, 59 \%$; d) $\mathrm{K}_{2} \mathrm{CO}_{3}$, 102, $\mathrm{CuCl}$ (kat.), DMF, RT, 24 h, 68\%; e) Pd/C (kat.), Chinolin, $\mathrm{H}_{2}$ (Ballon), Aceton, RT, 2.5 h, $79 \%$; f) $\mathrm{K}_{2} \mathrm{OsO}_{4} \cdot 2 \mathrm{H}_{2} \mathrm{O}$ (kat.), $\mathrm{NMO}, \mathrm{DABCO}$, Aceton, $0{ }^{\circ} \mathrm{C}, 3 \mathrm{~d}, 72 \%$; g) $\mathrm{MsCl}$, Pyridin, $0{ }^{\circ} \mathrm{C}$, 30 min dann $\mathrm{K}_{2} \mathrm{CO}_{3}, \mathrm{MeOH}, \mathrm{RT}, 3 \mathrm{~h}, 48 \%$; h) $n$-BuLi, THF, $-78{ }^{\circ} \mathrm{C}$ auf RT, $20 \mathrm{~h}, 62 \%$; i) $\mathrm{PPh}_{3}, \mathrm{CCl}_{4}$, 1,2-DCE, $50{ }^{\circ} \mathrm{C}, 18 \mathrm{~h}, 85 \%$. 
In-vitro-Zytotoxizitätuntersuchungen an humanen Bronchialkarzinomzellen (A549) für das seco-Drug rac-114 ergaben einen $\mathrm{IC}_{50}$-Wert von $1.04 \mu \mathrm{M}$. Es ist somit gelungen, durch Kombination von Teilstrukturen des Acronycins (45) und Duocarmycins (16) einen neuaritgen Acronycin-Duocarmycin-Hybriden rac-124 mit vielversprechender Zytotoxizität zu synthetisieren.

Es ist bekannt, dass die Kupplung mit einer DNA-bindenden Einheit, wie DMAI (84), zu einer Steigerung der biologischen Aktivität um mehrere Größenordnungen führen kann. ${ }^{116}$ Herausragende Steigerungen der Zytotoxizität wurden im Arbeitskreis Tietze auch durch die Bildung von dimeren Strukturen erzielt. ${ }^{8 b}$ Eine Kupplung des HybridMoleküls rac-124 mit DMAI (84) war jedoch ebenso wenig erfolgreich wie die Bildung von Dimeren.

Die Synthese eines Acronycin-Duocarmycin-Hybriden rac-138, mit leicht zugänglicher Aminofunktion zur weiteren Derivatisierung, konnte bis zum Epoxid rac-124 über acht Stufen realisiert werden. Eine Zyklisierung zum Furan-Derivat rac-138 gelang jedoch nicht.<smiles>COc1cc(OC)c2c(=O)c3cc([N+](=O)[O-])ccc3[nH]c2c1</smiles>

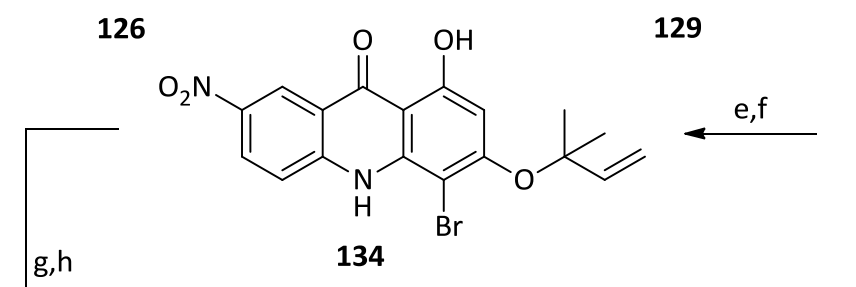<smiles>C#CC(C)(C)Oc1cc(O)c2c(=O)c3cc([N+](=O)[O-])ccc3[nH]c2c1</smiles>

.<smiles>CC(C)(Oc1cc(O)c2c(=O)c3cc([N+](=O)[O-])ccc3[nH]c2c1Br)C1CO1</smiles>

rac-124

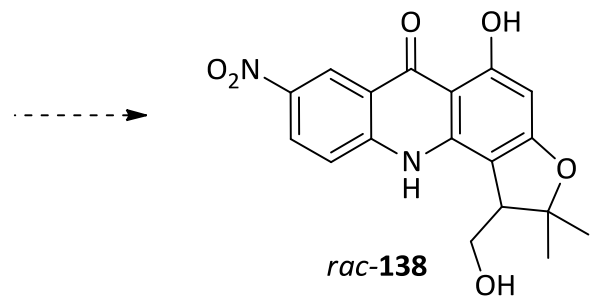

rac-138

Abbildung 68: Synthese von rac-124: a) 3,5-Dimethoxyanilin, $\mathrm{KOAc}, \mathrm{NEt}_{3}, \mathrm{Cu}(\mathrm{OAc})_{2}$ (kat.), ${ }^{t} \mathrm{BuOH}, \mathrm{Reflux}, 5 \mathrm{~d}$, 76\%; b) $\mathrm{POCl}_{3}, \mathrm{NEt}_{3}$, DCE, Reflux, $3 \mathrm{~h}, 83 \%$; c) HBR (konz.), MW, $140{ }^{\circ} \mathrm{C}, 40 \mathrm{~min}, 83 \%$; d) 102, $\mathrm{K}_{2} \mathrm{CO}_{3}, \mathrm{CuCl}$ (kat.), DMF, $0{ }^{\circ} \mathrm{C}, 11 \mathrm{~h}, 56 \%$; e) NBS, $\mathrm{CuCl}_{2}$, Aceton, $-78{ }^{\circ} \mathrm{C}, 1 \mathrm{~h}, 49 \% ; \mathrm{f}$ ) $\mathrm{H}_{2}$ (Ballon), $\mathrm{Pd} / \mathrm{C}$ (kat.), Chinolin, Aceton, $0{ }^{\circ} \mathrm{C}, 15 \mathrm{~min}, 70 \%$; g) $\mathrm{K}_{2} \mathrm{OsO}_{4} \cdot 2 \mathrm{H}_{2} \mathrm{O}$ (kat.), NMO, DABCO, Aceton, $\mathrm{H}_{2} \mathrm{O}, 0{ }^{\circ} \mathrm{C}, 12 \mathrm{~d}, 74 \%$; ) $\mathrm{MsCl}$, Pyridin, $0{ }^{\circ} \mathrm{C}, 1 \mathrm{~h}$, dann $\mathrm{K}_{2} \mathrm{CO}_{3}, \mathrm{MeOH}, \mathrm{RT}, 30 \mathrm{~min}, 62 \%$. 


\section{F EXPERIMENTELLER TEIL}

\section{Allgemeine Arbeitsvorschriften}

Die Umsetzungen wurden, soweit nötig, in ausgeheizten Glasapparaturen unter einem leichten Argon-Überdruck durchgeführt. Die Lösungsmittel wurden entsprechend den üblichen Laboratoriumsmethoden getrocknet und destilliert ${ }^{133}$ bzw. als p.a.-Ware über Molsieb gelagert. Soweit nicht anders vermerkt, wurden kommerziell erhältliche Produkte ohne weitere Reinigung eingesetzt. Das Entgasen von Lösungsmitteln geschah durch Einleiten eines Argon-Gasstroms über einen längeren Zeitraum. Konzentrationsangaben beziehen sich, sofern nicht anders erwähnt, auf wässrige Lösungen.

\section{$1.1 \quad$ Verwendete Geräte}

Infrarotspektren: Die Infrarotspektren wurden mit dem Modell FT/IR-4100 der Firma Jasco ohne KBr-Optik (neat) aufgenommen.

UV/VIS-Spektren: Die Aufnahme der UV/VIS-Spektren erfolgte mit den Modellen Lambda 2 der Firma Perkin-Elmer und V-630 der Firma Jasco.

${ }^{1}$ H-NMR-Spektren: Die ${ }^{1} \mathrm{H}-\mathrm{NMR}$-Spektren wurden mit den Modellen Mercury 300, Mercury-vx 300, Unity 300, Vnmrs 300 (jeweils 300 MHz) oder Inova 600 (600 MHz) der Firma Varian von in deuterierten Solventien gelösten Proben aufgenommen. Die chemischen Verschiebungen sind in Einheiten der $\delta$-Skala angegeben und auf das Signal des angegebenen Lösungsmittels referenziert. Zur Kennzeichnung der Multiplizitäten der Signale werden folgende Abkürzungen verwendet: s (Singulett), d (Dublett), t (Triplett), q (Quartett), dd (Dublett von Dubletts), dt (Dublett von Tripletts) usw. Signale, die durch Überlagerung oder Anteile höherer Ordnung nicht interpretierbar waren, wurden mit $\mathrm{m}$ (Multiplett) bzw. $\mathrm{m}_{\mathrm{c}}$ (symmetrisches, zentriertes Multiplett) bezeichnet und verbreiterte Signale durch den Zusatz br 
indiziert. Zur Bezeichnung aromatischer Protonen oder Kohlenstoffatome werden folgende Abkürzungen verwendet: $i$ (ipso), o (ortho), $m$ (meta), $p$ (para). Sofern nicht anders angegeben, beziehen sich alle Kopplungskonstanten auf ${ }^{1} \mathrm{H}-{ }^{1} \mathrm{H}$-Kopplungen.

${ }^{13}$ C-NMR-Spektren: Die, soweit nicht anders vermerkt, ${ }^{1} \mathrm{H}$-breitbandentkoppelten ${ }^{13}$ C-NMR-Spektren wurden mit den Geräten Unity $300(75 \mathrm{MHz})$, Inova 500 (125 MHz) und Inova 600 (150 MHz) der Firma Varian aufgenommen. Die chemischen Verschiebungen sind in Einheiten der $\delta$-Skala angegeben. Als interner Standard diente das angegebene Lösungsmittel.

Massenspektren: Zur Aufnahme der EI- und EI-HRMS-Spektren diente ein Time-ofFlight Massenspektrometer AccuTOF der Firma Jeol. ESI-Spektren wurden mit einem Ion-Trap-Massenspektrometer LCQ der Firma Finnigan oder einem Time-of-Flight Massenspektrometer microTOF der Firma Bruker aufgenommen. Die Messung der ESI-HRMS-Spektren erfolgte an einem 7-Tesla-Fourier-Transform-lon-CyclotronResonance (FTICR)-Massenspektrometer APEX IV der Firma Bruker und am micrOTOFGerät. Angegeben werden die Quotienten aus Masse zu Ladung sowie in Klammern die relativen Intensitäten bezogen auf den Basispeak ( $=100)$.

Kältetechnik: Die Reaktionsführung bei konstant tiefen Temperaturen über einen längeren Zeitraum erfolgte unter Einsatz von Kryostaten. Benutzt wurde das Modell EK 90 der Firma Haake. Darüber hinaus wurden übliche Kältemischungen wie Eis/Wasser- und Aceton/ Trockeneis-Gemische zur temporären Kühlung verwendet.

\subsection{Chromatographische Methoden}

Dünnschichtchromatographie (DC): Es wurden Aluminium-Fertigfolien Si60 $\mathrm{F}_{254}$ der Firma Merck verwendet. Angegeben sind $\mathrm{R}_{f}$-Werte (Laufhöhe der Substanz relativ zur Höhe der Laufmittelfront). Neben der UV-Detektion diente eine VanillinSchwefelsäure-Lösung ( $0.5 \mathrm{~g}$ Vanillin, $3 \mathrm{~mL}$ konz. $\mathrm{H}_{2} \mathrm{SO}_{4}, 85 \mathrm{~mL} \mathrm{MeOH}$ und $10 \mathrm{~mL}$ HOAc)) als Anfärbereagenz.

Säulenchromatographie: Alle säulenchromatographischen Trennungen wurden mit Kieselgel 60 (Korngröße: $0.032-0.063$ mm) der Firma Merck durchgeführt. 
Analytische HPLC: Analytische Trennungen wurden auf einer HPLC-Anlage der Firma Jasco, ausgestattet mit einer Lösungsmittelpumpe PU-2080, einer Mischkammer LG-1590-04, einem Multiwellenlängendetektor MD-2010 Plus und der Steuerung LC-Net II/ADC, vorgenommen. Für die Injektion wurde ein automatischer Probenwechsler (Autosampler AS-2055) derselben Firma verwendet. Zur Bedienung, Datenerfassung und Datenauswertung wurden die Computerprogramme Borwin PDA, HSS 2000 und Borwin Chromatography der Firma Jasco eingesetzt. Für die analytischen Messungen wurden die Säulen Chiralcel ${ }^{\circledR}$ OD $(250 \times 4.6 \mathrm{~mm}, 5 \mu \mathrm{m}$, Daicel Chemical Industries Ltd.), Chiralpak ${ }^{\circledR}$ IA $(250 \times 4.6 \mathrm{~mm}, 5 \mu \mathrm{m}$, Daicel Chemical Industries Ltd.) mit chiraler stationärer Phase sowie Aqua ${ }^{\oplus} \mathrm{C}_{18} 200 \mathrm{~A}(250 \times 4.6 \mathrm{~mm}$, $5 \mu \mathrm{m}$, Phenomenex) mit stationärer RP-Phase verwendet. Angegebene Lösungsmittel waren von HPLC-Qualität und das Wasser bidestilliert. Alle Proben wurden membranfiltriert mit Polytetrafluorethylen-(PTFE)-Filtern der Firma Roth ( $\varnothing 25 \mathrm{~mm}$, $0.2 \mu \mathrm{m})$ bzw. VWR (Ø $13 \mathrm{~mm}, 0.2 \mu \mathrm{m})$.

Präparative HPLC: Präparative Trennungen wurden auf einem HPLC-System der Firma Jasco, ausgestattet mit zwei Lösungsmittelpumpen Modell PU-2087 PLUS und einem UV-Detektor Modell UV-2075 PLUS, vorgenommen. Verwendet wurden die Säulen Chiralpak ${ }^{\oplus}$ IA $(250 \times 20$ mm, $5 \mu \mathrm{m}$, Daicel Chemical Industries Ltd.) mit chiraler stationärer Phase, Kromasil $100 \mathrm{C} 18(250 \times 20$ mm, $7 \mu \mathrm{m}$, Jasco und Dr. Maisch $\mathrm{GmbH})$ sowie Aqua ${ }^{\oplus} \mathrm{C} 18200 \mathrm{~A}(250 \times 21.2 \mathrm{~mm}, 5 \mu \mathrm{m}$, Phenomenex $)$ mit stationärer RP-Phase. Angegebene Lösungsmittel waren von HPLC-Qualität und das Wasser bidestilliert. Alle Proben wurden vor der Trennung membranfiltriert (siehe analytische HPLC).

\subsection{Materialien für die In-vitro-Zytotoxizitätsuntersuchungen}

Zellinie: A549, ATCC-CCL 185 (American Type Culture Collection Certified Cell Lines), eine 1972 aus einem kanzerogenen Tumorexplanat der Lunge eines 58-jährigen männlichen Patienten etablierte, epithelähnliche, adhärent in Monolayern wachsende Zellinie. Herkunft: Institut für Zellbiologie der Universität Essen. 
Medien: Alle Pulvermedien wurden in bidestilliertem Wasser angesetzt, mit $\mathrm{HCl}$ auf $\mathrm{pH} 7.4$ titriert und sterilfiltriert.

Kulturmedium für A549: DMEM (Dulbecco`s Modified Eagles Medium) mit $4.5 \mathrm{~g} \mathrm{~L}^{-1}$ Glucose (Biochrom, T043-10). Das Medium wurde mit $4 \mathrm{mM}$ L-Glutamin und $3.7 \mathrm{~g} \mathrm{~L}^{-1}$ Natriumhydrogencarbonat supplementiert.

Medium-Zusätze: 10\% FKS (Fötales Kälberserum) der Firma Biochrom, 30 min inaktiviert bei $56^{\circ} \mathrm{C}$.

Inkubationsmedium für die Toxinexposition: Als serumfreies Medium für die Toxinexposition wurde UltraCULTURE ${ }^{T M}$ der Firma Lonza eingesetzt.

Zellzählkammer: Netzeinteilung nach Bürker der Firma Assistent.

Testplatten: 6-well Testplatten der Firma TPP (über Biochrom). 


\section{Synthese der verwendeten Reagenzien}

2.1 3-Chlor-3-methylbut-1-in (102)

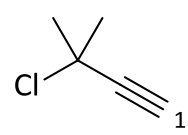

2-Methylbut-3-in-2-ol (23.3 mL, $238 \mathrm{mmol}, 1.00$ Äq.) wurde über $30 \mathrm{~min}$ zu einer auf $0{ }^{\circ} \mathrm{C}$ gekühlten Suspension aus $\mathrm{CaCl}_{2}\left(13.2 \mathrm{~g}, 119 \mathrm{mmol}, 0.50 \mathrm{Äq}\right.$ ), $\mathrm{CuCl}_{2}$ (12.8 g, $95.1 \mathrm{mmol}, 0.40$ Äq.), Cu (200 mg, 3.14 mmol, 0.01 Äq.) in konz. HCl (130 mL) getropft und $1 \mathrm{~h}$ bei dieser Temperatur gerührt. Die org. Phase wurde mit konz. $\mathrm{HCl}$ $(5 \times 100 \mathrm{~mL})$ und $\mathrm{H}_{2} \mathrm{O}(3 \times 100 \mathrm{~mL})$ gewaschen, über $\mathrm{K}_{2} \mathrm{CO}_{3}$ getrocknet und destillativ gereinigt. Die Titelverbindung 102 wurde in Form einer farblosen Flüssigkeit (11.6 g, $139 \mathrm{mmol}, 58 \%)$ erhalten.

${ }^{1} \mathrm{H}-\mathrm{NMR}(300 \mathrm{MHz}, \mathrm{DMSO}) \delta=1.84\left(\mathrm{~s}, 6 \mathrm{H}, 2 \times 3-\mathrm{CH}_{3}\right), 2.60(\mathrm{~s}, 1 \mathrm{H}, 1-\mathrm{H})$.

\subsection{Dimethyldioxiran (144)}

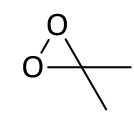

In einem 4-L-Dreihalskolben mit KPG-Rührer und Destillationsbrücke mit $500 \mathrm{~mL}$ Rundkolben als Vorlage, der auf $-78{ }^{\circ} \mathrm{C}$ gekühlt wurde, wurden $\mathrm{NaHCO}_{3}(360 \mathrm{~g}$, $4.30 \mathrm{~mol})$ in Aceton $(480 \mathrm{~mL})$ und $\mathrm{H}_{2} \mathrm{O}(660 \mathrm{~mL})$ suspendiert. Unter starkem Rühren wurde Oxon (640 g, $1.84 \mathrm{~mol}$ ), vorsichtig in vier Portionen (Zeitabstand etwa $20 \mathrm{~min}$ ) zugegeben, so dass das Reaktionsgemisch zu schäumen begann. Es wurde Vakuum (ca. 25 mbar) angelegt und der Druck so eingestellt, dass die Suspension nicht überschäumte. Das in der Vorlage gesammelte Destillat wurde 30 min über fein zerstoßenem Drierite (wasserfreies $\mathrm{CaSO}_{4}$ ) bei $-70^{\circ} \mathrm{C}$ getrocknet und über einen Glasfilter (Porengröße 3) filtriert. Die so hergestellte Lösung aus DMDO/Aceton (400 $\mathrm{mL}, 0.06 \mathrm{M}$ ) wurde über Molekularsieb 4 Å bei $-32^{\circ} \mathrm{C}$ aufbewahrt. 
$2.3 \quad$ 2-Oxiranyl-propan-2-ol (99)

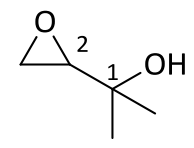

2-Methylbut-3-en-2-ol (2.00 g, $23.2 \mathrm{mmol}, 1.00$ Äq.) wurde in DCM (40 mL) gelöst und auf $0^{\circ} \mathrm{C}$ gekühlt. $\operatorname{mCPBA}(6.87 \mathrm{~g}, 76 \%$ ig, $27.9 \mathrm{mmol}, 1.20$ Äq.) wurde portionsweise zugegeben, auf RT erwärmt und $2.5 \mathrm{~h}$ gerührt. Anschließend wurde ges. $\mathrm{NaHCO}_{3}$-Lsg. (40 mL) zugegeben, bis zum Ende der Gasentwicklung gerührt, mit DCM extrahiert $(2 \times 40 \mathrm{~mL})$ und das Lösungsmittel unter vermindertem Druck entfernt. Die Titelverbindung 99 wurde nach säulenchromatographischer Reinigung an Kieselgel $\left(\mathrm{P} / \mathrm{Et}_{2} \mathrm{O}=3: 2\right)$ in Form einer farblosen Flüssigkeit erhalten (2.32 g, $22.7 \mathrm{mmol}, 98 \%)$.

$D C: R_{f}=0.51\left(P / E t_{2} \mathrm{O}=1: 1\right)$.

${ }^{1} \mathrm{H}-\mathrm{NMR}\left(300 \mathrm{MHz}, \mathrm{CDCl}_{3}\right) \delta=1.03-1.12\left(\mathrm{~m}, 6 \mathrm{H}, 2 \times 1-\mathrm{CH}_{3}\right), 2.59(\mathrm{~d}, J=3.4 \mathrm{~Hz}, 2 \mathrm{H}$, $\left.3-\mathrm{H}_{2}\right), 2.83(\mathrm{t}, \mathrm{J}=3.4 \mathrm{~Hz}, 1 \mathrm{H}, 2-\mathrm{H}), 4.38(\mathrm{~s}, 1 \mathrm{H}, \mathrm{OH})$.

${ }^{13} \mathrm{C}-\mathrm{NMR}\left(126 \mathrm{MHz}, \mathrm{CDCl}_{3}\right): \delta=25.4,26.0\left(2 \times 1-\mathrm{CH}_{3}\right), 43.1(\mathrm{C}-3), 58.1(\mathrm{C}-2), 67.0(\mathrm{C}-1)$. 


\section{Synthese des Benzo[b]acronycin-Duocarmycin-Hybrids}

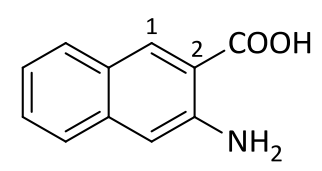

3-Hydroxy-2-naphthoesäure (92) (50.0 g, $266 \mathrm{mmol}, 1.00 \mathrm{Äq}$.) und $\mathrm{ZnCl}_{2}$ (36.2 g, $266 \mathrm{mmol}, 1.00$ Äq.) wurden in einem Autoklaven vorsichtig mit gekühlter, ges. $\mathrm{NH}_{3^{-}}$ Lsg. $(120 \mathrm{~mL})$ versetzt und $2.5 \mathrm{~d}$ bei $200^{\circ} \mathrm{C}$ erhitzt. Nach Abkühlen wurde das Reaktionsgemisch mit konz. $\mathrm{HCl}(180 \mathrm{~mL})$ versetzt, 30 min unter Rückfluss erhitzt und filtriert. Der Feststoff wurde in $\mathrm{H}_{2} \mathrm{O}(100 \mathrm{~mL})$ und konz. $\mathrm{HCl}(35 \mathrm{~mL})$ suspendiert, unter Rückfluss erhitzt und heiß filtriert. Die vereinigten Filtrate wurden für $2 \mathrm{~h}$ auf $0^{\circ} \mathrm{C}$ gekühlt, der ausgefallene, rosa Feststoff abfiltriert, in $\mathrm{H}_{2} \mathrm{O}(300 \mathrm{~mL})$ aufgenommen und mit 40\%iger $\mathrm{NaOH}-\mathrm{Lsg}$. (25 mL) versetzt, bis sich kein Feststoff mehr löste. Der unlösliche Feststoff wurde abfiltriert, das Filtrat mit konz. $\mathrm{HCl}(10 \mathrm{~mL})$ angesäuert und anschließend mit 10\%iger NaOAc-Lsg. ein pH-Wert von 5 eingestellt. Der Feststoff wurde abfiltriert, $3 \mathrm{~d}$ bei $70{ }^{\circ} \mathrm{C}$ getrocknet und die Titelverbindung 93 in Form eines gelben Feststoffs ( $25.9 \mathrm{~g}, 138 \mathrm{mmol}, 60 \%$ ) erhalten.

DC: $R_{f}=0.51\left(100 \% \mathrm{Et}_{2} \mathrm{O}\right)$

IR (Film): $v\left(\mathrm{~cm}^{-1}\right)=3472,3376,3297,3052,1606,1548,1450,1405,1219,1058,738$, 477.

UV (MeOH): $\lambda_{\max }(\lg \varepsilon)=226.0 \mathrm{~nm}$ (4.0826), 252.5 (4.3358), 280.0 (3.4267), 290.5 (3.4055), 396.5 (3.0077).

${ }^{1} \mathrm{H}-\mathrm{NMR}$ (300 MHz, DMSO): $\delta=6.96(\mathrm{~s}, 1 \mathrm{H}, 4-\mathrm{H}), 7.09$ (ddd, $J=8.0,6.7,1.1 \mathrm{~Hz}, 1 \mathrm{H}$, 6-H), 7.34 (ddd, J = 8.3, 6.7, $1.2 \mathrm{~Hz}, 1 \mathrm{H}, 7-\mathrm{H}), 7.50$ (d, J = 8.0 Hz, $1 \mathrm{H}, 5-\mathrm{H}), 7.74(\mathrm{~d}, J=$ 7.7 Hz, $1 \mathrm{H}, 8-\mathrm{H}), 8.41(\mathrm{~s}, 1 \mathrm{H}, 1-\mathrm{H})$. 
${ }^{13} \mathrm{C}-\mathrm{NMR}\left(125 \mathrm{MHz}, \mathrm{CDCl}_{3}\right.$ ): $\delta=107.36$ (C-4), 118.34 (C-2), 120.62 (C-7), 124.27 (C-5), 125.09 (C-8a), 126.92 (C-6), 128.58 (C-8), 131.89 (C-1), 136.01 (C-4a), 147.65 (C-3), $170.63(\mathrm{COOH})$.

$\mathrm{C}_{11} \mathrm{H}_{9} \mathrm{NO}_{2}(187.195)$

3.2 1,3-Dihydroxybenzo[b]acridin-12(5H)-on (94)<smiles>O=c1c2cc3ccccc3cc2[nH]c2cc(O)cc(O)c12</smiles>

3-Amino-2-naphthoesäure (93) (1.50 g, $8.01 \mathrm{mmol}, 1.00$ Äq.), Phloroglucin (1.11 g, $8.81 \mathrm{mmol}, 1.10$ Äq.) und $p$-Toluolsulfonsäure (152 mg, $0.80 \mathrm{mmol}, 0.10$ Äq.) wurden in Heptanol $(15 \mathrm{~mL})$ für $19 \mathrm{~h}$ unter Rückfluss am Wasserabscheider erhitzt. Anschließend wurde das Lösungsmittel unter vermindertem Druck entfernt, der Rückstand mit PE $(3 \times 50 \mathrm{~mL})$ gewaschen, mit Aceton $(2 \times 100 \mathrm{~mL})$ versetzt, aufgekocht und heiß filtriert. Das Filtrat wurde über $\mathrm{MgSO}_{4}$ getrocknet, mit groben Kieselgel (4 g) versetzt, das Lösungsmittel im Vakuum entfernt und die Titelverbindung 94 nach säulenchromatographischer Reinigung an Kieselgel $(P /$ Aceton $=6: 4)$ in Form eines orangen Feststoffs (1.39 g, $4.76 \mathrm{mmol}, 59 \%)$ erhalten.

DC: $R_{f}=0.52\left(100 \% \mathrm{Et}_{2} \mathrm{O}\right)$.

IR (Film): $v\left(\mathrm{~cm}^{-1}\right)=3297,1636,1585,1542,1508,1340,1269,1160,820,743,517$.

UV $\left(\mathrm{CH}_{3} \mathrm{CN}\right): \lambda_{\max }(\lg \varepsilon)=205 \mathrm{~nm}$ (9.8634), 278 (4.0288), 438 (2.7319).

Schmp.: $191.7^{\circ} \mathrm{C}$.

${ }^{1} \mathrm{H}-\mathrm{NMR}$ (300 MHz, DMSO): $\delta=5.98(\mathrm{~d}, J=2.1 \mathrm{~Hz}, 1 \mathrm{H}, 2-\mathrm{H}$ ), $6.30(\mathrm{~d}, J=2.1 \mathrm{~Hz}, 1 \mathrm{H}$, 4-H), $7.36-7.48(\mathrm{~m}, 1 \mathrm{H}, 8-\mathrm{H}), 7.52-7.64(\mathrm{~m}, 1 \mathrm{H}, 9-\mathrm{H}), 7.83(\mathrm{~s}, 1 \mathrm{H}, 6-\mathrm{H}), 7.96$ (d, J = $7.9 \mathrm{~Hz}, 1 \mathrm{H}, 7-\mathrm{H}), 8.12$ (d, J = 7.8 Hz, $1 \mathrm{H}, 10-\mathrm{H}), 8.86(\mathrm{~s}, 1 \mathrm{H}, 11-\mathrm{H}), 10.59(\mathrm{~s}, 1 \mathrm{H}$, 3-OH), 11.58 (s, $1 \mathrm{H}, \mathrm{NH}), 14.07$ (s, $1 \mathrm{H}, 1-\mathrm{OH})$.

${ }^{13}$ C-NMR (125 MHz, DMSO): $\delta=90.74$ (C-4), 94.73 (C-2), 101.80 (C-12a), 111.17 (C-6), 119.67 (C-5a), 123.96 (C-8), 126.22 (C-7), 126.28 (C-11), 127.51 (C-6a), 128.36 (C-9), 
129.32 (C-10), 135.66 (C-10a), 137.26 (C-11a), 144.26 (C-4a), 163.93 (C-1), 164.93 (C-3), 180.65 (C-12).

MS (ESI): $m / z(\%)=276.1(100)\left[\mathrm{M}-\mathrm{H}^{+}\right]^{-}, 553.5(16)\left[2 \mathrm{M}-\mathrm{H}^{+}\right]^{-}$

$\mathrm{C}_{17} \mathrm{H}_{11} \mathrm{NO}_{3}$ (277.274) ber.: 276.0666 gef.: 276.0668, [M-H'] $]^{-}$(ESI-HRMS).<smiles>O=c1c2cc3ccccc3cc2[nH]c2c(Br)c(O)cc(O)c12</smiles>

Zu frisch sublimiertem $\mathrm{ZnCl}_{2}$ (156 mg, 1.15 mmol, 1.00 Äq.) wurde eine Lösung von 94 (318 mg, $1.15 \mathrm{mmol}, 1.00$ Äq.) in Aceton (48 mL) gegeben, auf $-78{ }^{\circ} \mathrm{C}$ gekühlt und $30 \mathrm{~min}$ bei dieser Temperatur gerührt. Anschließend wurde NBS (255 mg, $1.43 \mathrm{mmol}$, 1.25 Äq.) zugegeben und $1.5 \mathrm{~h}$ bei $-78^{\circ} \mathrm{C}$ gerührt. Das Lösungsmittel wurde unter vermindertem Druck entfernt, das Rohprodukt mit $2 \mathrm{~N} \mathrm{HCl}(2 \times 50 \mathrm{~mL})$ gewaschen, in EtOAc $(50 \mathrm{~mL})$ gelöst, über $\mathrm{MgSO}_{4}$ getrocknet, mit grobem Kieselgel $(600 \mathrm{mg}$ ) versetzt und das Lösungsmittel unter vermindertem Druck entfernt. Die Titelverbindung 95 wurde nach säulenchromatographischer Reinigung an Kieselgel (PE/EtOAc $=3: 2$ ) als oranger Feststoff (241 mg, $677 \mu \mathrm{mol}, 59$ \%) erhalten.

DC: $R_{f}=0.65\left(100 \% \mathrm{Et}_{2} \mathrm{O}\right)$.

IR: $v\left(\mathrm{~cm}^{-1}\right)=3395,2906,1635,1447,1346,1136,1085,803,740,671,517$.

UV $\left(\mathrm{CH}_{3} \mathrm{CN}\right): \lambda_{\max }(\lg \varepsilon)=202 \mathrm{~nm}$ (4.5113), 284 (4.7598), 349 (3.9046), 442 (3.5943).

Schmp.: Zersetzung ab $140{ }^{\circ} \mathrm{C}$

${ }^{1}$ H-NMR (301 MHz, DMSO): $\delta=6.27$ (s, $\left.1 \mathrm{H}, 2-\mathrm{H}\right), 7.39-7.51(\mathrm{~m}, 1 \mathrm{H}, 8-\mathrm{H}), 7.60$ (ddd, $J=8.3,6.7,1.2 \mathrm{~Hz}, 1 \mathrm{H}, 9-\mathrm{H}), 7.92(\mathrm{~d}, J=8.0 \mathrm{~Hz}, 1 \mathrm{H}, 7-\mathrm{H}), 8.14(\mathrm{~d}, J=8.1 \mathrm{~Hz}, 1 \mathrm{H}, 10-$ H), $8.47(\mathrm{~s}, 1 \mathrm{H}, 6-\mathrm{H}), 8.86(\mathrm{~s}, 1 \mathrm{H}, 11-\mathrm{H}), 10.47(\mathrm{~s}, 1 \mathrm{H}, \mathrm{NH}), 11.51(\mathrm{~s}, 1 \mathrm{H}, 3-\mathrm{OH}), 14.33$ (s, $1 \mathrm{H}, 1-\mathrm{OH})$. 
${ }^{13}$ C-NMR (75 MHz, DMSO): $\delta=83.9$ (C-4), 95.0 (C-2), 102.4 (C-12a), 113.5 (C-6), 119.4 (C-5a), 124.6 (C-8), 126.2 (C-7), 126.7 (C-11), 128.1 (C-6a), 128.7 (C-9), 129.4 (C-10), 135.8 (C-10a), 137.0 (C-11a), 141.2 (C-4a), 161.6 (C-3), 163.3 (C-1), 181.1 (C-12).

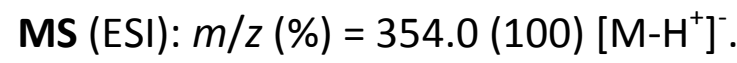

$\mathrm{C}_{17} \mathrm{H}_{10} \mathrm{BrNO}_{3}(356.170)$ ber.: 353.9771 gef.: 353.9774, [M-H'] $]^{-}$(ESI-HRMS).

3.4 4-Brom-3-(1,1-dimethylprop-2-inyloxy)-1-hydroxy-5H-benzo[b]acridin12-on (104)<smiles>C#CC(C)(C)Oc1cc(O)c2c(=O)c3cc4ccccc4cc3[nH]c2c1Br</smiles>

Die bromierte Verbindung 95 (559 mg, $1.41 \mathrm{mmol}, 1.00$ Äq.) gelöst in DMF (30 mL) wurde in einem Druckkolben mit $\mathrm{K}_{2} \mathrm{CO}_{3}(391 \mathrm{mg}, 2.83 \mathrm{mmol}, 2.00$ Äq.), Alkin 102 (1.27 mL, $11.3 \mathrm{mmol}, 8.00$ Äq.) und $\mathrm{CuCl}$ (1.40 mg, $14.1 \mu \mathrm{mol}, 0.01$ Äq.) versetzt und $24 \mathrm{~h}$ bei RT gerührt. Das Lösungsmittel wurde unter vermindertem Druck entfernt, der Rückstand in EtOAc $(150 \mathrm{~mL})$ aufgenommen, mit $2 \mathrm{~N} \mathrm{HCl}(2 \times 40 \mathrm{~mL})$ und ges. $\mathrm{NaCl}$-Lsg. $(3 \times 40 \mathrm{~mL})$ gewaschen, über $\mathrm{MgSO}_{4}$ getrocknet, mit grobem Kieselgel (2.5 g) versetzt und das Lösungsmittel unter vermindertem Druck entfernt. Die Titelverbindung 104 wurde nach säulenchromatographischer Reinigung an Kieselgel $(\mathrm{PE} /$ EtOAC $=8: 1 \rightarrow 4: 1)$ in Form eines orangen Feststoffs $(453 \mathrm{mg}, 1.07 \mathrm{mmol}, 68 \%)$ erhalten.

$D C: R_{f}=0.33\left(P E / E t_{2} O=2: 1\right)$.

IR: $v\left(\mathrm{~cm}^{-1}\right)=3749,3350,3257,2362,1636,1557,1340,1261,1131,866,820,742$, 578.

UV $\left(\mathrm{CH}_{3} \mathrm{CN}\right): \lambda_{\max }(\lg \varepsilon)=197 \mathrm{~nm}$ (4.4512), 227 (4.1904), 269 (4.7525), 283 (4.8039), 350 (4.0094), 442 (3.6294). 
Schmp.: Zersetzung ab $140^{\circ} \mathrm{C}$.

${ }^{1} \mathrm{H}-\mathrm{NMR}(301 \mathrm{MHz}, \mathrm{DMSO}) \delta=1.76\left(\mathrm{~s}, 6 \mathrm{H}, 2 \times 1^{\prime}-\mathrm{CH}_{3}\right), 3.91\left(\mathrm{~s}, 1 \mathrm{H}, 3^{\prime}-\mathrm{H}\right), 6.94(\mathrm{~s}, 1 \mathrm{H}$, 2-H), $7.39-7.50(m, 1 \mathrm{H}, 8-\mathrm{H}), 7.60(\mathrm{t}, J=7.1 \mathrm{~Hz}, 1 \mathrm{H}, 9-\mathrm{H}), 7.91(\mathrm{~d}, J=8.3 \mathrm{~Hz}, 1 \mathrm{H}$, 7-H), 8.13 (d, J = 8.3 Hz, $1 \mathrm{H}, 10-\mathrm{H}), 8.48$ (s, $1 \mathrm{H}, 6-\mathrm{H}), 8.86(\mathrm{~s}, 1 \mathrm{H}, 11-\mathrm{H}), 10.56(\mathrm{~s}, 1 \mathrm{H}$, $\mathrm{NH}), 14.33$ (s, $1 \mathrm{H}, 1-\mathrm{OH})$.

${ }^{13}$ C-NMR (75 MHz, DMSO): $\delta=29.3\left(2 \times 1^{\prime}-\mathrm{CH}_{3}\right), 74.1\left(\mathrm{C}-2^{\prime}\right), 78.1\left(\mathrm{C}-33^{\prime}\right), 84.5\left(\mathrm{C}-1^{\prime}\right)$, 88.4 (C-4), 97.1 (C-2), 103.5 (C-12a), 113.6 (C-6), 119.1 (C-5a), 124.6 (C-8), 126.2 (C-7), 126.6 (C-11), 128.0 (C-6a), 128.7 (C-9), 129.3 (C-10), 135.8 (C-10a), 136.9 (C-11a), 140.5 (C-4a), 158.6 (C-3), 162.56 (C-1), 181.6 (C-12).

MS (ESI): $m / z(\%)=422.0(100)\left[\mathrm{M}-\mathrm{H}^{+}\right]^{-}$.

$\mathrm{C}_{22} \mathrm{H}_{16} \mathrm{BrNO}_{3}(422.271)$

ber.: 420.0241

gef.: 420.0241, [M-H']- (ESI-HRMS).

3.5 4-Brom-3-(1,1-dimethylallyloxy)-1-hydroxy-5H-benzo[b]acridin-12-on (111)<smiles>C=CC(C)(C)Oc1cc(O)c2c(=O)c3cc4ccccc4cc3[nH]c2c1Br</smiles>

Eine Suspension aus Chinolin $(2.80 \mu \mathrm{L}, 23.7 \mu \mathrm{mol}, 0.10$ Äq.) und Pd/C (10 Gew.-\%, $7.56 \mathrm{mg}, 7.10 \mu \mathrm{mol}, 0.03$ Äq.) wurde $15 \mathrm{~min}$ bei RT gerührt. Diese wurde zu einer Lösung von Alkin 104 (100 mg, $237 \mu \mathrm{mol}, 1.00$ Äq.) in mit $\mathrm{H}_{2}$ gesättigtem Aceton $\left(20 \mathrm{~mL}\right.$ ) gegeben. Es wurde unter $\mathrm{H}_{2}$-Durchleiten (Ballon) für $2.5 \mathrm{~h}$ bei $\mathrm{RT}$ gerührt (ständige DC-Kontrolle). Die Reaktionslösung wurde zweimal über Celite filtriert, mit grobem Kieselgel (400 mg) versetzt und das Lösungsmittel unter vermindertem Druck entfernt. Die Titelverbindung 111 wurde in Form eines orangen Feststoffs $(79.5$ mg, $187 \mu \mathrm{mol}, 79 \%)$ nach säulenchromatographischer Reinigung an Kieselgel $(\mathrm{P} /$ EtOAc $=$ 8:1) erhalten.

$D C: R_{f}=0.49\left(P E / E t_{2} \mathrm{O}=2: 1\right)$. 
IR: $v\left(\mathrm{~cm}^{-1}\right)=3749,2361,1541,1507,1340,1137,817,740,532$.

UV $\left(\mathrm{CH}_{3} \mathrm{CN}\right): \lambda_{\max }(\lg \varepsilon)=196 \mathrm{~nm}$ (4.4955), 227 (4.2304), 270 (4.8161), 283 (4.8583), 351 (4.0582), 441 (3.6833).

Schmp.: Zersetzung ab $100^{\circ} \mathrm{C}$.

${ }^{1} \mathrm{H}-\mathrm{NMR}(301 \mathrm{MHz}, \mathrm{DMSO}): \delta=1.60\left(\mathrm{~s}, 6 \mathrm{H}, 2 \times 1{ }^{\prime}-\mathrm{CH}_{3}\right), 5.24-5.44\left(\mathrm{~m}, 2 \mathrm{H}, 3^{\prime}-\mathrm{H}_{2}\right)$, $6.22\left(\mathrm{dd}, J=17.6,10.9 \mathrm{~Hz}, 1 \mathrm{H}, 2^{\prime}-\mathrm{H}\right), 6.46(\mathrm{~s}, 1 \mathrm{H}, 2-\mathrm{H}), 7.42-7.53(\mathrm{~m}, 1 \mathrm{H}, 8-\mathrm{H}), 7.63$ (ddd, $J=8.2,6.7,1.2 \mathrm{~Hz}, 1 \mathrm{H}, 9-\mathrm{H}), 7.94(\mathrm{~d}, J=8.2 \mathrm{~Hz}, 1 \mathrm{H}, 7-\mathrm{H}), 8.16(\mathrm{~d}, J=7.9 \mathrm{~Hz}, 1$ H, 10-H), 8.51 (s, $1 \mathrm{H}, 6-\mathrm{H}), 8.89$ (s, $1 \mathrm{H}, 11-\mathrm{H}), 10.56$ (s, $1 \mathrm{H}, \mathrm{NH}), 14.28(\mathrm{~s}, 1 \mathrm{H}, 1-\mathrm{OH})$. MS (ESI): $m / z(\%)=422.0(100)\left[\mathrm{M}-\mathrm{H}^{+}\right]^{-}$.

$\mathrm{C}_{22} \mathrm{H}_{18} \mathrm{BrNO}_{3}$ (424.287) ber.: 426.0523 gef.: 426.0543, $\left[\mathrm{M}+\mathrm{H}^{+}\right]^{+}$(ESI-HRMS). benzo[b]acridin-12-on (rac-112)

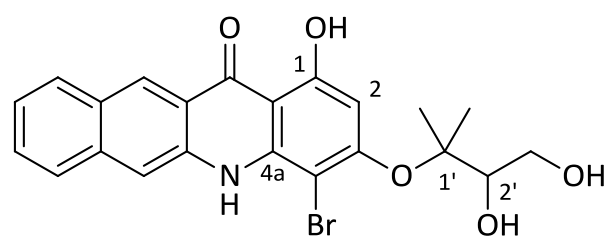

Zu einer Lösung von Alken 111 (224 mg, $529 \mu \mathrm{mol}, 1.00$ Äq.) in Aceton (10 mL) und $\mathrm{H}_{2} \mathrm{O}(2 \mathrm{~mL}$ ) wurde NMO (92.9 mg, $793 \mu \mathrm{mol}, 1.50$ Äq.), DABCO (89.0 mg, $793 \mu \mathrm{mol}$, 1.50 Äq.) und $\mathrm{K}_{2} \mathrm{OsO}_{4} \cdot 2 \mathrm{H}_{2} \mathrm{O}\left(19.5 \mathrm{mg}, 52.9 \mu \mathrm{mol}, 0.10\right.$ Äq.) gegeben und $3 \mathrm{~d}$ bei $0{ }^{\circ} \mathrm{C}$ gerührt. Es wurde ges. $\mathrm{NaHSO}_{3}$-Lsg. $(2 \mathrm{~mL})$ zugegeben, $10 \mathrm{~min}$ bei RT gerührt, das Lösungsmittel unter vermindertem Druck entfernt, in $1 \mathrm{~N} \mathrm{HCl}(2 \mathrm{~mL})$ aufgenommen, mit EtOAc $(4 \times 20 \mathrm{~mL})$ extrahiert und über $\mathrm{MgSO}_{4}$ getrocknet. Die Lösung wurde mit grobem Kieselgel (1 g) versetzt, das Lösungsmittel unter vermindertem Druck entfernt und die Titelverbindung rac-112 nach säulenchromatographischer Reinigung an Kieselgel $(\mathrm{PE} /$ EtOAC $=1: 1 \rightarrow 100 \%$ EtOAC) in Form eines dunkelorangen Feststoffs (174 mg, $380 \mu \mathrm{mol}, 72 \%$ ) erhalten. 
DC: $R_{f}=0.17(P E / E t O A C=1: 1)$.

IR: $v\left(\mathrm{~cm}^{-1}\right)=3468,3252,1634,1505,1341,1269,1029,815,729,602,533$.

UV $\left(\mathrm{CH}_{3} \mathrm{CN}\right): \lambda_{\max }(\lg \varepsilon)=196 \mathrm{~nm}$ (4.2831), 228 (4.0319), 270 (4.6594), 282 (4.6908), 351 (3.8642), 443 (3.4867).

${ }^{1} \mathrm{H}-\mathrm{NMR}$ (301 MHz, DMSO): $\delta=1.43,1.47$ (s, $\left.6 \mathrm{H}, 2 \times 1{ }^{\prime}-\mathrm{CH}_{3}\right), 3.47$ (ddd, $J=11.0,8.0$, $5.3 \mathrm{~Hz}, 1 \mathrm{H}, 3^{\prime}-\mathrm{H}_{\mathrm{a}}$ ), 3.74 (ddd, $J=8.1,5.2,2.9 \mathrm{~Hz}, 1 \mathrm{H}, 2^{\prime}-\mathrm{H}$ ), 3.86 (ddd, $J=11.0,6.0$, $\left.2.8 \mathrm{~Hz}, 1 \mathrm{H}, 3^{\prime}-\mathrm{H}_{\mathrm{b}}\right), 4.49\left(\mathrm{t}, J=5.7 \mathrm{~Hz}, 1 \mathrm{H}, 3^{\prime}-\mathrm{OH}\right), 5.11\left(\mathrm{~d}, J=5.2 \mathrm{~Hz}, 1 \mathrm{H}, 2^{\prime} \mathrm{O}-\mathrm{H}\right), 6.63$ (s, $1 \mathrm{H}, 2-\mathrm{H}), 7.38-7.53(\mathrm{~m}, 1 \mathrm{H}, 8-\mathrm{H}), 7.61$ (dd, J = 11.1, 4.0 Hz, $1 \mathrm{H}, 9-\mathrm{H}), 7.93$ (d, J = $8.4 \mathrm{~Hz}, 1 \mathrm{H}, 7-\mathrm{H}), 8.15(\mathrm{~d}, J=8.2 \mathrm{~Hz}, 1 \mathrm{H}, 10-\mathrm{H}), 8.50(\mathrm{~s}, 1 \mathrm{H}, 6-\mathrm{H}), 8.88(\mathrm{~s}, 1 \mathrm{H}, 11-\mathrm{H})$, 10.54 (s, $1 \mathrm{H}, \mathrm{NH}), 14.26$ (s, $1 \mathrm{H}, 1-\mathrm{OH})$.

${ }^{13}$ C-NMR (75 MHz, DMSO): $\delta=22.0,24.2\left(2 \times 1^{\prime}-\mathrm{CH}_{3}\right), 62.0$ (C-3'), 76.9 (C-2'), 86.0 (C-1'), 90.4 (C-4), 99.5 (C-2), 103.5 (C-12a), 113.6 (C-6), 119.1 (C-5a), 124.6 (C-8), 126.2 (C-7), 126.6 (C-11), 128.0 (C-6a), 128.7 (C-9), 129.3 (C-10), 135.8 (C-10a), 136.9 (C-11a), 140.5 (C-4a), 159.4 (C-3), 162.5 (C-1), 181.5 (C-12).

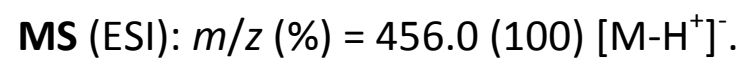

$\mathrm{C}_{22} \mathrm{H}_{20} \mathrm{BrNO}_{5}$ (458.302)

ber.: 454.0296

gef.: 454.0292, [M-H'] $]^{-}$(ESI-HRMS).

3.7 4-Brom-1-hydroxy-3-(1-methyl-1-oxiranylethoxy)-5H-benzo[b]acridin-12-on (rac-101)

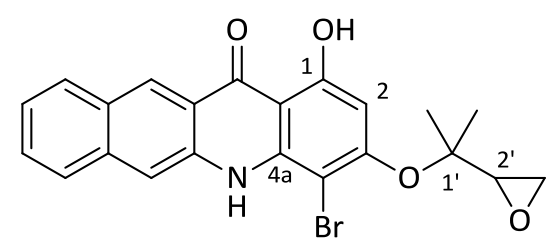

Eine Lösung von Diol rac-112 (347 mg, $756 \mu \mathrm{mol}, 1.00$ Äq.) in Pyridin (13 mL) wurde für $30 \mathrm{~min}$ bei $0{ }^{\circ} \mathrm{C}$ gerührt. Anschließend wurde Mesylchlorid $(117 \mu \mathrm{L}, 1.51 \mathrm{mmol}$, 2.00 Äq.) zugegeben, $1 \mathrm{~h}$ bei $0{ }^{\circ} \mathrm{C}$ gerührt, das Lösungsmittel unter vermindertem Druck entfernt, der Rückstand in $\mathrm{MeOH}(20 \mathrm{~mL})$ gelöst und $\mathrm{K}_{2} \mathrm{CO}_{3}(523 \mathrm{mg}$, 
$3.78 \mathrm{mmol}$, 5.00 Äq.) zugegeben. Nach $3 \mathrm{~h}$ wurde das Lösungsmittel unter vermindertem Druck bei RT entfernt, das Rohprodukt in $1 \mathrm{~N} \mathrm{HCl}(5 \mathrm{~mL})$ aufgenommen, mit EtOAc $(3 \times 10 \mathrm{~mL})$ extrahiert, über $\mathrm{Na}_{2} \mathrm{SO}_{4}$ getrocknet, mit grobem Kieselgel (2 g) versetzt und das Lösungsmittel unter vermindertem Druck entfernt. Die Titelverbindung rac-101 wurde nach säulenchromatographischer Reinigung an Kieselgel $(\mathrm{PE} /$ EtOAC $=4: 1 \rightarrow 3: 1 \rightarrow 2: 1)$ in Form eines orangen Feststoff $(160 \mathrm{mg}$, $363 \mu \mathrm{mol}, 48 \%)$ erhalten.

DC: $R_{f}=0.71(P E / E t O A C=2: 1)$.

IR: $v\left(\mathrm{~cm}^{-1}\right)=3748,3395,2354,1636,1557,1394,1258,1107,1068,826,747,517$.

UV $\left(\mathrm{CH}_{3} \mathrm{CN}\right): \lambda_{\max }(\lg \varepsilon)=197 \mathrm{~nm}$ (4.5027), 269 (4.7818), 282 (4.8023), 334 (3.9431), 351 (3.988), 444 (3.6317).

Schmp.: Zersetzung ab $160^{\circ} \mathrm{C}$.

${ }^{1} \mathrm{H}-\mathrm{NMR}$ (301 MHz, DMSO): $\delta=1.32,1.50\left(\mathrm{~s}, 6 \mathrm{H}, 2 \times 1\right.$ 1'- $\left.^{-} \mathrm{CH}_{3}\right), 2.84$ (dd, J = 4.7, $2.8 \mathrm{~Hz}$, $\left.1 \mathrm{H}, 3^{\prime}-\mathrm{H}_{\mathrm{a}}\right), 2.90\left(\mathrm{t}, J=4.5 \mathrm{~Hz}, 1 \mathrm{H}, 3^{\prime}-\mathrm{H}_{\mathrm{b}}\right), 3.35$ (dd, J = 4.3, $\left.2.8 \mathrm{~Hz}, 1 \mathrm{H}, 2^{\prime}-\mathrm{H}\right), 6.67$ (s, $1 \mathrm{H}, 2-\mathrm{H}), 7.46$ (d, J = 7.9 Hz, $1 \mathrm{H}, 8-\mathrm{H}), 7.59$ (d, J = 7.2 Hz, $1 \mathrm{H}, 9-\mathrm{H}), 7.91(\mathrm{~d}, J=8.3 \mathrm{~Hz}$, $1 \mathrm{H}, 7-\mathrm{H}), 8.13(\mathrm{~d}, J=8.3 \mathrm{~Hz}, 1 \mathrm{H}, 10-\mathrm{H}), 8.48(\mathrm{~s}, 1 \mathrm{H}, 6-\mathrm{H}), 8.86(\mathrm{~s}, 1 \mathrm{H}, 11-\mathrm{H}), 10.53$ (s, $1 \mathrm{H}, \mathrm{NH}), 14.26(\mathrm{~s}, 1 \mathrm{H}, 1-\mathrm{OH})$.

${ }^{13}$ C-NMR (75 MHz, DMSO): $\delta=20.1,25.0\left(2 \times 11^{\prime}-\mathrm{CH}_{3}\right), 44.6$ (C-3'), 56.5 (C-2'), 82.4 (C-1'), 89.6 (C-4), 98.7 (C-2), 103.5 (C-12a), 113.6 (C-6), 119.1 (C-5a), 124.5 (C-8), 126.2 (C-7), 126.5 (C-11), 127.9 (C-6a), 128.7 (C-9), 129.3 (C-10), 135.8 (C-10a), 136.8 (C-11a), 140.4 (C-4a), 158.8 (C-3), 162.7 (C-1), 181.5 (C-12).

MS (ESI): $m / z(\%)=438.0(100)\left[\mathrm{M}-\mathrm{H}^{+}\right]^{-}$.

$\mathrm{C}_{22} \mathrm{H}_{18} \mathrm{BrNO}_{4}$ (440.287) ber.: 438.0346 gef.: 438.0330, [M-H $]^{+}$(ESI-HRMS). 
3.8

5-Hydroxy-1-(hydroxymethyl)-2,2-dimethyl-1,2-dihydrobenzo[b]furo[3,2-

h]acridin-6(13H)-on (rac-113)

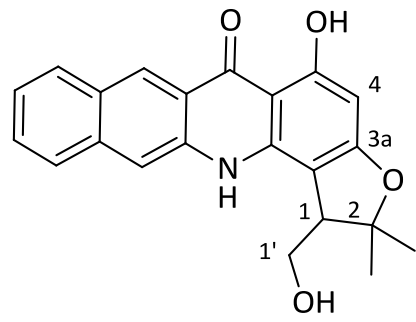

Epoxid rac-101 (59.4 mg, $135 \mu \mathrm{mol}, 1.00$ Äq.) wurde in THF (10 mL) gelöst, auf $-78^{\circ} \mathrm{C}$ gekühlt und $15 \mathrm{~min}$ bei dieser Temperatur gerührt. Es wurde $n$-BuLi $(205 \mu \mathrm{L}$, $472 \mu \mathrm{mol}, 3.50$ Äq., $2.5 \mathrm{M}$ in Hexan) bei $-78^{\circ} \mathrm{C}$ zugegeben und innerhalb von $20 \mathrm{~h}$ auf RT erwärmt. Es wurde ges. $\mathrm{NH}_{4} \mathrm{Cl}$-Lsg. $(2 \mathrm{~mL})$ zugegeben und mit EtOAc $(3 \times 20 \mathrm{~mL})$ extrahiert, über $\mathrm{MgSO}_{4}$ getrocknet, mit grobem Kieselgel (250 mg) versetzt und das Lösungsmittel unter vermindertem Druck entfernt. Die Titelverbindung rac-113 wurde nach säulenchromatographischer Reinigung an Kieselgel (PE/EtOAc $=3: 1 \rightarrow$ 2:1) als oranger Feststoff (30.3 mg, $83.9 \mu \mathrm{mol}, 62 \%)$ erhalten.

DC: $R_{f}=0.21(P E / E t O A C=2: 1)$.

IR: $v\left(\mathrm{~cm}^{-1}\right)=3295,2972,2360,1651,1591,1470,1346,1259,1089,852,736,538$.

UV $\left(\mathrm{CH}_{3} \mathrm{CN}\right): \lambda_{\max }(\lg \varepsilon)=197 \mathrm{~nm}$ (4.4955), 227 (4.3603), 243 (4.2745), 270 (4.7539), 284 (4.8261), 321 (4.057), 357 (4.0747), 446 (3.6577).

${ }^{1} \mathrm{H}-\mathrm{NMR}$ (301 MHz, DMSO): $\delta=1.42,1.50\left(\mathrm{~s}, 6 \mathrm{H}, 2 \times 2-\mathrm{CH}_{3}\right), 3.45$ (dd, J = 8.0, $4.4 \mathrm{~Hz}$, $1 \mathrm{H}, 1-\mathrm{H}), 3.73\left(\mathrm{t}, J=9.3 \mathrm{~Hz}, 1 \mathrm{H}, 1^{\prime}-\mathrm{H}_{\mathrm{a}}\right), 3.93\left(\mathrm{dd}, J=10.5,4.2 \mathrm{~Hz}, 1 \mathrm{H}, 1^{\prime}-\mathrm{H}_{\mathrm{b}}\right), 5.96(\mathrm{~s}, 1$ $\left.\mathrm{H}, 1^{\prime}-\mathrm{OH}\right), 6.01(\mathrm{~s}, 1 \mathrm{H}, 4-\mathrm{H}), 7.42(\mathrm{ddd}, J=8.0,6.7,1.1 \mathrm{~Hz}, 1 \mathrm{H}, 10-\mathrm{H}), 7.58$ (ddd, $J=$ 8.3, 6.7, 1.2 Hz, $1 \mathrm{H}, 9-\mathrm{H}), 7.85(\mathrm{~s}, 1 \mathrm{H}, 12-\mathrm{H}), 7.95$ (d, J = $8.1 \mathrm{~Hz}, 1 \mathrm{H}, 11-\mathrm{H}), 8.11(\mathrm{~d}, J=$ $8.3 \mathrm{~Hz}, 1 \mathrm{H}, 8-\mathrm{H}), 8.86$ (s, $1 \mathrm{H}, 7-\mathrm{H}), 11.49$ (s, $1 \mathrm{H}, \mathrm{NH}), 14.53$ (s, $1 \mathrm{H}, 5-\mathrm{OH})$.

${ }^{13}$ C-NMR (75 MHz, DMSO): $\delta=22.0,28.4\left(2 \times 2-\mathrm{CH}_{3}\right), 51.0(\mathrm{C}-1), 60.1\left(1-\mathrm{CH}_{2}\right), 89.9$ (C-4), 90.1 (C-2), 102.4 (C-5a), 102.6 (C-13b), 111.4 (C-12), 119.5 (C-12a), 124.1 (C-10), 126.2 (C-7), 126.3 (C-11), 127.7 (C-11a), 128.4 (C-9), 129.3 (C-8), 135.7 (C-7a), 136.9 (C-6a), 139.8 (C-13a), 165.0 (C-3a), 165.3 (C-5), 180.9 (C-6). 


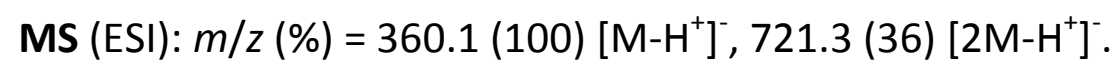

$\mathrm{C}_{22} \mathrm{H}_{19} \mathrm{NO}_{4}$ (361.391)

ber.: 360.1241

gef.: 360.1236, [M-H'] $]^{-}$(ESI-HRMS).

3.9

1-(Chlormethyl)-5-hydroxy-2,2-dimethyl-1,2-dihydrobenzo[b]furo[3,2-

h]acridin-6(13H)-on (rac-114)

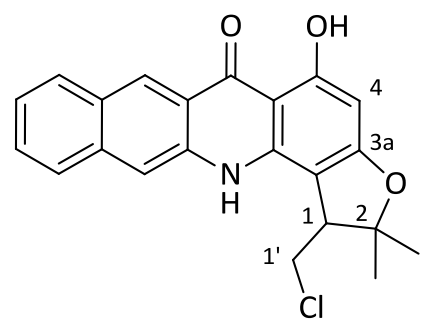

Eine Lösung von Alkohol rac-113 $(9.30 \mathrm{mg}, 25.7 \mu \mathrm{mol}, 1.00$ Äq.), PPh 3 (20.3 mg, $77.2 \mu \mathrm{mol}, 3.00$ Äq.) und $\mathrm{CCl}_{4}(23.0 \mu \mathrm{L}, 232 \mathrm{mmol}, 9.00$ Äq.) in DCE (6 mL) wurde in einem Druckkolben für $18 \mathrm{~h}$ bei $50^{\circ} \mathrm{C}$ gerührt. Das Rohprodukt wurde mit grobem Kieselgel (50 mg) versetzt, das Lösungsmittel unter vermindertem Druck entfernt und die Titelverbindung rac-114 nach säulenchromatographischer Reinigung an Kieselgel $(\mathrm{PE} /$ EtOAc $=10: 1)$ in Form eines orangen Feststoffs $(8.31 \mathrm{mg}, 21.9 \mu \mathrm{mol}, 85 \%)$ erhalten.

DC: $R_{f}=0.71(P E / E t O A C=2: 1)$.

${ }^{1} \mathrm{H}-\mathrm{NMR}(600 \mathrm{MHz}, \mathrm{DMSO}): \delta=1.42,1.71\left(\mathrm{~s}, 6 \mathrm{H}, 2 \times 2-\mathrm{CH}_{3}\right), 3.77(\mathrm{dd}, \mathrm{J}=6.9,2.5 \mathrm{~Hz}$, $1 \mathrm{H}, 1-\mathrm{H}), 3.95\left(\mathrm{dd}, J=12.1,2.5 \mathrm{~Hz}, 1 \mathrm{H}, 1^{\prime}-\mathrm{H}_{\mathrm{a}}\right), 4.01\left(\mathrm{dd}, J=12.0,7.0 \mathrm{~Hz}, 1 \mathrm{H}, 1^{\prime}-\mathrm{H}_{\mathrm{b}}\right)$, $6.05(\mathrm{~s}, 1 \mathrm{H}, 4-\mathrm{H}), 7.46\left(\mathrm{~m}_{\mathrm{c}}, 1 \mathrm{H}, 10-\mathrm{H}\right), 7.62\left(\mathrm{~m}_{\mathrm{c}}, 1 \mathrm{H}, 9-\mathrm{H}\right), 8.00(\mathrm{~d}, J=8.7 \mathrm{~Hz}, 1 \mathrm{H}$, 11-H), 8.09 (s, $1 \mathrm{H}, 12-\mathrm{H}), 8.16(\mathrm{~d}, J=8.4 \mathrm{~Hz}, 1 \mathrm{H}, 8-\mathrm{H}), 8.90(\mathrm{~s}, 1 \mathrm{H}, 7-\mathrm{H}), 11.12(\mathrm{~s}, 1 \mathrm{H}$, $\mathrm{NH}), 14.63(\mathrm{~s}, 1 \mathrm{H}, 5-\mathrm{OH})$.

${ }^{13} \mathrm{C}-\mathrm{NMR}(126 \mathrm{MHz}, \mathrm{DMSO}): \delta=21.6,28.7\left(2 \times 2-\mathrm{CH}_{3}\right), 43.0\left(\mathrm{C}-1^{\prime}\right), 48.7$ (C-1), 89.9 (C4), 90.3 (C-2), 100.4 (C-13b), 102.4 (C-5a), 112.0 (C-12), 119.6 (C-12a), 124.3 (C-10), 126.2 (C-7), 126.4 (C-11), 127.7 (C-11a), 128.5 (C-9), 129.3 (C-8), 135.6 (C-7a), 137.1 (C-6a), 139.7 (C-13a), 165.2 (C-3a), 165.6 (C-5), 181.0 (C-6). 
HPLC: Kromasil ${ }^{\circledR} 100 \mathrm{C}_{18}, \mathrm{MeOH} / \mathrm{H}_{2} \mathrm{O}=90: 10$, Flussrate $6.0 \mathrm{~mL} / \mathrm{min}, 254 \mathrm{~nm}$, $t_{R}=6.725 \mathrm{~min}$.

MS (ESI): $m / z(\%)=378.1(100)\left[\mathrm{M}-\mathrm{H}^{+}\right]^{-}, 757.2(20)\left[2 \mathrm{M}-\mathrm{H}^{+}\right]^{-}$.

$\mathrm{C}_{22} \mathrm{H}_{19} \mathrm{ClNO}_{3}$ (379.836)

ber.: 378.0902

gef.: $378.0886\left[\mathrm{M}-\mathrm{H}^{+}\right]^{-} \quad$ (ESI-HRMS). 


\section{Synthese des Nitro-Acronycin-Duocarmycin-Hybrids}

4.1 2-((3,5-Dimethoxyphenyl)amino)-5-nitrobenzoesäure (128)

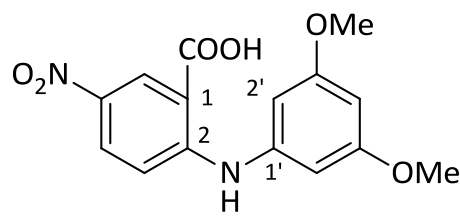

Eine Suspension aus 2-Chlor-5-nitro-benzoesäure (126) (9.29 g, 46.1 mmol, 1.00 Äq.), 3,5-Dimethoxyanilin (127) (7.41 g, 48.4 mmol, 1.05 Äq.), KOAc (11.3 g, 115 mmol,

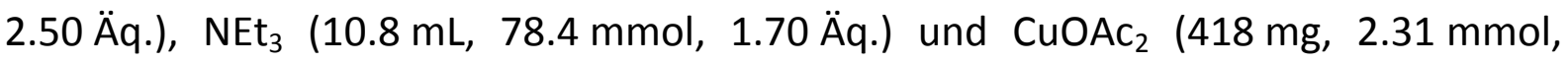
0.05 Äq.) in $t$-BuOH (500 mL) wurde für $5 \mathrm{~d}$ unter Rückfluss erhitzt. Das Lösungsmittel wurde unter vermindertem Druck entfernt, der Rückstand in $1 \mathrm{~N} \mathrm{HCl}(50 \mathrm{~mL})$ suspendiert, der Feststoff abfiltriert und mit $\mathrm{CH}_{2} \mathrm{Cl}_{2}(200 \mathrm{~mL})$ gewaschen. Die Titelverbindung 128 wurde ohne weitere Reinigung in Form eines gelben Feststoffs (11.1 g, $35.0 \mathrm{mmol}, 76 \%)$ erhalten.

IR: $v\left(\mathrm{~cm}^{-1}\right)=3309,1662,1572,1206,1153,813,375,209$.

UV $\left(\mathrm{CH}_{3} \mathrm{CN}\right): \lambda_{\max }(\lg \varepsilon)=199 \mathrm{~nm}$ (4.5264), 219 (4.5265), 263 (3.9281), 273 (4.2994).

${ }^{1} \mathrm{H}-\mathrm{NMR}(301 \mathrm{MHz}, \mathrm{DMSO}): \delta=3.75\left(\mathrm{~s}, 6 \mathrm{H}, 2 \times \mathrm{OCH}_{3}\right), 6.40\left(\mathrm{t}, \mathrm{J}=2.1 \mathrm{~Hz}, 1 \mathrm{H}, 4^{\prime}-\mathrm{H}\right)$, $6.51\left(\mathrm{~d}, J=2.1 \mathrm{~Hz}, 2 \mathrm{H}, 2^{\prime}-\mathrm{H}, 6^{\prime}-\mathrm{H}\right), 7.24(\mathrm{~d}, J=9.5 \mathrm{~Hz}, 1 \mathrm{H}, 3-\mathrm{H}), 8.18$ (dd, J = 9.5, $2.8 \mathrm{~Hz}, 1 \mathrm{H}, 4-\mathrm{H}), 8.69$ (d, J = 2.8 Hz, $1 \mathrm{H}, 6-\mathrm{H}), 10.29$ (s, $1 \mathrm{H}, \mathrm{NH}), 13.88$ (s, $1 \mathrm{H}, \mathrm{COOH})$.

${ }^{13} \mathrm{C}-\mathrm{NMR}(75 \mathrm{MHz}, \mathrm{DMSO}): \delta=55.3\left(2 \times \mathrm{OCH}_{3}\right), 97.8$ (C-4'), 101.8 (C-2', C-6'), 111.1 (C-1), 113.8 (C-3), 128.2 (C-6), 129.2 (C-4), 136.6 (C-5), 139.9 (C-1'), 152.0 (C-2), 161.2 (C-3', C-5'), 168.5 (COOH).

MS (ESI): $m / z(\%)=317.1(100)\left[\mathrm{M}-\mathrm{H}^{+}\right]^{-}$.

$\mathrm{C}_{15} \mathrm{H}_{14} \mathrm{~N}_{2} \mathrm{O}_{6}$ (318.281) ber.: 317.0768 gef.: 317.0774, [M-H'] $]^{-}$(ESI-HRMS). 
4.2 1,3-Dimethoxy-7-nitro-10H-acridin-9-on (129)<smiles>COc1cc(OC)c2c(=O)c3cc([N+](=O)[O-])ccc3[nH]c2c1</smiles>

Eine Suspension von Säure $128\left(1.22 \mathrm{~g}, 3.83 \mathrm{mmol}, 1.00\right.$ Äq.), $\mathrm{POCl}_{3}(1.75 \mathrm{~mL}$, $19.2 \mathrm{mmol}, 5.00$ Äq.) und $\mathrm{NEt}_{3}(797 \mu \mathrm{L}, 5.75 \mathrm{mmol}, 1.50$ Äq.) in DCE (30 mL) wurde für 2.5 h unter Rückfluss erhitzt. Es wurde erneut $\mathrm{POCl}_{3}(875 \mu \mathrm{L}, 9.58 \mathrm{mmol}, 2.50$ Äq.) zugegeben und weitere 30 min unter Rückfluss erhitzt. Es wurde auf RT gekühlt, vorsichtig ges. $\mathrm{NaHCO}_{3}$-Lsg. zugegeben, mit $\mathrm{CH}_{2} \mathrm{Cl}_{2}(3 \times 100 \mathrm{~mL})$ extrahiert, über $\mathrm{MgSO}_{4}$ getrocknet und das Lösungsmittel unter vermindertem Druck entfernt. Die Titelverbindung 129 wurde nach Umkristallisation aus $\mathrm{CH}_{2} \mathrm{Cl}_{2}$ in Form rot-brauner Kristalle (955 mg, $3.18 \mathrm{mmol}, 83 \%$ ) erhalten.

DC: $\mathrm{R}_{\mathrm{f}}=0.80\left(\mathrm{CH}_{2} \mathrm{Cl}_{2} / \mathrm{MeOH}=95: 5\right)$.

IR: $v\left(\mathrm{~cm}^{-1}\right)=2936,1600,1472,1324,1185,1155,1051,824,743,517$.

UV $\left(\mathrm{CH}_{3} \mathrm{CN}\right): \lambda_{\max }(\lg \varepsilon)=208 \mathrm{~nm}$ (4.2071), 235 (4.4127), 300 (4.2779), 387 (4.0211).

${ }^{1} \mathrm{H}-\mathrm{NMR}(301 \mathrm{MHz}, \mathrm{DMSO}): \delta=3.85,3.87\left(\mathrm{~s}, 6 \mathrm{H}, 1-\mathrm{OCH}_{3}, 3-\mathrm{OCH}_{3}\right), 6.33(\mathrm{~d}, J=2.2 \mathrm{~Hz}$, $1 \mathrm{H}, 2-\mathrm{H}), 6.55(\mathrm{~d}, J=2.2 \mathrm{~Hz}, 1 \mathrm{H}, 4-\mathrm{H}), 7.53(\mathrm{~d}, J=9.1 \mathrm{~Hz}, 1 \mathrm{H}, 5-\mathrm{H}), 8.32$ (dd, J = 9.1, 2.7 Hz, $1 \mathrm{H}, 6-\mathrm{H}), 8.82(\mathrm{~d}, J=2.7 \mathrm{~Hz}, 1 \mathrm{H}, 8-\mathrm{H}), 12.21(\mathrm{~s}, 1 \mathrm{H}, \mathrm{NH})$.

${ }^{13} \mathrm{C}-\mathrm{NMR}(75 \mathrm{MHz}, \mathrm{DMSO}): \delta=55.5,55.8\left(2 \times \mathrm{OCH}_{3}\right), 91.6$ (C-4), 93.9 (C-2), 106.4 (C-4a), 117.6 (C-5), 121.0 (C-10a), 122.8 (C-8), 126.6 (C-6), 140.5, 143.9, 144.6 (C-7, C8a, C-9a), 162.0 (C-1), 164.0 (C-3), 173.8 (C-9).

MS (ESI): $m / z(\%)=923.2(100) \quad\left[3 \mathrm{M}+\mathrm{Na}^{+}\right]^{+}, 623.2$ (55) $\left[2 \mathrm{M}+\mathrm{Na}^{+}\right]^{+}, \quad 323.1$ (24) $\left[\mathrm{M}+\mathrm{Na}^{+}\right]^{+}$.

$\mathrm{C}_{15} \mathrm{H}_{12} \mathrm{~N}_{2} \mathrm{O}_{5}(300.266)$ ber.: 323.0638 gef.: 323.0637, [M+Na] ${ }^{+}$(ESI-HRMS). 
4.3 1,3-Dihydroxy-7-nitroacridin-9(10H)-on (130)

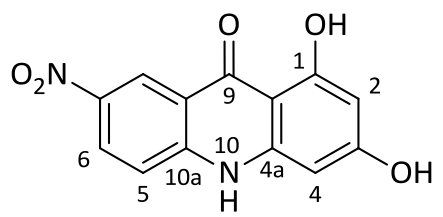

129 (2.30 g, $7.96 \mathrm{mmol}$, 1.00 Äq.) wurde auf sechs Mikrowellen-Vials aufgeteilt, in konz. $\mathrm{HBr}$ (je $20 \mathrm{~mL}$ ) gelöst und für $40 \mathrm{~min}$ bei $140{ }^{\circ} \mathrm{C}$ in der Mikrowelle (Absorptionslevel: very high, $5 \mathrm{~min}$ pre-stirring) erhitzt. Die vereinigten Reaktionslösungen wurden auf $0^{\circ} \mathrm{C}$ gekühlt, der entstandene Feststoff mit ges. $\mathrm{NaHCO}_{3}$-Lsg. $(100 \mathrm{~mL})$ und $\mathrm{H}_{2} \mathrm{O}(100 \mathrm{~mL})$ neutral gewaschen und am Hochvakuum getrocknet. Die Titelverbindung 130 wurde ohne weitere Aufreinigung in Form eines orange-braunen Feststoffs (1.80 g, $6.61 \mathrm{mmol}, 83 \%)$ erhalten.

DC: $\mathrm{R}_{\mathrm{f}}=0.45\left(\mathrm{CH}_{2} \mathrm{Cl}_{2} / \mathrm{MeOH}=95: 5\right)$.

IR: $v\left(\mathrm{~cm}^{-1}\right)=3345,1583,1540,1506,1346,1269,1152,812,648,528,516$.

UV $\left(\mathrm{CH}_{3} \mathrm{CN}\right): \lambda_{\max }(\lg \varepsilon)=197 \mathrm{~nm}$ (4.1187), 223 (3.9123), 241 (3.8052), 278 (4.426), 330 (3.5591), 347 (3.573), 439 (3.2388).

Schmp.: Zersetzung ab $150^{\circ} \mathrm{C}$.

${ }^{1} \mathrm{H}-\mathrm{NMR}(301 \mathrm{MHz}, \mathrm{DMSO}): \delta=6.06(\mathrm{~d}, J=2.1 \mathrm{~Hz}, 1 \mathrm{H}, 2-\mathrm{H}), 6.31(\mathrm{t}, J=2.3 \mathrm{~Hz}, 1 \mathrm{H}$, 4-H), 7.51 (dd, J = 9.2, 2.7 Hz, $1 \mathrm{H}, 5-\mathrm{H}), 8.37$ (dd, $J=9.2,2.7 \mathrm{~Hz}, 1 \mathrm{H}, 6-\mathrm{H}), 8.80$ (d, $J=$ $2.9 \mathrm{~Hz}, 1 \mathrm{H}, 8-\mathrm{H}), 10.76(\mathrm{~s}, 1 \mathrm{H}, 3-\mathrm{OH}), 12.20(\mathrm{~s}, 1 \mathrm{H}, \mathrm{NH}), 13.56(\mathrm{~d}, \mathrm{~J}=2.6 \mathrm{~Hz}, 1 \mathrm{H}$, 1-OH).

${ }^{13}$ C-NMR (75 MHz, DMSO): $\delta=92.3$ (C-4), 97.0 (C-2), 103.3 (C-4a), 117.7 (C-10a), 118.1 (C-5), 121.9 (C-8), 127.4 (C-6), 140.6 (C-8a), 142.8 (C-9a), 144.1 (C-7), 163.4 (C1), 165.2 (C-3), 179.2 (C-9).

MS (ESI): $m / z(\%)=271.0(100)\left[\mathrm{M}-\mathrm{H}^{+}\right]^{-}$.

$\mathrm{C}_{13} \mathrm{H}_{8} \mathrm{~N}_{2} \mathrm{O}_{5}$ (272.213) ber.: 271.0360 gef.: $271.0362\left[\mathrm{M}-\mathrm{H}^{+}\right]^{-}$(ESI-HRMS). 
4.4 3-(1,1-Dimethylprop-2-inyloxy)-1-hydroxy-7-nitro-10H-acridin-9-on (132)

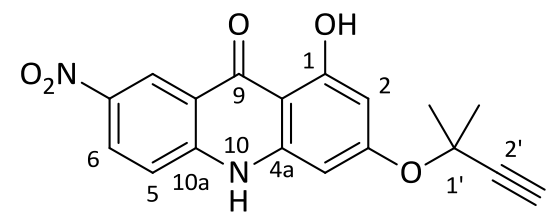

Eine Lösung von 130 (25.1 mg, $92.2 \mu \mathrm{mol}, 1.00$ Äq.), $\mathrm{K}_{2} \mathrm{CO}_{3}(25.5 \mathrm{mg}, 184 \mu \mathrm{mol}$, 2.00 Äq.), Alkin 102 (104 $\mu \mathrm{L}, 922 \mu \mathrm{mol}, 10.0$ Äq.) und $\mathrm{CuCl}(0.21 \mathrm{mg}, 2.31 \mu \mathrm{mol}$, $2.5 \mathrm{~mol}-\%)$ in DMF $(1.5 \mathrm{~mL})$ wurde für $18 \mathrm{~h}$ bei $-20^{\circ} \mathrm{C}$ und anschließend für $30 \mathrm{~h}$ bei $0{ }^{\circ} \mathrm{C}$ im Druckkolben gerührt. Es wurde $1 \mathrm{~N} \mathrm{HCl}(1 \mathrm{~mL})$ hinzugefügt und mit EtOAC $(3 \times 5 \mathrm{~mL})$ extrahiert, mit ges. $\mathrm{NaCl}$-Lsg. $(3 \times 5 \mathrm{~mL})$ gewaschen und über $\mathrm{Na}_{2} \mathrm{SO}_{4}$ getrocknet. Die Titelverbindung 132 wurde nach säulenchromatographischer Reinigung an Kieselgel $\left(100 \% \mathrm{CH}_{2} \mathrm{Cl}_{2}\right)$ in Form eines gelben Feststoffs $(17.6 \mathrm{mg}$, $52.0 \mu \mathrm{mol}, 56 \%)$ erhalten.

$D C: R_{f}=0.22\left(100 \% \mathrm{CH}_{2} \mathrm{Cl}_{2}\right)$.

IR: $v\left(\mathrm{~cm}^{-1}\right)=3264,1645,1516,1331,1169,1134,828,745,675$.

UV $\left(\mathrm{CH}_{3} \mathrm{CN}\right): \lambda_{\max }(\lg \varepsilon)=214 \mathrm{~nm}$ (4.2015), 237 (4.4206), 305 (4.349), 370 (3.9902), 396 (4.0314).

Schmp.: $256.6^{\circ} \mathrm{C}$.

${ }^{1}$ H-NMR (301 MHz, DMSO): $\delta=1.72\left(\mathrm{~s}, 6 \mathrm{H}, 2 \times 1^{\prime}-\mathrm{CH}_{3}\right), 3.92\left(\mathrm{~s}, 1 \mathrm{H}, 3^{\prime}-\mathrm{H}\right), 6.38(\mathrm{~d}, \mathrm{~J}=$ $2.1 \mathrm{~Hz}, 1 \mathrm{H}, 2-\mathrm{H}), 6.86(\mathrm{~d}, J=2.2 \mathrm{~Hz}, 1 \mathrm{H}, 4-\mathrm{H}), 7.61(\mathrm{~d}, J=9.2 \mathrm{~Hz}, 1 \mathrm{H}, 5-\mathrm{H}), 8.46$ (dd, $J=9.2,2.7 \mathrm{~Hz}, 1 \mathrm{H}, 6-\mathrm{H}), 8.88(\mathrm{~d}, J=2.6 \mathrm{~Hz}, 1 \mathrm{H}, 8-\mathrm{H}), 12.53(\mathrm{~s}, 1 \mathrm{H}, \mathrm{NH}), 13.51(\mathrm{~s}, 1 \mathrm{H}$, $1-\mathrm{OH})$.

${ }^{13} \mathrm{C}-\mathrm{NMR}$ (75 MHz, DMSO): $\delta=29.2\left(2 \times 1^{\prime}-\mathrm{CH}_{3}\right), 72.4\left(\mathrm{C}-2^{\prime}\right), 78.0$ (C-3'), 84.6 (C-1'), 95.4 (C-4), 99.4 (C-2), 104.5 (C-9a), 117.8 (C-8a), 118.6 (C-5), 122.0 (C-8), 127.7 (C-6), 140.8 (C-10a), 142.4 (C-4a), 144.3 (C-7), 162.2, 162.7 (C-1, C-3), 179.9 (C-9).

MS (ESI): $m / z(\%)=675.2(100)\left[2 \mathrm{M}-\mathrm{H}^{+}\right]^{-}, 337.1(82)\left[\mathrm{M}-\mathrm{H}^{+}\right]^{-}$

$\mathrm{C}_{18} \mathrm{H}_{14} \mathrm{~N}_{2} \mathrm{O}_{5}(338.314)$

ber.: 337.0830

gef.: 337.0827, [M-H $\left.{ }^{+}\right]^{-}$(ESI-HRMS). 
4.5

4-Brom-3-(1,1-dimethylprop-2-inyloxy)-1-hydroxy-7-nitro-10H-acridin-9-on (133)

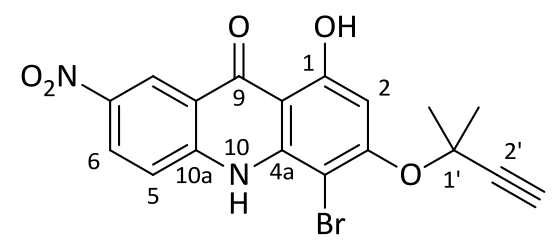

$\mathrm{CuCl}_{2}$ (190 mg, $1.41 \mu \mathrm{mol}, 1.00$ Äq.) wurde im Kolben ausgeheizt. Dazu wurde eine Lösung von Alkin 132 (477 mg, $1.41 \mu \mathrm{mol}, 1.00$ Äq.) in Aceton (100 mL) gegeben und für $30 \mathrm{~min}$ bei $-78^{\circ} \mathrm{C}$ gerührt. Es wurde NBS (201 mg, $1.27 \mu \mathrm{mol}, 0.90$ Äq.) zugegeben und $30 \mathrm{~min}$ bei $-78{ }^{\circ} \mathrm{C}$ gerührt. Das Lösungsmittel wurde unter vermindertem Druck entfernt, der Rückstand in EtOAc $(200 \mathrm{~mL})$ aufgenommen, mit $2 \mathrm{~N} \mathrm{HCl}(3 \times 20 \mathrm{~mL})$ gewaschen, über $\mathrm{Na}_{2} \mathrm{SO}_{4}$ getrocknet, grobes Kieselgel $(2 \mathrm{~g})$ hinzugefügt und das Lösungsmittel unter vermindertem Druck entfernt. Die Titelverbindung $\mathbf{1 3 3}$ wurde nach säulenchromatographischer Reinigung an Kieselgel $\left(100 \% \mathrm{CH}_{2} \mathrm{Cl}_{2}\right)$ als gelber Feststoff (290 mg, $696 \mu \mathrm{mol}, 49 \%$ ) erhalten.

DC: $R_{f}=0.78(P E / E t O A C=2: 1)$.

IR: $v\left(\mathrm{~cm}^{-1}\right)=3337,3283,1606,1562,1507,1459,1323,1267,1128,1070,837,825$, $746,693,601$.

UV $\left(\mathrm{CH}_{3} \mathrm{CN}\right): \lambda_{\max }(\lg \varepsilon)=199 \mathrm{~nm}$ (4.1723), 215 (4.1381), 239 (4.3315), 253 (4.3299), 300 (4.2066), 313 (4.1981), 368 (3.9142), 395 (3.9459), 504 (2.9198).

Schmp.: $169.0^{\circ} \mathrm{C}$.

${ }^{1}$ H-NMR (301 MHz, DMSO): $\delta=1.75\left(\mathrm{~s}, 6 \mathrm{H}, 2 \times 1\right.$ 1'-CH $\left._{3}\right), 3.95\left(\mathrm{~s}, 1 \mathrm{H}, 3^{\prime}-\mathrm{H}\right), 6.97(\mathrm{~s}, 1 \mathrm{H}$, 2-H), $8.14(\mathrm{~d}, J=9.3 \mathrm{~Hz}, 1 \mathrm{H}, 5-\mathrm{H}), 8.40(\mathrm{dd}, J=9.5,1.9 \mathrm{~Hz}, 1 \mathrm{H}, 6-\mathrm{H}), 8.72$ (d, J = 2.0 $\mathrm{Hz}, 1 \mathrm{H}, 8-\mathrm{H}), 11.09$ (s, $1 \mathrm{H}, \mathrm{NH}), 13.81$ (s, $1 \mathrm{H}, 1-\mathrm{OH})$.

${ }^{13} \mathrm{C}-\mathrm{NMR}(75 \mathrm{MHz}, \mathrm{DMSO}) \delta=29.2\left(2 \times 1^{\prime}-\mathrm{CH}_{3}\right), 74.4\left(\mathrm{C}-2^{\prime}\right), 78.4\left(\mathrm{C}-3^{\prime}\right), 84.3\left(\mathrm{C}-1^{\prime}\right)$, 89.8 (C-4), 99.2 (C-2), 105.1 (C-9a), 117.8 (C-8a), 119.9 (C-5), 121.4 (C-8), 127.8 (C-6), 139.6 (C-4a), 141.5 (C-10a), 144.4 (C-7), 158.8 (C-3), 162.1 (C-1), 180.0 (C-9).

MS (ESI): $m / z(\%)=833.0(100)\left[2 \mathrm{M}-\mathrm{H}^{+}\right]^{-}, 415.0(88)\left[\mathrm{M}-\mathrm{H}^{+}\right]^{-}$ 
$\mathrm{C}_{18} \mathrm{H}_{13} \mathrm{BrN}_{2} \mathrm{O}_{5}(417.210)$

ber.: 414.9935

gef.: 414.9930, [M-H'] $]^{-}$(ESI-HRMS).

4.6 4-Brom-3-(1,1-dimethylallyloxy)-1-hydroxy-7-nitro-10H-acridin-9-on (134)

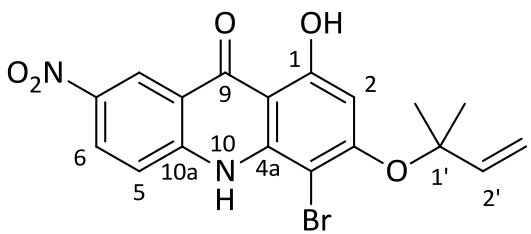

Eine Suspension aus Chinolin $(1.80 \mu \mathrm{L}, 15.1 \mu \mathrm{mol}, 0.10$ Äq.) und Pd/C (10 Gew.-\%, $3.25 \mathrm{mg}, 3.02 \mu \mathrm{mol}, 0.02 \mathrm{Äq}$.) wurde $15 \mathrm{~min}$ bei RT gerührt. Diese wurde zu einer Lösung von Alkin 133 (63.0 mg, $151 \mu \mathrm{mol}, 1.00$ Äq.) in $0{ }^{\circ} \mathrm{C}$ kaltem, mit $\mathrm{H}_{2}$ gesättigtem Aceton $\left(30 \mathrm{~mL}\right.$ ) gegeben. Es wurde unter $\mathrm{H}_{2}$-Durchleiten (Ballon) für $15 \mathrm{~min}$ bei $0^{\circ} \mathrm{C}$ gerührt (ständige DC-Kontrolle). Die Reaktionslösung wurde zweimal über Celite filtriert, mit grobem Kieselgel (300 mg) versetzt und das Lösungsmittel unter vermindertem Druck entfernt. Die Titelverbindung 134 wurde in Form eines gelben Feststoffs (39.9 mg, $105 \mu \mathrm{mol}, 70 \%$ ) nach säulenchromatographischer Reinigung an Kieselgel $(\mathrm{PE} /$ EtOAC $=6: 1 \rightarrow 1: 1)$ erhalten.

DC: $R_{f}=0.80(P E / E t O A C=2: 1)$.

IR: $v\left(\mathrm{~cm}^{-1}\right)=3327,1560,1390,1336,1272,1122,1073,940,827,588$.

UV $\left(\mathrm{CH}_{3} \mathrm{CN}\right): \lambda_{\max }(\lg \varepsilon)=199 \mathrm{~nm}$ (4.2841), 217 (4.2423), 238 (4.4181), 253 (4.3947), 314 (4.3291), 395 (4.0319), 505 (2.8533).

${ }^{1} \mathrm{H}-\mathrm{NMR}$ (301 MHz, DMSO): $\delta=1.58\left(\mathrm{~s}, 6 \mathrm{H}, 2 \times 1{ }^{\prime}-\mathrm{CH}_{3}\right), 5.34$ (ddd, $J=14.3,11.6$, $\left.0.7 \mathrm{~Hz}, 2 \mathrm{H}, 3^{\prime}-\mathrm{H}_{2}\right), 6.20$ (dd, J = 17.6, $\left.10.9 \mathrm{~Hz}, 1 \mathrm{H}, 2^{\prime}-\mathrm{H}\right), 6.50(\mathrm{~s}, 1 \mathrm{H}, 2-\mathrm{H}), 8.16$ (d, J = $9.4 \mathrm{~Hz}, 1 \mathrm{H}, 5-\mathrm{H}), 8.41(\mathrm{dd}, J=9.4,2.7 \mathrm{~Hz}, 1 \mathrm{H}, 6-\mathrm{H}), 8.74(\mathrm{~d}, J=2.7 \mathrm{~Hz}, 1 \mathrm{H}, 8-\mathrm{H}), 11.09$ (s, $1 \mathrm{H}, \mathrm{NH}), 13.78(\mathrm{~s}, 1 \mathrm{H}, 1-\mathrm{OH})$.

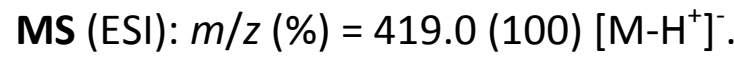

$\mathrm{C}_{18} \mathrm{H}_{15} \mathrm{BrN}_{2} \mathrm{O}_{5}(419.226)$ ber.: 417.0092 gef.: 417.0086, [M-H'] $]^{-}$(ESI-HRMS). 
4.7

4-Brom-3-(2,3-dihydroxy-1,1-dimethylpropoxy)-1-hydroxy-7-nitro-10Hacridin-9-on (rac-135)

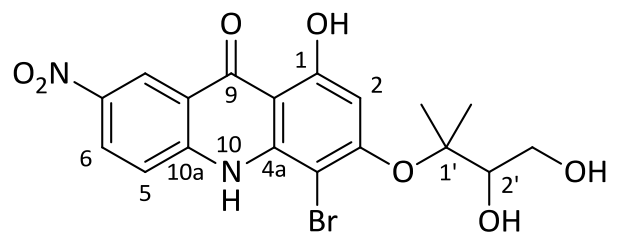

Zu einer Lösung von Alken 134 (36.6 mg, $87.3 \mu \mathrm{mol}, 1.00$ Äq.) in Aceton (15 mL) und $\mathrm{H}_{2} \mathrm{O}(1 \mathrm{~mL})$ wurde NMO (15.3 mg, $131 \mu \mathrm{mol}, 1.50$ Äq.), DABCO (1.96 mg, $17.5 \mu \mathrm{mol}$, 0.20 Äq.) und $\mathrm{K}_{2} \mathrm{OsO}_{4} \cdot 2 \mathrm{H}_{2} \mathrm{O}\left(3.22 \mathrm{mg}, 8.73 \mu \mathrm{mol}, 0.10 \mathrm{Äq}\right.$.) gegeben und $12 \mathrm{~d}$ bei $0{ }^{\circ} \mathrm{C}$ gerührt. Es wurde 5\%ige $\mathrm{NaHSO}_{3}$-Lsg. $(2 \mathrm{~mL}$ ) zugegeben, $10 \mathrm{~min}$ bei RT gerührt, das Lösungsmittel unter vermindertem Druck entfernt, mit EtOAc $(2 \times 10 \mathrm{~mL})$ extrahiert und über $\mathrm{Na}_{2} \mathrm{SO}_{4}$ getrocknet. Die Lösung wurde mit grobem Kieselgel (200 mg) versetzt, das Lösungsmittel unter vermindertem Druck entfernt und die Titelverbindung rac-135 nach säulenchromatographischer Reinigung an Kieselgel $\left(\mathrm{CH}_{2} \mathrm{Cl}_{2} / \mathrm{MeOH}=100: 3 \rightarrow 100: 6\right)$ in Form eines gelben Feststoffs $(29.3 \mathrm{mg}, 64.6 \mu \mathrm{mol}$, 74\%) erhalten.

DC: $\mathrm{R}_{\mathrm{f}}=0.24\left(\mathrm{CH}_{2} \mathrm{Cl}_{2} / \mathrm{MeOH}=95: 5\right)$.

UV $\left(\mathrm{CH}_{3} \mathrm{CN}\right): \lambda_{\max }(\lg \varepsilon)=199 \mathrm{~nm}$ (4.315), 216 (4.2444), 238 (4.4218), 253 (4.396), 302 (4.2908), 314 (4.3022), 368 (4.003), 396 (4.0317), 501 (2.8043).

Schmp.: $165.2^{\circ} \mathrm{C}$.

${ }^{1} \mathrm{H}-\mathrm{NMR}(301 \mathrm{MHz}, \mathrm{DMSO}) \delta=1.42,1.47\left(\mathrm{~s}, 6 \mathrm{H}, 2 \times 1^{\prime}-\mathrm{CH}_{3}\right), 3.39-3.54(\mathrm{~m}, 1 \mathrm{H}$, 3'- $\left.\mathrm{H}_{\mathrm{a}}\right), 3.68-3.76\left(\mathrm{~m}, 1 \mathrm{H}, 2^{\prime}-\mathrm{H}\right), 3.84\left(\mathrm{~d}, J=10.6 \mathrm{~Hz}, 1 \mathrm{H}, 3^{\prime}-\mathrm{H}_{\mathrm{b}}\right), 4.49$ (s, $\left.1 \mathrm{H}, 3^{\prime}-\mathrm{OH}\right)$, $5.13\left(\mathrm{~d}, J=4.1 \mathrm{~Hz}, 1 \mathrm{H}, 2^{\prime}-\mathrm{OH}\right), 6.74(\mathrm{~s}, 1 \mathrm{H}, 2-\mathrm{H}), 8.21(\mathrm{~d}, J=9.3 \mathrm{~Hz}, 1 \mathrm{H}, 5-\mathrm{H}), 8.45$ (dd, J = 9.3, 2.7 Hz, $1 \mathrm{H}, 6-\mathrm{H}), 8.82(\mathrm{~d}, J=2.7 \mathrm{~Hz}, 1 \mathrm{H}, 8-\mathrm{H}), 11.11(\mathrm{~s}, 1 \mathrm{H}, \mathrm{NH}), 13.81$ (s, $1 \mathrm{H}, 1-\mathrm{OH})$.

${ }^{13}$ C-NMR (75 MHz, DMSO): $\delta=21.8,24.1\left(2 \times 1^{\prime}-\mathrm{CH}_{3}\right), 62.0$ (C-3'), 76.9 (C-2'), 86.4 (C-1'), 91.7 (C-4), 101.5 (C-2), 105.2 (C-9a), 117.8 (C-10a), 120.0 (C-5), 121.5 (C-8), 127.7 (C-6), 139.6 (C-4a), 141.4 (C-8a), 144.5 (C-7), 159.6 (C-3), 162.1 (C-1), 180.0 (C9). 
MS (ESI): $m / z(\%)=453.0(100)\left[\mathrm{M}-\mathrm{H}^{+}\right]^{-}$.

$\mathrm{C}_{18} \mathrm{H}_{17} \mathrm{BrN}_{2} \mathrm{O}_{7}$ (453.241)

ber.: 451.0146

gef.: $451.0138\left[\mathrm{M}-\mathrm{H}^{+}\right]^{-}$(ESI-HRMS).

4.8 4-Brom-1-hydroxy-3-(1-methyl-1-oxiranylethoxy)-7-nitro-10H-acridin-9-on $($ rac-124)

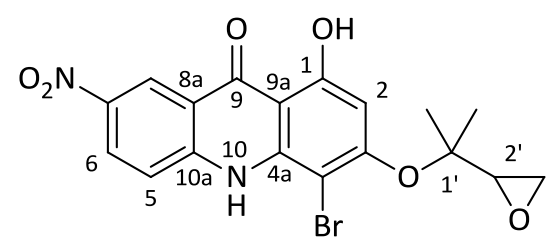

Eine Lösung von Diol rac-135 (50.5 mg, $111 \mu \mathrm{mol}, 1.00$ Äq.) in Pyridin (3 mL) wurde für $15 \mathrm{~min}$ bei $0^{\circ} \mathrm{C}$ gerührt. Anschließend wurde Mesylchlorid $(17.2 \mu \mathrm{L}, 221 \mu \mathrm{mol}$, 2.00 Äq.) zugegeben, $30 \mathrm{~min}$ bei $0{ }^{\circ} \mathrm{C}$ gerührt, das Lösungsmittel unter vermindertem Druck entfernt, der Rückstand in $\mathrm{MeOH}(8 \mathrm{~mL})$ gelöst und $\mathrm{K}_{2} \mathrm{CO}_{3}(77.0 \mathrm{mg}, 557 \mu \mathrm{mol}$, 5.00 Äq.) zugegeben. Nach 75 min wurde das Lösungsmittel unter vermindertem Druck bei RT entfernt, das Rohprodukt in $1 \mathrm{~N} \mathrm{HCl}(2 \mathrm{~mL})$ aufgenommen, mit EtOAc $(3 \times 10 \mathrm{~mL})$ extrahiert, über $\mathrm{Na}_{2} \mathrm{SO}_{4}$ getrocknet, mit grobem Kieselgel $(200 \mathrm{mg})$ versetzt und das Lösungsmittel unter vermindertem Druck entfernt. Die Titelverbindung rac-129 wurde nach säulenchromatographischer Reinigung an Kieselgel (PE/EtOAc $=2: 1)$ in Form eines gelben Feststoffs (30.2 mg, $69.4 \mu \mathrm{mol}, 62 \%)$ erhalten.

$D C: R_{f}=0.34(P E / E t O A C=2: 1)$.

Schmp.: $152.2^{\circ} \mathrm{C}$.

${ }^{1} \mathrm{H}-\mathrm{NMR}$ (301 MHz, DMSO). $\delta=1.31,1.51\left(\mathrm{~s}, 6 \mathrm{H}, 2 \times 1\right.$ ' $\left.-\mathrm{CH}_{3}\right), 2.84(\mathrm{dd}, J=4.7,2.8 \mathrm{~Hz}$, $\left.1 \mathrm{H}, 3^{\prime}-\mathrm{H}_{\mathrm{a}}\right), 2.90\left(\mathrm{t}, J=4.6 \mathrm{~Hz}, 1 \mathrm{H}, 3^{\prime}-\mathrm{H}_{\mathrm{b}}\right), 3.35\left(\mathrm{dd}, J=4.1,2.8 \mathrm{~Hz}, 1 \mathrm{H}, 2^{\prime}-\mathrm{H}\right), 6.77(\mathrm{~d}$, $J=5.2 \mathrm{~Hz}, 1 \mathrm{H}, 2-\mathrm{H}), 8.20(\mathrm{t}, J=7.9 \mathrm{~Hz}, 1 \mathrm{H}, 5-\mathrm{H}), 8.45(\mathrm{dd}, J=9.2,2.6 \mathrm{~Hz}, 1 \mathrm{H}, 6-\mathrm{H})$, $8.85-8.78(\mathrm{~m}, 1 \mathrm{H}, 8-\mathrm{H}), 11.14(\mathrm{~s}, 1 \mathrm{H}, \mathrm{NH}), 13.84$ (d, J = 9.1 Hz, $1 \mathrm{H}, 1-\mathrm{OH})$.

${ }^{13}$ C-NMR (125 MHz, DMSO): $\delta=19.9,25.1\left(2 \times 1^{\prime}-\mathrm{CH}_{3}\right), 44.6$ (C-3'), 56.4 (C-2'), 82.7 (C-1'), 91.0 (C-4), 100.6 (C-2), 105.1 (C-9a), 117.7 (C-8a), 119.9 (C-5), 121.4 (C-8), 
127.5 (C-6), 139.6 (C-4a), 141.2 (C-10a), 144.4 (C-7), 158.9 (C-3), 162.2 (C-1), 179.7 (C-9).

MS (ESI): $m / z(\%)=433.0(100)\left[\mathrm{M}-\mathrm{H}^{+}\right]^{-}$.

HPLC Chiralpak ${ }^{\circledR} \mathrm{IA}, n$-Hexan/iPrOH $=80: 20$, Flussrate $7.0 \mathrm{~mL} / \mathrm{min}, 210 \mathrm{~nm}$, $t_{R}=36.108 \mathrm{~min}$.

$\mathrm{C}_{18} \mathrm{H}_{15} \mathrm{BrN}_{2} \mathrm{O}_{6}(435.225)$

ber.: 433.0041

gef.: 433.0035, [M-H'] $]^{-}$(ESI-HRMS). 


\section{G ANHANG}

\section{Daten aus Röntgenstrukturanalysen}

$1.1 \quad$ Daten für Alkin 104

\begin{tabular}{|c|c|c|c|}
\hline & Summenformel & $\mathrm{C}_{22} \mathrm{H}_{16} \mathrm{BrNO}_{3}$ & \\
\hline & Molmasse & $422.27 \mathrm{~g} / \mathrm{mol}$ & \\
\hline & Kristallsystem & monoklin & \\
\hline & Raumgruppe & P1 21/c 1 (14) & \\
\hline & Zelldimensionen & $a=18.6012(8) \AA$ & $\alpha=90^{\circ}$ \\
\hline & & $b=8.0283(2) \AA$ & $\beta=108.064(3)^{\circ}$ \\
\hline & & $c=12.3551(5) \AA$ & $\gamma=90^{\circ}$ \\
\hline & Zellverhältnis & $\mathrm{a} / \mathrm{b}=2.3170$ & \\
\hline & & $b / c=0.6498$ & \\
\hline & & $c / a=0.6642$ & \\
\hline & Zellvolumen & $1754.12(12) \AA^{3}$ & \\
\hline & Z & 4 & \\
\hline & Berechnete Dichte & $1.59887 \mathrm{~g} / \mathrm{cm}^{3}$ & \\
\hline & RAll & 0.0343 & \\
\hline & Pearsoncode & mP172 & \\
\hline & Fomeltyp & NOP3Q16R22 & \\
\hline & Wyckoffsequenz & e43 & \\
\hline Tabelle 14: & Kristalldaten für Verbindung 104. & & \\
\hline & $\mathbf{x}$ & y & $\mathrm{U}[\mathrm{eq}]$ \\
\hline & $0.30332(1)$ & $0.60684(2)$ & $0.17072(2)$ \\
\hline & $0.20807(10)$ & $0.5160(2)$ & $0.32575(15)$ \\
\hline & $0.17604(9)$ & $0.06345(18)$ & $0.45303(13)$ \\
\hline & $0.25783(10)$ & $-0.07156(18)$ & $0.34779(14)$ \\
\hline & $0.35712(9)$ & $0.28202(18)$ & $0.11572(13)$ \\
\hline
\end{tabular}




\begin{tabular}{|c|c|c|c|c|}
\hline $\mathrm{C} 1$ & $0.36590(14)$ & $-0.1183(3)$ & $0.0056(2)$ & \\
\hline $\mathrm{H} 1 \mathrm{~A}$ & 0.34980 & -0.21940 & -0.03050 & 0.0800 \\
\hline $\mathrm{C} 2$ & $0.38648(12)$ & $0.0111(3)$ & $0.05178(18)$ & \\
\hline C3 & $0.41712(12)$ & $0.1718(3)$ & $0.10503(18)$ & \\
\hline C4 & $0.44863(14)$ & $0.2682(3)$ & $0.0231(2)$ & \\
\hline H4A & 0.40940 & 0.28400 & -0.04790 & 0.0800 \\
\hline H4B & 0.48940 & 0.20650 & 0.01030 & 0.0800 \\
\hline $\mathrm{H} 4 \mathrm{C}$ & 0.46680 & 0.37470 & 0.05550 & 0.0800 \\
\hline C5 & $0.47743(14)$ & $0.1473(3)$ & $0.2202(2)$ & \\
\hline $\mathrm{H} 5 \mathrm{~A}$ & 0.49460 & 0.25390 & 0.25330 & 0.0800 \\
\hline H5B & 0.51930 & 0.08650 & 0.20990 & 0.0800 \\
\hline $\mathrm{H} 5 \mathrm{C}$ & 0.45630 & 0.08600 & 0.26980 & 0.0800 \\
\hline C6 & $0.31843(11)$ & $0.2530(3)$ & $0.19056(17)$ & \\
\hline C7 & $0.28571(12)$ & $0.3939(2)$ & $0.22263(17)$ & \\
\hline C8 & $0.24148(11)$ & $0.3792(2)$ & $0.29534(16)$ & \\
\hline C9 & $0.17057(11)$ & $0.5115(2)$ & $0.40588(17)$ & \\
\hline $\mathrm{C} 10$ & $0.14277(12)$ & $0.6552(2)$ & $0.44018(18)$ & \\
\hline $\mathrm{H} 10$ & 0.14810 & 0.75640 & 0.40680 & 0.0800 \\
\hline C11 & $0.10676(11)$ & $0.6509(2)$ & $0.52417(17)$ & \\
\hline C12 & $0.07846(13)$ & $0.7984(3)$ & $0.5612(2)$ & \\
\hline $\mathrm{H} 12$ & 0.08360 & 0.90060 & 0.52900 & 0.0800 \\
\hline $\mathrm{C} 13$ & $0.04409(13)$ & $0.7902(3)$ & $0.6434(2)$ & \\
\hline $\mathrm{H} 13$ & 0.02540 & 0.88720 & 0.66600 & 0.0800 \\
\hline C14 & $0.03602(13)$ & $0.6367(3)$ & $0.69538(19)$ & \\
\hline H14 & 0.01290 & 0.63400 & 0.75210 & 0.0800 \\
\hline C15 & $0.06230(12)$ & $0.4931(3)$ & $0.66199(18)$ & \\
\hline H15 & 0.05680 & 0.39280 & 0.69620 & 0.0800 \\
\hline C16 & $0.09796(11)$ & $0.4950(3)$ & $0.57565(17)$ & \\
\hline C17 & $0.12504(11)$ & $0.3507(2)$ & $0.53776(17)$ & \\
\hline H17 & 0.11890 & 0.24860 & 0.56930 & 0.0800 \\
\hline C18 & $0.16048(11)$ & $0.3555(2)$ & $0.45524(17)$ & \\
\hline
\end{tabular}




\begin{tabular}{lcccc}
\hline C19 & $0.18862(11)$ & $0.2033(2)$ & $0.41719(17)$ & \\
C20 & $0.23160(11)$ & $0.2211(2)$ & $0.33878(17)$ & \\
C21 & $0.26598(12)$ & $0.0802(2)$ & $0.30559(17)$ & \\
C22 & $0.30811(12)$ & $0.0956(3)$ & $0.23176(18)$ & \\
H22 & 0.32950 & 0.00200 & 0.20960 & 0.0800 \\
H1 & $0.2126(15)$ & $0.605(3)$ & $0.299(2)$ & $0.020(6)$ \\
H2 & $0.230(2)$ & $-0.056(4)$ & $0.392(3)$ & $0.050(9)$ \\
\hline
\end{tabular}

Tabelle 15: $\quad$ Atomkoordinaten und äquivalente isotrope Auslenkungsparameter $\left[\AA^{2}\right]$ für 104. U(eq) ist definiert als ein Drittel der Spur orthogonaler $\mathrm{U}_{\mathrm{ij}}$-Tensors.

\begin{tabular}{|c|c|c|c|c|c|c|}
\hline Atom & $\mathrm{U}_{11}$ & $\mathbf{U}_{22}$ & $U_{33}$ & $\mathrm{U}_{12}$ & $U_{13}$ & $\mathbf{U}_{23}$ \\
\hline $\mathrm{Br} 1$ & $0.02751(12$ & $0.01668(11$ & $0.02414(12$ & $-0.00071(8)$ & $0.01493(8)$ & $0.00230(8)$ \\
\hline N1 & $0.0228(9)$ & $0.0135(8)$ & $0.0213(8)$ & $0.0012(7)$ & $0.0127(7)$ & $0.0031(7)$ \\
\hline O1 & $0.0336(9)$ & $0.0144(7)$ & $0.0275(8)$ & $0.0002(6)$ & $0.0175(7)$ & $0.0020(6)$ \\
\hline $\mathrm{O} 2$ & $0.0378(9)$ & $0.0135(7)$ & $0.0308(8)$ & $0.0035(6)$ & $0.0215(7)$ & $0.0038(6)$ \\
\hline $\mathrm{O} 3$ & $0.0284(8)$ & $0.0215(7)$ & $0.0246(8)$ & $0.0060(6)$ & $0.0183(6)$ & $0.0043(6)$ \\
\hline $\mathrm{C} 1$ & $0.0298(12)$ & $0.0272(12)$ & $0.0285(11)$ & $0.0015(9)$ & $0.0138(9)$ & $-0.0018(9)$ \\
\hline $\mathrm{C} 2$ & $0.0240(11)$ & $0.0267(11)$ & $0.0225(10)$ & $0.0040(9)$ & $0.0124(9)$ & $0.0018(9)$ \\
\hline C3 & $0.0211(10)$ & $0.0226(10)$ & $0.0243(10)$ & $0.0023(8)$ & $0.0127(8)$ & $-0.0003(8)$ \\
\hline $\mathrm{C} 4$ & $0.0311(12)$ & $0.0291(12)$ & $0.0338(13)$ & $0.0008(9)$ & $0.0219(10)$ & $0.002(1)$ \\
\hline $\mathrm{C} 5$ & $0.0274(11)$ & $0.0299(12)$ & $0.0304(12)$ & $0.0002(9)$ & $0.0056(10)$ & $-0.0020(9)$ \\
\hline C6 & $0.0205(10)$ & $0.0190(9)$ & $0.0155(9)$ & $0.0011(8)$ & $0.0083(8)$ & $0.0002(7)$ \\
\hline $\mathrm{C7}$ & $0.0213(10)$ & $0.0158(9)$ & $0.0187(9)$ & $-0.0001(8)$ & $0.0088(8)$ & $0.0013(8)$ \\
\hline $\mathrm{C} 8$ & $0.0181(9)$ & $0.0167(9)$ & $0.0151(9)$ & $0.0001(7)$ & $0.0061(7)$ & $0.0007(7)$ \\
\hline C9 & $0.0166(9)$ & $0.0156(9)$ & $0.0179(9)$ & $-0.0006(7)$ & $0.0072(8)$ & $0.0010(7)$ \\
\hline $\mathrm{C} 10$ & $0.0222(10)$ & $0.0154(9)$ & $0.0236(10)$ & $-0.0013(8)$ & $0.0120(8)$ & $0.0011(8)$ \\
\hline C11 & $0.0181(9)$ & $0.0169(9)$ & $0.0195(9)$ & $-0.0026(7)$ & $0.0068(8)$ & $-0.0039(7)$ \\
\hline $\mathrm{C} 12$ & $0.0297(11)$ & $0.016(1)$ & $0.0304(11)$ & $-0.0012(8)$ & $0.0163(9)$ & $-0.0013(8)$ \\
\hline $\mathrm{C} 13$ & $0.0303(12)$ & $0.0217(11)$ & $0.0321(12)$ & $0.0000(9)$ & $0.0171(10)$ & $-0.0066(9)$ \\
\hline C14 & $0.0258(11)$ & $0.0275(12)$ & $0.0232(10)$ & $-0.0030(8)$ & $0.0137(9)$ & $-0.0041(8)$ \\
\hline C15 & $0.0223(10)$ & $0.0233(10)$ & $0.020(1)$ & $-0.0013(8)$ & $0.0094(8)$ & $0.0010(8)$ \\
\hline
\end{tabular}




\begin{tabular}{lllllll}
\hline C16 & $0.0163(9)$ & $0.020(1)$ & $0.0170(9)$ & $-0.0015(7)$ & $0.0056(7)$ & $0.0006(7)$ \\
C17 & $0.0198(9)$ & $0.0165(9)$ & $0.0186(9)$ & $-0.0016(7)$ & $0.0068(8)$ & $0.0023(7)$ \\
C18 & $0.0185(9)$ & $0.0157(9)$ & $0.0184(9)$ & $0.0004(7)$ & $0.0066(7)$ & $0.0003(7)$ \\
C19 & $0.0202(9)$ & $0.0151(9)$ & $0.0170(9)$ & $0.0011(7)$ & $0.0069(8)$ & $0.0023(7)$ \\
C20 & $0.0197(9)$ & $0.0155(9)$ & $0.018(1)$ & $0.0007(7)$ & $0.0067(8)$ & $-0.0003(7)$ \\
C21 & $0.0239(10)$ & $0.0155(9)$ & $0.0182(9)$ & $0.0013(8)$ & $0.0081(8)$ & $0.0025(7)$ \\
C22 & $0.0259(10)$ & $0.0173(10)$ & $0.0218(10)$ & $0.0027(8)$ & $0.0113(8)$ & $-0.0021(8)$ \\
\hline
\end{tabular}

Tabelle 16: $\quad$ Anisotrope Auslenkungsparameter $\left[\AA^{2} \times 10^{3}\right]$ für 104.

\begin{tabular}{llll}
\hline Atome 1,2 & Bindungslänge [ppm] & Atome 1,2 & Bindungslänge [ppm] \\
\hline $\mathrm{Br} 1-\mathrm{C} 7$ & $1.890(2)$ & $\mathrm{C} 9-\mathrm{C} 10$ & $1.384(3)$ \\
$\mathrm{N} 1-\mathrm{C} 8$ & $1.370(3)$ & $\mathrm{C} 9-\mathrm{C} 18$ & $1.430(3)$ \\
$\mathrm{N} 1-\mathrm{C} 9$ & $1.377(3)$ & $\mathrm{C} 10-\mathrm{C} 11$ & $1.399(3)$ \\
$\mathrm{O} 1-\mathrm{C} 19$ & $1.255(2)$ & $\mathrm{C} 11-\mathrm{C} 12$ & $1.428(3)$ \\
$\mathrm{O} 2-\mathrm{C} 21$ & $1.352(2)$ & $\mathrm{C} 11-\mathrm{C} 16$ & $1.436(3)$ \\
$\mathrm{O} 3-\mathrm{C} 6$ & $1.356(2)$ & $\mathrm{C} 12-\mathrm{C} 13$ & $1.358(3)$ \\
$\mathrm{O} 3-\mathrm{C} 3$ & $1.462(2)$ & $\mathrm{C} 13-\mathrm{C} 14$ & $1.419(3)$ \\
$\mathrm{C} 1-\mathrm{C} 2$ & $1.189(3)$ & $\mathrm{C} 14-\mathrm{C} 15$ & $1.365(3)$ \\
$\mathrm{C} 2-\mathrm{C} 3$ & $1.480(3)$ & $\mathrm{C} 15-\mathrm{C} 16$ & $1.420(3)$ \\
$\mathrm{C} 3-\mathrm{C} 5$ & $1.527(3)$ & $\mathrm{C} 16-\mathrm{C} 17$ & $1.401(3)$ \\
$\mathrm{C} 3-\mathrm{C} 4$ & $1.528(3)$ & $\mathrm{C} 17-\mathrm{C} 18$ & $1.375(3)$ \\
$\mathrm{C} 6-\mathrm{C} 22$ & $1.398(3)$ & $\mathrm{C} 18-\mathrm{C} 19$ & $1.463(3)$ \\
$\mathrm{C} 6-\mathrm{C} 7$ & $1.399(3)$ & $\mathrm{C} 19-\mathrm{C} 20$ & $1.442(3)$ \\
$\mathrm{C} 7-\mathrm{C} 8$ & $1.399(3)$ & $\mathrm{C} 20-\mathrm{C} 21$ & $1.421(3)$ \\
$\mathrm{C} 8-\mathrm{C} 20$ & $1.412(3)$ & $\mathrm{C} 21-\mathrm{C} 22$ & $1.380(3)$ \\
\hline
\end{tabular}

Tabelle 17: Bindungslängen für 104. 


\begin{tabular}{|c|c|c|c|}
\hline Atome 1-2-3 & Bindungswinkel $\left[{ }^{\circ}\right]$ & Atome 1-2-3 & Bindungswinkel $\left[{ }^{\circ}\right]$ \\
\hline $\mathrm{C} 8-\mathrm{N} 1-\mathrm{C} 9$ & $123.38(17)$ & $\mathrm{C} 10-\mathrm{C} 11-\mathrm{C} 16$ & 119.79(18) \\
\hline $\mathrm{C} 6-\mathrm{O} 3-\mathrm{C} 3$ & $122.62(16)$ & $\mathrm{C} 12-\mathrm{C} 11-\mathrm{C} 16$ & $118.46(19)$ \\
\hline $\mathrm{C} 1-\mathrm{C} 2-\mathrm{C} 3$ & $175.3(2)$ & $\mathrm{C} 13-\mathrm{C} 12-\mathrm{C} 11$ & $120.3(2)$ \\
\hline $\mathrm{O} 3-\mathrm{C} 3-\mathrm{C} 2$ & 111.61(17) & $\mathrm{C} 12-\mathrm{C} 13-\mathrm{C} 14$ & $121.4(2)$ \\
\hline $\mathrm{O} 3-\mathrm{C} 3-\mathrm{C} 5$ & $110.78(17)$ & $\mathrm{C} 15-\mathrm{C} 14-\mathrm{C} 13$ & $119.9(2)$ \\
\hline $\mathrm{C} 2-\mathrm{C} 3-\mathrm{C} 5$ & 111.83(19) & $\mathrm{C} 14-\mathrm{C} 15-\mathrm{C} 16$ & $120.8(2)$ \\
\hline $\mathrm{O} 3-\mathrm{C} 3-\mathrm{C} 4$ & $102.35(17)$ & $\mathrm{C} 17-\mathrm{C} 16-\mathrm{C} 15$ & $122.84(19)$ \\
\hline $\mathrm{C} 2-\mathrm{C} 3-\mathrm{C} 4$ & $108.73(18)$ & $\mathrm{C} 17-\mathrm{C} 16-\mathrm{C} 11$ & $118.07(18)$ \\
\hline $\mathrm{C} 5-\mathrm{C} 3-\mathrm{C} 4$ & 111.15(19) & $\mathrm{C} 15-\mathrm{C} 16-\mathrm{C} 11$ & $119.09(18)$ \\
\hline $\mathrm{O} 3-\mathrm{C} 6-\mathrm{C} 22$ & $124.41(18)$ & $\mathrm{C} 18-\mathrm{C} 17-\mathrm{C} 16$ & $121.95(18)$ \\
\hline $\mathrm{O} 3-\mathrm{C} 6-\mathrm{C} 7$ & $115.07(18)$ & $\mathrm{C} 17-\mathrm{C} 18-\mathrm{C} 9$ & $119.80(18)$ \\
\hline $\mathrm{C} 22-\mathrm{C} 6-\mathrm{C} 7$ & $120.48(19)$ & $\mathrm{C} 17-\mathrm{C} 18-\mathrm{C} 19$ & $121.08(18)$ \\
\hline $\mathrm{C} 8-\mathrm{C} 7-\mathrm{C} 6$ & $120.52(18)$ & $\mathrm{C} 9-\mathrm{C} 18-\mathrm{C} 19$ & $119.12(18)$ \\
\hline $\mathrm{C} 8-\mathrm{C} 7-\mathrm{Br} 1$ & $119.53(15)$ & $\mathrm{O} 1-\mathrm{C} 19-\mathrm{C} 20$ & $121.89(18)$ \\
\hline $\mathrm{C} 6-\mathrm{C} 7-\mathrm{Br} 1$ & 119.93(15) & $\mathrm{O} 1-\mathrm{C} 19-\mathrm{C} 18$ & $120.61(18)$ \\
\hline $\mathrm{N} 1-\mathrm{C} 8-\mathrm{C} 7$ & $121.04(18)$ & $\mathrm{C} 20-\mathrm{C} 19-\mathrm{C} 18$ & $117.49(17)$ \\
\hline $\mathrm{N} 1-\mathrm{C} 8-\mathrm{C} 20$ & $119.50(18)$ & $\mathrm{C} 8-\mathrm{C} 20-\mathrm{C} 21$ & $118.86(19)$ \\
\hline $\mathrm{C} 7-\mathrm{C} 8-\mathrm{C} 2 \mathrm{O}$ & $119.46(18)$ & $\mathrm{C} 8-\mathrm{C} 20-\mathrm{C} 19$ & $120.59(18)$ \\
\hline $\mathrm{N} 1-\mathrm{C} 9-\mathrm{C} 10$ & $121.28(18)$ & $\mathrm{C} 21-\mathrm{C} 20-\mathrm{C} 19$ & $120.53(18)$ \\
\hline $\mathrm{N} 1-\mathrm{C} 9-\mathrm{C} 18$ & $119.47(18)$ & $\mathrm{O} 2-\mathrm{C} 21-\mathrm{C} 22$ & $119.36(18)$ \\
\hline $\mathrm{C} 10-\mathrm{C} 9-\mathrm{C} 18$ & $119.25(19)$ & $\mathrm{O} 2-\mathrm{C} 21-\mathrm{C} 2 \mathrm{O}$ & $119.45(19)$ \\
\hline $\mathrm{C} 9-\mathrm{C} 10-\mathrm{C} 11$ & 121.11(19) & $\mathrm{C} 22-\mathrm{C} 21-\mathrm{C} 20$ & $121.18(18)$ \\
\hline $\mathrm{C} 10-\mathrm{C} 11-\mathrm{C} 12$ & 121.75(19) & $\mathrm{C} 21-\mathrm{C} 22-\mathrm{C} 6$ & $119.47(18)$ \\
\hline
\end{tabular}

Tabelle 18: Bindungswinkel für 104.

\begin{tabular}{|c|c|c|c|c|}
\hline Atome $\mathrm{D}, \mathrm{H}, \mathrm{A}$ & Dist. D,H [Å] & Dist. $H, A[\AA]$ & Dist. D,A [Å] & Angle $\mathrm{D}, \mathrm{H}, \mathrm{A}\left[{ }^{\circ}\right]$ \\
\hline $\mathrm{N} 1-\mathrm{H} 1-\mathrm{Br} 1$ & $0.80(3)$ & $2.65(3)$ & $3.0732(17)$ & 115.(2) \\
\hline $\mathrm{N} 1-\mathrm{H} 1-\mathrm{O}^{\mathrm{i}}$ & $0.80(3)$ & $2.74(3)$ & $3.426(2)$ & 145.(2) \\
\hline $\mathrm{O} 2-\mathrm{H} 2-\mathrm{O} 1$ & $0.86(4)$ & $1.73(4)$ & $2.531(2)$ & 154.(3) \\
\hline
\end{tabular}


Tabelle 19: Wasserstoffbrückenbindungen für 104.

1.2 Daten für rac-114.

\begin{tabular}{|c|c|c|}
\hline Summenformel & $\mathrm{C}_{22} \mathrm{H}_{18} \mathrm{ClNO}_{3}$ & \\
\hline Molmasse & $379.82 \mathrm{~g} / \mathrm{mol}$ & \\
\hline Kristallsystem & triklin & \\
\hline Raumgruppe & $P-1(2)$ & \\
\hline \multirow[t]{3}{*}{ Zelldimensionen } & $a=9.7045(9) \AA$ & $\alpha=66.796(7)^{\circ}$ \\
\hline & $\mathrm{b}=9.8398(9) \AA$ & $\beta=67.785(7)^{\circ}$ \\
\hline & $c=10.4729(9) \AA$ & $\gamma=81.552(7)^{\circ}$ \\
\hline \multirow[t]{3}{*}{ Zellverhältnis } & $a / b=0.9862$ & \\
\hline & $b / c=0.9395$ & \\
\hline & $c / a=1.0792$ & \\
\hline Zellvolumen & $850.93(15) \AA^{3}$ & \\
\hline Z & 2 & \\
\hline Berechnete Dichte & $1.4823 \mathrm{~g} / \mathrm{cm}^{3}$ & \\
\hline RAII & 0.0559 & \\
\hline Pearsoncode & aP100 & \\
\hline Fomeltyp & NOP3Q18R22 & \\
\hline Wyckoffsequenz & ¡50 & \\
\hline
\end{tabular}

Tabelle 20: $\quad$ Kristalldaten der Verbindung rac-114.

\begin{tabular}{ccccc}
\hline & $\mathbf{X}$ & $\mathbf{y}$ & $\mathbf{z}$ & $\mathbf{U}[\mathrm{eq}]$ \\
\hline $\mathrm{C} 1 \mathrm{X}$ & $0.7245(5)$ & $0.6533(5)$ & $0.0613(4)$ & \\
$\mathrm{H} 1 \mathrm{X}$ & 0.83410 & 0.67280 & 0.01480 & 0.0220 \\
$\mathrm{C} 15 \mathrm{X}$ & $0.6855(3)$ & $0.5200(3)$ & $0.0402(3)$ & \\
$\mathrm{H} 15 \mathrm{~A}$ & 0.68350 & 0.55080 & -0.06120 & 0.0260 \\
$\mathrm{H} 15 \mathrm{~B}$ & 0.58530 & 0.48280 & 0.11200 & 0.0260 \\
$\mathrm{C} 1 \mathrm{Y}$ & $0.6619(12)$ & $0.6197(9)$ & $0.094(1)$ & \\
$\mathrm{H} 1 \mathrm{Y}$ & 0.57800 & 0.55370 & 0.12110 & 0.0310 \\
$\mathrm{C} 15 \mathrm{Y}$ & $0.8026(7)$ & $0.5796(6)$ & $-0.0028(7)$ & \\
$\mathrm{H} 15 \mathrm{C}$ & 0.88720 & 0.62510 & -0.00300 & 0.0340
\end{tabular}




\begin{tabular}{|c|c|c|c|c|}
\hline H15D & 0.80350 & 0.61670 & -0.10580 & 0.0340 \\
\hline $\mathrm{C} 2$ & $0.6354(3)$ & $0.7936(2)$ & $-0.0062(2)$ & \\
\hline C3A & $0.5591(2)$ & $0.75362(19)$ & $0.2416(2)$ & \\
\hline C4 & $0.4951(2)$ & $0.7882(2)$ & $0.3675(2)$ & \\
\hline $\mathrm{H} 4$ & 0.41960 & 0.86120 & 0.37390 & 0.0290 \\
\hline C5 & $0.5457(2)$ & $0.71219(19)$ & $0.4832(2)$ & \\
\hline C5A & $0.6565(2)$ & $0.59957(18)$ & $0.47450(19)$ & \\
\hline C6 & $0.7102(2)$ & $0.52442(19)$ & $0.5954(2)$ & \\
\hline C6A & $0.8233(2)$ & $0.41009(19)$ & $0.57985(19)$ & \\
\hline $\mathrm{C7}$ & $0.8810(2)$ & $0.33297(19)$ & $0.69105(19)$ & \\
\hline $\mathrm{H7}$ & 0.84670 & 0.35540 & 0.77840 & 0.0250 \\
\hline C7A & $0.9889(2)$ & $0.22249(19)$ & $0.6780(2)$ & \\
\hline $\mathrm{C} 8$ & $1.0509(2)$ & $0.1432(2)$ & $0.7898(2)$ & \\
\hline $\mathrm{H} 8$ & 1.01940 & 0.16530 & 0.87710 & 0.0300 \\
\hline C9 & $1.1549(2)$ & $0.0361(2)$ & $0.7739(2)$ & \\
\hline $\mathrm{H} 9$ & $1.19 . .510$ & -0.01580 & 0.85000 & 0.0310 \\
\hline C10 & $1.2033(2)$ & $0.0020(2)$ & $0.6442(2)$ & \\
\hline $\mathrm{H} 10$ & 1.27600 & -0.07270 & 0.63370 & 0.0320 \\
\hline C11 & $1.1465(2)$ & $0.0753(2)$ & $0.5349(2)$ & \\
\hline $\mathrm{H} 11$ & 1.17970 & 0.05050 & 0.44910 & 0.0310 \\
\hline C11A & $1.0381(2)$ & $0.18897(19)$ & $0.5464(2)$ & \\
\hline C12 & $0.9795(2)$ & $0.2677(2)$ & $0.4341(2)$ & \\
\hline $\mathrm{H} 12$ & 1.01190 & 0.24520 & 0.34690 & 0.0300 \\
\hline $\mathrm{C} 12 \mathrm{~A}$ & $0.8751(2)$ & $0.37764(19)$ & $0.4487(2)$ & \\
\hline C13A & $0.7141(2)$ & $0.56567(18)$ & $0.3434(2)$ & \\
\hline C14 & $0.6648(2)$ & $0.6440(2)$ & $0.2254(2)$ & \\
\hline C16 & $0.7493(3)$ & $0.9155(2)$ & $-0.0921(2)$ & \\
\hline $\mathrm{H} 16 \mathrm{~A}$ & 0.70010 & 101.000 & -0.12700 & 0.0570 \\
\hline H16B & 0.82320 & 0.89600 & -0.17750 & 0.0570 \\
\hline $\mathrm{H} 16 \mathrm{C}$ & 0.79890 & 0.91990 & -0.02780 & 0.0570 \\
\hline C17 & $0.5488(3)$ & $0.7870(2)$ & $-0.0972(3)$ & \\
\hline
\end{tabular}




\begin{tabular}{ccccc}
\hline H17A & 0.47110 & 0.71120 & -0.03540 & 0.0670 \\
H17B & 0.61640 & 0.76230 & -0.18200 & 0.0670 \\
H17C & 0.50290 & 0.88330 & -0.13320 & 0.0670 \\
N13 & $0.82020(19)$ & $0.45758(17)$ & $0.33634(18)$ & \\
O1 & $0.49019(16)$ & $0.74520(15)$ & $0.60577(15)$ & \\
O2 & $0.66332(15)$ & $0.55405(14)$ & $0.71123(14)$ & \\
O3 & $0.52435(16)$ & $0.82963(15)$ & $0.11834(15)$ & \\
Cl1 & $0.82140(7)$ & $0.37284(5)$ & $0.06795(6)$ & \\
H1 & $0.548(3)$ & $0.690(3)$ & $0.658(3)$ & $0.052(8)$ \\
H13 & $0.847(2)$ & $0.427(2)$ & $0.263(3)$ & $0.030(6)$ \\
\hline
\end{tabular}

Tabelle 21: $\quad$ Atomkoordinaten und äquivalente isotrope Auslenkungsparameter $\left[\AA^{2}\right]$ für rac-114. U(eq) ist definiert als ein Drittel der Spur orthogonaler $\mathrm{U}_{\mathrm{ij}}$-Tensors.

\begin{tabular}{ccccccc}
\hline Atom & $\mathbf{U}_{11}$ & $\mathbf{U}_{22}$ & $\mathbf{U}_{33}$ & $\mathbf{U}_{12}$ & $\mathbf{U}_{13}$ & $\mathbf{U}_{23}$ \\
\hline C1X & $0.021(2)$ & $0.0172(19)$ & $0.0175(18)$ & $-0.0015(15)$ & $-0.0084(17)$ & $-0.0049(14)$ \\
C15X & $0.0270(18)$ & $0.0194(14)$ & $0.0191(14)$ & $0.0040(11)$ & $-0.0109(12)$ & $-0.0072(10)$ \\
C1Y & $0.037(6)$ & $0.021(4)$ & $0.021(4)$ & $-0.003(4)$ & $-0.016(4)$ & $-0.004(3)$ \\
C15Y & $0.034(4)$ & $0.025(3)$ & $0.024(3)$ & $0.005(3)$ & $-0.013(3)$ & $-0.007(2)$ \\
C2 & $0.0541(14)$ & $0.0311(10)$ & $0.0305(11)$ & $0.021(1)$ & $-0.0283(10)$ & $-0.0188(9)$ \\
C3A & $0.0263(10)$ & $0.0209(8)$ & $0.0254(10)$ & $-0.0003(7)$ & $-0.0140(8)$ & $-0.0060(7)$ \\
C4 & $0.0213(10)$ & $0.0236(9)$ & $0.0249(10)$ & $0.0051(7)$ & $-0.0068(8)$ & $-0.0085(8)$ \\
C5 & $0.021(1)$ & $0.0233(9)$ & $0.0197(9)$ & $-0.0005(7)$ & $-0.0034(7)$ & $-0.0079(7)$ \\
C5A & $0.0219(10)$ & $0.0204(9)$ & $0.0201(9)$ & $0.0006(7)$ & $-0.0077(8)$ & $-0.0077(7)$ \\
C6 & $0.0196(9)$ & $0.0207(8)$ & $0.0189(9)$ & $-0.0028(7)$ & $-0.0037(7)$ & $-0.0076(7)$ \\
C6A & $0.0210(9)$ & $0.0205(8)$ & $0.0195(9)$ & $-0.0014(7)$ & $-0.0070(7)$ & $-0.0072(7)$ \\
C7 & $0.0233(10)$ & $0.0231(9)$ & $0.0167(9)$ & $-0.0006(7)$ & $-0.0060(7)$ & $-0.0084(7)$ \\
C7A & $0.023(1)$ & $0.0217(9)$ & $0.0198(9)$ & $-0.0017(7)$ & $-0.0075(8)$ & $-0.0065(7)$ \\
C8 & $0.0289(10)$ & $0.0255(9)$ & $0.0202(9)$ & $0.0000(8)$ & $-0.0098(8)$ & $-0.0080(8)$ \\
C9 & $0.0285(11)$ & $0.0253(9)$ & $0.0248(10)$ & $0.0015(8)$ & $-0.0147(8)$ & $-0.0053(8)$ \\
C10 & $0.0273(10)$ & $0.0222(9)$ & $0.0305(10)$ & $0.0057(8)$ & $-0.0120(8)$ & $-0.0097(8)$ \\
C11 & $0.0292(11)$ & $0.0251(9)$ & $0.0235(10)$ & $0.0048(8)$ & $-0.0093(8)$ & $-0.0111(8)$
\end{tabular}




\begin{tabular}{ccccccc}
\hline C11A & $0.0237(10)$ & $0.0197(8)$ & $0.0208(9)$ & $0.0003(7)$ & $-0.0081(8)$ & $-0.0067(7)$ \\
C12 & $0.0317(11)$ & $0.0253(9)$ & $0.0203(9)$ & $0.0050(8)$ & $-0.0099(8)$ & $-0.0125(7)$ \\
C12A & $0.026(1)$ & $0.0207(8)$ & $0.0203(9)$ & $0.0016(7)$ & $-0.0105(8)$ & $-0.0079(7)$ \\
C13A & $0.0265(10)$ & $0.0179(8)$ & $0.0227(9)$ & $0.0021(7)$ & $-0.0116(8)$ & $-0.0082(7)$ \\
C14 & $0.0337(11)$ & $0.0228(9)$ & $0.0251(10)$ & $0.0048(8)$ & $-0.0153(9)$ & $-0.0119(8)$ \\
C16 & $0.0415(13)$ & $0.0449(12)$ & $0.0322(12)$ & $0.0161(10)$ & $-0.0175(10)$ & $-0.0199(10)$ \\
C17 & $0.0731(18)$ & $0.0341(11)$ & $0.0491(14)$ & $0.0187(11)$ & $-0.0453(13)$ & $-0.0207(10)$ \\
N13 & $0.039(1)$ & $0.0281(8)$ & $0.0230(8)$ & $0.0139(7)$ & $-0.0176(8)$ & $-0.0167(7)$ \\
O1 & $0.0325(8)$ & $0.0335(7)$ & $0.0216(7)$ & $0.0126(6)$ & $-0.0080(6)$ & $-0.0131(6)$ \\
O2 & $0.0289(8)$ & $0.0306(7)$ & $0.0186(6)$ & $0.0071(5)$ & $-0.0078(6)$ & $-0.0136(5)$ \\
O3 & $0.0384(9)$ & $0.0302(7)$ & $0.0279(7)$ & $0.0129(6)$ & $-0.0196(6)$ & $-0.0126(6)$ \\
C11 & $0.0593(4)$ & $0.0301(3)$ & $0.0330(3)$ & $0.0188(2)$ & $-0.0267(3)$ & $-0.0198(2)$ \\
\hline
\end{tabular}

Tabelle 22: $\quad$ Anisotrope Auslenkungsparameter $\left[\AA^{2} \times 10^{3}\right]$ für rac-114.

\begin{tabular}{|c|c|c|c|}
\hline Atome 1,2 & Bindungslänge [ppm] & Atome 1,2 & Bindungslänge [ppm] \\
\hline $\mathrm{C} 1 \mathrm{X}-\mathrm{C} 15 \mathrm{X}$ & $1.533(5)$ & $\mathrm{C} 5 \mathrm{~A}-\mathrm{C} 6$ & $1.439(3)$ \\
\hline $\mathrm{C} 1 \mathrm{X}-\mathrm{C} 14$ & $1.561(4)$ & $\mathrm{C} 6-\mathrm{O} 2$ & $1.259(2)$ \\
\hline $\mathrm{C} 1 \mathrm{X}-\mathrm{C} 2$ & $1.580(4)$ & $\mathrm{C} 6-\mathrm{C} 6 \mathrm{~A}$ & $1.464(2)$ \\
\hline $\mathrm{C} 15 \mathrm{X}-\mathrm{Cl} 1$ & $1.821(3)$ & $\mathrm{C} 6 \mathrm{~A}-\mathrm{C} 7$ & $1.385(3)$ \\
\hline $\mathrm{C} 1 \mathrm{Y}-\mathrm{C} 15 \mathrm{Y}$ & $1.469(12)$ & $\mathrm{C} 6 \mathrm{~A}-\mathrm{C} 12 \mathrm{~A}$ & $1.421(2)$ \\
\hline $\mathrm{C} 1 \mathrm{Y}-\mathrm{C} 14$ & $1.498(8)$ & $\mathrm{C} 7-\mathrm{C} 7 \mathrm{~A}$ & $1.404(3)$ \\
\hline $\mathrm{C} 1 \mathrm{Y}-\mathrm{C} 2$ & $1.660(9)$ & $\mathrm{C} 7 \mathrm{~A}-\mathrm{C} 8$ & $1.420(3)$ \\
\hline $\mathrm{C} 15 \mathrm{Y}-\mathrm{Cl} 1$ & $1.878(6)$ & $C 7 A-C 11 A$ & $1.433(2)$ \\
\hline $\mathrm{C} 2-\mathrm{O} 3$ & $1.475(2)$ & $\mathrm{C} 8-\mathrm{C} 9$ & $1.362(3)$ \\
\hline $\mathrm{C} 2-\mathrm{C} 16$ & $1.502(3)$ & $\mathrm{C} 9-\mathrm{C} 10$ & $1.418(3)$ \\
\hline $\mathrm{C} 2-\mathrm{C} 17$ & $1.513(3)$ & $\mathrm{C} 10-\mathrm{C} 11$ & $1.358(3)$ \\
\hline $\mathrm{C} 3 \mathrm{~A}-\mathrm{O} 3$ & $1.354(2)$ & $\mathrm{C} 11-\mathrm{C} 11 \mathrm{~A}$ & $1.427(3)$ \\
\hline $\mathrm{C} 3 \mathrm{~A}-\mathrm{C} 4$ & $1.384(3)$ & $\mathrm{C} 11 \mathrm{~A}-\mathrm{C} 12$ & $1.402(3)$ \\
\hline $\mathrm{C} 3 \mathrm{~A}-\mathrm{C} 14$ & $1.389(3)$ & $\mathrm{C} 12-\mathrm{C} 12 \mathrm{~A}$ & $1.382(3)$ \\
\hline $\mathrm{C} 4-\mathrm{C} 5$ & $1.377(3)$ & $\mathrm{C} 12 \mathrm{~A}-\mathrm{N} 13$ & $1.382(2)$ \\
\hline $\mathrm{C5}-\mathrm{O} 1$ & $1.341(2)$ & $\mathrm{C} 13 \mathrm{~A}-\mathrm{N} 13$ & $1.371(2)$ \\
\hline
\end{tabular}




$\begin{array}{llll}\mathrm{C} 5-\mathrm{C} 5 \mathrm{~A} & 1.431(2) & \mathrm{C} 13 \mathrm{~A}-\mathrm{C} 14 & 1.393(3) \\ \mathrm{C} 5 \mathrm{~A}-\mathrm{C} 13 \mathrm{~A} & 1.426(2) & \end{array}$

Tabelle 23: Bindungslängen für rac-114.

\begin{tabular}{|c|c|c|c|}
\hline Atome 1-2-3 & Bindungswinkel $\left[{ }^{\circ}\right]$ & Atome 1-2-3 & Bindungswinkel $\left[{ }^{\circ}\right]$ \\
\hline $\mathrm{C} 15 \mathrm{X}-\mathrm{C} 1 \mathrm{X}-$ & $114.8(3)$ & $\mathrm{C} 5 \mathrm{~A}-\mathrm{C} 6-\mathrm{C} 6 \mathrm{~A}$ & $117.48(15)$ \\
\hline$C 15 X-C 1 X-C 2$ & $109.8(3)$ & $\mathrm{C} 7-\mathrm{C} 6 \mathrm{~A}-\mathrm{C} 12 \mathrm{~A}$ & 119.32(16) \\
\hline $\mathrm{C} 14-\mathrm{C} 1 \mathrm{X}-\mathrm{C} 2$ & $99.1(2)$ & $\mathrm{C} 7-\mathrm{C} 6 \mathrm{~A}-\mathrm{C} 6$ & $121.03(16)$ \\
\hline $\mathrm{C} 1 \mathrm{X}-\mathrm{C} 15 \mathrm{X}-\mathrm{Cl} 1$ & $110.7(2)$ & $\mathrm{C} 12 \mathrm{~A}-\mathrm{C} 6 \mathrm{~A}-\mathrm{C} 6$ & 119.65(16) \\
\hline $\mathrm{C} 15 \mathrm{Y}-\mathrm{C} 1 \mathrm{Y}-$ & $117.5(7)$ & $\mathrm{C} 6 \mathrm{~A}-\mathrm{C} 7-\mathrm{C} 7 \mathrm{~A}$ & $121.66(16)$ \\
\hline $\mathrm{C} 15 \mathrm{Y}-\mathrm{C} 1 \mathrm{Y}-\mathrm{C} 2$ & $103.5(6)$ & $\mathrm{C} 7-\mathrm{C} 7 \mathrm{~A}-\mathrm{C} 8$ & $122.64(16)$ \\
\hline $\mathrm{C} 14-\mathrm{C} 1 \mathrm{Y}-\mathrm{C} 2$ & $98.3(5)$ & $\mathrm{C} 7-\mathrm{C} 7 \mathrm{~A}-\mathrm{C} 11 \mathrm{~A}$ & $118.42(16)$ \\
\hline $\mathrm{C} 1 \mathrm{Y}-\mathrm{C} 15 \mathrm{Y}-\mathrm{Cl} 1$ & $108.8(5)$ & $\mathrm{C} 8-\mathrm{C} 7 \mathrm{~A}-\mathrm{C} 11 \mathrm{~A}$ & 118.94(16) \\
\hline $\mathrm{O} 3-\mathrm{C} 2-\mathrm{C} 16$ & $107.57(15)$ & $\mathrm{C} 9-\mathrm{C} 8-\mathrm{C} 7 \mathrm{~A}$ & 121.11(17) \\
\hline $\mathrm{O} 3-\mathrm{C} 2-\mathrm{C} 17$ & $105.24(18)$ & $\mathrm{C} 8-\mathrm{C} 9-\mathrm{C} 10$ & $120.14(17)$ \\
\hline $\mathrm{C} 16-\mathrm{C} 2-\mathrm{C} 17$ & 111.87(19) & $\mathrm{C} 11-\mathrm{C} 10-\mathrm{C} 9$ & $120.46(17)$ \\
\hline $\mathrm{O} 3-\mathrm{C} 2-\mathrm{C} 1 \mathrm{x}$ & 107.70(19) & $\mathrm{C} 10-\mathrm{C} 11-\mathrm{C} 11 \mathrm{~A}$ & 121.33(17) \\
\hline $\mathrm{C} 16-\mathrm{C} 2-\mathrm{C} 1 \mathrm{X}$ & $104.2(2)$ & $\mathrm{C} 12-\mathrm{C} 11 \mathrm{~A}-\mathrm{C} 11$ & $122.38(16)$ \\
\hline $\mathrm{C} 17-\mathrm{C} 2-\mathrm{C} 1 \mathrm{X}$ & $119.7(2)$ & $\mathrm{C} 12-\mathrm{C} 11 \mathrm{~A}-\mathrm{C} 7 \mathrm{~A}$ & 119.61(16) \\
\hline $\mathrm{O} 3-\mathrm{C} 2-\mathrm{C} 1 \mathrm{Y}$ & $96.2(4)$ & $\mathrm{C} 11-\mathrm{C} 11 \mathrm{~A}-\mathrm{C} 7 \mathrm{~A}$ & $118.01(16)$ \\
\hline $\mathrm{C} 16-\mathrm{C} 2-\mathrm{C} 1 \mathrm{Y}$ & $126.7(4)$ & $\mathrm{C} 12 \mathrm{~A}-\mathrm{C} 12-$ & $120.78(16)$ \\
\hline $\mathrm{C} 17-\mathrm{C} 2-\mathrm{C} 1 \mathrm{Y}$ & $106.3(3)$ & $\mathrm{N} 13-\mathrm{C} 12 \mathrm{~A}-\mathrm{C} 12$ & $120.69(16)$ \\
\hline $\mathrm{O} 3-\mathrm{C} 3 \mathrm{~A}-\mathrm{C} 4$ & $121.27(16)$ & $\mathrm{N} 13-\mathrm{C} 12 \mathrm{~A}-\mathrm{C} 6 \mathrm{~A}$ & 119.13(16) \\
\hline $\mathrm{O} 3-\mathrm{C} 3 \mathrm{~A}-\mathrm{C} 14$ & $113.44(16)$ & $\mathrm{C} 12-\mathrm{C} 12 \mathrm{~A}-\mathrm{C} 6 \mathrm{~A}$ & $120.18(16)$ \\
\hline $\mathrm{C} 4-\mathrm{C} 3 \mathrm{~A}-\mathrm{C} 14$ & $125.27(17)$ & $\mathrm{N} 13-\mathrm{C} 13 \mathrm{~A}-\mathrm{C} 14$ & $121.65(16)$ \\
\hline $\mathrm{C} 5-\mathrm{C} 4-\mathrm{C} 3 \mathrm{~A}$ & $117.00(16)$ & $\mathrm{N} 13-\mathrm{C} 13 \mathrm{~A}-\mathrm{C} 5 \mathrm{~A}$ & $118.38(16)$ \\
\hline $\mathrm{O} 1-\mathrm{C} 5-\mathrm{C} 4$ & 119.12(16) & $\mathrm{C} 14-\mathrm{C} 13 \mathrm{~A}-\mathrm{C} 5 \mathrm{~A}$ & 119.95(16) \\
\hline $\mathrm{O} 1-\mathrm{C} 5-\mathrm{C} 5 \mathrm{~A}$ & 119.64(16) & $\mathrm{C} 3 \mathrm{~A}-\mathrm{C} 14-\mathrm{C} 13 \mathrm{~A}$ & $117.57(16)$ \\
\hline $\mathrm{C} 4-\mathrm{C} 5-\mathrm{C} 5 \mathrm{~A}$ & $121.24(16)$ & $\mathrm{C} 3 \mathrm{~A}-\mathrm{C} 14-\mathrm{C} 1 \mathrm{Y}$ & $103.9(4)$ \\
\hline $\mathrm{C} 13 \mathrm{~A}-\mathrm{C} 5 \mathrm{~A}-\mathrm{C} 5$ & $118.89(16)$ & $\mathrm{C} 13 \mathrm{~A}-\mathrm{C} 14-\mathrm{C} 1 \mathrm{Y}$ & $136.1(4)$ \\
\hline$C 13 A-C 5 A-C 6$ & $120.97(15)$ & $\mathrm{C} 3 \mathrm{~A}-\mathrm{C} 14-\mathrm{C} 1 \mathrm{X}$ & $109.7(2)$ \\
\hline
\end{tabular}




$\begin{array}{lccc}\mathrm{C} 5-\mathrm{C} 5 \mathrm{~A}-\mathrm{C} 6 & 120.13(16) & \mathrm{C} 13 \mathrm{~A}-\mathrm{C} 14-\mathrm{C} 1 \mathrm{X} & 131.8(2) \\ \mathrm{O} 2-\mathrm{C} 6-\mathrm{C} 5 \mathrm{~A} & 122.30(16) & \mathrm{C} 13 \mathrm{~A}-\mathrm{N} 13- & 124.35(16) \\ \mathrm{O} 2-\mathrm{C} 6-\mathrm{C} 6 \mathrm{~A} & 120.21(16) & \mathrm{C} 3 \mathrm{~A}-\mathrm{O} 3-\mathrm{C} 2 & 108.27(14)\end{array}$

Tabelle 24: $\quad$ Bindungswinkel für rac-114.

\begin{tabular}{ccccc}
\hline Atome D,H,A & Dist. D,H [Å] & Dist. H,A [Å] & Dist. D,A [Å] & Angle D,H,A [ $\left.{ }^{\circ}\right]$ \\
\hline $\mathrm{N} 13-\mathrm{H} 13-\mathrm{Cl} 1$ & $0.87(2)$ & $2.41(2)$ & $3.2273(16)$ & $157.2(19)$ \\
$\mathrm{O} 1-\mathrm{H} 1-\mathrm{O} 2$ & $0.90(3)$ & $1.68(3)$ & $2.5334(19)$ & $158 .(3)$ \\
\hline
\end{tabular}

Tabelle 25: $\quad$ Wasserstoffbrückenbindungen für rac-114. 


\section{In-vitro-Zytotoxizitätsassays}

Die Zytotoxizität der synthetisierten seco-Drugs und Prodrugs wurde mit Hilfe des HTCFA-Assays an humanen Bronchialkarzinomzellen der Linie A549 bestimmt. Angegeben sind die aus mindestens drei voneinander unabhängig durchgeführten Experimenten gemittelten relativen Klonbildungsraten (Kapitel D1.8.1).

Die Untersuchungen wurden von Dr. I. Schuberth, A. Rübeling und A. Herdlitschke in der Abteilung für Zellkultur des Instituts für Organische und Biomolekulare Chemie der Georg-August-Universität Göttingen durchgeführt.

2.1 Ergebnisse des seco-Drugs rac-114

\begin{tabular}{cc}
\hline $\begin{array}{c}\text { Konzentration } \\
\text { [nM] }\end{array}$ & Klonbildungsrate [\%] \\
\hline 0 & 100 \\
2.633 & 105.66 \\
26.33 & 106.13 \\
131.63 & 94.91 \\
263.27 & 86.93 \\
658.17 & 75.72 \\
1316 & 37.51 \\
1974.5 & 8.22 \\
2632.7 & 5.44 \\
3949.03 & 1.24 \\
4607.2 & 0.52 \\
5265.4 & 0.21
\end{tabular}

Tabelle 26: In-vitro-Zytotoxizitätsuntersuchungen des seco-Drugs rac-114. 


\section{Abkürzungen und Akronyme}

Ac

ADEPT

Äq.

aq.

ber.

$\mathrm{Bu}$

BuLi

CBI

CBIQ

$\mathrm{Cl}$

COSY

CPI

CPyl

CT

Cys

DABCO

DC

DCE

DCM

DIPEA

DMAI

DMBI

DMDO

DMEM

DMF

DMMI

DMSO

DNA

$\mathrm{EDC} \cdot \mathrm{HCl}$
Acetyl

antibody-directed enzyme prodrug therapy

Äquivalente

wäßrig

berechnet

Butyl

Butyllithium

Cyclopropabenzoindol

Cyclopropabenzochinolin

Cyclopropaindol

correlated spectroscopy

Cyclopropapyrroloindol

7-Methoxycarbonyl-cyclopropapyridoindol

Computertomographie

Cystein

1,4-Diazabicyclo[2.2.2]octan

Dünnschichtchromatographie

1,2-Dichlorethan

Dichlormethan

$N, N$-Diisopropylethylamin

5-[2-(N,N-Dimethylamino)-ethoxy]-1H-indol

5-[2-(N,N-Dimethylamino)-ethoxy]-6-benzyloxy-1H-indol

Dimethyldioxiran

Dulbeccos Modified Eagles Medium

$N, N$-Dimethylformamid

5-(2-N,N-Dimethylaminoethoxy)-6-methoxy-1H-indol

Dimethylsulfoxid

Desoxyribonucleinsäure

$N$-(3-Dimethylaminopropyl)-N'-ethylcarbodiimid-Hydrochlorid 


\begin{tabular}{|c|c|}
\hline ESI & Elektrospray-Ionisation \\
\hline Et & Ethyl \\
\hline EtOAc & Essigsäureethylester \\
\hline gef. & gefunden \\
\hline ges. & gesättigt \\
\hline HOAT & 1-Hydroxy-7-azabenzotriazol \\
\hline HPLC & high performance (pressure) liquid chromatography \\
\hline HRMS & high resolution mass spectrometry \\
\hline HSQC & heteronuclear single-quantum correlation \\
\hline HTCFA & human tumor colony forming ability \\
\hline $\mathrm{Hz}$ & Hertz \\
\hline$i$ & iso \\
\hline $\mathrm{IC}_{50}$ & $\begin{array}{l}\text { inhibitory concentration; Toxinkonzentration, bei der das } \\
\text { Zellwachstum um 50\% unterbunden wird }\end{array}$ \\
\hline in vitro & $\begin{array}{l}\text { außerhalb lebender Organismen; hier: Versuche an lebenden } \\
\text { Zellen in Zellkultur }\end{array}$ \\
\hline in vivo & im lebenden Organismus \\
\hline IR & Infrarot-Spektroskopie \\
\hline$m$ & meta \\
\hline kat. & katalytische Mengen \\
\hline konz. & konzentriert \\
\hline$m C P B A$ & meta-Chlorperbenzoesäure \\
\hline Me & Methyl \\
\hline $\mathrm{MeCN}$ & Acetonitril \\
\hline $\mathrm{MeOH}$ & Methanol \\
\hline MMI & 5-Methoxy-1H-indol \\
\hline MPMI & $\begin{array}{l}\text { 5-[2-(N-Methyl- } N \text {-propargylamino)ethoxy]-6-methoxy-1H- } \\
\text { indol }\end{array}$ \\
\hline MS & Massenspektrometrie \\
\hline $\mathrm{MsCl}$ & Mesylchlorid \\
\hline NBS & $N$-Bromsuccinimid \\
\hline NMO & $N$-Methylmorpholin- $N$-oxid \\
\hline NMR & nuclear magnetic resonance \\
\hline
\end{tabular}




$\begin{array}{ll}0 & \text { ortho } \\ p & \text { para } \\ \mathrm{P} & n \text {-Pentan } \\ p \text {-TsOH } & \text { para-Toluolsulfonsäure } \\ \mathrm{PE} & \text { Petrolether } \\ \mathrm{Ph} & \text { Phenyl } \\ \mathrm{PyBOP} & \text { Benzotriazol-1-yl-oxytripyrrolidinophosphoniumhexafluoro- } \\ \mathrm{R} & \text { phosphat } \\ t_{\mathrm{R}} & \text { Retentionswert für DC } \\ \mathrm{RP} & \text { Retentionszeit für HPLC } \\ \mathrm{RT} & \text { reversed-phase (Umkehrphase) } \\ \text { seco } & \text { Raumtemperatur } \\ t & \text { Präfix zur Bezeichnung von Vorstufen zyklischer Verbindungen } \\ \text { TMEDA } & \text { (Ringöffnung) } \\ \text { TsCl } & \text { tertiär } \\ \text { THF } & \text { Tetramethylethylenediamin } \\ \text { TMS-NCS } & \text { Tosylchlorid } \\ \text { UV } & \text { Tetrahydrofuran } \\ & \text { Trimethylsilylisothiocyanat } \\ & \text { Ultraviolett-Spektroskopie } \\ & \end{array}$




\section{Literaturverzeichnis}

3

D. J. Newman, Nat. Prod. Rep. 2000, 17, 215-234.

G. M. Cragg, Natural Product Chemistry for Drug Discovery 2009, 3-27.

J. Drews, Drug Discovery 2000, 287, 1960-1964.

M. Gordaliza, Clinical \& Translational Oncology 2007, 9(12), 767-776.

D. J. Newman, J. Nat. Prod. 2007, 70, 461-477.

S. Borman, Chem. Eng. News 2002, Jan 14, 23-24.

L. F. Tietze, Angew. Chem. 2003, 115, 4128-4160.

Kapitel B2 - B4 wurden in weiten Teilen übernommen aus: a) K. Schmuck, Dissertation, Göttingen 2011; b) J. M. von Hof, Dissertation, Göttingen 2009; c) B. Krewer, Disseration, Göttingen 2008; d) F. Major, Dissertation, Göttingen 2006.

W. Pschyrembel, Pschyrembel, de Gruyter, 261. Auflage, Berlin 2007, S. 714, 1315.

J. Rassow, Biochemie, Georg Thieme Verlag KG, Stuttgart 2008, S. $522 \mathrm{ff}$.

E. Mutschler, G. Geisslinger, H. K. Kroemer, P. Ruth, M. Schäfer-Korting, Mutschler Arzneimittelwirkungen, Wissenschaftliche Verlagsgesellschaft mbH, 9. Auflage, Stuttgart 2008, S. 907, 919, 923.

a) S. Grimm, Chem. Unserer Zeit 2003, 37, 172-178; b) A. Lawen, Bioassays 2003, 25, 888-896; c) A. Gewies, ApoReview 2003, 1-26.

W. Burkart, Spektrum der Wissenschaft 1994, 12, 112-120.

H.-G. Neumann, Chemie in unserer Zeit 1991, 25, 102-107.

D. M. Prescott, A. S. Flexer, Krebs, Spektrum der Wissenschaft Verlagsgesell-schaft, Heidelberg, 1990.

G. Löffler, Basiswissen Biochemie mit Pathobiochemie, Springer Verlag, Berlin, 2000.

P. Tiollais, M. Buendia in Krebs - Forschung, Diagnostik, Therapie, Spektrum Akademischer Verlag, Heidelberg, 1992.

a) R. A. Weinberg in Spektrum der Wissenschaft Spezial: Krebsmedizin, Spektrum der Wissenschaft Verlagsgesellschaft, Heidelberg, 1996; b) W. W. Gibbs in Spektrum der Wissenschaft Spezial: Krebsmedizin II, Spektrum der Wissenschaft Verlagsgesellschaft, Heidelberg, 2003. 
H. Varmus, R. A. Weinberg, Gene und Krebs - Biologische Wurzeln der Tumorentstehung, Spektrum Akademischer Verlag, Heidelberg, 1996.

(1)

a) R. A. Weinberg, Science 1985, 230, 770-776; b) L. Römer, C. Klein, A. Dehner, H. Kessler, J. Buchner, Angew. Chem. 2006, 118, 6590-6611.

O. D. Schärer, Angew. Chem. 2003, 115, 3052-3082.

K. E. Hellström, I. Hellström, Tumor Antigens, in J. R. Bertino, Encyclopedia of Cancer, 1. Auflage, Academic Press, San Diego 1997.

a) S. Kumar, M. Shelley, C. Harrison, B. Coles, T. J. Wilt, M. D. Mason, Cochrane database Syst. Rev. 2006, 4, CD006019; b) C.-H. Lai, H.-J- Huang, Curr. Opin. Obstetr. and Gynecol. 2006, 18, 29-34; c) S. B. Decruze, J. A. Green, Int. J. Gynecol. Canc. 2007, 17, 964-978; d) R. E. Greene, J. Pharmacy Practice 2008, 21, 36-45.

a) Spektrum der Wissenschaft Spezial 5: Krebsmedizin, Spektrum Akademischer Verlag, Heidelberg, 1996; b) E. Jäger, D. Jäger, A. Knuth, Int. J. Cancer 2003, 106, 817-820; c) L. Gattinoni, D. J. Powell Jr.; S. A. Rosenberg, N. P. Restifo, Nat. Rev. Immunol. 2006, 6, 383-393.

a) C. Nieder, N. Wieden Andratschke, M. Molls, Cancer Treatment Rev. 2003, 32, 348-364; b) C. Verhoef, J. H. W. de Wilt, H. M. W. Verheul, Curr. Pharm. Des. 2006, 12, 2623-2630; c) F. Hillen, A. W. Griffioen, Cancer and Metastasis Rev. 2007, 26, 489-502.

a) S. P. Davies, H. Reddy, M. Caivano, P. Cohen, Biochem. J. 2000, 351, 95-105; b) M. Deininger, E. Buchdunger, B. J. Druker, Blood 2005, 105, 2640-2653; c) V. Gandhi, J. M. Kilpatrick, W. Plunkett, M. Ayres, L. Harman, M. Du, S. Bantia, J. Davisson, W. G. Wierda, S. Faderl, H. Kantarjian, D. Thomas, Blood 2005, 106, 4253-4260.

K. Aktories, U. Förstermann, F. Hofmann, K. Starke, Allgemeine und spezielle Pharmakologie und Toxikologie, Urban \& Fischer, 10. Auflage, München 2009, S. 233 f., 948, 970.

a) O. M. Friedman, A. M. Seligman, J. Am. Chem. Soc. 1954, 76, 655-658; b) H. Arnold, F. Bourseaux, Angew. Chem. 1958, 70, 539-544; c) H. Arnold, F. Bourseaux, N. Brock, Nature 1958, 181, 931.

a) A. I. Pinto, S. J. Lippard, Biochim. Biophys. Acta 1985, 780, 167-180; b) S. E. Sherman, S. J. Lippard, Chem. Rev. 1987, 87, 1153-1181; c) J. P. Caradonna, S. J. Lippard, Inorg. Chem. 1988, 27, 1454-1466.

C. Bystroff, S. J. Oatley, J. Kraut, Biochemistry 1990, 29, 3263-3277.

W.B. Parker, Chem. Rev. 2009, 109, 2880-2893.

a) J. Rohr, Angew. Chem. 1997, 109, 2284-2289; b) K. C. Nicolaou, R. K. Guy, P. Potier, Sci. Am. 1996, 272, 84-88; c) M. E. Wall, M. C. Wani, Cancer Res. 1995, 55, 753-760; d) K. C. Nicolaou, W.-M. Dai, R. K. Guy, Angew. Chem. 1994, 106, 38-69; e) A. G. Chaudhary, M. M. Gharpure, J. M. Rimoldi, M. D. 
Chordia, A. A. L. Gunatilaka, D. G. I. Kingston, S. Grover, C. M. Lin, E. Hamel, J. Am. Chem. Soc. 1994, 116, 4097-4098; f) K. C. Nicolaou, W.-M. Dai, R. K. Guy, Angew. Chem. 1994, 106, 38-69; g) D. G. I. Kingston, Pharmac. Ther. 1991, 52, 1-34; h) S. B. Horwitz, I. Ringel, J. Nat. Cancer Inst. 1991, 83, 288291; i) M. C. Wani, H. L. Taylor, M. E. Wall, P. Coggon, A. T. McPhail, J. Am. Chem. Soc. 1971, 93, 23252327.

K. Gascoigne, S. Taylor, Journal of Cell Science 2009, 122, 2579-2585.

Y. Pommier, Chem. Rev. 2009, 109, 2894-2902.

H. C.-Funes, C. Coronado, Cardiovasc Toxicol 2007, 7, 56-60.

R. C. Young, R. F. Ozols, C. E. Myers, New Eng. J. Med. 1981, 305, 139-153.

H. ZurHausen, Krebs - Forschung, Diagnostik, Therapie, Spektrum Akad, Vlg., Heidelberg 1992.

a) C. H. Huber, J. Cancer Res. Clin. Oncol. 2004, 130, 367-374; b) M. Dougan, Annu. Rev. Immunol. 2009, 27, 83-117, c) T. M. Kündig, C. Renner, Therapeutische Umschau 2006, 63, 262-266.

a) C. H. June, J. Clin. Invest. 2007, 117, 1204-1212; b) C. H. June, J. Clin. Invest. 2007, 117, 1466-1476.

S. E. McArdle, Cancer Res. 2009, 69, 7157-7159.

a) L. F. Tietze, K. Schmuck, Curr. Pharm. Des. 2011, zur Publikation angenommen; b) L. F. Tietze, B. Krewer, Anti-Cancer Agents Med. Chem. 2009, 9, 304-325; c) L. F. Tietze, B. Krewer, Chem. Biol. Drug Des. 2009, 74, 205-211; d) L. F. Tietze, T. Feuerstein Curr. Pharm. Des. 2003, 9, 2155-2175; e) L. F. Tietze, T. Feuerstein, Aust. J. Chem. 2003, 56, 841-854.

a) K. D. Bagshawe, Br. J. Cancer 1987, 56, 531-532; b) K. D. Bagshawe, Expert Rev. Anticancer Ther. 2006, 6, 1421-1431; c) K. D. Bagshawe, Curr. Drug Targets 2009, 10, 152-157; d) K. D. Bagshawe, S. K. Sharma, R. H. J. Begent, Expert Opin. Biol. Ther. 2004, 4, 1777-1789; e) T. W. Doyle, Pharmacology \& Therapeutics 1999, 83, 67-123; f) P. D. Senter, C. J. Springer, Adv. Drug Delivery Rev. 2001, 53, 247264.

a) L. J. Hanka, A. Dietz, S. A. Gerpheide, S. L. Kuentzel, D. G. Martin, J. Antibiot. 1978, 31, 1211-1217; b)

D. G. Martin, C. Biles, S. A. Gerpheide, L. J. Hanka, W. C. Krueger, J. P. McGovren, S. A. Mizsak, G. L. Neil, J. C. Stewart, J. Visser, J. Antibiot. 1981, 34, 1119-1125.

P. McGroven, G. L. Clarke, E. A. Pratt, T. F. DeKoning, J. Antibiot. 1984, 37, 63-70.

M. Ichimura, T. Ogawa, K. Takahashi, E. Kobayashi, I. Kawamoto, T. Yasuzawa, I. Takahashi, H. Nakano, J. Antibiot. 1990, 43, 1037-1038.

a) Y. Igarashi, K. Futamata, T. Fujita, A. Sekine, H. Senda, H. Naoki, T. Furumai, J. Antibiot. 2003, 56, 107; b) M. S. Tichenor, D. B. Kastrinsky, D. L. Boger, J. Am. Chem. Soc. 2004, 126, 8396-8398. 
a) L. H. Hurley, C.-S. Lee, J. P. McGovren, M. A. Warpehoski, M. A. Mitchell, R. C. Kelly, P. A. Aristoff, Biochemistry 1988, 27, 3886-3892; b) L. H. Hurley, M. A. Warpehoski, C.-S. Lee, J. P. McGovren, T. A. Scahill, R. C. Kelly, M. A. Mitchell, N. A. Wicnienski, I. Gebhard, P. D. Joohnson, V. S. Bradford, J. Am. Chem. Soc. 1990, 112, 4633-4649.

a) Y. Ambroise, D. L. Boger, Bioorg. Med. Chem. 2002, 12, 303-306; b) K. Spiegel, Dissertaion, Triest 2004; c) K. Spiegel, U. Rothlisberger, P. Carloni, J. Phys. Chem. B 2006, 110, 3647-3660.

a) W. C. Tse, D. L. Boger, Chem. Biol. 2004, 11, 1607-1617; b) D. L. Boger, D. L. Hertzog, B. Bollinger, D. S. Johnson, H. Cai, J. Goldberg, P. Turnbull, J. Am. Chem. Soc. 1997, 119, 4977-4986; c) D. L. Boger, B. Bollinger, D. L. Hertzog, D. S. Johnson, H. Cai, P. Mésini, R. M. Garbaccio, Q. Jin, P. A. Kitos, J. Am. Chem. Soc. 1997, 119, 4987-4998; d) D. L. Boger, R. M. Garbaccio, Acc. Chem. Res. 1999, 32, 10431052.

a) K. N. Kirschner, M. Lee, R. C. Stanley, J. P. Bowen, Bioorg. Med. Chem. 2000, 8, 329-335; b) P. Cimino, G. Bifulco, R. Riccio, L. Gomez-Paloma, V. Barone, Org. Biomol. Chem. 2006, 4, 1242-1251.

A. V. Vargiu, P. Ruggerone, A. Magistrato, P. Carloni, Biophys. J. 2008, 94, 550-561.

a) J. P. McGovern, G. L. Clarke, E. A. Pratte, T. F. deKoning, J. Antibiot. 1983, 37, 63-70; b) S. Nagamura, A. Asai, E. Kobayashi, K. Gomi, H. Saito, Bioorg. Med. Chem. 1997, 5, 623-630; c) B. Cacciari, R. Romagnoli, P. G. Baraldi, T. Da Ros, G. Spalluto, Exp. Opin. Ther. Pat. 2000, 10, 1853-1871; d) A. Sato, L. McNulty, K. Cox, S. Kim, A. Scott, K. Daniell, K. Summerville, C. Price, S. Hudson, K. Kiakos, L. A. Hartley, T. Asao, M. Lee, J. Med. Chem. 2005, 48, 3903-3918; e) P. G. Baraldi, A. Bovero, F. Fruttarolo, D. Preti, M. A. Tabrizi, M. G. Pavani, R. Romagnoli, Med. Res. Rev. 2004, 24, 475-528; f) W. A. Denny, Curr. Med. Chem. 2001, 8, 533-544; g) B. S. P. Reddy, S. K. Sharma, J. P. W. Lown, Curr. Med. Chem. 2001, 8, 475-508.

a) D. L. Boger, C. W. Boyce, R. M. Garbaccio, J. A. Goldberg, Chem. Rev. 1997, 97, 787-828; b) D. L. Boger, D. S. Johnson, Angew. Chem. 1996, 108, 1542-1580; c) S. E. Wolkenberg, D. L. Boger, Chem. Rev. 2002, 102, 2477-2496.

a) J. P. Parrish, T. V. Hughes, I. Hwang, D. L. Boger, J. Am. Chem. Soc. 2004, 126, 80-81; b) M. S. Tichenor, K. S. MacMillen, J. S. Stover, S. E. Wolkenberg, M. G. Pavani, L. Zanella, A. N. Zaid, G. Spalluto, T. J. Rayl, I. Hwang, P. G. Baraldi, D. L. Boger, J. Am Chem. Soc. 2007, 129, 14092-14099.

a) P. G. Baraldi, G. Balboni, M. G. Pavani, G. Spalluto, M. A. Tabrizi, E. De Clercq, J. Balzarini, T. Bando, H. S., R. Romagnoli, J. Med. Chem. 2001, 44, 2536-2543; b) J. P. Parrish, D. B. Kastrinsky, F. Stauffer, M. P. Hedrick, I. Hwang, D. L. Boger, Bioorg. Med. Chem. 2003, 11, 3815-3838; c) Y. Wang, L. Li, W. Ye, Z. Tian, W. Jiang, H. Wang, S. C. Wright, J. W. Larrick, J. Med. Chem. 2003, 46, 634-637. 
a) R. I. Pinto, S. J. Lippard, Biochem. Biophys. Acta 1985, 780, 167-180; b) S. E. Sherman, S. J. Lippard, Chem. Rev. 1987, 87, 1153-1181; c) J. P. Caradonna, S. J. Lippard, Inorg. Chem. 1988, 27, 1454, -1466. a) R. D. Hightower, B. U. Sevin, J. P. Pevras, M. Untch, R. Angioli, H. Averette, Gynecol. Oncol. 1992, 42, 186-190; b) B. J. Foster, P. M. Larusso, E. Poplin, M. Zalupski, M. Valdivieso, A. Wozniak, L. Flaherty, D. A. Kasunic, R. H. Earhart, L. H. Baker, Invest. New Drugs 1996, 13, 321-326; c) H. A. Burris, V. C. Dleras, M. Tunca, R. H. Earhart, J. R. Echardt, G. I. Rodriguez, D. S. Shaffer, S. M. Fields, E. Campbell, L. Scaaf, D. Kasunic, D. D. Von Hoff, Anticancer Drugs 1997, 8, 588-596.

a) L. H. Li, T. F. deKoning, R. C. Kelly, W. C. Krueger, J. P. McGovren, G. E. Padbury, G. L. Petzold, T. L. Wallace, R. J. Ouding, M. D. Prairie, I. Gebhard, Canc. Res. 1992, 52, 4904-4913; b) I. Wolff, K. Bench, J. S. Beijnen, U. Bruntsch, F. Cavalli, J. de Jong, Y. Groot, O. van Tellingen, J. Wanders, C. Sessa, Clin. Canc. Res. 1996, 2, 1717-1723; c) O. van Telligen, C. J. A. Punt, A. Awada, D. J. T. Wagener, M. J. Piccart, Y. Groot, L. J. Scaaf, R. E. C. Henrar, W. J. Nooijen, J. H. Beijnen, Cancer Chemother. Pharmacol. 1998, 41, 377-384.

a) H. C. Pitot, C. Erlichman, J. M. Reid, J. A. Sloan, M. M. Ames, P. G. Bagniewski, P. Atherton-Skaff, A. A. Adjei, J. Rubin, D. Rayson, R. M. Goldberg, Proc. Am. Assoc. Cancer Res. 1999, 40, 91; b) H. C. Pitot, J. M. Reid, J. A. Sloan, M. M. Ames, A. A. Adjei, J. Rubin, P. G. Bagniewski, P. Atherton, D. Rayson, R. M. Goldberg, C. Ehrlichman, Clin. Cancer Res. 2002, 8, 712-717; c) G. H. Schwartz, A. Patnaik, L. A. Hammond, J. Rizzo, K. Berg, D. D. Von Hoff, E. K. Rowinsky, Ann. Oncol. 2003, 14, 775-782.

a) S. R. Alberts, C. Ehrlichman, J. M. Reid, J. A. Sloan, M. M. Ames, R. L. Richardson, R. M. Goldberg, Clin. Canc. Res. 1998, 4, 2111-2117; b) A. Asai, S. Nagamura, E. Kobayashi, K. Gomi, H. Saito, Bioorg. Med. Chem. Lett. 1999, 9, 2995-2998; c) J. Rubin, S. Alberts, V. Suman, H. Pitot, M. Greene, J. Camoriano, Proc. Am. Soc. Clin. Oncol. 2000, 19, abstr. 1198; d) S. N. Markovic, V. J. Suman, A. M. Vokov, T. R. Fitch, D. W. Hillman, A. A. Adjei, S. R. Alberts, J. S. Kaur, T. A. Braich, J. M. Leitch, E. T. Creagan, Am. J. Clin. Oncol. 2002, 25, 308-312.

R. Baird, S. Winstein, J. Am. Chem. Soc. 1963, 85, 567-578.

a) L. F. Tietze, M. Lieb, T. Herzig, F. Haunert, I. Schuberth, Bioorg. Med. Chem. 2001, 9, 1929-1939; b) M. P. Hay, R. F. Anderson, D. M. Ferry, W. R. Wilson, W. A. Denny, J. Med. Chem. 2003, 46, 5533-5545; c) S. C. Jeffrey, M. Y. Torgov, J. B. Andreyka, L. Boddington, C. G. Cerveny, W. A. Denny, K. A. Gordon, D. Gustin, J. Haugen, T. Kline, M. T. Nguyen, P. D. Senter, J. Med. Chem. 2005, 48, 1344-1358.

W. A. Denny, J. Biomed. Biotech. 2003, 1, 48-70. 
a) Y. Wang,; S. C. Wright, J. W. Larrick, United States Patent, Number 5843937, 1998; b) Y. Wang, H. Yuan, S. C. Wright, H. Wang, J. W. Larrick, Bioorg. Med. Chem. 2003, 11, 1569-1575.

a) J. M. von Hof, Dissertation, Göttingen 2009; b) B. Krewer, Dissertation, Göttingen 2008; c) H. Schuster, Dissertation, Göttingen, 2008; d) F. Major, Dissertation, Göttingen, 2006; e) O. Panknin, Dissertation, Göttingen 2004; f) T. Feuerstein, Dissertation, Göttingen 2003; g) F. Colunga, Dissertation, Göttingen 2007; h) A. Fecher, Dissertation, Göttingen 2000; i) T. Herzig, Dissertation, Göttingen 2000. a) L. F. Tietze, T. Herzig, A. Fecher, F. Haunert, I. Schuberth, ChemBioChem 2001, 2, 758-765; b) L. F. Tietze, T. Feuerstein, A. Fecher, F. Haunert, O. Panknin, U. Borchers, I. Schuberth, F. Alves, Angew. Chem. 2002, 114, 785-787; c) L. F. Tietze, T. Herzig, T. Feuerstein, I. Schuberth, Eur. J. Org. Chem. 2002, 1634-1645.

L. F. Tietze, J. M. von Hof, M. Müller, B. Krewer, I. Schuberth, Angew. Chem. 2010, 122, 7494-7497.

K. Schmuck, Dissertation, Göttingen, 2011.

a) G. K. Hughes, Nature 1948, 162, 223-224. b) L. P. Macdonald, Aust. J. Chem. 1966, 19, $275-281$.

a) G. H. Svoboda, Lloydia 1966, 29, 206-224. b) G. H. Svoboda, J. Pharm. Sci. 1966, 55, 758-768.

J. H. Scarffe, Cancer Treat. Rep. 1983, 67, 93-94.

M. Brum-Bousquet, Planta Med. 1988, 54, 470-471.

T.-C. Chou, Phyt. Res. 1989, 3(6), 237-242.

A. Elomri, Chem. Pharm. Bull. 1999, 47(11), 1604-1606.

F. Tillequin, Phytochem. Rev. 2007, 6, 65-79.

a) J.-B. Bongui, Chem. Pharm. Bull. 2005, 53, 1540-1546. b) N. Costes, J. Med. Chem. 2000, 43, 2395-2402. c) T. M. Nguyen, J. Med. Chem. 2006, 49, 5712-5724.

a) A. Elomri, J. Med. Chem. 1996, 43, 2395-2402, b) N. Costes, J. Med. Chem. 2000, 43, 2395-2402, c) M.-H. David-Cordonnier, Biochemistry 2002, 41, 9911-9920.

A. Elomri, J. Med. Chem. 1996, 39, 4762-4766.

H. D. Thi Mai, J. Med. Chem. 2003, 46, 3072-3082.

N. G. Bisset in Alkaloids, Chemical and Biological Perspectives, New York, 1992, S. 1-150.

P. Leon, J. Med. Chem. 1988, 31, 1021-1026.

T. Gaslonde, Chem. Pharm. Bull. 2007, 55(5), 734-738.

a) G. M. Cragg, J. Nat. Prod. 1997, 60, 52-60; b) G. A. Cordell, Phytochemistry 2000, 55, 463-480; c) A. Zeeck, Intermist 2001, 42, 1422-1427. 
H. Shiozawa, J. Antibiot. 1993, 46, 1834-1842.

S. D. Kuduk, Bioorg. Med. Chem. Lett. 1999, 9, 1233-1238.

P. G. Baraldi, Bioorg. Med. Chem. 2007, 15, 17-35.

a) D. L. Boger, Chem. Biol. 2004, 11, 1607; b) S. K. Sharma, Drugs Future 2001, 26, 39.

D. E. Thurston, Chem. Rev. 1994, 94, 433-465.

T. A. Miller, J. Med. Chem. 1997, 40, 3836-3841.

T. Fotsis, Nature 1994, 368, 237-239.

H. E. Skipper, Cancer Research 1964, 24(8), 1295-1302.

C. F. H. Allen, Organic Syntheses 1942, 22, 19-23.

F. Fringuelli, Synth. Comm. 1989, 19, 1939-1943.

P. N. Culshaw, Tetrahedron Letters 1990, 31(17), 2457-2460.

H. Masada, Tetrahedron Letters 1979, 15, 1315-1316.

J.-G. Kim, Synlett 2007, 16, 2501-2504.

A. de Meijere, Chemistry - A European Journal 2005, 11(1), 308-320.

I. Iwai, Chem. Pharm. Bull. 1963, 11, 1042-1049.

J. D. Godfrey, Tetrahedron Lett. 1994, 35(35), 6405-6408.

H. Zhang, Eur. J. Org. Chem. 2003, 1918-1922.

J.-J. Brunet, J. Org. Chem. 1984, 49, 4060-4063.

R. T. Tedeschi, J. Org. Chem 1962, 27, 4323-4326.

R. Tirado, J. Org. Chem. 1993, 58, 5666-5673.

a) R. W. Murray, J. Org. Chem. 1985, 50, 2847-2853. b) R. W. Murray, Chem. Rev. 1989, 89, 11871201.

A. Heins, Diplomarbeit, Göttingen, 2008.

H. E. B. Lempers, Rec. Trav. Chim. Pays-Bas 1996, 115, 542.

V. VanRheenen, Tetrahedron Lett. 1976, 1973-1976.

a) S. Boutefnouchet, J. Med. Chem. 2008, 51, 7287-7297. b) Y. Morimoto, Org. Biomol. Chem., 2008, 6, 1709-1719.

S. Hampel, Diplomarbeit, Göttingen 2006. 
a) Y T. Sakamoto, Angew. Chem. 1996, 108, 818-820 b) T.Sakamoto, J. Am. Chem. Soc. 1998, 120, 4934-4946.

T. Feuerstein, Dissertation, Göttingen 2003.

R. Appel, Angew. Chem. intern. Ed. 1975, 14(12), 801-811.

W. von Lenz, Deutsche medizinische Wochenschrift 1962, 87(24): 1232-1242.

L. F. Tietze, Anti-Cancer Agents Med. Chem. 2009, 9, 304-325.

K. B. Sharpless, Chem. Rev. 1994, 94, 2483-2547.

G. L. Boshart, J. Org. Chem. 1961, 26(7), 2525-2528.

P. Jouin, Tetrahedron 1991, 47(2), 259-270.

W. König, Chem. Ber. 1970, 103, 788-798.

H. Goldstein, Helv. Chim. Acta 1957, 40, 1187-1188.

J.-B. Bongui, Chem. Pharm. Bull. 2005, 53, 1540-1546.

D. B. Capps, J. Med. Chem. 1992, 35, 4770.

P. G. M. Wuts, Greene's Protective Groups in Organic Synthesis, John Wiley \& Sons, 4. Auflage, 2006.

G.-B. Liu, Bioorganic \& Medicinal Chemistry 2009, 17, 5433-5441.

S. L. MacNeil, Org. Lett. 2006, 8(6), 1133-1136.

O. Tabarrini, J. Med. Chem. 2006, 49, 2621-2627.

T. M. Nguyen, J. Med. Chem. 2006, 49, 3383-3394.

E. Weiss, Angew. Chem. Int. Ed. 1993, 32, 1501-1523.

P. Stanetty, J. Org. Chem. 1992, 57, 6833-3837.

Krebs in D2005/2006, Häufigkeiten und Trends, 7. Ausgabe, Berlin 2010, S. 19 f.

J. W.-H. Li, Science 325, 161 (2009), 161-165.

D. D. Perrin, W. L. F. Arnarego, Purif eutschland ication of Laboratory Chemicals, $3^{\text {rd }}$ Ed., Pergamon Press, Oxford, 1988. 


\section{Danksagung}

Für eine erfolgreiche Doktorarbeit ist, und so sollte es auch sein, fundiertes chemisches Können und Wissen die Grundvoraussetzung.

Wer jedoch der Meinung ist, dass diese Eigenschaften ausreichen, um in der Chemie erfolgreich promovieren zu können, der ist entweder ein absolutes Genie, ein sozialer Pflegefall oder hat schlicht und ergreifend keine Ahnung (die ersten beiden Fälle schließen sich dabei nicht aus). Da ich mich zu keiner der drei Kategorien zähle, möchte ich im Folgenden den Menschen danken, die auf gänzlich unterschiedliche Art und Weise zu dem Gelingen dieser Doktorarbeit beigetragen haben.

Bei den Mitarbeitern der analytischen Abteilung des Instituts für Organische und Biomolekulare Chemie, namentlich Herrn Reinhard Machinek, Frau Christiane Siebert, Herrn Martin Weitemeyer, Frau Carola Zolke und Herrn Frank Hambloch, Frau Gabriele Krökel, Frau Györgyi Sommer-Udvarnoki, bedanke ich mich für ihre stets freundliche, hilfsbereite Art und das Ermöglichen meiner zahlreichen Sonderwünsche. Insbesondere im Endspurt wart ihr eine echte Stütze!

Herrn Holm Frauendorf danke ich für seine unvergleichlich zuvorkommende Art, Herrn Olaf Senge für das Messen von HPLC-Proben in Rekordzeit.

Frau Ingrid Schuberth, Frau Anja Herdlitschke und Frau Angela Rübeling aus der Zellbiologie danke ich für die Messung der Zytotoxizitäten sowie für ihre Hilfsbereitschaft und Geduld, wenn es um das Erklären und Diskutieren biologischer Fragen ging.

Den Mitarbeitern der Chemikalienausgabe und der Werkstätten danke ich ebenfalls für ihr großes Engagement und ihre Hilfsbereitschaft bei Spezialanfertigungen und Sonderwünschen jeder Art. Die Elektro- und Kältetechnik war hier ein Ort, an dem besonders gern geholfen wurde.

Unserer Sekretärin Frau Sabine Schacht danke ich für die Erleichterung des bürokratischen Wahnsinns, Frau Martina Pretor danke ich für die Pflege unserer 
Computer und die Unterstützung bei PC-Problemen. Den Mitgliedern der Abteilung Tietze sowie Daniel und seiner Abteilung danke ich für die vielen nützlichen Tipps und Ratschläge.

Für das sorgfältige Korrekturlesen dieser Arbeit danke ich Frank Behrendt, Chris Eichhorst, Sven Heidemann, Iris Heins und Johannes Reiner. Sollten sich immer noch Fehler eingeschlichen haben, eure Schuld ist es nicht!

Neben der universitären Unterstützung war mir das "Leben abseits der Uni" immer wichtig. Da ein Chemiestudium eins der längsten überhaupt ist, war es mir vergönnt über die Jahre mit vielen unterschiedlichen Menschen eine WG teilen zu dürfen. Danke Steffi, Caro, Maren, Pia, Katha und Becci für offene Ohren, Unterstützung, Erheiterung, Verärgerung, neue Ansichten, veraltete Ansichten, tiefgründige Diskussionen, weniger tiefgründige Diskussionen - kurzum alles, was ein WG-Leben so zu bieten hat!

In meiner Zeit in Göttingen hatte ich das Glück, viele gute Freunde gefunden zu haben. Manche Freundschaften, da bin ich mir sicher, werden für ein Leben halten, andere leider recht schnell einschlafen. Annika, Basti, Claudia, Francesco, Frank, Frerk, Futti, Hannes, Julle, Kiki, Lina, Matthias, Miggn, Stefan, Steve, Timo, Tillmann, Wimbo, grüßt euch! Sabine, danke für alles!

Neben meinen Freunden "hier" möchte ich mich noch bei denen "zu Hause" bedanken. Auch wenn wir uns nicht so häufig sehen, heißt es nicht, dass ihr mir nicht ebenso wichtig seid. Danke Eike, Hendrik, Holger, Kirsten, Leo, Mark, Meike, Michi, Moritz, Nils, Otto, Sonja, Steffen, Svenja, Tine, Weier.

Zu guter Letzt danke ich meiner Familie, dafür, dass es sie gibt und hoffentlich noch lange geben wird: Danke Mama \& Papa, Iris und Werner!

Meine akademischen Lehrer waren u.a. die folgenden Professoren und Dozenten:

G. Beuermann, P. Botschwina, A. de Meijere, U. Diederichsen, L. Fitjer, R. Gillenkirch, U. Klingebiel, H. Laatsch, J. Magull, F. Meyer, H. W. Roesky, J. Schroeder, G. M. Sheldrick, J. Stülke, M. Suhm, L. F. Tietze, W. Toporovski, H. Wedell, D. B. Werz. 


\section{Lebenslauf}

Persönliche Angaben

Name

Arne Heins

Geburtsdatum

8. Juni 1982

Geburtsort

Soltau

Eltern

Heinrich Heins und Anette Heins, geb. Vogt

Nationalität

deutsch

Familienstand

ledig

\section{Schulausbildung und Wehrdienst}

1989 bis 1993

1993 bis 1995

1996 bis 2002

05. Juni 2002

$7 / 2002$ bis $3 / 2003$

Hochschulausbildung

$10 / 2003$

$10 / 2007$ bis $3 / 2008$

09. Juni 2008

$8 / 2008$ bis $12 / 2011$
Grundschule Benefeld, Benefeld

Orientierungsstufe Bomlitz, Bomlitz

Gymnasium Walsrode, Walsrode

Allgemeine Hochschulreife

Grundwehrdienst im 2.PzGrenBtl 92 in Munster

Beginn des Chemiestudiums an der Universität Göttingen

Diplomarbeit am Institut für Organische und

Biomolekulare Chemie Göttingen unter der Leitung von

Prof. Dr. Dr. h.c. L. F. Tietze über das Thema

"Synthese von Heterocyclen durch enantioselektive

Domino-Wacker-Carbonylierungsreaktionen"

Diplomprüfung im Studiengang Chemie

Dissertation am Institut für Organische und Biomolekulare Chemie der Georg-August-Universität Göttingen unter der Leitung von Prof. Dr. Dr. h.c. Lutz F. Tietze über das Thema

"Synthese und biologische Evaluierung neuartiger Acronycin-Duocarmycin-Hybride" 
